\title{
CONTROVERSIES IN WATER MANAGEMENT: FRAMES AND MENTAL MODELS
}


Samenstelling promotiecommissie:

prof. dr. ir. H.J. Grootenboer

prof. dr. A. van der Veen

dr. P.A.T.M. Geurts

prof. dr. J.T.A. Bressers

prof. dr. W. van Rossum

prof. dr. V.N. de Jonge

prof. dr. C. Pahl-Wostl

dr. J.P. van der Sluijs

prof. dr. ir. H.J. de Vriend
Universiteit Twente, voorzitter

Universiteit Twente, promotor

Universiteit Twente, assistent-promotor

Universiteit Twente

Universiteit Twente

Universiteit Groningen

Universiteit van Osnabrück

Universiteit Utrecht

Universiteit Delft

Cover pictures:

Top (courtesy of Water Board Groot Salland): Construction of the Zwolle barrier, showing the flood gate door being lowered into position at the bottom of the gate.

Middle (courtesy of Historisch Centrum Overijssel nr. PBKR0591): People looking at the high water in the Zwolle city centre from behind the (former) small retaining wall along the Diezerkade, during the NW storm on 14 January 1916.

Bottom (courtesy of Water Board Groot Salland): Inundation of the Soeslo polder in Salland cause by excessive precipitation on 30 October 1998.

Background (courtesy of DWW): The map in appendix 1 of the "Wet op de Waterkeringen" (1996), showing the Sallandse Weteringen to be part of dike ring 53.

Copyright (c) 2005 by M.J. Kolkman, Enschede, the Netherlands.

All rights reserved. No part of this publication may be reproduced, stored in a retrieval system, or transmitted, in any form or by any means without the permission in writing from the publisher.

Printed by Febodruk BV, Enschede, the Netherlands.

ISBN 90-365-2214-5 


\title{
CONTROVERSIES IN WATER MANAGEMENT: FRAMES AND MENTAL MODELS
}

\author{
PROEFSCHRIFT \\ ter verkrijging van \\ de graad van doctor aan de Universiteit Twente, \\ op gezag van de rector magnificus, \\ prof. dr. W.H.M. Zijm, \\ volgens besluit van het College van Promoties \\ in het openbaar te verdedigen \\ op vrijdag 17 juni 2005 om 16.45 uur
}

door

Marinus Johannes Kolkman

geboren op 31 januari 1955

te Wierden 
Dit proefschrift is goedgekeurd door de promotor prof. dr. A. van der Veen

en de assistent-promotor

dr. P.A.T.M. Geurts 


\section{Preface}

Professionally raised in applied physics and formerly working at the Netherlands Organization for applied scientific research (TNO) in the field of industrial safety and risk analysis, I often wondered how decision makers could cope with the huge amount of uncertainty contained within hazardous materials transport models. A model outcome range of a factor 80 existed between worldwide available atmospheric dispersion models (see e.g. Beychok 1995), and even for highly specialized dedicated models the range can still be as high as a factor 8 (see e.g. Brighton et al. 1994). I concluded that dealing with uncertainty due to model conceptualisation and parameter values, and quality of model use more in general (see e.g. Oreskes et al. 1994; Dee 1995), should be important issues for research.

Changing my field of work to integrated water management at the University of Twente, in 1994, offered the opportunity to start this research. The curiosity continued, for example about how proposed actions based on model calculations failed to produce an expected algae bloom reduction when implemented. It turned out that the reason was due to hitherto insufficient knowledge on cause-effect relations (see e.g. the shallow lake projects Nannewijd, Bezuijen 1996, and Zuidlaardermeer, Klinge et al. 2000). I also wondered how optimal technical solutions failed to be accepted. This, I discovered, was due to different problem perceptions, causing project delay (see e.g. the case study presented in this dissertation, EIA-report 2001). It seemed to me that, next to uncertainty and model quality, the issue of model usage, and more in general, knowledge usage in decision making was even more important to understand abovementioned phenomena. I share above personal experiences with authors in other disciplinary fields. In 't Veld\&Verheij (2000), for example, mention the "Betuweroute", the Schiphol airport noise production calculations, and the Environmental Balance ${ }^{1}$.

The above examples raise the question what perspective could offer a new understanding of knowledge usage in decision making. In developing new approaches to education on modelling that would implement the department's mission statement (see e.g. Terwindt 2001), the required perspective gradually emerged. The concept of model quality was key to this. It was developed in the course "Inleiding modelleren A" (221231), and extended to the use of knowledge in the decision making cycle in the course "Inleiding modelleren B" (221232). In this quality perspective the conceptual understanding of models and their application area were considered the a central issue.

In my first PhD research proposal, dated 1999, the focus was on solving difficulties in dealing with uncertainties in integrated decision support model systems. Searching for a

\footnotetext{
${ }^{1}$ Each year the Netherlands Environmental Assessment Agency at the National Institute for Public Health and the Environment (RIVM) publishes an Environmental Balance. The Environmental Balance describes and analyses trends in the state of the environment in the Netherlands and the effectiveness of Dutch environmental policy. It also evaluates the degree to which targets for a large number of environmental problems are being met under currently adopted policies and the costs of the policies to government and society.
} 
problem diagnosis, it appeared that the problem was rooted much more in the usage of knowledge in the decision making cycle, and not so much in the models produced by scientific disciplines. Models, however, do play a role in the generation of understanding for decision makers and stakeholders, and in the clarification of positions in the decision making process. This resulted, in 2000 , in a re-focus on the use of scientific knowledge in complex, unstructured problem situations. The conceptualisation stage of problem definition was explored as a possible cause for knowledge application difficulties in the decision making cycle. Mental models, already used in other disciplines, appeared to offer a suitable description for conceptualisation issues in water management too. Starting from 2002, my research focused at the exploration of the viability of a theoretical framework built on mental models, and on the development of research methods required to implement the theory. The results are presented in this dissertation.

The work presented in this thesis was conducted during my tenure as assistant professor at department of Civil Engineering and Management of the University of Twente. In 2001 my initial supervisor prof. Huib de Vriend changed Twente for Delft, and prof. Anne van der Veen took over the both critical and stimulating discussions that motivated me to pursue an explanation of the process of knowledge usage in decision making, hitherto unexplored in the department. The work could not have been done without the help of many other persons who provided the discussions and feedback needed to focus this PhD research. The support of Victor de Jonge, Matthijs Kok and Govert Geldof is especially acknowledged. Several students explored aspects of the theoretical framework in their masters theses, for example Rinus Grimberg (GIS based modelling for DSS), Rik de Roode (quality of decision methods), Mark van Koningsveld (conceptual modelling using knowledge graphs), and Remco Vogelezang (participation processes). Special thanks are due to my colleagues Caroline van Bers and Anne Wesselink, involved in similar research on the boundary between natural and social sciences, for correcting my English drafts and structuring my arguments. Hanneke, Meijke, Tijmen and Daan, thank you for putting up with all the time I spent on my PhD research. 


\section{Table of contents}

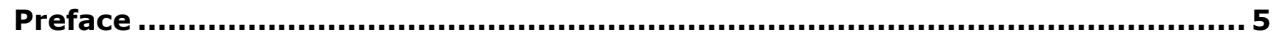

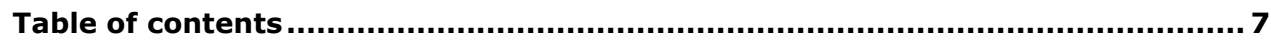

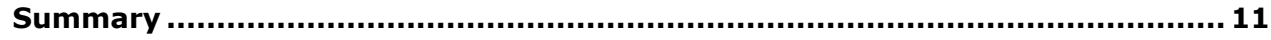

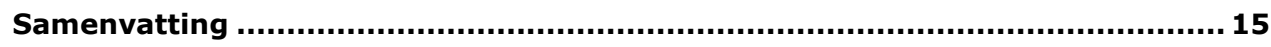

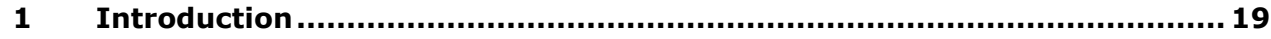

$1.1 \quad$ Difficulties in integrated problem solving ..................................... 19

1.1.1 Decision makers delegate responsibilities to models ...................... 19

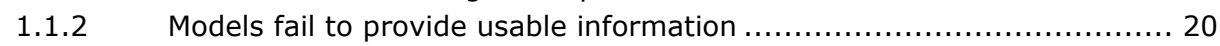

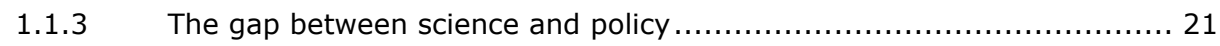

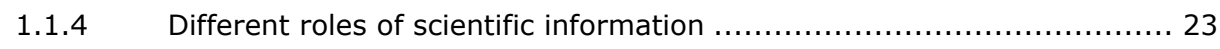

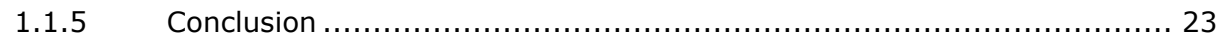

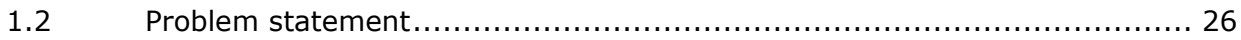

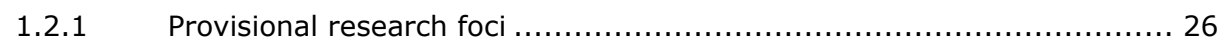

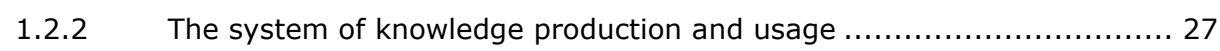

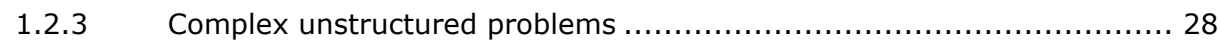

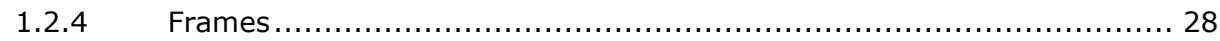

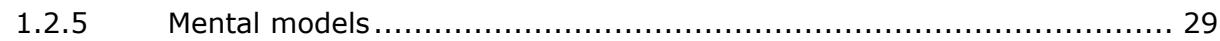

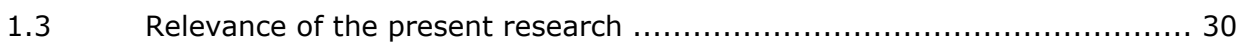

1.3.1 Relevance to decision making .......................................... 31

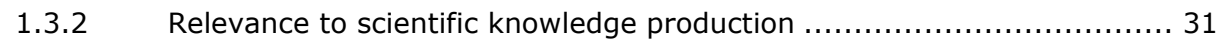

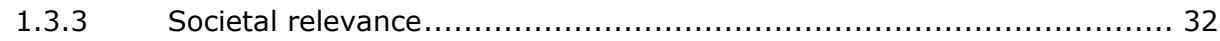

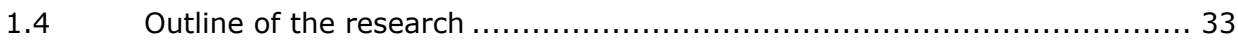

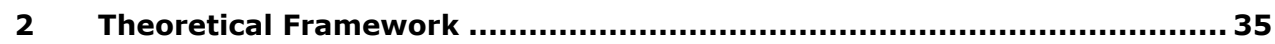

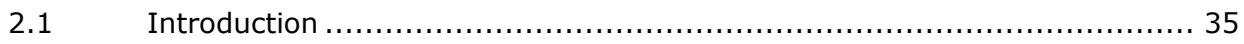

2.2 A descriptive model of knowledge production and use ..................... 36

2.2.1 Problem solving and decision making cycle: a theoretical model ........... 36

2.2.2 Knowledge production and modelling cycle: a theoretical model ............ 38

2.2.3 Model as interface for knowledge transfer between science and policy ... 41

2.3 Problematisation: complex multifunctional systems ......................... 43

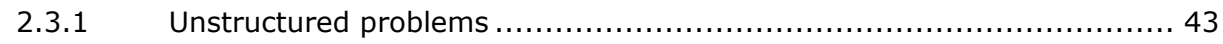

2.3.2 Communities of knowledge construction and valuation .................... 45

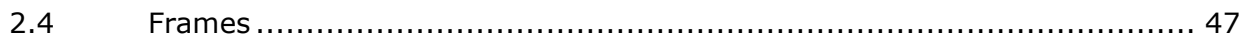

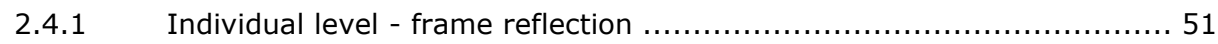

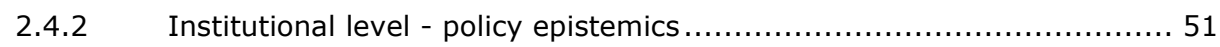

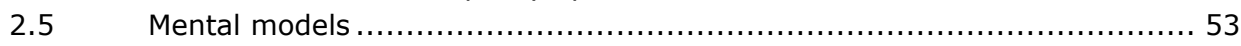

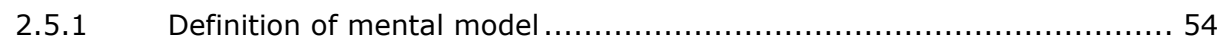

2.5.2 Concluding words on mental models and mapping ....................... 55 


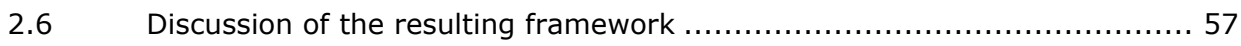

2.6.1 Mental models at the heart of the problem solving process ................ 57

2.6.2 Problem solving seen as a learning process.............................. 59

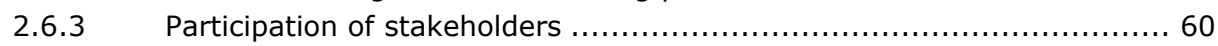

2.6.4 Integration between disciplines through coupling of models ...............60 60

2.6.5 Uncertainty and the process of negotiated construction of knowledge.... 61

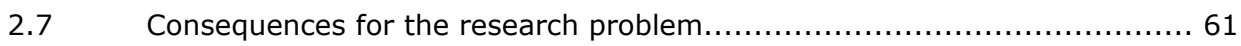

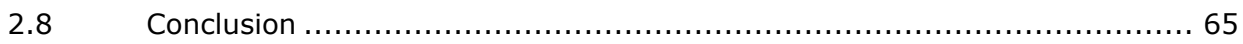

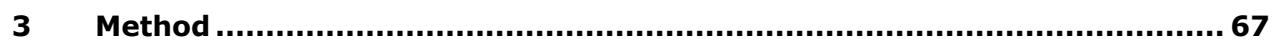

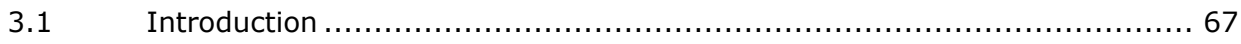

3.2 Frame reflection as a method to analyse persistent problems ...............6 67

3.2.1 Solving controversies using the method of frame reflection ................6 68

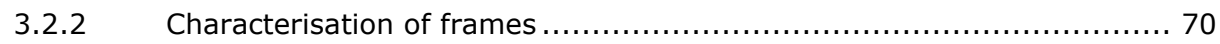

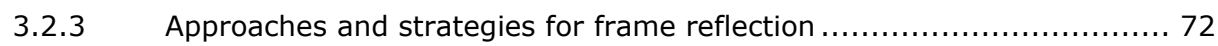

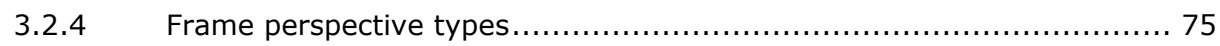

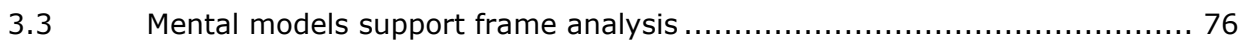

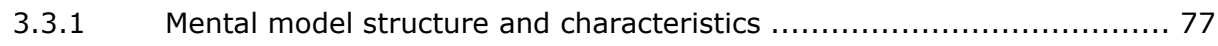

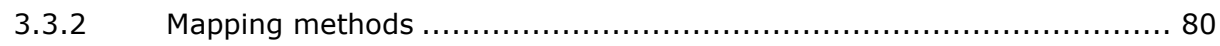

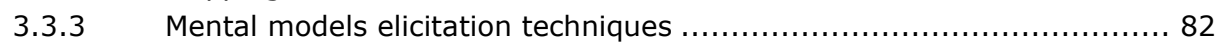

3.3.4 Potential benefits of the use of mental models........................... 85

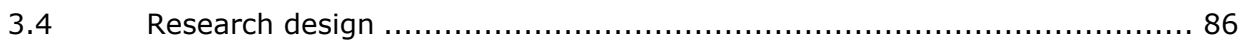

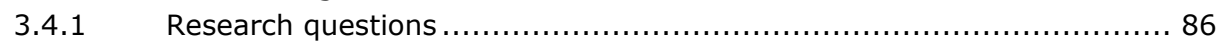

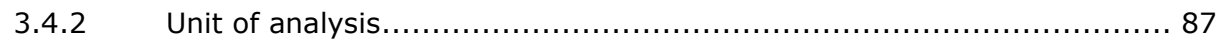

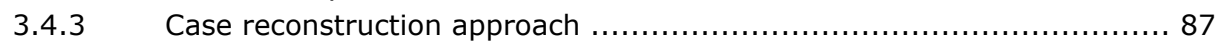

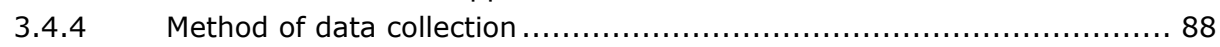

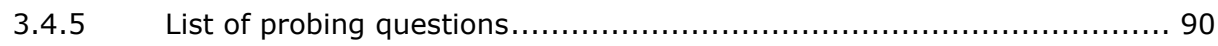

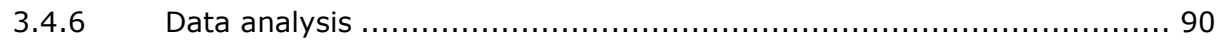

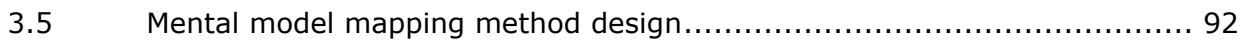

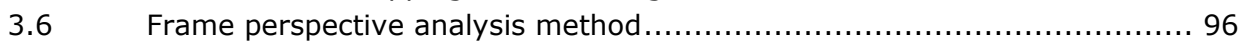

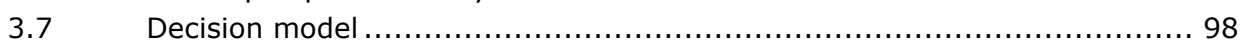

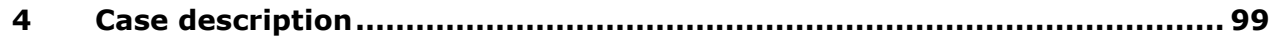

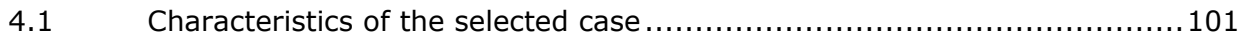

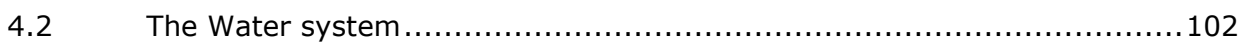

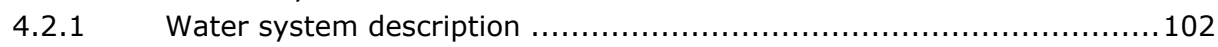

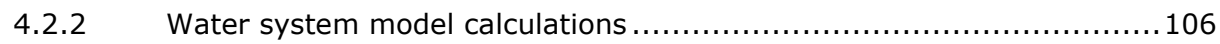

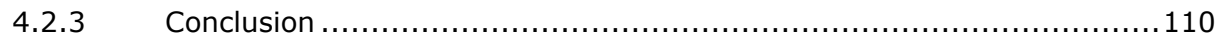

4.3 Administrative and legal system and institutional stakeholders ...............110

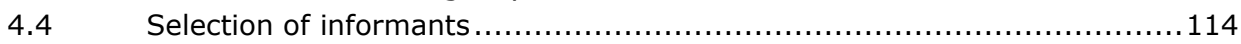

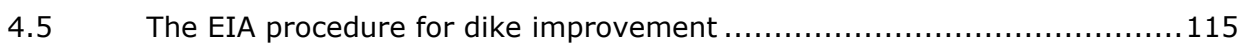

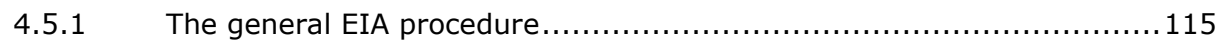

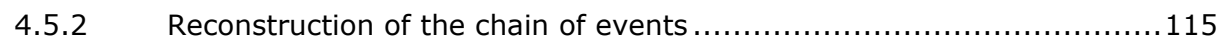

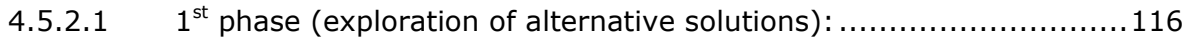

4.5.2.2 2nd phase (detailed research on selected alternative solutions): .....117

4.5.2.3 3rd phase (production of the EIA report): ...........................119

4.5.2.4 4th phase (objection and appeal): ................................. 119 


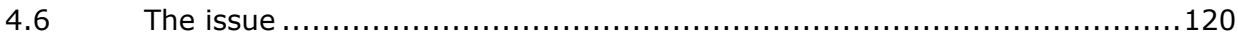

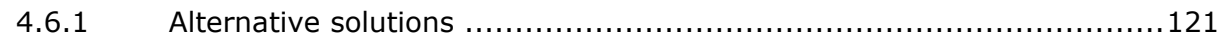

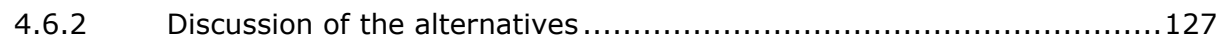

4.6.3 Decision method and selection criteria used in the EIA ......................129

4.6.4 Conflicts between stakeholders.............................................. 130

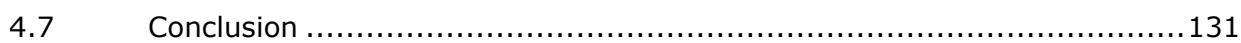

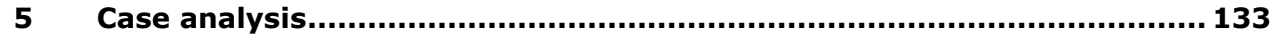

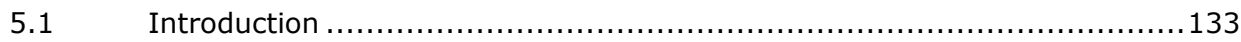

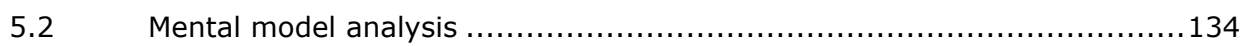

5.2.1 Data matrix of conflicting elements ...................................... 134

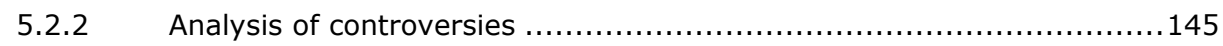

5.2.2.1 Administrative controversies ....................................... 145

5.2.2.2 Controversies in the distribution of legal responsibilities ................148

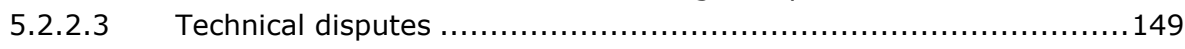

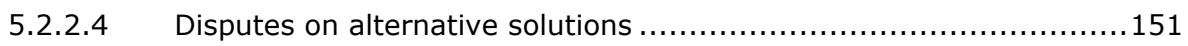

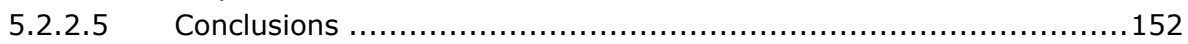

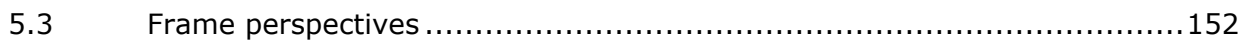

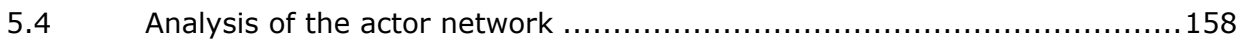

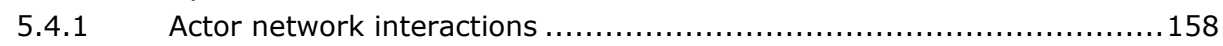

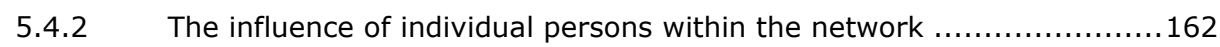

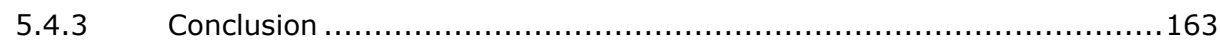

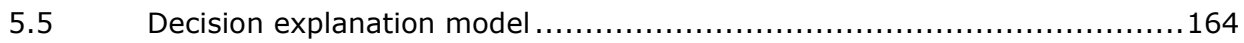

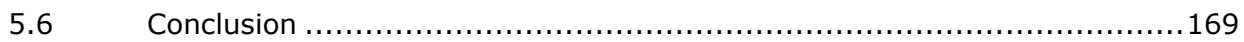

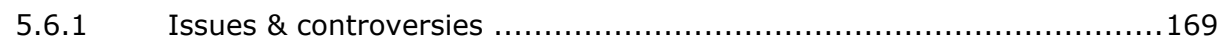

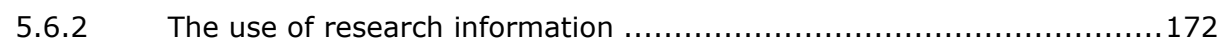

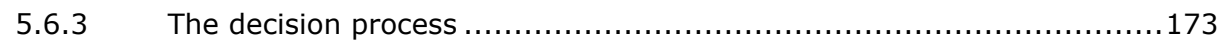

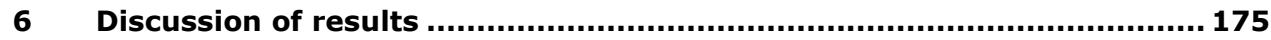

6.1 Reflection on the theoretical framework ..................................... 175

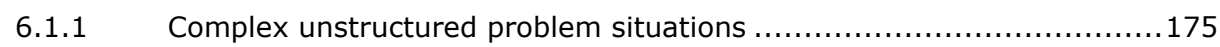

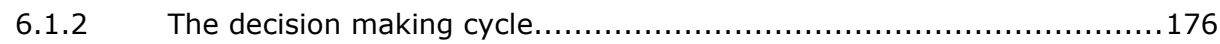

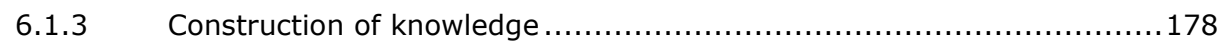

6.1.3.1 Actor network structured as post-normal fora of decision making ....178

6.1.3.2 Examples of knowledge construction ................................ 181

6.1.3.3 Examples of deconstruction of adversaries................................ 183

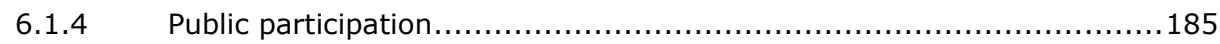

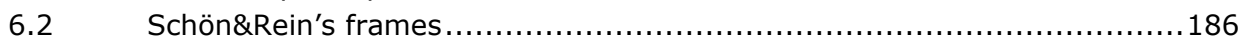

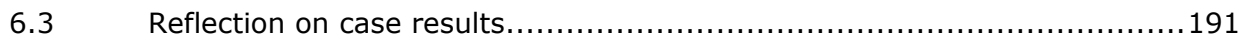

6.3.1 Has the unstructured problem been solved? ............................... 191

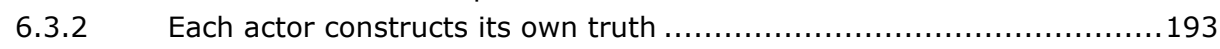

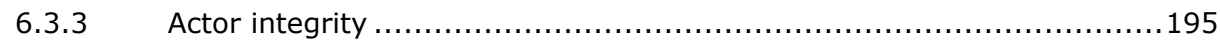

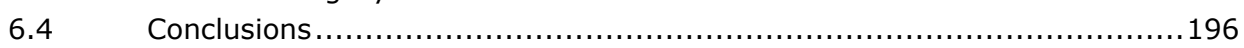

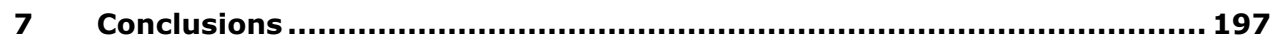

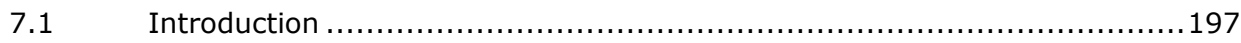

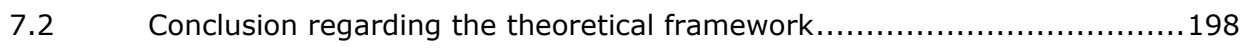


10 CONTROVERSIES IN WATER MANAGEMENT: FRAMES AND MENTAL MODELS

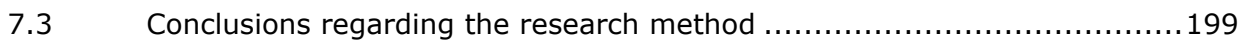

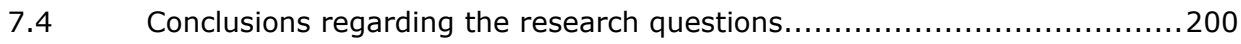

7.5 Conclusions regarding the post-normal hypothesis ..........................202

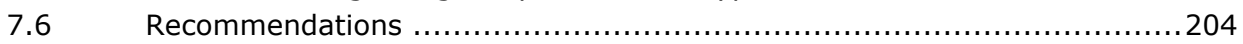

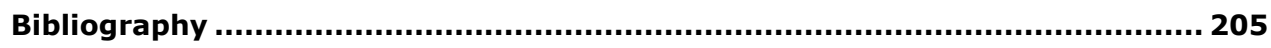

APPENDIX A: Translation of some Dutch terms related to water management..........217

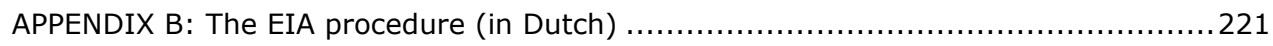

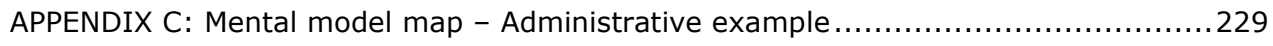

APPENDIX D: Mental model map - Technical example ..................................231 


\section{Summary}

\section{Introduction}

From a technical perspective, the way scientific knowledge is used in a decision making process sometimes presents incomprehensible difficulties. Decision makers appear to disregard technical argumentation in favour of administrative or political arguments. This situation can be understood by analysing the frames of perception of the stakeholders, through the comparison of their mental models.

Dealing with unstructured problems presents the scientist with new responsibilities. In structured problems an optimal solution can be designed given the fixed objectives, boundaries and constraints, contexts and criteria. Unstructured problems, however, require an approach that deals with shifting problem perceptions and values of actors involved in the problem. But the knowledge, assumptions, interests, and interpretations present within an actor's frame of perception are not always openly communicated. This may result in a communication gap between decision makers, scientists and stakeholders. An integrated approach to decision making in complex unstructured problem situations, therefore, has to deal with the communication gaps between these three parties in order to make knowledge usable.

The purpose of the present research is to improve the quality of the information and interpretations available to decision makers, by surfacing and juxtaposing the differing frames of decision makers, experts, and special interests groups. This thesis provides a new method to analyse frames.

\section{Theoretical framework}

The theoretical framework describes the decision making cycle as a system where knowledge is produced, stored, retrieved, communicated, and utilised. This system consists of an institutional and social environment in which the problem is defined and a solution is designed (the problem solving or decision making cycle). Added to that are the scientific disciplines which produce the relevant knowledge (the modelling cycle).

The meaning of the available information to a specific actor is the result of an interpretation and valuation process that occurs within the frame of perception of this actor (Schön\&Rein 1994). In this way a frame determines the use of knowledge and influences every step of the decision making cycle. It is within the frames that information is judged and synthesised into a problem solution. Therefore, the frame shapes decision positions and underlies controversy. Frames are not only operative in the decision making cycle, but also in the modelling cycle. Frame differences between actors cause communication barriers that prevent mutual learning and understanding, and thus an optimal problem solution.

In extension to the above author, the present research defines a frame to consist of perspective types and a mental model, that are in close mutual interaction (Courtney 2001). A mental model resides in the mind of an individual person, and contains the 
knowledge elements and relationships a stakeholder considers relevant to his position in the decision making process. The mental model acts like a "filter" through which the problem situation is observed. Perspective types guide the construction of meaning out of the information delivered by the mental model, and determine what a stakeholder sees as his interest. The perspective types are related to an actor's institutional and personal position in the decision making process. We claim that the persistence of the controversies, and thus the continuing incompatibility of the frames can be traced back to the fundamental positions of actors. These positions can be characterised by the perspective types.

\section{Method}

The mental models and perspective types that underlie different problem perspectives were reconstructed in the specific case in regional water management: the Zwolle storm surge barrier environmental impact assessment. The data was collected by means of document analysis and interviews with representatives of institutional stakeholders involved. The data was analysed on mental model elements that were disputed between one or more stakeholders and on the specific perspective types used by actors. The results of the analyses were collected in a data matrix. Mental model maps were drawn for some of the stakeholders only (who stand as examples for the major frame perspectives), in insofar as was needed for the researcher to become familiar with the case details. This approach offers considerable saving of time in comparison with the methods described in literature.

\section{Results and discussion}

The Zwolle barrier case exhibits all characteristics of a complex unstructured problem situation. These characteristics caused the decision making process to become problematic. In the case, the controversies mainly concern disputes on the interpretation of both technical and legal aspects between the administrative and the technical perspectives. Added to this are disputes on distribution of responsibilities between different institutes, involving persons of both perspectives. These latter disputes appear to have historical roots.

Both scientific uncertainty and debated values play an important role. The different argumentations produced by the actor groups from the technical and the administrative perspective can be positioned at opposite ends of the available uncertainty range. Not only with regard to technical uncertainty, but also with regard to administrative interpretation of the Flood defences Act and TAW guidelines. In the "battle" of arguments examples are present of personal deconstruction of adversaries and of rhetorical presentation of selected information to support the decision finally taken.

The controversies identify the frame conflicts present in the case. The frames of different actors evolved over time, in that more details were accommodated in the mental model, and insight into both the physical and administrative systems grew. The frame differences, however, were not overcome and the decision was ultimately forced by the decision maker-in-charge. This decision explained by a causal model. 
Our case presents an example of how the solution of complex, unstructured problems in integrated water management is faced with controversy and dispute, unused en misused knowledge, project delay and failure, and decline of public trust in governmental decisions. Although a decision was finally reached several years after the intended deadline, an integrated problem solution was not reached. The solution was limited to the well structured part of the problem by deliberately separating in form it broader context. This limitation can, in our opinion, be contributed to the lack of possibilities to involve all levels of authority in the search for an integrated solution, discussing with them the additional problems that were raised by the integrated approach in the initial phase of the EIA project. The notion of "truth" appeared, in our case, to be relative to the position of an actor within the actor network.

The persistence of the disputes in our case shows that open communication, which is encouraged in the post-normal science of Funtowicz\&Ravetz (1993b), is not enough to prevent decision making barriers. Apparently institutional and personal perspectives ultimately play a dominant role. Technical factors were discussed extensively, but had limited effect on the final decision. Political feasibility appeared to be the decisive factor. 



\section{Samenvatting}

\section{Inleiding}

De toepassing van wetenschappelijke kennis in besluitvormingsprocessen zorgt soms voor, vanuit een technisch perspectief, onbegrijpelijke moeilijkheden. Besluitvormers lijken technische argumenten te negeren en hun besluit vooral te baseren op administratieve of politieke argumenten. Inzicht in deze situatie kan verkregen worden door de perceptie-raamwerken ("frames of perception") van de betrokken personen te analyseren, met name door een onderlinge vergelijking van hun mentale modellen.

Omgaan met ongestructureerde problemen confronteert de wetenschapper met nieuwe verantwoordelijkheden. In gestructureerde problemen kan een optimale oplossing ontworpen worden binnen gegeven, vaste doelstellingen, randvoorwaarden en beperkingen. Echter, in ongestructureerde problemen is een andere aanpak nodig die om kan gaan met veranderende probleemopvattingen en waarden van betrokkenen. Maar de kennis, aannames, belangen en interpretaties die in een frame aanwezig zijn worden niet altijd openlijk gecommuniceerd. Dit kan een communicatiekloof veroorzaken tussen besluitvormers, wetenschappers en belanghebbenden. Om kennis bruikbaar te maken, zal een integrale probleemaanpak van complexe ongestructureerde problemen daarom rekening moeten houden met de kloven tussen de drie betrokken partijen.

Dit onderzoek heeft als doel om de kwaliteit van de informatie en interpretaties, welke de besluitvormers ter beschikking staan, te verbeteren middels het boven water brengen en het met elkaar confronteren van de verschillende frames van besluitvormers, experts en belangengroepen. Dit proefschrift presenteert een nieuwe methode voor het analyseren van frames.

\section{Theoretisch raamwerk}

Het theoretisch raamwerk beschrijft het besluitvormingsproces als een systeem waarin kennis wordt geproduceerd, opgeslagen, teruggezocht, gecommuniceerd en gebruikt. Dit systeem bestaat enerzijds uit een sociaal-institutioneel deel, waarin een probleem wordt gedefinieerd en een oplossing ontworpen (de probleemoplos- of besluitvormingscyclus). Daarnaast bestaat het systeem uit een deel waarin relevante kennis wordt geproduceerd door wetenschappelijke disciplines (de modelleercyclus).

In het "frame" van een betrokkene wordt bovenstaand informatie geïnterpreteerd en gewaardeerd t.a.v. de betekenis ervan voor het besluitvormingsproces (Schön\&Rein 1994). Het "frame" beïnvloed daarmee elke stap in besluitvormingscyclus, en ligt daarom ten grondslag aan besluitvormingscontroverses. Frames beïnvloeden niet alleen de besluitvormingscyclus, maar evenzo de ontwikkeling van wetenschappelijke kennis. Frameverschillen tussen bij een besluitvormingsproces betrokken actoren veroorzaken communicatieblokkades. Deze verhinderen op hun beurt wederzijds begrip en van elkaar leren, waardoor een suboptimale probleemoplossing kan ontstaan. 
Bovenstaande theorie wordt in dit onderzoek uitgebreid door het begrip "frame" nader in te vullen met een mentaal model dat in interactie staat met "standpunt typen" ("perspective types", Courtney 2001). Een mentaal model zetelt in de geest van een individueel persoon, en bevat de kenniselementen en relaties daartussen welke deze perszoon relevant acht voor zijn positie in het betreffende besluitvormingsproces. Een mentaal model werkt als een "filter" waardoor de probleemsituatie wordt waargenomen, en beperkt daarmee de beschikbare hoeveelheid informatie. Standpunttypen bepalen de constructie van betekenis uit de informatie afkomstig van het mentale model. De "typen" worden bepaald op basis van persoonlijke en institutionele karakteristieken van een actor. Dit onderzoek claimt dat de persistentie van besluitvormingscontroverses teruggevoerd kan worden op, door standpunttypen gekarakteriseerde, posities van actoren. Hiermee samen hangt de onverenigbaarheid van frames en de beperkte toepasbaarheid van "frame reflection".

\section{Methode}

De bruikbaarheid van het theoretisch raamwerk is onderzocht door het toe te passen in een casestudie in regionaal watermanagement: de milieueffectrapportage van de stormvloedkering in Zwolle (onderdeel van het dijkverbeteringsproject "Dijken Achter Ramspol - DAR 1+2). Onderzoeksgegevens zijn verzameld door analyse van documenten en interviews met vertegenwoordigers van de betrokken institutionele actoren.

Op basis van deze gegevens zijn de mentale modellen van enkele informanten opgesteld, waaruit vervolgens die modelelementen zijn geselecteerd die controversiële kwesties aanduiden. Zulke elementen zijn herkenbaar aan het verschil in opvatting welke bij informanten over zo'n element bestaat. Deze elementen zijn verzameld in een datamatrix, welke vervolgens is uitgebreid met andere elementen welke rechtstreeks uit de resterende interviewtranscripties zijn bepaald. Deze werkwijze geeft een aanzienlijke tijdbesparing ten opzichte van het volledig uitwerken van de mentale modellen van alle informanten. De standpunttypen zijn bepaald door interpretatie van de gegevens door de onderzoeker.

\section{Resultaten en discussie}

De case vertoont alle karakteristieke eigenschappen van een complexe, ongestructureerde probleemsituatie. Deze karakteristieken blijken verantwoordelijke voor het problematische karakter van het besluitvormingsproces. De controverses in de case betreffen hoofdzakelijk meningsverschillen over de interpretatie van zowel technische als wettelijke besluitvormingsaspecten, tussen enerzijds personen met een bestuurlijke standpunt en anderzijds personen met een technische standpunt. Daarnaast zijn er meningsverschillen over de verdeling van verantwoordelijkheden tussen de verschillende betrokken instituten, waarbij geen duidelijk onderscheid is tussen voornoemde standpunten. Deze laatste meningsverschillen blijken historische achtergronden te hebben.

Zowel onzekerheid in kennis als onenigheid over waarden spelen een belangrijke rol in de case. Informanten met een technisch of een bestuurlijk standpunt blijken verschillende argumentatielijnen te hanteren, waarbij ze tegengesteld gebruik maken van de aanwezige onzekerheidsruimte. Dit betreft niet alleen technische onzekerheden, maar 
ook onzekerheden in interpretaties van de "Wet op de Waterkering" en de bijbehorende TAW-richtlijnen. In de case blijken voorbeelden aanwezig te zijn van deconstructie van tegenstanders en van het gericht interpreteren van geselecteerde informatie om het genomen besluit achteraf te kunnen verantwoorden.

De elementen in de datamatrix verwijzen naar in de case aanwezige frameconflicten. Hoewel de frames van de informanten zich gedurende het besluitvormingsproces ontwikkelden (in de zin dat er meer elementen aan het mentale model werden toegevoegd, en inzicht in zowel het fysische als bestuurlijke als wettelijke systeem toenam), werden de conflicten niet overbrugd. Uiteindelijk werd een beslissing afgedwongen door de eerstverantwoordelijke bestuurder. Voor deze beslissing is een verklaringsmodel opgesteld.

De case geeft een voorbeeld van hoe de oplossing van een complex ongestructureerd probleem in integraal waterbeheer gepaard gaat met meningsverschillen en conflicten, ongebruikte en mis-bruikte kennis, projectvertraging en niet werkende oplossingen, en een afkalven van publiek vertrouwen in overheidsbeslissingen. Hoewel uiteindelijk, een aantal jaren na de geplande deadline, een besluit genomen werd, is er geen sprake van een integrale probleemoplossing. De gekozen oplossing is beperkt tot het goed gestructureerde deel van het probleem, door dit bewust los te beschouwen van de bredere context. Deze beperking is, naar onze mening, een gevolg van een gebrek aan mogelijkheden om in samenwerking met alle betrokken bestuurslagen naar een integrale oplossing te zoeken, en daarbij de nieuwe problemen te bespreken die tijdens de initiele fase van het m.e.r. project aan het licht kwamen. In die beginfase was er overigens wel sprake van een integrale aanpak. Het begrip "waarheid" blijkt in de case relatief te zijn ten opzichte van de positie van een informant in het besluitvormingsnetwerk.

De hardnekkigheid van conflicten in onze case laat zien dat een open communicatie, zoals die voorgestaan word door de post-normale wetenschap van Functowicz\&Ravetz (1993b), geen garantie is voor het voorkomen en/of oplossen van besluitvormingsknelpunten. Blijkbaar spelen institutionele en persoonlijke perspectieven uiteindelijk een doorslaggevende rol. Technische aspecten zijn in het bestudeerde besluitvormingsproces uitgebreid besproken, maar hadden nauwelijks effect op de uiteindelijke beslissing. Politieke haalbaarheid bleek de doorslaggevende factor. 



\section{Introduction}

\subsection{Difficulties in integrated problem solving}

Solving the complex problems that are addressed in water management ask for an integrated approach. Such an approach incorporates interests like environment, safety, health, nature development and management, liveability and cultural/historical heritage, economic interests, and social interests. Its aim is to provide insight into all relevant aspects of the problem, in order to reach a balanced and sustainable decision. According to Parson (1997), integrated assessment consists of gathering, synthesising, interpreting, and communicating knowledge from various expert domains and disciplines, to help responsible policy actors think about problems and evaluate possible actions. Jäger (1998) adds that assessment means making knowledge relevant and helpful for decision makers, not doing new research. An integrated approach will generally be applied in situations that require a multitude of knowledge types, including a heavy accent on technical aspects, and where the preparation and decision making takes place in several different arenas. It is the process of making knowledge relevant and helpful for the decision making process, and the difficulties therein, that is the object of the present research.

\subsubsection{Decision makers delegate responsibilities to models}

Ravetz (1987) and Funtowicz\&Ravetz (1994) detail the policy legitimisation process by describing how decision makers delegate choice responsibilities to scientific information. Rip (1996) describes how models facilitate the delegation of responsibilities from decision makers to experts by offering methods, predictions, explorations, etc. Models, according to Rip, do not solve the decision problem. Models, however, do make the problem manageable, by reflecting the way reality is reduced to simple abstractions, and by offering a way to demonstrate effects of possible choices. The model is the connection between the scientists that want to solve the technical problem and the social context in which it is often not completely clear what the problem is. This situation is schematically depicted in figure 1-1. 


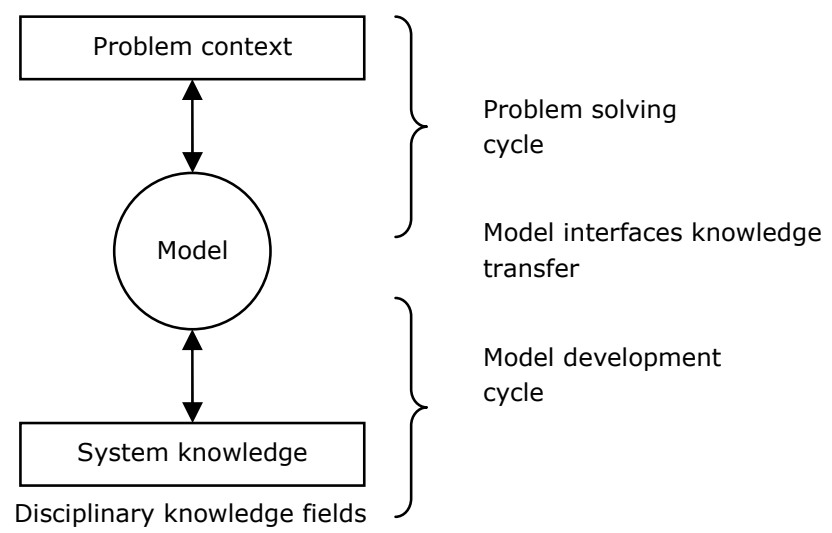

Figure 1-1: The preliminary framework: a simple sketch of the intermediate function of models in the transfer of disciplinary knowledge. The notion of model is not limited to computerised models, but can refer to any type of model. An experienced model user is required to "operate" the model for this purpose.

This situation may create an area of tension. The essence of this tension lies, according to Birrer (1996) in the imparity of knowledge between the experts and non-experts. Experts are often indispensable for the determination of the best possible options and thereby the non-expert becomes dependent on the expert. If there were pure, unambiguous criteria for scientific knowledge, data would not be such a problem. However, especially when it is about socially relevant topics, the quality of scientific knowledge is often not relatable to a univocal standard. The question presents itself whether a scientist does or does not smuggle certain value judgements or prejudiced choices into the study. For experts it is difficult to make relevant statements that are entirely free of a normative problem definition. The model user, in his intermediate position, has to weigh the interests of the problem owner and the scientific modeldeveloper, and will experience pressure of from either side. Hence the use of models in the decision making process requires an experienced model user who will function as an intermediate between abstract scientific knowledge and the specific decision situation.

\subsubsection{Models fail to provide usable information}

Rogers\&Fiering (1986) have identified 2582 papers published since 1965 in three journals in which authors present system analysis tools for water-resource planning and management. They argue that model builders often show a lack of concern with user involvement. Model results are not welcomed with open arms, and are not instantly accepted, as readers of the papers might be led to believe. The problem seems to be not in developing the model system, but in getting someone to use it. Woolsey\&Swanson (1975) already wrote: $90 \%$ of the problem faced by the practitioner is not technical. In 
many examples the right method yielding the optimum solution was not used because the analyst was unable to sell it. According to Ford (1991) this situation has little improved since. Ford (1991) concludes this to have become commonplace in the development of computer-aided support systems for water resources research and management. Listening to users appears not to be a strong point of many model developers. Also Brunner (1996), in a discussion on global climate change, concluded that a predictive model is neither sufficient nor necessary for improvements in the rationality of policy decisions and that the contribution of science should be to provide insights not predictions.

In those cases when decision makers do actually accept computerised models as representation of scientific knowledge, and believe that they can utilize the information contained in the model output correctly, there can be another type of problem. Schneider (1997) mentions that not all potential users of integrated assessment models will be aware of hidden values or assumptions that are inherent in all such tools. He suggested that for both the explanatory and policy purposes of such models, it is necessary to test the credibility of their structural assumptions, input data, parameter values, outputs and predictability limits. Jäger (1998) mentions the broader problem that the values, choices, assumptions, limitations and difficulties within a scientific model builder paradigm are seldom openly communicated. This calls for some form of quality assessment of integrated models.

These examples indicate a problem with user involvement in the model use. On the other hand there seem to be problems with the involvement of model developers in de decision making process. The consequence is a sub-optimal decision from the technical or scientific point of view.

\subsubsection{The gap between science and policy}

There appears to be a gap between scientists and decision makers, which can have different aspects.

Holling et al. (1997) point at a communication gap between ecological science and policy, and observe that the process through which relevant scientific knowledge is translated into policy is extremely slow, cumbersome and expensive. At the same time, policy makers are faced with the need to make decisions without sufficient scientific knowledge that could doom entire ecosystems. The gap between science and policy is exacerbated by the fact that the process of the growth of knowledge in both areas is often geographically contained - involving only one branch of science or one agency of one government or even one ecosystem at a time. Bridging this gap seems to be problematic. Schön\&Rein (1994) speak of the "rigor or relevance" gap between researchers and policy practitioners. This is the gap between, on the one hand, scientists tackling only structured problems that allow a rigorous scientific approach, and on the other hand, the relevant but unstructured societal problems that policy practitioners have to deal with, which cannot be approached within the scientific paradigm. Priddy (1999) remarks that most science is an extension of what has occurred before, such that it is often not equipped to handle cross-disciplinary questions and cross-cultural issues. Therefore 
bridging the gap seems to have serious fundamental problems. Edwards (1996) states that models can play an important role in communicating community beliefs, assumptions and shared data between stakeholders and decision makers.

Picking up on Schön\&Rein's rigor or relevance gap, we can see that integrated problem solving considers problems to be part of a larger context. This context will interact with the problem, meanwhile changing the problem itself. In this context it is impossible to design problem solutions within a given set of fixed objectives, decision criteria, boundaries and constraints (as is the case in the typical 'traditional' approach to developing solutions for structured problems). Rather, the problem is constantly being re-defined under influence of changes in the scientific and political context, and changing opinions and insights should be anticipated and dealt with. This asks for a problem finding approach, in contrast to the 'traditional' solution finding approach. In the discipline of process design for building and construction projects, the difference between these approaches is summarised with the terms "tame" and "wicked", respectively (Rittel 1972). In the discipline of business management the concepts "hard" and "soft" are used (Checkland 1981). In the discipline of public policy the concepts "structured" and "unstructured" are used (Hisschemöller 1993). In unstructured problems, the separation of facts and values is no longer discernible. Which part of the natural system is considered relevant, what counts as knowledge, and how knowledge may support decision-making is subject to discussion between the different paradigms involved in the problem. Each community of knowledge construction will apply its own paradigm (Funtowicz\&Ravetz 1993b). The problematic nature and role of knowledge can be ascribed to social construction and deconstruction of knowledge in and between paradigm groups. Knowledge appears to be used to legitimise positions in stakeholder discussions.

The discussion between different paradigms involved is not without problems. The value of scientific information in decision making becomes more and more debated. Scientists are seen to produce their knowledge from specific, not objective 'frames of reference' which may represent the scientists own interests and which is not infallible. This results into scientific information that is not taken for granted any longer and can be explained in different ways. But, contrary to the expected broad discussion about the relevance of the knowledge, a closed discussion network policy is used to "get specific knowledge through". This knowledge appears to be unassailable. Jasanoff (1990) studied the USA Health and Safety regulatory processes to analyse the above processes. From the perspective of sociology of science, she argues how scientific knowledge is socially constructed within a scientific peer group, and therefore can be deconstructed by opposed stakeholders. She furthermore challenges the notion that scientific facts are tested and established with reference to objective criteria of validity. Jasanoff states that science merely conforms to the prevailing paradigm of the group, and scientific knowledge has a contingent and relativistic character. Nonetheless science succeeds in acquiring and maintaining cognitive authority in a distrustful world, by applying boundary-defining strategies to establish who is in and who is out of the relevant peer groups and networks. The creation of such boundaries seems crucial to the political acceptability of scientific advice. They prevent non-scientists from challenging or reinterpreting claims labelled as "science". USA practices at EPA and FDA studied by 
Jasanoff show that negotiation - among scientists as well as between scientists and the lay public - is one of the keys to the success of the advisory process.

Policy makers use the available uncertainty ranges of the information to construct their argumentation (Thompson 1997:147). This observation corresponds with Van Asselt et al. (1995), who explained different policy positions from the interpretation of uncertainties. From the discipline of integrated assessment modelling, the interpretation of information, resulting from calculations with integrated assessment models, in different frames of perception is considered to be another of the problem causes. Van Asselt $(1995 ; 2000)$ uses cultural theory to establish frames of perception for each stakeholder. For each frame specific scenarios are developed, using different realisations of uncertain parameters. The underlying theory is that the reaction of people to uncertainties will show distinct patterns which can be understood from cultural theory, and that these patterns can be categorised in four or five cultural types. Each type has its own management style, archetype for problem definition, rationality, value judgement on nature, and way of life. Thus each type will have a scenario according to its own cultural perspective, showing the impact of the cultural perception on forecasted effects. The above literature indicates that the social construction is guided by frames of perception. Frame differences may disturb information transfer and communication processes.

\subsubsection{Different roles of scientific information}

Even in the event that scientific knowledge succeeds in bridging the gap, it is used as 'just another' element in the policy making process.

Jasanoff (1990) concluded that in the decision-making discourse scientific information is not taken for granted, can be explained in different ways, and is 'just another' element in the policy making process. This is confirmed by Petersen\&Zandbergen (1995), who describe the different roles of scientific information in the science, public policy and business organisation domains, namely to establish truth, to legitimise choices and to challenge regulations, respectively. They follow the line of reasoning described by Ravetz (1987) and Funtowicz (1994), to conclude that the value of scientific information in complex decision making processes is important, ambiguous and debated between stakeholders. They also conclude that scientists should explicitly recognise complexity, unpredictability, and the uncertain nature of natural systems, trying to expose difficulties, and exploring alternative approaches and assumptions across disciplinary boundaries.

\subsubsection{Conclusion}

The difficulties described above can result in a lack of information and insight on alternatives, a lack of exchange of information and communication, a lack of cooperation, a lack of consensus and thus feasibility of the selected alternative, and a lack of participation and democratic involvement, as is also indicated by Pröpper\&Steenbeek (1998) in the field of interactive policy making. 
In their analysis of current theories about the relationship between science and policy on the issue of knowledge production and knowledge use, In 't Veld\&Verheij (2000) studied four major Dutch policy development projects. They recommend that, in order to prevent difficulties like the ones presented above $(: 125)$ :

1) knowledge must not be produced from one single dominant paradigm, but from the whole range of paradigms that are present in the policy arena;

2) open debate is needed concerning choices and basic assumptions that underlie the production of knowledge;

3) debate should also include non-scientific stakeholders from the policy arena; the intensity of this communication depends on the complexity of the problem. In addition to In 't Veld\&Verheij (2000), we remark that points 1 and 2 can also be applied to the problem definition phase, which involves policy actors at different levels working on the specification of what exactly the problem is, and therefore also concern the policy making process.

In conclusion, literature reviewed indicates that difficulties in the decision-making cycle exist with argumentation, and communication and interpretation of information. The problems are related to paradigm differences between policy actors from different stakeholder groups, policy actors and scientists, and scientists from different discipline groups. These differences are expressed in the notion of a "gap" between the actors (see figure 1-2). A major problem seems to be that the values, choices, assumptions, limitations and difficulties present within a paradigm are seldom openly communicated. Computer models are considered to play a role in communicating knowledge, but interpretation of model results is subject to paradigmatic distortion.

In response to the perceived difficulties in integrated problem solving, a transparent decision-making process is sought (by authors reviewed above) that reveals assumptions, limitations, etcetera in available knowledge, and offers democratic decisionmaking through participation. This implies a need for transparent and open communication about the problem analysis from all perspectives involved. But communication across the science - policy (or engineering - management) interface is difficult because of paradigm differences, even more so because of the uncertainty associated with predictions of policy effects. The same applies for the science stakeholder and the stakeholder - policy interface. The emphasis of the research presented in this dissertation is not on the role of scientists. Scientists are only part of the problem, which also involves decision makers and stakeholders. Integrated decision making in complex unstructured problem situations, therefore, has to deal with all communication gaps between these three parties. Therefore, this research will not limit to experts, but also include the same aspects from decision makers, experts, special interests groups and the wider public, in accordance with figure 1-2. 


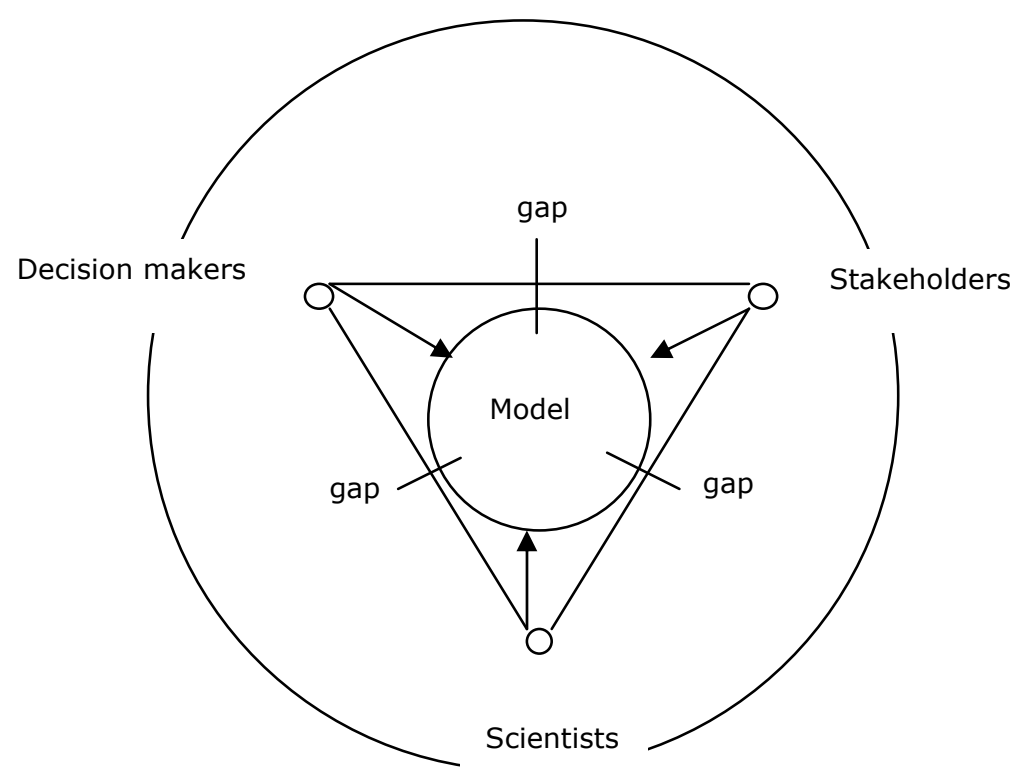

Figure 1-2: The communication gaps between decision makers, scientists and stakeholders. Decision makers and stakeholders are part of the problem situation (and sometimes scientists also). System knowledge is available from scientists, but also (local knowledge) from stakeholders. The model can facilitate the bridging of each of the gaps. E.g. by alternative effect forecasting, uncertainty analysis, participative modelling, conceptual problem exploration, and insight generation. 


\subsection{Problem statement}

The rationale for the present research is the observation that the solution of unstructured problems in complex, multifunctional systems is faced with policy controversy and dispute, unused, misused and misinterpreted knowledge, sub-optimal solutions and solutions for the wrong problem, project delay, and decline of public trust in governmental decisions.

The purpose of the present research is to improve the quality of the information and interpretations available to decision makers, by surfacing and juxtaposing the differing, also tacitly held, contextual perspectives, knowledge, values, viewpoints and demands of decision makers, experts, and special interests groups. This will contribute to the bridging of the science-policy interface in integrated water management, by improving the communication.

A solution direction is sought by looking at integrated problem solving from the perspective of knowledge production and usage. Usage concerns the institutional and social environment in which the problem is defined and a solution is designed. Production concerns scientific disciplines and the knowledge and products produced (including computer models) therein. The solution will contribute to bridging the gap between knowledge production and knowledge usage. Reviewed literature on integrated problem solving indicates a need for open communication of assumptions and difficulties that underlie the production and use of knowledge within and between different paradigm groups.

\subsubsection{Provisional research foci}

Before we can design a method to support these needs, we first need to diagnose the causes of the non-optimal communication, which in turn needs a description of the system to be diagnosed. This leads to the following provisional research foci:

1. The development of a theoretical framework for integrated problem solving seen from the perspective of knowledge production and use, which will accommodate the literature reviewed in the foregoing, by selecting relevant elements and relationships from literature.

This focus will result in a comprehensive description of the process of knowledge production and use. The description is envisaged to contribute to the development of approaches enabling in-depth multidisciplinary analysis of complex problems.

2. The formulation of a diagnosis for the decision making difficulties identified in the foregoing, by applying the theoretical framework developed under 1, based on an ideally functioning process related to knowledge communication. 
Once the source of the communication problems has been identified, we can start looking for a method to improve communication.

3. The development of a method that can remedy the communication difficulties, diagnosed under the second focus, in the process described under the first focus.

The research sets of by viewing knowledge production and usage as a solution for so called wicked or complex problem situations with the help of models. Uncertainty is dealt with in frames that produce an interpretation of the knowledge and models used, and different perspectives will result in different solution alternatives.

\subsubsection{The system of knowledge production and usage}

In order to make the reader familiar with the most important notions used in the theoretical framework, an overview is presented in section 1.2.2 through 1.2.5. These notions are the decision making cycle, the model, the frame, the frame perspective and the mental model. These notions are analysed in the context of a complex unstructured problem environment.

Policy development and decision making are characterised here as a process of systematic problem solving. All the problem solving methods used in various disciplines have a sequence of general steps in common: a problem solving cycle. Although such a method seems to produce a clear and rational choice at its end, in reality choice is influenced all along the cycle. Knowledge is produced, transferred and interpreted in every step of the cycle. Major choices are made already in the early steps of problem conceptualisation, under the influence of the perceived meaning of the available information. We will come back to this later in the discussion of frames in section 1.2.4. Models deliver knowledge to the problem solving cycle, not only quantitative or qualitative data, but also in the form of insight into the problem situation.

The knowledge production process is described here in the form of a modelling cycle. The development of the models follows its own method, depending on the scientific discipline involved (see e.g. Jørgensen\&Bendoricchio 2001). The model includes choices of conceptual abstraction and limitations that might not be communicated with the users of the results in the problem solving cycle. A model does not offer a unique, privileged perspective on the system. Therefore communication problems and decision making conflicts may occur when the conceptualisations between knowledge providers and decision makers differ. The criteria for selection of data, truncation of models, and formation of theoretical constructs are value-laden, and the values are those embodied in the societal or institutional system in which the science is embedded (see e.g. Funtowicz\&Ravetz 1999).

The different functions a model can have for its user, and the different model types, will result in different levels of insight for a decision-maker. Communication on a conceptual level will be an important factor in the successful use of computerised calculation models in the problem solving cycle. 


\subsubsection{Complex unstructured problems}

It is within this system of knowledge production and use that the discourse, discussion, deconstruction and legitimisation surrounding the application of scientific knowledge occur. These processes can be explained from the characteristics of multidisciplinary, multi-stakeholder, complex problems (see e.g. In 't Veld\&Verheij 2000). This type of problem arising in integrated assessment is considered to be part of a larger context, which will interact with the problem, meanwhile changing the problem itself. In this context it is impossible to design problem solutions within given, fixed objectives, decision criteria, boundaries and constraints. This is the typical engineering approach of solution finding for structured problems (see e.g. Hendricks et al. 2000). Rather, changing opinions and insights should be anticipated and dealt with, which asks for a problem finding approach. The difference between these approaches is indicated with the concepts "tame" and "wicked" (Rittel 1972) or "structured" and "unstructured", respectively (see section 1.1.3). In unstructured problems knowledge is uncertain and values are disputed. This gives rise to discussion and discourse not only on a societal level, but also on the level of professional consultancy and the level of applied science. The discussions within and between the communities that represent these levels can be structured by the notion of problem solving strategies introduced by Funtowicz\&Ravetz (1993b).

Models are used to convey knowledge into the problem solving cycle. Each scientific discipline group's models are specific, limited abstractions of reality, and they are produced according the group's version of the modelling cycle. Construction and deconstruction of knowledge can happen because of the unstructured nature of problems, which can be characterised along the dimensions knowledge uncertainty, value uncertainty and system complexity. In unstructured problems the interpretation of knowledge is negotiated against value and system perceptions, within and between paradigm groups.

The unstructured character of this type of problems explains why a straightforward technical solution, using the system described in section 1.2 .2 , is hardly possible. Intensive and hard communication on the actual meaning of available information will be needed between all actors involved in the problem.

\subsubsection{Frames}

The meaning of the available information to a specific actor is the result of an interpretation and valuation process that occurs within the "frame of perception" of this actor. A frame includes an actors' assumptions, interests, values and beliefs, and determines what he sees as being in his interests and, subsequently, what interests he perceives as conflicting. A frame guides interpretation of information, and thereby shapes decision positions and contributes to controversy. It is within the frames that information is judged and synthesised into a problem solution. The frame determines the boundaries of the problem solution space, and the allowable alternatives. Frames are influenced by 
the personal cultural and educational background. Frames are also grounded in the institutions that sponsor them. Frame differences between actors cause communication barriers that prevent mutual learning and understanding, and thus an optimal problem solution.

Within a frame, perspectives determine what stakeholders see as their interests (Courtney 2001). Perspectives differ between stakeholders, influence every step of the decision making cycle, and will result in the creation or support of various alternative solutions. The perspectives are related to a stakeholder's position in the decision making process. Examples of different perspectives are the technical and the organizational perspective. It is the perspectives from which alternative problem solutions are deliberated and decided upon.

At this point in our analysis of the system of knowledge production and use, we can already conclude that frame conflicts explain many of the decision making problems described in section 1.1. The identification and resolution of frame conflicts would make an important contribution to the purpose of the present research. Yet, the question that remains is how to proceed with the identification and resolution of frame conflicts.

\subsubsection{Mental models}

Guided by the notions 'learning', 'communication' and 'knowledge' appearing in literature, we continue our analysis with the question how knowledge enters a frame. The theory of Churchman (1971), Grant\&Thompson (1977), and Mitroff\&Linstone (1993) is used to substantiate that mental models are at the core of the problem solving and knowledge production processes.

A mental model resides in the mind of an individual person, and contains the elements and relationships a stakeholder considers relevant to his position in the decision making process. A mental model restricts information flows to only those aspects that affect the person, more specifically, those aspects that can be accommodated in the mental model present in the person's mind. Restrictions may be on the scale (geographical boundaries, time horizon, and level of detail) and on the processes and relationships he or she considers relevant (physical, biological, legal, financial, social, etc.). In this way the mental model acts like a "filter" through which the problem situation is observed.

The mental model represents a causal chain of argumentation that starts from the original problem and contains selected data and interpretation thereof, to present convincing evidence for a favoured solution. The mental model can be "run" to simulate the effects of intended actions, and in this way determines what knowledge an actor derives from the real-world data flow. "Running" the model is equivalent to following a chain of argumentation (Doyle et al. 2001). Different stakeholders may use the same starting point and the same data, but with different interpretations, to arrive at different effects. These effects are subsequently evaluated in the frame against the perspectives. But the perspectives are not independent of the mental model. The mental model determines what interests are perceived to be at stake. And the insights gained within the perspectives can update the mental model by adding elements and relationships. The 
feedback represents an iterative learning process that occurs continuously during the decision making process.

Communication is the process where a sender produces an utterance about one or more elements of his mental model. The receiver can only understand the message when his mental model contains the same, or closely related, elements. Thus mutual differences in stakeholder mental models determine whether the communication may succeed.

Analysing both the process of knowledge production and knowledge use, many assumptions and limitations appear to find their origin in the conceptualisation phase of both processes, and will already be part of the mental models of the diverse actors in the early stages of the problem solving cycle. Different mental models of the problem situation, and mismatch of decision data (including computer model output) with the mental models, will result in different opinions on the problem solution - in different frames, that is, and in this way constitute the basis of many difficulties in the decision making cycle. The, mostly implicit, differences in mental model complicate communication and learning between stakeholders. This makes it difficult to surface knowledge, contextual perspectives, values, viewpoints and demands.

Mental models are at the root of learning, interpretation, meaning construction, communication and therefore at the root of decision-making. Contrary to the common literature on frames, the present research separates knowledge from perspectives. Knowledge is located in the mental model. Both perspective and mental model are placed within our definition of frames. Inside a frame mental models are in close interaction with perspectives. Information is judged and synthesised into a problem solution based on a stakeholder's perspective, which ultimately depends on the stakeholder's mental model.

\subsection{Relevance of the present research}

Literature indicates that a successful integrated problem solving approach is to reveal, and deal with, assumptions, limitations, uncertainties, interests, opinions, and expose difficulties in application of knowledge. Participation, learning, and construction of meaning are to become important issues.

The overall claim of this dissertation is that the analysis of mental models will identify communication barriers, by revealing the experiences, perceptions, assumptions, knowledge and subjective beliefs that a "mental model user" draws upon to reach his conclusion about some issue. Mental model analysis assesses tacit knowledge, broadens the narrow understanding of a problem by confronting one decision maker's, stakeholders' or scientist's map with the map of others, makes aware of alternative perspectives on the problem, encourages negotiation and helps to reduce destructive conflict. The basic idea is to elicit a person's knowledge and consequently open it up to discussion. The results will be useful in assisting decision makers, but also for scientists and stakeholders.

The approach used in the present research integrates over several dimensions: it uses a definition of knowledge from cognitive psychology, and it uses mental model mapping 
methods from social science. The approach comes across several scientific issues on mental model mapping techniques. The approach investigates the regulatory and institutional dimension, which are thought to influence knowledge transfer in the case, and are assumed to be brought to light through mental model mapping. The present research introduces mental model analysis as a scientific basis for participatory approaches, because it will reveal the frames of decision makers and other actors. Mental model analysis should be part of a toolbox that is suitable for implementation, involving integration of all aspects: science, engineering, social sciences, law, management and institutions.

\subsubsection{Relevance to decision making}

The complex, multifunctional and multidisciplinary nature of integrated water management problems causes a large range of interacting mental models to spring into existence. When all parties are not adequately involved early in the problem solution process, to share each others mental models, the (often implicitly) developed mental model could be insufficient to fully legitimise the preferred solution. If mental models explain sub-optimal decisions, than it must be possible to develop an instrument that analyses mental modes and use that information to optimise strategic decision making through supporting communication and learning between different frame positions. Comparison of mental models, decision process structure and actual use of knowledge will reveal potential points of conflict, which then could be dealt with. Making mental model differences explicit offers an opportunity for communication and learning on the subject of the optimum problem solution.

The experiences acquired during the case analysis will give valuable clues for the development of an instrument for supporting the decision making process. This instrument will use the knowledge that is available within the different mental models of stakeholders involved for a discussion of a broad range of problem aspects.

Underlying the present research is the implicit intention to help decision makers in integrated water management improve their decision-making. This implies evaluation of decision-making in a specific task, requiring both a description of the current decisionmaking and a comparison with some "ideal" representation of decision making in the actual task studied (Fuglseth\&Grønhaug 2002:358). The maps produced by the researcher are a suitable representation of the "decision model", and are also an ideal representation that can be used to critically assess and to offer advice to the decision maker (Axelrod 1976:6). From the purely technical - scientific problem perception one could regard the outcome of a non-technical decision process to be sub-optimal as a consequence of miscommunication which frustrates the optimal technical solution.

\subsubsection{Relevance to scientific knowledge production}

In order to accomplish an information flow across the borders of (or the gaps between) the frames of actors, the research frame of the (scientific) expert and the learning frame of the public but also the learning or decision frame of the managers and policy makers 
should connect. The information becomes knowledge only when it is interpreted within the frame of the specific actor for its consequences on the actors' position or behaviour or actions. Scientists have an obligation to educate stakeholders or the public in order to enable them to judge the bearing of the information supplied. Finally, scientists need to connect their facts to the frames and causal discourses between diverse stakeholders. Therefore, frame analysis should be part of every policy design. Based on our analysis of literature, mental model mapping promises to be a technique that can provide the connection between the frames.

The present research has the aim of bridging the gap between stakeholders, especially the science-policy interface, i.e. to generate a dialogue and find a common understanding between scientists, involved in integrated assessment and modelling, and policy makers, involved in decision making. The present research starts from the assumption that improving communication can bridge the gap, by:

- Improving the understanding of the requirements of policy makers;

- Improving the quality and application of modelling tools used by policy makers;

- $\quad$ Encouraging the better use of integrated participatory modelling and assessment.

It is envisaged that these aims can be contributed to by mental model mapping. For that purpose, the present research:

- Defines the current state of the art in mental model mapping issues, and recognises the integration of human dimensions in frames. Mental model mapping is considered to be a suitable basis for participatory modelling.

- $\quad$ Reconstructs and explains the decision making process in the specific case studied.

- Identifies current policy making practices in River Basin Management on a regional scale, and analyses the constraints on policy making in the specific case studied.

Based on the results of the present research:

- The requirements can be defined of both scientists and policy makers - what the scientists need to know from policy makers in order to do their work and vice-versa.

- A dialogue can be initiated between the two communities on a common understanding of what can be achieved to improve and develop Integrated Water Management. This dialogue should also involve stakeholders.

\subsubsection{Societal relevance}

Dealing with unstructured problems presents the scientist with new responsibilities. The traditional notion of "product quality" responsibility used in structured problems assumes that an optimal solution can be designed given the objectives, boundaries and constraints, contexts, and values and criteria (see e.g. Findeisen\&Quade 1985). Unstructured problems, however, require a different approach that deals with shifting problem perceptions and values of all actors involved in the problem. Mental model analysis is a tool which scientists can use to face the dilemmas that arise when morality comes into conflict with property and power (Ravetz 2002). It can help them to build integrity, in that it exposes the different perceptions of a problem as well as its solution. In this way scientists can live up to their obligation to educate stakeholders and public in order to enable them to judge the bearing of the information supplied (Birrer 1996). Thus mental model analysis can be an instrument for restoring public trust in science. 


\subsection{Outline of the research}

Chapter 2 of this dissertation deals with the first and second focus (see section 1.2.1), chapter three with the third. The development was an iterative process where the framework and method gradually emerged in working on a specific case.

After the development of the theoretical framework, we are able to formulate our diagnosis. We hypothesise that the transparent and open communication, suggested in literature, as a means for solving potentially persistent controversies, is not sufficient, because differences in frame perspectives prevent the construction of a common mental model between actors. Consequently a common problem solving frame cannot be constructed and controversies remain.

Before we can design a research method for analysing frame differences and their causes, we need to describe the theoretical notions of frame perspectives and mental models in further detail to allow making them operational. This is described in chapter 3.

Based on the theoretical insights that emerged during the development of the theoretical framework, we will be able to formulate our research questions. We will endeavour the reconstruction of a decision making process in a case. The case is described in chapter 4 .

The method used is directed at a quick analysis of the mental models and perspectives present within the frames of actors involved in the problem situation, based on texts and interviews. The mutual conflicting elements in mental models of actors are collected in a data matrix, and related to actors' perspectives. The method is applied to a single case in order to test its viability. The case analysis is described in chapter 5 .

In chapter 6 the case analysis results will be compared with the theoretical framework presented in chapter 2 .

The final chapter 7 will present the conclusions of this research.

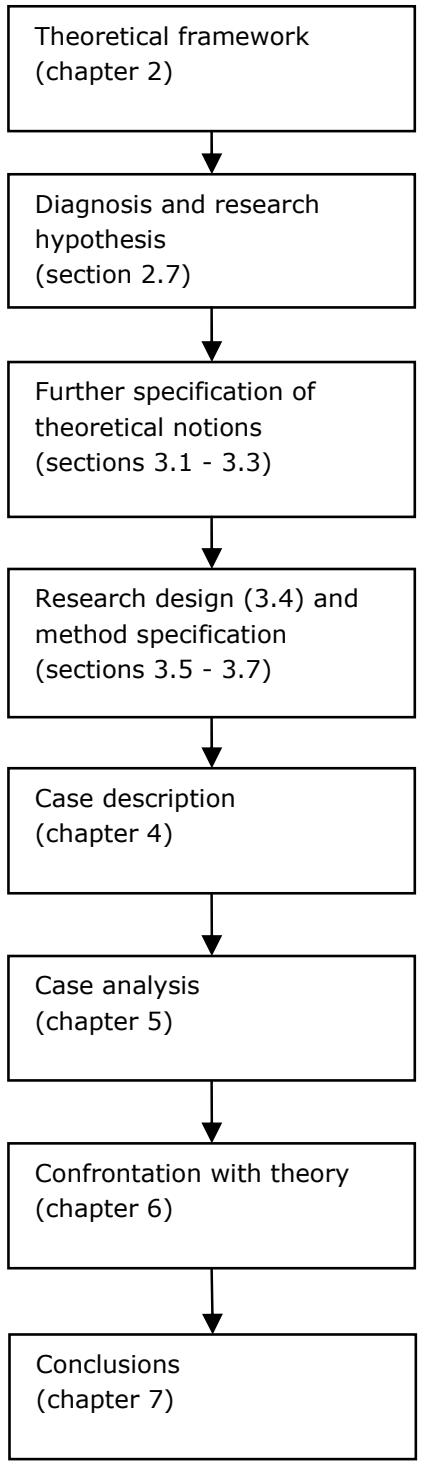





\section{Theoretical Framework}

\subsection{Introduction}

In this chapter a theoretical framework is developed (already briefly introduced in section 1.2). This framework may support integrated problem assessment given the difficulties and recommendations mentioned in section 1.1. Such a framework must structure the notions presented in section 1.1 in a consistent manner, and facilitate further analysis of the causes of decision-making difficulties.

This chapter begins with a description of the system where knowledge is produced, stored, retrieved, communicated, and utilised. The purpose of the description is to find an answer to the question what drives the use of information in the decision making process. Consideration is given to the intermediate role of models in the transfer of knowledge, especially the conceptual type of models. The relationship between science and policy will be described in terms of knowledge production and knowledge use. It consists of the two separate cycles of problem solving (figure 2-1) and knowledge production (figure 2-2), respectively, coupled by a computerised model or decision support system.

The resulting description is then confronted with theories on decision making in complex, unstructured problems. The question addressed is why knowledge utilisation in the system, described so far, is problematic, by looking at characteristics of unstructured problems (uncertain knowledge and disputed values, see figure 2-3) and communities of knowledge construction (paradigmatic differences, see figure 2-4). These characteristics add detail to the previous analysis and also serve as a first validation of the system description, in that it must be consistent with these two theories.

The confrontation results in the conclusion that knowledge is interpreted from different perspectives when it is used to design solutions for complex problems. These perspectives might delimit the possibilities to turn the available knowledge into usable knowledge, and cause controversies. The present research localises perspectives within the notion of "frame". 


\subsection{A descriptive model of knowledge production and use}

\subsubsection{Problem solving and decision making cycle: a theoretical model}

Decision making involves the problem of choice (between alternatives - doing nothing also being an alternative). Choices are made in all steps of the cycle, and are driven by the frames of actors. But behind the frames are mental models that determine what data the actor perceives in the real world, and what knowledge the actors derives from it. This section describes the decision making cycle, frames and mental models, and the relationship between them.

Policy development and decision making can be characterised as a process of systematic problem solving, see for example Nieuwkamer (1995). Because various paradigms are involved in the complex policy problems that are considered in the present research, different problem solving methods are also involved. For the discipline of policy development, methods for problem solving are described by for example Findeisen\&Quade (1985), Hoogerwerf (1989), and Hoppe\&Grenstad (1999). For the discipline of business process development and organisations management, methods are described by, for example Checkland (1981), Dick (2000), and Courtney (2001). For product development, the methodological examples are provided by Roozenburg\&Eekels (1998), and for engineering by Hendricks et al. (2000). Among all these methods a distinction can be made between, on the one hand, problem analysis and, on the other, problem solving. The latter is equivalent to decision-making concerning possible alternative solutions (e.g. using effect forecasting and decision methods). Figure 2-1 presents the steps that are generally taken, in one way or another, within all problemsolving methods. The steps partly overlap and interact with each other. The process of problem solution is an iterative one, where the iterations continue until the project demands and conditions are met, or the project resources depleted. The figure represents the "simple" decision making cycle (or policy life-cycle, or problem solving cycle) (see e.g. Courtney 2001).

Description of the steps:

1. The decision process begins with the awareness of its existence. This implies than concepts (words) must be available to recognise the situation and to establish deviation from the desired situation.

2. The problem situation is analysed and a definition of the actual problem is stated. For this it is necessary that the problem is put on the agenda of the stakeholders involved. The definition could be in terms that facilitate the creation of a mathematical model. Problem definition can be in terms that facilitate the creation of a mathematical model.

3. Before a proper definition can be given, the problem must be further articulated by developing conceptual models (on different levels of aggregation) of the problem situation. In this way the solution space is explored. This step may also result in a representative simulation model which describes the relationship between the observed problematic behaviour and causes thereof. From the conceptual models 
decision parameters (indicators) can be identified, and sometimes be organised in a

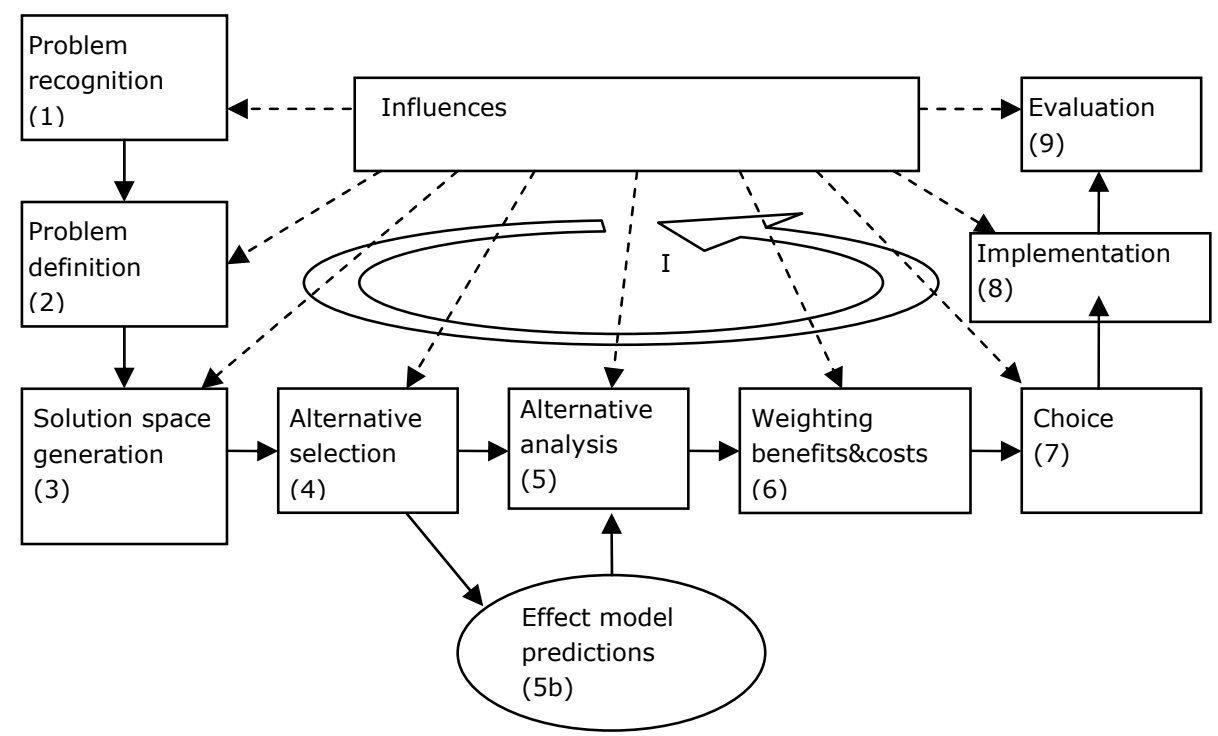

hierarchical structure.

Figure 2-1: The bare problem solving process. The dotted lines represent the influences actors exercise on the process. The process is cyclical in that new alternatives may be sought within a given problem definition and solution space.

Steps $2+3$ constitute the problem articulation phase, were entities and relationships between these are selected, and relationships between possible problem causes and the problematic system behaviour are analysed on causality and sensitivity.

4. The decision alternatives will be a subset of the solution space. For each alternative data has to be collected and appropriate forecasting models have to be selected.

5. Alternative analysis includes the gathering of data, scenarios for future developments, and expert opinions. Assessment of effects of alternative solutions (this need not be a computerised calculation), and presentation of assessment results. When computerised models are used (5b), special care is to be given to model selection and interpretation of model results

6. Weighing factors can be developed as part of the problem articulation process.

7. Choice between alternatives using decision methods. Including presentation of final solution. The actual choice can be made with help of a decision method. Many methods are available, see for instance the software package BOSDA (Janssen et al. 2000).

8. Implementation of the chosen alternative. This step includes all kinds of small choices related to the practical situation.

9. Evaluation on whether the intended effects are established. 
Environmental Impact Analysis (EIA) supplies knowledge into this decision making cycle. Often by means of model calculations, but also by generating insight in the problem. The end product of an EIA is (often) an impact table (e.g. score-card). In this table the effect scores represent the (scientific) knowledge, the criteria and (when present) weights represent the stakeholders. Possible alternatives and relevant criteria also depend on available (scientific) knowledge. In complex problems knowledge from different scientific paradigms is involved, and will be evaluated from different stakeholder paradigms.

Models have the role of supporting the decision-making process the purpose. Not only by quantifying the expected effects of decision alternative, but also by non-quantitative support. In addition to this instrumental application of models, a model can also be use to acquire insight in the problem situation and processes involved. It is the conceptualisation of the situation which is relevant here, and insight in the typical behaviour of identified system archetypes. Conceptualisation is often considered from the perspective of system theory (e.g. Kramer\&Smit 1991). Also a model offers decision makers, in addition to the functions mentioned above, the possibility to experiment with possible alternatives, in order to explore their effects and to attain a feeling for the relative importance of data and processes. Scientists introduce their specific knowledge into the decision making process through models and/ or model results. Computerised (calculation) models support the decision making process by making available data, assumptions, causalities, and effect predictions.

The choice for the most favourable alternative appears to be made toward the end of the problem solving cycle. In reality, however, choices are made at all steps of the cycle. The problem can be defined in many ways, or awareness can be deliberately stimulated (e.g. by publications in social circles, discussion groups, newspapers and journals). Putting the problem issue on the agenda of responsible or affected stakeholders can be stimulated or resisted. The amount of data gathered on the problematic behaviour of the system can differ from noting to full scale monitoring. The formulation of the problem definition demarcates the solution space, which can be broad, or narrow and focus on a stakeholders' favourite issue. Within the solution space some alternatives will be chosen for further analysis, depending on prevailing preferences. The choice of effect prediction models will depend on the client's preferences, stakes, budget, time, and legal obligations, and will influence the outcome of the predictions. Selection of decision criteria and weighing factors depend on the client and the participation of some or all of the stakeholders involved. The choice of the decision method may influence the ranking of alternatives (Kolkman et al. 2000). Thus, before a decision method is applied, many choices in fact have already been made. In conclusion, a good quality problem solving should make all the choices and the underlying assumptions, values en preferences visible for the stakeholders involved, thus promoting an open discussion about the most favourable alternative.

\subsubsection{Knowledge production and modelling cycle: a theoretical model}

This section will describe the process of knowledge generation from the perspective of model building. It will indicate how this process links with the mental models in the decision making cycle, identified in the previous section. 
The process of model development can be seen as a series of transformation steps, in which at each step a more abstract and simplified projection of reality is constructed, which corresponds less with the original reality with every step that is taken (see figure 2-2. The steps along which a model is developed, also called modelling cycle, are described in, for example, (Kramer\&Smit 1991; Young 1983; Jørgensen\&Bendoricchio 2001; Janssen et al. 1990; Beck 1998; Molen 1999; STOWA 1999;

Goldsborough\&Kolkman 1999; and De Blois 2000) .

Models are viewed as specific representations of the real world. The information collected within models is authored by model developers, and inevitably contains distortions.

Depending on the purpose, a model builder (ideally) selects, from available information, the aggregation level and the amount of detail required and constructs a more or less user-friendly computer system. After each transformation-step the correspondence with reality will be less. Not only the model itself, but also input and output data from the real system must be translated in the same process, in order to perform a calibration of the resulting model software. The end result is a narrow view on reality, from a specific scientific viewpoint.

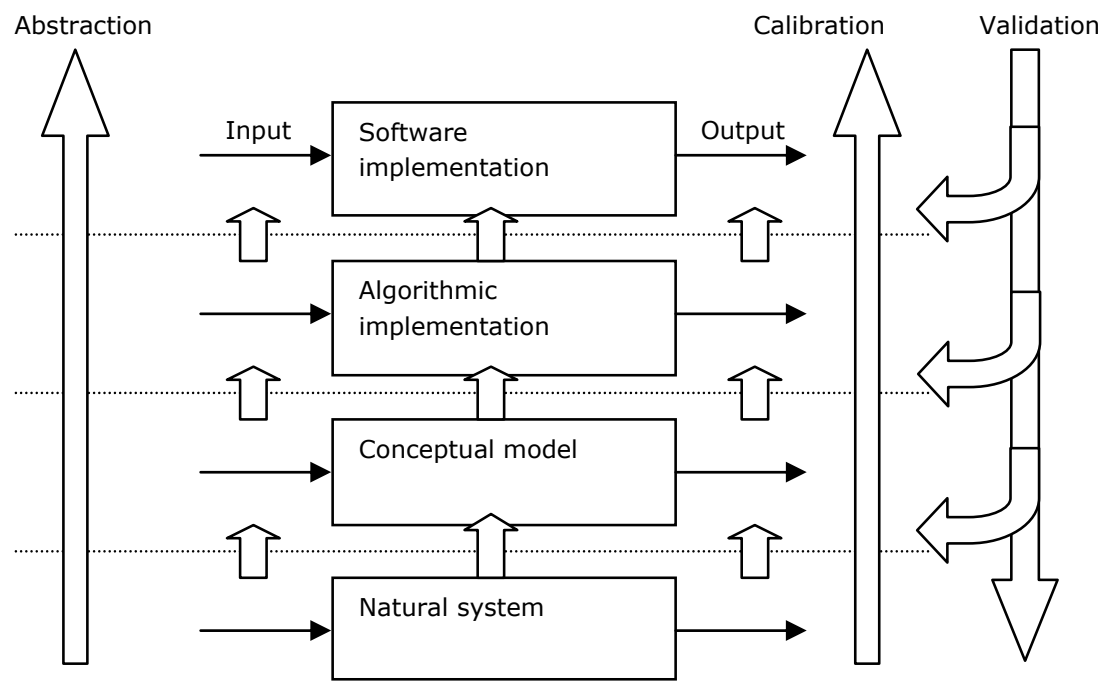

Figure 2-2: Production of knowledge in the modelling cycle. The modelling process is described as a process of transformation and validation (adapted after Dee 1995). The steps of the cycle are:

a) delineation of the part of the natural system to be studied,

b) construction of a conceptual model containing relevant system elements, their mutual relationships, and external influences,

c) algorithmic (mathematical) implementation of the conceptual model

d) implementation of the algorithm in software,

e) calibration of the model parameters,

f) validation of the model results.

Anticipating the discussion of the notion "mental model" in section 2.5, we already note that the conceptual model has the same function as the mental model in figure 2-5. 
Different disciplines will produce different software for the same problem in the same natural system. The various scientific disciplines are reflected in the different types of models that are constructed. For an overview of model types (see e.g.

Jørgensen\&Bendoricchio 2001).

When applying the model the user has to be aware that the conclusions based on the model results are primary valid only within the imaginary model world. The interpretation of the results in the real world context involves an inverse transformation. In both the modelling and the interpretation of results the model validity is an important issue (see e.g. Suter II et al. 1987; Boersma\&Hoenderkamp 1988; Morgan\&Henrion 1990; Dee 1993; Oreskes et al. 1994; Dee 1995). When integrating information from different scientific disciplines in the solution of complex problems, validation has to deal with the different methods of inquiry of the disciplines. Each discipline has its own rules for gathering relevant evidence and uses various types of evidence (see e.g. Dick\&Swepson 1994). A good modelling practice (see e.g. STOWA 1999; Anonymous 2000; Scholten et al. 2000) can help to produce valid modelling results, but is in itself no guarantee of good quality decision making. It is important that in the first two steps (natural system and conceptual model) that aspect of the actual problem that will be considered in the problem analysis and solution finding is selected. These steps will sharply define the solution space, and should resemble the second step (problem definition) of the policy development cycle. When this is not the case, there is a danger of applying the model outside its range of validity. The other way around, a model may, intentionally or not, constrict the solution space.

Haag\&Kaupenjohann (2001) describe model building as:

... a subjective procedure, in which every step requires judgement and decisions, making model development 'half science, half art' and a matter of experience. The selections employed in the course of ecosystem abstraction and encoding are subject to criticism precisely because they are selections, i.e. because they include the possibility of alternative selections and hence appear as contingent. Owing to the contingent character of the selections embedded into models, models may face critique from both scientists and laymen, when employed in the course of decision-making.(:50)

This gives some explanation for the difficulties presented in the first section. In order to mitigate the difficulties, Haag and Kaupenjohann recommend that:

... models should become more transparent, framing of models and model choice and the evaluation of models should involve extended peer groups

(stakeholders, local actors), and knowledge conveyed by models is to be configured for concrete problem contexts.(:57)

Their description and recommendation focus attention on the discussion of models on a conceptual level, in stead of discussing software implementations.

An important relationship of the modelling cycle with the problem solving / decisionmaking cycle lies on the conceptual level. Conceptualisation of a problem is often considered from the perspective of system theory (e.g. Kramer\&Smit 1991). It would be possible to use already the conceptual model for decision-making support at this stage. 
However, the danger of using conceptual modes in complex situations is that the model may be incomplete and / or inconsistent. This danger may be partly remedied by discussing the conceptual model and thus bring to light the model structure and causeeffect relationships. Also the underlying assumptions, values and preferences can be made visible. In this way the conceptual model is a source of information. Still, the problem of incompleteness and inconsistency remains unresolved. Aggravating this situation is the fact that intuitive ideas about the behaviour of the system are often incorrect. The expectation of the long-term dynamic behaviour of systems involving feedback mechanisms solely on the basis of descriptive models is especially problematic. This could lead to choosing the incorrect alternatives and result in unexpected effects (Geldof 2001).

A more rigorous remedy (than a mere discussion of the conceptual model), that uses system dynamics, is described by Forrester (1994). Here, the conceptual statements are programmed in a computer simulation model. The computer model forces logical completeness and consistence by producing error messages for incomplete or inconsistent model-entries. The simulation brings to light any assumptions that were implicitly included in the conceptual model and in the alternative solutions, because these have to be explicitly stated in the model structure or the model input. Also knowledge of local actors can be included. The logical consequences (outputs) of a simulation model are often different from expectations, especially for long-term system behaviour. The insight gained by the simulation model building and execution process can be used to improve the conceptual model. The conceptual model will, however, remain the basis for most decisions. The use of system dynamics to validate (to some extent) conceptual models in complex situations is also described (see e.g. Wolfenden 1997; Belt et al. 1998; Gill 1998). The use of simulation models, however, does not explicitly recognise the role of mental models in the selection of model elements and interpretation of observational data.

In conclusion, the scientist's or modeller's conceptualisation of the problematic behaviour under consideration (i.e. their conceptual model) should match the conceptualisation of the problem solver or policy designer. The latter may have conceptualisations that are illogical and may have intuitive expectations of system behaviour that are wrong. Therefore communication on a conceptual level, the level of the mental model, is important for the successful use of computerised calculation models. Such a model delivers meaningful information only because the information can be connected to the mental model, where observational data from reality also gets its meaning.

\subsubsection{Model as interface for knowledge transfer between science and policy}

In the process of problem solving, described in section 2.2.1, models (mathematical or otherwise) have the purpose of supporting the decision-making process. Rip (1996) describes how models can facilitate delegation of responsibilities of decision-makers, by offering them methods, predictions, explorations, etc. Models do not solve the decision problem, but models do make the problem manageable, by reflecting the way reality is reduced to simple abstractions, and by offering a way to demonstrate effects of possible choices. According to Edwards (1996) the decision makers are part of, and have to deal 
with the problem context. The disciplinary experts possess the knowledge of a certain subsystem (natural, economical, ecological). The relationships between the problem context and the system knowledge is characterised, in unstructured problems, by the search for the exact nature and definition of the problem. Each stakeholder identifies other problems. On the basis of a problem-, system- and stakeholder analysis and several discussions a multitude of different conceptual models can, ideally, be converted into a common model concept, which then can be implemented in a decision support system.

Scientists introduce their specific knowledge into the decision making process through models and/ or model results. Computerised (mathematical or empirical) models support the decision making process by making available quantitative information like data and outcome predictions. Non-quantitative models (like schematic representations of causal relationships, or even textual descriptions) can be used to acquire insight in the problem situation and processes involved. In this way, the model is the connection between the scientists (who wants to solve the technical problem) and the social context (in which it is often not completely clear what exactly the problem is). As was described in the previous section, already conceptual models can be used for knowledge transfer.

The process oriented quantitative models produced by scientific research exhibit several limitations when applied to real world problem solving (e.g. in decision support systems). These limitations include, among other things, long computer runtime, extensive amount of input and output data, considerable amount of expertise needed for model use, and model use limited to specific research situation. These limitations can be addressed then by using a meta-model, which is a simplified version of the original model suitable for a specific application (Schoumans et al. 2002). By abstracting the detailed information the original process models can supply information to a meta-model at a level where less detail is required, like decision support. The disadvantage is that insight in the relevant processes is not available within the meta-models. The process-oriented models, therefore, are still necessary to generate insight and to quantify effects on a detailed level.

Models that are used in problem solving may serve a significantly different purpose than the original research model, and details regarding knowledge of the specific research situation may not be readily available for the model user. It is, again, the communication of the conceptualisation of the problem that is the relevant issue here, that should give the model user insight into the common behaviour of identified system archetypes (see e.g. Randers 1980; Sterman 2000b; Luna-Reyes 2003).

According to Funtowicz\&Ravetz (1999) the specific perspective on the system offered by a single model is not a unique, privileged one. The criteria for selection of data, truncation of models, and formation of theoretical constructs are value-laden, and the values are those embodied in the societal or institutional system in which the science is being done. The difficulties described in section one could be in part attributed to a mismatch between calculation results and the mental models of the various stakeholders involved. Therefore problems in the use of information in policy design or decisionmaking can be traced back to mismatches between information produced by the 
computer model and the mental model. In fact, when we realise that the computer model is based on the mental model of the researcher, it is a mismatch between mental models of the decision maker and the researcher.

\subsection{Problematisation: complex multifunctional systems}

This section analyses why knowledge utilisation in the framework, presented in the previous section, is problematic, by looking at unstructured problems and communities of knowledge construction. It also serves as a kind of validation of the framework, in that the framework must be consistent with these two theories.

\subsubsection{Unstructured problems}

This section describes some characteristics of multidisciplinary, multi-stakeholder, complex problems that can explain the discourse, discussion, deconstruction and legitimisation surrounding the application of scientific knowledge in the public policy system.

Integrated assessment considers problems to be part of a larger context, that will interact with the problem, meanwhile changing the problem itself. In this context it is impossible to design problem solutions within a given set of fixed objectives, decision criteria, boundaries and constraints (the typical 'traditional' engineering approach to developing solutions). Rather, changing opinions and insights should be anticipated and dealt with, which asks for a problem finding approach. In the discipline of process design in building and construction, the difference between these approaches are summarised with the terms "tame" and "wicked", respectively (Rittel 1972; Ackof 1979). In the discipline of business management the concepts "hard" and "soft" are used (Checkland 1981; Pidd 2003). In the discipline of public policy the concepts "structured" and "unstructured" are used (Hisschemöller 1993). In the remainder of this section the notion of unstructured problems is analysed, and the notion of system complexity is added, to create a three-dimensional matrix in which problems can be characterised.

Figure 2-3 shows a general problem space spanned by the three dimensions of system, knowledge and society. The system is the 'reality-out-there', which one experiences through sensory observations. It provides the data one transforms into information and subsequently into meaning. The system can be divided into a natural (physical, ecological) system and a human (organisational, economical, political) system. Knowledge of the system is gained by building models that explain observational data. Each scientific discipline constructs its own models using its own paradigm. Society represents the individual values and opinions, and group norms and paradigms of each stakeholder group involved in the problem, which all influence behaviour and choice. Perceptions of the system also determine interests and stakes that interact with norms \& values. The three dimensions influence each other. Modelling is complemented by monitoring, forecasting of effects of alternative solutions by debate about validity, and problem perception by remedial action. Models are based on data, but can also be helpful in the design of monitoring programs and the interpretation of data. Weighting of 
decision criteria depends on gaining new knowledge (learning) from scientific disciplines, and so does the development of the set of criteria. The modelling and forecasting makes knowledge explicitly available for the decision making process. Integration can take place between the different aspects within one dimension, after which the interaction processes between dimensions become much more complicated.

The plus sign at the end of each axis indicates complexity. For a system, complexity means more entities having more properties and more relationships, which relationships can also be more complicated (e.g. Forrester 1968; Checkland 1981; Kramer\&Smit 1991; Wilson 1993). De Groot (1992; 1994) and Rotmans (1999) extend this definition with the notion of user functions, which indicate the interaction of social, economic, and institutional dimensions with the natural dimension. For knowledge, complexity equals uncertainty in disciplinary knowledge (due to limited knowledge and/or disagreement on analysis methods) and in the coupling of knowledge from different disciplines. Although scientific knowledge at first sight appears to be objective, it is seen by Ravetz (1987) and Jasanoff (1990), however, as socially constructed within the paradigm of the limited scientific group that produces the knowledge. For society complexity means uncertainty and disagreement about values and norms of stakeholders. This is the field of discussion and negotiation. The choice of who takes part in this discussion and negotiation depends on values and world view.

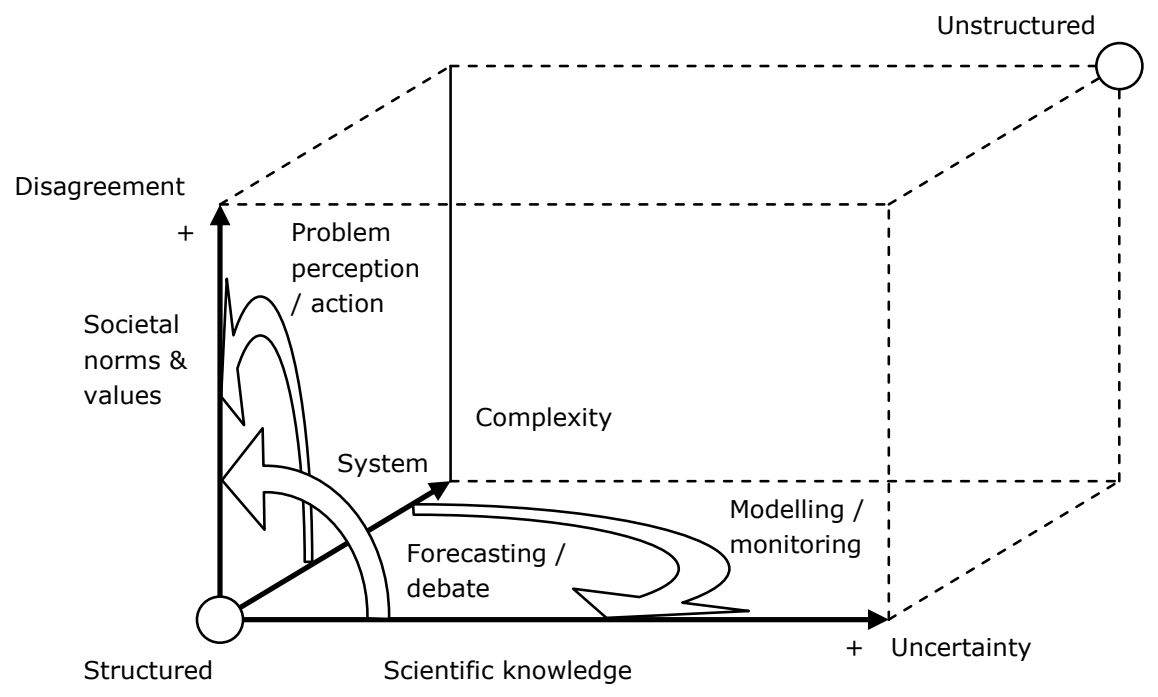

Figure 2-3: The three dimensions of complex unstructured problems. Adapted after (Hisschemöller 1993). 
In unstructured problems, the separation of facts and values is no longer discernible. Which part of the natural system is considered relevant, what counts as knowledge, and how knowledge may support decision-making is subject to discussion between the different paradigms involved in the problem. Figure 2-3 depicts the elements entering such a discussion. Quantitative models may not be the most appropriate tools for communication and discussion, because they hide complexity, uncertainty and disagreement. Mental models, and the frames they are used in, may be more suitable because they more readily allow discussion of these aspects.

\subsubsection{Communities of knowledge construction and valuation}

The unstructured nature of problems gives rise to discussion and discourse not only on a societal level, but also on the level of professional consultancy and the level of applied science. The discussions within and between the communities that represent these levels can be structured by the notion of problem solving strategies. The following description is based on Funtowicz\&Ravetz (1993b; 1999) and (Ravetz (1999).

The traditional problem-solving strategies of core science, applied science, and professional consultancy do not suffice for solving complex social type of problems. For this type of problems Funtowicz\&Ravetz (1993b) have devised an approach which call "post-normal" science. Funtowicz\&Ravetz use systems uncertainties and decision stakes as attributes to distinguish between problem types. The term "systems uncertainties" conveys the notion that the problem is concerned not with the discovery of a particular fact, but with the comprehension or management of an inherently complex reality. The term "decision stakes" incorporates all the various costs, benefits, and value commitments that are involved in the issue according to the various stakeholders. Depending on the amount of uncertainty and disagreement, one of three problem solving strategies can be identified as appropriate. The first type is applied science (which includes as a sub-type core-science), the second professional consultancy, and the third post-normal science. These problem solving approaches are represented in figure 2-4 as concentric segments with increasing uncertainty and disagreement. 


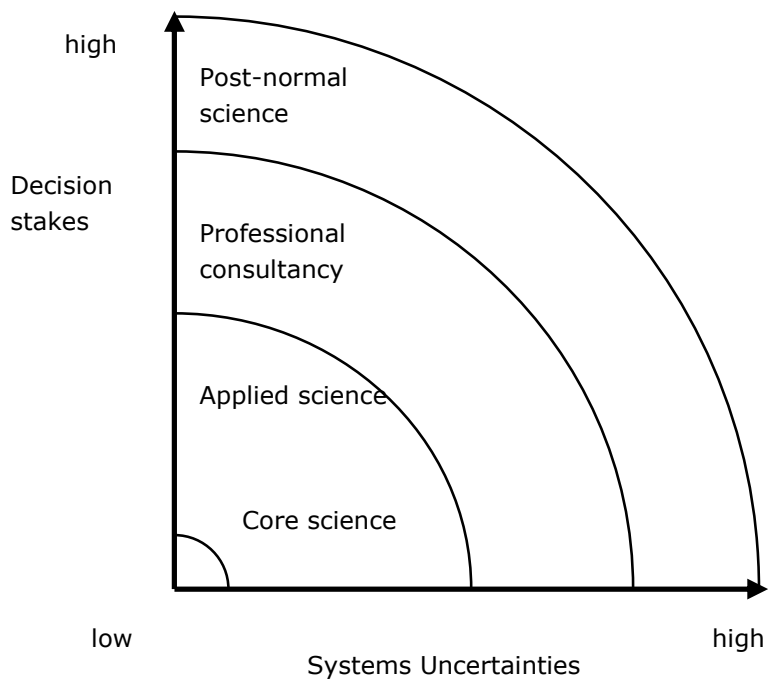

Figure 2-4: Communities of knowledge construction and their different problem solving strategies, from Funtowicz\&Ravetz (1993b). Post-normal science takes place in the social-political arena.

The traditional "pure", "basic" or "core" science is concentrated around the origin of figure 2-4. By definition, there are no external interests at stake in curiosity-motivated research, so decision stakes are low. Also, this type of research is generally not undertaken unless there is confidence that the uncertainties are low, that is that the problem is likely to be solvable using a normal, puzzle-solving approach. Quality is assured through the traditional processes of peer review of projects and refereeing of papers - the process of scientific knowledge production is reviewed, that is.

When both uncertainty and disagreement are small, "applied science" can be used, where expertise is fully effective. Here the quality assurance is performed by users of the research products, who have less need to understand the research process. The outcomes of both applied science and core science have the features of reproducibility and prediction, for they operate on isolated, controlled natural systems.

When there is an intermediate level of either uncertainty or disagreement, the application of routine techniques requires supplementation with skill, judgement, and sometimes even courage, and the "professional consultancy" would be applicable. Professional consultancy includes applied science, but deals with problems that require a different methodology for their complete resolution (e.g. the application of "engineering judgment"). The problem solving task is performed for a client, whose requirements are to be met. Consultancy searches for a "workable and acceptable" solution within the given boundaries. The tasks deal with unique complex situations, and each practitioner may conclude with different results and even disagree.

When either uncertainty or disagreement is high, "post-normal science" applies, and the problem enters the societal/political arena. Stakeholders will each search for their most opportune solution. Knowledge is used to defend positions and to deconstruct opponents' 
arguments. An issue in post-normal science is characterised as one where facts are uncertain, values in dispute, stakes high and decisions urgent. For such an issue, methodologically true scientific facts do not simply determine the correct policy conclusions. The traditional certainty and value neutrality of science do not apply any more. Quality assurance can be the guiding principle in post-normal science. This goes beyond the traditional scientific methods, in that it requires an "extended peer community", consisting of all stakeholders involved in a problem. Extending the discussion arena provides a path to the democratisation of science. Because conclusions are not completely determined by the scientific facts, inferences will (naturally and legitimately) be conditioned by the values held by the actor. If the stakes are very high (as when an institution is seriously threatened by a policy) then a defensive policy will involve challenging every step of a scientific argument, even if the systems uncertainties are actually small. Such tactics become wrong only when they are conducted covertly, as by scientists who present themselves as impartial judges when they are actually committed advocates. Ethical aspects now enter the quality assessment.

The figure of Funtowicz\&Ravetz (1993b) reproduced in figure 2-4, fits, under the assumption that stakes relate to values, on the front side of the cube presented in figure $2-3$, in that it describes the types of interaction between scientific knowledge and value aspects of unstructured problems. It illustrates how actors from various communities give priority to different fields of constraints: for policy makers, it is the political environment; for researchers, peer review and funding; and for practitioners, the clienteles they directly serve. These priorities are expected to reflect in the mental models each actor uses. The difficulties described in the first section can be positioned into the various levels in figure 2-4. 'Good quality' implies the illumination of all facts and values involved in an issue, including their relationship to the specific positions of the actors. Mental models can play a role in this illumination.

\subsection{Frames}

What drives the choices made in all steps of the problem solving cycle? We start with the observation that in complex, multifunctional problems the meaning of information is socially constructed, and guided by different frames of perception (see e.g.

Funtowicz\&Ravetz 1994; Schön\&Rein 1994). Schön\&Rein (1994) see policy positions as resting on underlying structures of belief, perception, and appreciation. They call these structures "frames", a term which they take from Vickers (1983). An earlier origin of the term "framing" is Goffman (1974) cited in Pidd (1998). Goffman introduced the term framing as a way of explaining how we make sense of events by employing a scheme of interpretation (a framework). When we come upon some new experience we tend to interpret it in the light of our existing frameworks even if we are unable to articulate what these frameworks may be. The term "framing" is used by Schön\&Rein (1994) in the meaning of "making sense of complex, information-rich situations through the operation of selectivity and organisation" (:30). Schön\&Rein note that their use of the idea of framing is radical constructivist, in the sense described by e.g. Piaget (1962), Goodman (1978), and Von Glasersfeld (1995). They consider their term "frame" to be synonym with world view, paradigm and perspective (:56). Mitroff\&Linstone (1993), working in the discipline of complex business organisation problems, argue that a new paradigm for 
decision-making is needed within decision support systems, which requires consideration not only of the technical perspective, but also broad organizational and personal perspectives, and ethical and aesthetic issues, as well. These perspectives can be seen as separate parts of a frame.

Schön\&Rein (1994) see policy controversies as disputes in which the contending parties hold conflicting frames. The frames held by the actors determine what they see as being in their interests and, therefore, what interests they perceive as conflicting. Disputes are resistant to resolution by appeal to facts or reasoned argumentation because the parties' conflicting frames determine what counts as a fact and what arguments are taken to be relevant and compelling. Moreover, the frames that shape policy positions and underlie controversy are usually tacit, which means that they are exempt from conscious attention and reasoning. Frames are grounded in the institutions that sponsor them. Frame differences cause communication barriers that prevent mutual learning and understanding. It is within the frames that information is judged and synthesised into a problem solution (see figure 2-5). Figure 2-5 also shows how the "noisy" data from the real world is filtered by the mental model by connecting it to specific elements one wishes to discern in the real world. The connection to specific elements constitutes the information. Information is transformed into meaning by relating it to the possible actions and their consequences in a specific situation. According to Schön\&Rein policy makers' ability to reach agreement depends on their learning to understand one another's' point of view. In order to do this each party would have to be able to put in terms of his or her own frame the meaning of the situation as seen by the other in terms of the other's frame. They call this process "reciprocal frame reflection". According to Schön\&Rein academics could help with the process of reciprocal frame reflection (by constructing from a record of practitioners' doing and thinking the frames that underlie their policy positions) and with creating conditions of mutual trust (by surfacing dilemmas of participation, by testing publicly assumptions that policymakers make about their counterparts, and by educative demonstration and dialogue). This corresponds to the ideas of Mittroff\&Linstone (1993) who state that an open, honest, effective dialogue among all relevant stakeholders is a critical aspect of developing multiple perspectives. The view of Schön\&Rein (1994) also corresponds with the view of Fischer (2001), who describes how the participatory expert functions as an interpretive mediator operating between the analytical frameworks of (social) science and competing local perspectives of citizen stakeholders.

Mitroff\&Linstone (1993) introduced the multiple perspective approach in the field of organisational decision making. Their TOP-approach involves three very different types of perspectives in addressing complex problems. These perspectives are: $\mathrm{T}$ : the technical perspective; $\mathrm{O}$ : the organizational or societal perspective; $\mathrm{P}$ : the personal or individual perspective. Courtney (2001) added the E: ethical and A: Aesthetic aspects, in order that decisions include the human aspect, especially in situations where the decision includes social aspects. More recently Hall et al. (2003), in a comparative study of perspective models, extended these aspects with an economic aspect which they take from Spranger (1928/1966). Moreover, they use the six types of personal values (perspectives) that individuals exhibit, according to Spranger, to compare with the perspective definitions of different authors. 


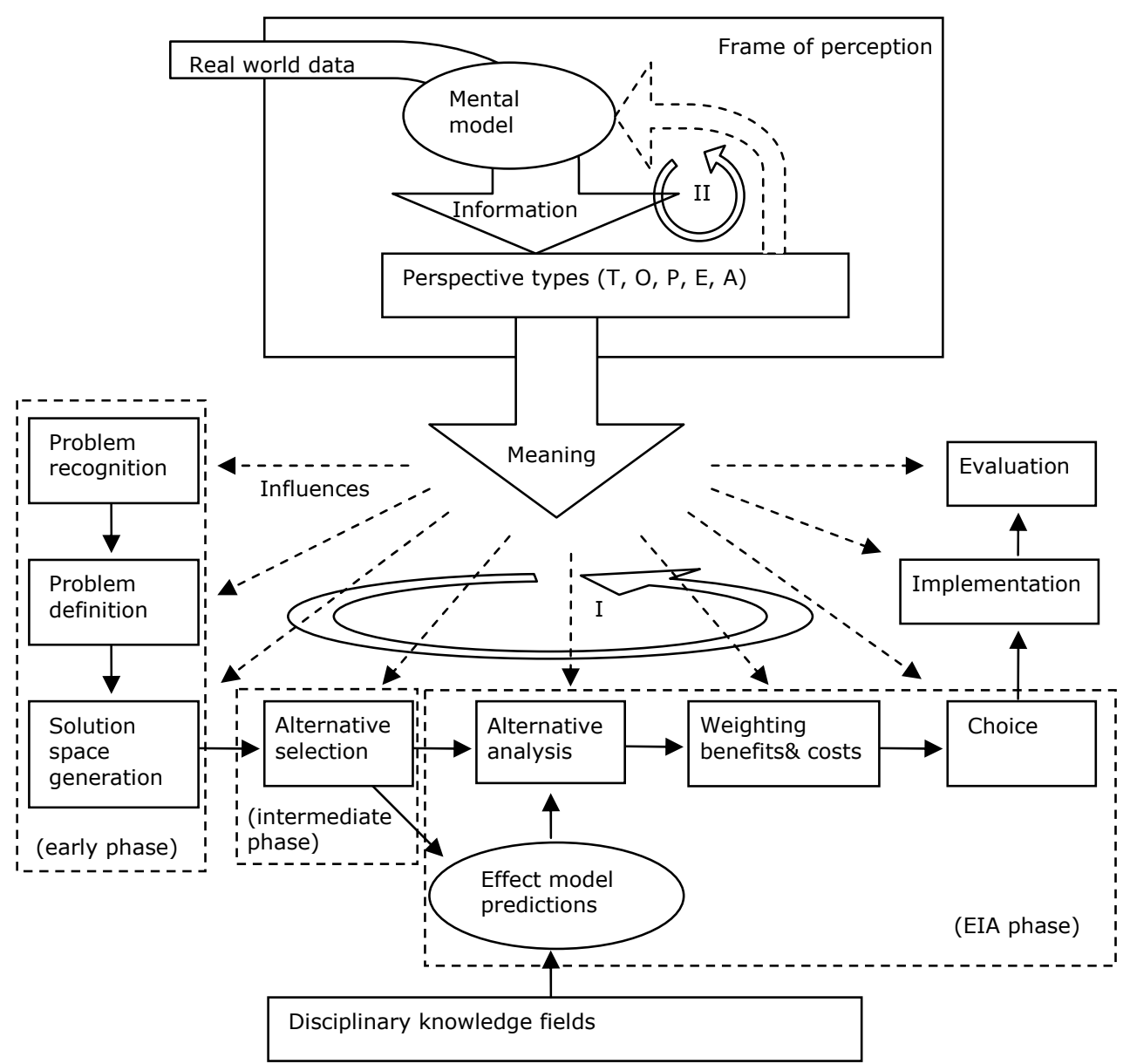

Figure 2-5: Our full theoretical framework, showing the frame with its mental model en perspectives in the upper part, the decision making cycle in the middle and the use of disciplinary models in the lower part. The decision making cycle is influenced by the frame of perception and, indirectly, by the mental model. The mental model acts as a 'filter' that selects information from the 'real world' to be used in the frame. The frame can induce changes in the mental model by second order (II) learning processes. First (I) order learning is also indicated. Solution of complex problems need second order learning. Disciplinary knowledge enters the decision making process through the effect models used. Anticipating the case description in chapter 4, several phases are identified in the decision making cycle. In general, an environmental impact assessment (EIA) concerns a limited set of steps from the cycle. In the preceding (intermediate) phase the number of alternatives to be studied in the EIA is reduced. In the early phase of the cycle the possible alternatives are limited by setting restrictions for the solution space. 
Spranger's six types of values are: theoretical, social, political, religious, aesthetic, and economic. Courtney (2001) describes the use of frames as follows:

The decision process begins, of course, with the recognition that a problem exists; that is, a decision needs to be made. But rather than jumping simply into analysis (the technical perspective), the process consists of developing multiple perspectives of the various kinds described above. The various perspectives provide much greater insight into the nature of the problem and its possible solutions than the heavy reliance on the technical perspective that DSS has advocated in the past. (:30)

Haag\&Kaupenjohan (2001), from the discipline of ecological modelling, also plead for the construction of, what they call broad 'reading frames' that guide the description of the ecological system (in terms of parameters and relationships), in order to produce models that are usable for decision support:

'Different perspectives, domains of phenomena of interest and decision stakes lead to differing, non-equivalent system descriptions.'(:53)

'There is no privileged epistemic access to complex systems that would allow for a single, objective description. Instead, different perspectives lead to a plurality of legitimate system descriptions that cannot be reduced to a common denominator.' (:54)

'Following the guideline "deliberation frames analysis-analysis guides deliberation" established by the US National Research Council for risk issues (Stern and Fineberg, 1996), deliberation and discourse among stakeholders serve to identify phenomena and parameters of interest, to formulate problems and to frame observation.' (:55)

Haag\&Kaupenjohan (2001) note that model builders construct reading frames not only driven by the system under study, but also by pragmatic features related to the interests of the mode builder and the purpose for which the model is built $(: 47)$. The resulting model or model based knowledge represents a truth statement which does say little about its desirability and applicability to real-world conditions (p.48). When it comes to environmental decision making, different scientific disciplines and different stakeholders of social sub-systems organize their observation of the environment in accordance with their specific codes, distinctions, values and norms, giving rise to non-equivalent or even incommensurable descriptions of complex ecological or ecological -economic systems (:49). This observation corresponds to the notion of complex unstructured systems. It is within such systems that post-normal science has to cope with the framing of complex systems under conditions of uncertainty and perspectivity. In such systems the quality and validity of scientific results become a matter of debate, and knowledge of local conditions can also determine which data is strong and relevant $(: 54)$.

In summary, the solving of complex problems implies the integration of perspectives between stakeholders (including decision makers, disciplinary experts and public). These perspectives are shaped in frames that guide the construction of the meaning of information, and thereby shape policy positions and underlie controversy. Reciprocal frame reflection can overcome communication barriers and stimulate mutual learning and understanding, and thus stimulate stakeholders to reach agreement. Frames can be found on the level of an individual person and on the level of institutions. 


\subsubsection{Individual level - frame reflection}

The goal of policy science is to improve the concrete content of the information and the interpretations available to policy makers (Lasswell 1971). In order to improve we must become aware of our frames, which is to say that we must construct them, either from the texts of debates and speeches or from the decision, laws, regulations, and routines that make up policy practice (Kuhn 1964). Schön\&Rein (1994:57) introduce frame reflection as a method to help explain policy controversies, and to design new strategies for their resolution. Its two main purposes are:

1. "To articulate a frame-critical approach that challenges the prevailing, objectivist view of policy analysis," which "recognizes the discrepant frames from which conflicting policy positions arise, that seeks to bring them to consciousness, and that subjects them to critical reflection."

2. To advocate "a frame-reflective approach to policy practice, which recognizes the ability of practitioners to reflect on the frames that shape their conflicting positions and thereby foster a normative approach to public discourse within which policy controversies are more likely to be resolved through reflective inquiry."

The research presented in this dissertation will develop a method that will support these two purposes.

According to Schön\&Rein (1994:45) policy makers' ability to reach agreement depends on their learning to understand one another's' point of view. In order to do this each party would have to be able to put in terms of his or her own frame the meaning of the situation as seen by the other in terms of the other's frame. The antagonists might then create a reciprocal, frame-reflective discourse. Schön\&Rein (:189) approach the "rigor of relevance" dilemma through their notion of design rationality, which attributes to practitioners a capability for reflective inquiry on all aspects involved in the complex problem. Schön\&Rein (:194) suggest to examine:

a) The controversies that arise around issues and to construct the frames that underlie them,

b) The forms situational controversies take in different policy situations,

c) The different trajectories of inquiry to which they give rise,

d) The communicative interactions central to controversies, in retrospective study. The process that Schön\&Rein $(: 170,171)$ call co-design resembles the term "participatory inquiry" used by (Fischer 2001), which is discussed in the next section.

\subsubsection{Institutional level - policy epistemics}

Fischer (2001:1) uses the notion "participatory inquiry" to denote the facilitation of collective deliberation between the analytical frameworks of social science experts and the competing local perspectives of citizens. The process of inquiry extends the horizons of both scientists and citizens through discursive confrontations. (:2) The development of discursive practices capable of informing and guiding the processes of participatory inquiry needs knowledge about the ways people communicate across differences, the flow and transformation of ideas across borders of different fields, how different 
professionals groups and local communities see and inquire differently, along with the ways in which differences become disputes. Fischer $(: 2)$ describes policy epistemics as a social science specialization which is to produce such knowledge. The term "epistemics" Fischer (:12) borrowed form Willard (1996). Policy epistemics examines the interplay between specific statements or claims (Fischer:13). Fischer describes the goal of policy epistemics to be:

"to study the ways in which its members [of a policy community] share background assumptions about the particular problem areas, their ideas about the relations of particular science to decision-making, the role for citizen involvement, how they respond to outside opposition. ...The goal is to understand how these varying [between groups] cognitive elements interact to discursively shape that which comes to be taken as knowledge. " (:14)

According to Fischer $(2001: 15,20)$ policy epistemics analyses the interrelationships between the empirical and the normative inquiry, between the quantitative and the qualitative inquiry. ... It investigates the way interpretive judgments work in the production and distribution of knowledge. In particular, it's goal would be to study:

1. the ways in which both experts and laypersons share background assumptions about the particular problem areas,

2. their ideas about the relations of particular science to decision-making,

3. the role (if any) for citizen involvement, and

4. how they respond to opposition.

In particular, it has to focus on:

5. the movements and uses of information,

6. the social assumptions embedded in research designs,

7. the specific relations of different types of information to decision-making,

8. the different ways arguments move across different disciplines and discourses,

9. the translation of knowledges from one community to another, and

10. the interrelationships between discourses and institutions. (:20)

Most important, according to Fischer (2001), policy epistemics would involve innovating methods needed for coordinating multiple discourses in and across institutions. In doing so, the differing, often tacitly held, contextual perspectives and values could be juxtaposed, the viewpoints and demand of experts, special interests groups and the wider public directly compared, and the dynamics among the participants could be scrutinized.

Fischer $(2001: 15,20)$ concludes that policy epistemics is in need of innovating methods to coordinate multiple discourses in and across institutions. According to Schön\&Rein (1994:195) academics could help with the process of reciprocal frame reflection (by constructing from a record of practitioners' doing and thinking the frames that underlie their policy positions) and with creating conditions of mutual trust (by surfacing dilemmas of participation, by testing publicly assumptions policymakers make about their counterparts, by educative demonstration and dialogue). Based on Schön\&Rein (1994) the present research concludes that frame reflection might be on of those methods asked for by Fischer. 
But instead of using frame analysis as a method to alleviate difficulties in the problem solving cycle, the present research will search for a cause of these difficulties at a deeper, cognitive level - the level of mental models. We will investigate whether the elicitation and analysis of mental models can give answers to some of the research questions formulated by these authors.

\subsection{Mental models}

The present research follows Courtney (2001) by analysing the mental models that underlie frames. A frame contains actors' knowledge, assumptions, interests, values and beliefs. But it is the mental model that determines what data the actor perceives in the real world, and what knowledge the actor derives from it. Because the construction of new knowledge is based on existing mental concepts, these existing concepts determine what new data the actor cares to observe in reality, i.e. existing concepts act as a "filter" through which the actor observes the problem situation (see figure 2-5). Therefore the perspective from which alternative problem solutions are deliberated and decided upon is ultimately based on an actor's mental model. Different mental models of the problem situation, and mismatch of decision data with the mental models, will result in different opinions of the problem solution, and in this way constitute the basis of many difficulties in the policy design or problem solving cycle. Courtney (2001) puts the mental model at the heart of the decision making process (see figure 2-5):

At the heart of the process is a mental model. Actually, this could be several mental models, or a collective model of some sort. As Churchman (1971; 1982) and Mitroff\&Linstone (1993) and point out, this model and the data selected by it (and hence the problems selected for solution) are strongly inseparable. Our mental model, either personally or collectively, determines what data and what perspectives we examine in a world of overabundant data sources and a plethora of ways of viewing that data. The mental models influence and are influenced by every step of the process. That is, the models determine what is examined and what perspectives are developed. As perspectives are developed, insight is gained, and the mental models are updated. That is, learning takes place. Tacit knowledge is created. (:30)

According to Courtney (2001) enhanced perspective development will naturally expand an individual's (or organisation's) mental model and therefore positively affect the decision making process (in that it reduces conflict). (Hall et al. 2003) refer to earlier research that indicates that facilitating the development of multiple perspectives may be beneficial in encouraging individuals to overcome their innate mental models during specific problem-solving context. This boils down to fostering communication between individuals, recognising individual differences. (Courtney 2001) states that different perspectives originate by the process of "framing" reality from different mental models, during which process new insights may be created that can adapt the mental model - a learning process takes place. The process of framing is described in e.g. (Pidd 1999:76).

In addition to the role of mental models in Courtney (2001) and Costanza \& Ruth (1998), referenced in (Haag\&Kaupenjohann 2001), have noted that dynamical simulation models 
offer a remarkable potential for consensus building in concrete environmental decision situations, by stimulating discussion of the choice of the domain of phenomena of interest, of adequacy of the theory and of the parameters and the selection and evaluation of models for decision purposes. These discussions again are concerned with the cognitive level of knowledge of stakeholders and experts involved, on the level of mental models. The role of the simulation model described by Haag\&Kaupenjohann (2001) can by linked to the mental model in that the mental model drives the simulation model building, and running a simulation model promotes the update of the mental model. A more detailed analysis of the interaction between the mental model and the simulation model can be found in Doyle et al. (2001).

The development of mental models takes place mainly in the problem articulation phase of the decision making cycle. The complex, multifunctional and multidisciplinary nature of problems causes a large range of mental models to spring into existence. When all parties are not adequately involved early in the problem solution process, to share each others mental models, the (often implicitly) developed mental model could be insufficient to legitimise the preferred solution, and incomplete or even wrong information/ knowledge could have been produced in the project or selected for inclusion in the project report. Comparison of mental models, decision process structure and actual use of knowledge will reveal (potential) points of conflict, which could then be addressed.

The description of the problem solving cycle presented previously (figure 2-1) is now extended with frames and mental models, as is depicted in figure 2-5:

- $\quad$ An actor's mental model restricts information flows to only those aspects that affect the actor in question. Restrictions may by on the scale (geographical boundaries, time horizon, resolutions c.q. level of detail) and on the processes and relationships considered relevant (including physical, biological, legal, social and scientific actors to be included).

- Choice, in turn, is constrained and framed by the actor's information or perception (about physical possibilities and legal rules and customary norms), which constitute the actor's solution space (i.e. set of opportunities).

- Choice also follows the expected consequences over the full range of (economic, political, social, ethical, well-being) benefits and costs experienced by the decision making actor.

- Solution space and consequences are explored and interpreted or valuated (using conceptual models and frames of reference and simulation models). The danger exists of a "self contained" solution, which is basically restricted by the actor's conceptual model.

- $\quad$ Learning (second order learning, i.e. the updating of a persons conceptual model) offers a way out of this "self contained" solution loop.

This description is in agreement with Grant\&Thompson (1977).

\subsubsection{Definition of mental model}

The term "mental model" is used in many disciplines, each having its own specific definition, for example:

- $\quad$ System dynamics (Forrester 1971; 1994; Sterman 2000), 
- Cognitive sciences / psychology (Craik 1943),

- Deductive reasoning (Johnson- Laird 1983),

- $\quad$ Business management science (Axelrod 1976; Eden 1994; Senge 1990),

- Human-machine and human-computer interaction (Norman 1983; Schwamb 1990),

- Design of interactive, web-based, learning environments (Barker 1999),

- $\quad$ Learning and instruction (Ausubel 1968; Novak\&Gowin 1984; Kinnear 1994; Jonassen 2003),

- $\quad$ Development of expert systems (Ford et al. 1991; Cañas et al. 1999).

The ambiguity and confusion in the definition of "mental model" is reflected in communication problems with integrated approaches. Doyle\&Ford (1998) argue that the term "mental model" should be used to refer to only a small subset of the wide variety of mental phenomena with which it is often associated. Here we use the definition proposed by Doyle\&Ford:

"A mental model of a dynamic system is a relatively enduring and accessible, but limited, internal conceptual representation of an external system whose structure maintains the perceived structure of that system". (p.17)

A mental model includes not only knowledge but also information about interconnection and organization of that knowledge (in nodes and links). According to Doyle\&Ford $(: 20) a$ mental model does not include attitudes or goals, because these do not represent something external to an individual's mind, nor does a mental model include exogenous variables and a time horizon. These excluded aspects are "inputs" for the mental model. "Running" a mental model is equivalent to propagating information through the conceptual structure. The "model output" is used to plan actions and to explain and predict external events.

Doyle\&Ford (1998) suggest the term "cognitive map" to refer to the external representation of the mental model. This term, however, has been used by Axelrod (1976) and Eden (1994) for specific use in Operations Research situations. Therefore, in contrast with Doyle this research follows Ausubel et al. (1978) and Novak\&Gowin (1984) in using the term "conceptual map" to denote the external representation of the mental model. This map is the researcher's conceptualisation of a subjects' mental model.

Experiences with concept mapping in the above mentioned disciplinary fields, and also in the field of water management (Lumpkin 1999), show that mental model mapping can support understanding, learning and decision making.

\subsubsection{Concluding words on mental models and mapping}

The validity of figure 2-5 as a general model that is valid for different situations of problem solving is proposed based on literature from the three different theories that are integrated in this figure (problem solving, frames, and mental models), as described in the previous sections. Different fields of research all indicate that elicitation of mental models can reveal the experiences, perceptions, assumptions, knowledge and subjective beliefs that a "model user" draws upon to reach his conclusion about some issue.

Mapping mental models assesses tacit knowledge, broadens the narrow understanding of a problem by confronting one stakeholders' map with the map of others, makes aware of 
alternative perspectives on the problem, encourages negotiation and helps to reduce destructive conflict. The basic idea is to elicit a person's knowledge and consequently open it up to discussion. This is precisely how mental models may link to the needs signalled in the first section by many authors in the field of integrated problem solving.

A main advantage of the analysis of mental models above the analysis of frames is the unchallenged institutional and normative position of the actors, because mental model mapping does not doubt the validity of an actor's frame, but merely wants it illuminate it by focusing on the information used within the frame. Focusing on the mental model respects and allows the decision maker or stakeholder to be responsible for his/her own valuation of the information in the context of his specific situation. Of course, this can be the starting point of a learning process or critical dispute.

Concept mapping is an instrument for revealing points of departure, goals and assumptions. Concept maps may exhibit the reasoning behind the decision maker's or expert's purposeful actions and they provide a way to structure and simplify thoughts and beliefs, to make sense of them, and to communicate information about them. It can be used in the selection and interpretation of information, and supports information transfer and open communication between actors. In this way concept mapping can be a key to transparent and accountable, good quality decision-making.

An integrated approach to Environmental Impact Analysis implies the integration of perspectives between stakeholders, a process which involves group learning. A way in which multiple perspectives can be taken into account has been described by Courtney (2001) for urban water management:

'The decision process begins, of course, with the recognition that a problem exists; that is, a decision needs to be made. But rather than jumping simply into analysis (the technical perspective), the process consists of developing multiple perspectives of the various kinds described above $[\mathrm{T}, \mathrm{O}, \mathrm{P}, \mathrm{E}, \mathrm{A}]$. The various perspectives provide much greater insight into the nature of the problem and its possible solutions than the heavy reliance on the technical perspective that DSS has advocated in the past. It is suggested that diagramming tools such as cognitive maps ... may be of great use both in showing the connectedness of elements in unstructured systems, and in surfacing assumptions that people hold about wicked [= unstructured] problems.'

The aim of the present research is, in response to Courtney's suggestion, to investigate whether the mapping of mental models can indeed support Schön\&Rein's frame reflection and Fischer's policy epistemics. A major research question is whether the method to construct concept maps meets the criteria described by these authors, and whether map analysis will produce the information wanted. 


\subsection{Discussion of the resulting framework}

\subsubsection{Mental models at the heart of the problem solving process}

The results of the analysis of knowledge production and use are summarised in figure 26. This is a re-arrangement of figure $2-5$ to give the conceptual model a more central place, and to include the main dimensions of integration from figure 2-3 and the communities of knowledge from figure $2-4$. The problem solving cycle is positioned in the upper half of the figure. Connected to the model, and positioned in the lower half of the figure, is the scientific research process (see figure 2-2) that resulted in the model. The model itself can be any type of model, e.g. a set of rules-of-the-thumb, empirical relationships in graphical presentation, a research prototype model, or a meta-model. The model can be made available in a computer application that is less or more userfriendly. As mentioned earlier, the knowledge represented in the models is subject to the epistemological paradigms of the specific scientific disciplines involved. This is represented by the different blocks in the lower half of figure 2-6 which each give a specific view on the problem.

The mental models can be located in each major phase of the problem solving and knowledge production cycles. On the upper left is the mental model of the problem owner, on the upper right are the various mental models of stakeholders, and in the lower half are the various mental models of scientific disciplines involved. The computer model contains a version of the corresponding disciplinary mental model, which the user experiences through the script of the model (Rip 1997).

Integrated problem solving has to cope with technical problems in a social context or with social problems in a technical context. The project-engineer, in his intermediate role, is the connection between the scientists that offer technical information and the social context in which the nature of the problem is often not completely clear. Scientific information is not taken for granted, can be explained in different ways, and the scientific information is 'just another' element in the policy making process. Scientists are admitted to produce their knowledge from specific, and not objective 'frames of reference' which may represent the scientists' own interests and is not infallible. Not all potential users of integrated assessment models will be aware of hidden values or assumptions that are inherent in such tools. Discussion about the applied calculation models can play an important role in communicating beliefs, assumptions and data. This discussion will show the conceptual models lying behind the calculation modes, and reveal mismatches between the different problem conceptualisations of client and stakeholders. According to Birrer (1996) scientists have an obligation to educate stakeholders and the public in order to enable them to judge the value of the information supplied. Discussion of the models applied in solving complex problems can play an important role in communicating beliefs, hidden values, assumptions, limitations and data. This discussion will reveal the conceptual models lying behind the computerised models, and reveal the mismatches between the various problem conceptualisations of decision makers and stakeholders. 


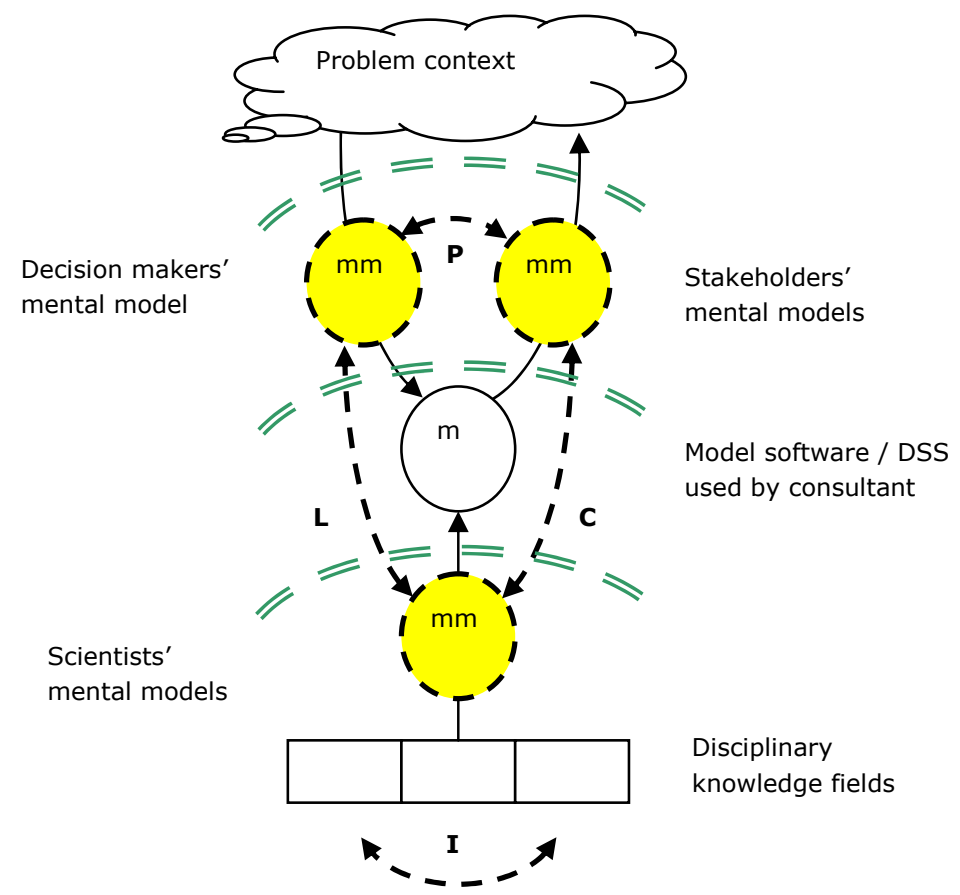

Figure 2-6: The final framework, showing the positions of the various mental models. Compared to figure 2-5, interactions between mental models are added. In the problem solving cycle the decisionmaker's mental model is positioned in the problem analysis phase, and the mental models of various stakeholders in the problem-solving phase. In the modelling cycle the mental models of various disciplinary experts are positioned. Mismatch between these models, it is hypothesised, can explain various decision-making difficulties experienced in practice. The mismatch is commonly denoted as "the gap" between science and policy. The dotted arrows represent the communication processes $L$ (learning), C (social construction of knowledge), P (public participation) and I (integration between scientific disciplines. The curved "umbrella" lines represent the three different communities of Funtowicz\&Ravetz (see figure 2-4). Community paradigms, it is hypothesised, present barriers for the construction of a common mental model.

Figure 2-6 allows indicating some fundamental aspects of integrated assessment. The decision process includes negotiation and legitimisation of alternatives, and validation of knowledge. Discussion on the scientific knowledge used in models will stimulate second order learning processes. Involvement of different knowledge disciplines will stimulate integration between them. Involvement of stakeholders and public in the decision discussion will stimulate participation. 


\subsubsection{Problem solving seen as a learning process}

Learning can be part of the problem solving process, as indicated by Hisschemöller (1993) in Van der Sluijs (1997:38) in his policy typology of policy. Hisschemöller types policy as learning, control, negotiation and pacification. Verbeeten (1999:209) gives a definition of policy-oriented learning in ICZM which starts from the dynamics in management and policies, and which is directed at the management of natural resource systems. She defines policy-oriented learning as 'the interactive process by which an increase in knowledge and insights leads to changes in the definition of a policy issue, the policy objectives and/or the policy goals; the new policy is considered at least as legitimate as before'. Policy-oriented learning is seen as a process of socio-collective learning. Stakeholders learn with each other, which implies that they reach a certain amount of agreement about what is learned.

According to Hisschemöller (1993), structuring a problem in the context of public policy is a social political interaction which is directed at the developing of consciousness regarding the problem by means of the generation, use, exchange, confrontation, evaluation and integration of as much (including contradicting) information as possible. The information regards causal, normative and final assumptions about the problem and its solutions. Hisschemöller considers citizen participation required in the structuring process. At the same time this participation raises the awareness of the tension between "problem finding" and "problem solving" (see section 1.2.3). This tension is, according to Hisschemöller, exactly what makes a problem oriented solution rational. In a solution directed policy effectiveness and efficiency are the central focus to find the best means to the goals intended. This presumes a economical and technical rationality, which can be located in steps 5, 6 and 7 of the problem solving cycle (figure 2-1 and section 2.2.1). Problem oriented policy, on the other hand, presumes a social and political rationality. A social rationality is revealed in the process of problem structuring. It is what Verbeeten (1999:204) calls the "structured interaction between parties". This rationality is located in steps 3 and 4 . A political rationality is revealed in the argumentation for the specific choice of the problem. It is what Verbeeten (1999:203) calls a "break in strategy with regard to the political societal agenda". This rationality is located in step 2 of figure 2-1. The description of Hisschemöller is in fact the description of learning activities that are part of a policy design process. Important learning processes are located in the early phases of the cycle.

With regard to the development of models the term "participatory modelling" indicates the active involvement of problem owner and stakeholders in the development process. The involvement is predominantly with the description on a conceptual level of the knowledge to be included in the model. It presumes that problem owner and stakeholders will participate in a learning process, in which they learn to speak each other's language, and exchange experiences, knowledge, values and norms (a process also described by DeTombe (1994)). Examples of participatory modelling are given by e.g. Wolfenden (1997), Belt (1998) and Gill (1998). 


\subsubsection{Participation of stakeholders}

Participation is concerned with the methods by which local citizens can participate in policy development and decision making. Participation can also be extended to project partners like building contractors or scientific researchers. The general question is to which extend participation benefits the problem solving process. When participation is to low, the wrong problem might be solved, the implementation may be delayed by legal appeal procedures, or there might ultimately be not enough support to implement the solution. When participation is to high, the problem solving process becomes overly complex, reaching a consensus can become time consuming, and participants might become frustrated when their input is not recognized in the chosen solution. The selection of an appropriate level of participation in each of the steps in figure 2-1 is problematic. Literature (e.g. Pröpper\&Steenbeek 1999; Arnstein 1969 cited in Vogelezang 2002) suggests that participation is favourable in the early problem articulation phase and in the definition of decision alternatives, steps 3 and 4 in figure 21. Knowledge of local conditions can also determine which data is strong and relevant, particularly as scientists are trained to abstract and generalized conceptions. Deliberation and discourse among stakeholders could serve to identify phenomena and parameters of interest, to formulate problems and to frame observations.

\subsubsection{Integration between disciplines through coupling of models}

Rotmans (1999) describes integration as the coupling of models in a sequential manner, connecting the different stand-alone models within an integrating environment which facilitates the routing of and translation between inputs and outputs of models.

Knowledge is passed from one model to the next by means of a database. This method cannot deal with feedback relationships between models. The 'sum of models' will not produce more knowledge than already exists within each sub model, no synergy is attained. Computerised decision support systems commonly offer a 'suite' of models in the manner described above.

de Jonge et al. (2000) mention Bertalanffy (1968) and Holling (2001), who describe a general way in which complex systems can be described and studied in an integrated manner, and draw attention on the availability of basic the bridging parameters 'forces and fluxes' as explained by e.g. Ulanowicz (1980). Forces and fluxes are both related to thermo dynamics and thus to energy which term for already a long time has been an accepted parameter in marine ecology (Odum 1971). It is in use for describing e.g. the production of organic carbon or to represent a certain amount of biomass. Other authors (e.g. Glansdorff \& Prigogine 1971; Ulanowicz 1980; 1997) explained that application of thermodynamics to complex systems provides promising opportunities.

Rieger (1977) cites Morris (1971) who already described how semiotics (Peirce 1877) offers ways of integration of scientific disciplines on the level of concepts. His basic idea is that semiotic signs are simply the objects studied by the e.g. biological and physical sciences, and therefore semiotic theory can be used to study the combination of objects in an integrated model. 


\subsubsection{Uncertainty and the process of negotiated construction of knowledge}

With respect to uncertainty literature (e.g. Van der Sluijs 1997; Van Asselt 2000; Walker et al. 2003) indicates that:

- Uncertainty is inherent to the system (e.g. spatial and temporal fluctuations).

- Uncertainty exists in the scientific knowledge, e.g. data uncertainty, model uncertainty, which will result in uncertainty in model results.

- On top of this there is the epistemological paradigm uncertainty between different scientific disciplines, and the policy paradigm uncertainty between actors in the policy arena.

In the policy arena the game is to use uncertainties to deconstruct the opponents argumentation, or to defend the own position against opponents (see section 1.1.3). This makes an objective validation of knowledge a problematic errand. Basically, uncertainty will create room for negotiation across paradigm boundaries (this is sometimes labelled as 'boundary work', Halffman\&Hoppe (2004). Arguments, and the knowledge implied therein are relative to the 'frame of reference' in use by the persons judging the argument. Uncertainty within and between frames limits validation possibilities. Communication of data, assumptions and beliefs is crucial for reaching a mutual understanding of the problem. Models can be used to discuss knowledge, opinions, uncertainties, e.t.c. Science should indicate assumptions and validity ranges of knowledge c.q. models. Van der Sluijs $(1996 ; 1999)$ and Van der Sluijs\&Schulte Fischedick (1997) describes how the NUSAP method introduced by Funtowicz\&Ravetz (1990) can facilitate this discussion. The central issue here is the validity of information. Dick\&Swepson (1994) refer to the definition of validity given by John Dewey (1916): 'Dewey said that scientists, like workers in other areas, were in the business of providing "warranted assertion": being able to mount evidence to support their convictions, at least for the moment'. They argue that different disciplines of research, or 'paradigms of inquiry, aspire different goals and require different kinds of evidence to support their assertions. To reach the goals each discipline has its own, different method to gather the relevant evidence. Consequently validity assessment of decision supporting knowledge has to recon with the differences between scientific paradigms. The importance of validation is indicated by the discussion 'Environmental Science Under Siege' described in http://www.house.gov/science democrats/archive/envrpt96.htm\#Rep4-A .

\subsection{Consequences for the research problem}

In response to the first research focus (on a framework for description, see section 1.2.1) we can now state that our theoretical framework for integrated problem solving seen from the perspective of knowledge production and use contains the following elements: a decision making cycle, a model to forecast effects of alternatives, a frame to establish the meaning of situation specific information, and a mental model to select relevant data from the real word (scientist included). The relationships between the elements is presented in figure 2-5. Although frames are presented as influencing the decision making cycle, they are also present in the development of scientific knowledge (see sections 1.1.3 and 2.2.2) 
From the theoretical framework we expect that a person (or institution) can take one or more dominant frame positions or perspectives from which to influence the decision making process. Decision disputes are resistant to resolution by appeal to facts or reasoned argumentation present within the mental model because stakeholders' conflicting frames determine what counts as a fact and what arguments are taken to be relevant and compelling. We therefore hypothesise that a mental model's general structure can be explained from a stakeholder's dominant perspective. We expect to find categories of mental models that differ between types of stakeholders. Each category has its preferred typical alternative solution. For the purpose of the present research these different favoured perspectives are regarded as equally valid.

Regarding the second research focus (on a possible diagnosis) we can now analyse the situation as follows. Based on the theoretical framework presented in this chapter, and the literature on decision making difficulties in section 1.1, we would expect that an open communication between actors involved should be able to produce an optimal decision. When decision difficulties and controversies occur, these could be the result of the following causes:

- A first diagnosis is that differences in mental models prevent adequate communication between stakeholders (Doyle\&Ford 1998). This could, in principle, be solved by eliciting the mental models and discussing them between stakeholders in the hope to come to a single common consensus model. Critique on this approach is that this has been done (e.g. in participatory modelling) and in examples failed to lead to better decisions (Doyle et al. 2001:15).

- A second diagnosis, which is indirectly supported by Haag\&Kaupenjohann (2001:53), is that frame differences prevent the construction of a common mental model. This could, in principle, be solved by the reciprocal frame reflection described by Schön\&Rein (1994). Critique on this approach is that frame reflection cannot be separated from the mental model linked to it.

Both diagnoses disregard the interaction between frame and mental model. We reconstruct from literature the following interactions (see the numbers in figure 2-7). Institutional and personal positions will cause different frame perspectives (1). Different perspectives reflect (2) in different mental models (3), which are in fact differing, nonequivalent system descriptions. Different mental models will result (through 4-5) in different solution alternatives, which are optimised for the specific perspective only. More specifically, a Technical solution will have to compete with the Other perspectives once the decision making process leaves the technical domain and enters the broader socialpolitical arena. The resulting divergent opinions and discussions on the preferred alternative will cause controversies that can be traced back (5) to difference between the underlying perspectives and (4), more fundamental, mental models. Communication could, in principle, be able to create a learning process that bridges the differences in mental models and perspectives. 


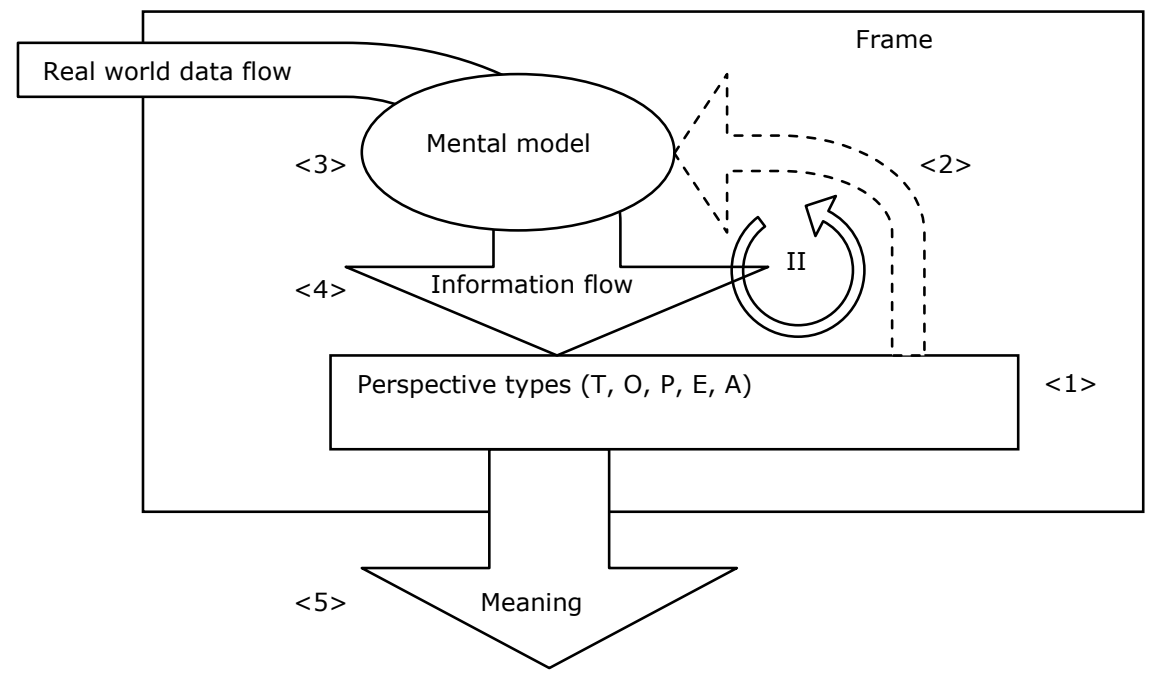

Figure 2-7: Our frame analysis approach discerns between mental models and perspective types. The mental model is based on the language an actor uses to describe the problem and reconstructs the arguments and reasoning of an actor. The five perspective types describe the position of an actor with regard to conflicting elements in the controversy, and guides the interpretation of the mental model from which an actor constructs the meaning of data and events for the decision making process. The perspectives and mental models mutually influence each other.

(Schön\&Rein 1994) regard policy controversies as frame conflicts, and introduce reciprocal frame reflection, where contrasting interests and world visions are made accessible and discussable, hopefully to reach some kind of common frame. The present research adds that open communication should also explicitly include the level of mental models. We will summarise the aspects of such an open communication under the notion "post-normal principle", referring to the 'post-normal science' of Funtowicz\&Ravetz (1993b), where the meaning of the knowledge is evaluated in a wider context by a postnormal extended peer review of technical-scientific knowledge. Our definition of this principle states that a good quality of decision making can be reached by:

a) Open communication of values, choices, assumptions, limitations and difficulties that underlie the use of knowledge produced by different paradigm groups within other paradigm groups.

b) Explicit recognition by scientists of complexity, unpredictability, and the uncertain nature of natural systems, exposure of difficulties, exploration of alternative approaches and assumptions across disciplinary boundaries.

c) Involvement of stakeholders in an "extended peer review" process, which includes a discussion of applicable norms and values (this involvement should be on a level of participation on the "participation ladder" which is well above the bottom steps usually found in stakeholder involvement).

We implicitly assume that the post-normal principles offer adequate criteria to evaluate the use of knowledge. 
At this point in our diagnosis, we conclude, based on the literature that leads to the first two diagnoses and the "post normal principle", that transparent and open communication is needed in order to construct a common mental model between actors, from which a common problem solving framework can be constructed to solve the problem. Persistent controversies would than be caused by malfunctioning communication because of perspective driven barriers.

The various difficulties experienced in current practices in integrated problem solving (see section 1.1) indicate, however, that the post-normal principle apparently can not be used effectively in the process of decision-making. There appear to be restrictions in the application of the principle of open communication. The question rises what exactly are these restrictions and what causes them, other then the two diagnoses identified before. The observation of Schön\&Rein (1994) that the success of their reciprocal frame reflection depends on learning to understand one another's' point of view gives an important clue. It implicates that restrictions in the communication process may be found in the communication related to the frames of actors involved and their frame conflicts. Extrapolating the work of Schön\&Rein (1994) to mental models, differences in mental models may originate from the same causes. Insurmountable differences in frame perspectives may prohibit the construction of a common mental model. Also Schön\&Rein (1994) noted that frames are grounded in the institutes that sponsor them.

The above considerations lead to a third diagnosis: in our research we hypothesise that social (personal and institutional) limitations prevent the adequate use of the postnormal principles. Therefore, in the studied problem situations we expect to find differences between mental models of actors that will explain the decision making process difficulties. We hypothesise that, starting from a (potentially) common database (in the real world), these differences are created or have not been remedied (by learning processes) because of the influence of insurmountable differences in frame perspectives (like institutional responsibilities and culture, and personal interests and values). More specifically, we expect a sub-optimal decision from the technical or scientific point of view to be explained by prevalence of one or more non-technical mental models. Therefore mental models will be the starting point for the empirical part of the present research.

The central thesis of this dissertation reads as follows: Persistent controversies are a result of insurmountable differences between a technical and a organisational frame that are grounded in perspectives and can be brought to light by analysing mental models of actors. 


\subsection{Conclusion}

A theory is a fundamental set of propositions about how the world works, which has been subjected to repeated tests and in which we have gained some confidence (Senge et al. 1994), or an organised set of assertions about a generic behaviour or structure assumed to hold throughout a significantly broad range of specific instances (Sutherland 1975:9 in (Weick 1989:517). Weick (1989) proposes a definition that is less onerous with regard to the testing and holding in specific situations. He defines a theory as

"a system of assumptions, accepted principles and rules of procedure devised to analyse, predict, or otherwise explain the nature of behaviour of a specified set of phenomena". (:386)

In the latter sense, the theoretical framework presented in this chapter is thought to be applicable, based on its original literature, for a broad range of decision making and problem solving situations. The problem solving cycle and modelling cycle (see section 2.2.1 and 2.2.2, respectively) are methodical elements that describe, in a generic way, the procedures which ensure that all of the important relationships described by the framework are adequately addressed. In order to facilitate the search for basic causes to the apparent mismatch between post-normal principles and decision making practices, the conceptual framework developed in this chapter accommodates both knowledge production and use, and the institutional and social environments that could delimit the possibilities to turn post-normal values and principles into practices. The conceptual framework is able to contain the present situation of the research object, to track causes of actual mismatch, and to provide suggestions of how to overcome the mismatch.

The major elements of our theoretical framework are:

- Problem solving in policy design, using a systems approach and differentiating between 'hard' and 'soft' problem solving strategies.

- Knowledge production and use, which both are driven by frames and mental models that differ between paradigm groups.

- Knowledge viewed as cognitive structures in the mind of individual persons, which form the basis for reasoning, communication and learning.

- Recognition of the various user functions and related actors involved in the problem, which each have their own needs, interests, and ways to optimise their situation.

- Recognition of various scientific disciplines, which each have their own needs, interests, and ways to optimise their situation.

- Recognition of the various institutions, which each have their own roles, interests, needs, history, culture.

The unstructured nature of problems in complex, multifunctional systems may result in the creation of a large range of mental models. When all actors involved in the problem are not adequately participating into sharing each others mental models early in the problem solution process, the (often implicitly) developed mental models could be insufficient to legitimise the preferred solution, and incomplete or even incorrect knowledge could have been produced in the problem solving project. Comparison of mental models, decision process structure and actual use of knowledge can reveal potential points of conflict, which can then be addressed. The potential benefits of mental model mapping are: 
- The identification of differences among and overlaps between actor maps.

- Identification of competing perspectives, which may lead to different judgments about the same situation, which are in themselves all valid from their own perspective.

- Identification of blind spots in knowledge and solutions produced by regulatory science and group thinking.

- $\quad$ The revealing of experiences, perceptions, assumptions, knowledge and subjective beliefs, which might be invisible for an actor within a certainty trough.

- The providing of clues that scientists need to produce knowledge that fits into the frames of the diverse stakeholders, in order that the knowledge can be of use to the stakeholders.

- $\quad$ Better insights into possible and desirable problem solutions.

- Improved communication between actors.

Applying concept mapping techniques in the early phase of decision-making for these purposes could thus improve the problem solving and decision making process.

In order to accomplish an information flows across the borders of (or the gaps between) the frames of actors, the research frame of the (scientific) expert and the learning frame of the public but also the decision frame of the managers and policy makers should connect. The information becomes knowledge only when it is interpreted within the frame of the specific actor for its consequences on the actors' position, behaviour and actions. Scientists have an obligation to educate stakeholders/ the public in order to enable them to judge the bearing of the information supplied. Finally, scientists need to connect their facts to the frames and causal discourses between diverse stakeholders. Therefore, frame analysis should be part of every policy design. Mental model mapping is a technique which can provide the connection between the frames.

Responsibilities are different between structured (hard) and unstructured (soft) problems. Dealing with unstructured problems presents the scientist with new responsibilities. The traditional "product quality" responsibility assumes that an optimal solution can be designed given the objectives, boundaries and constraints, contexts, and values and criteria (Findeisen\&Quade 1985). Unstructured problems, however, require a different approach that deals with shifting problem perceptions and values of all actors involved in the problem. Mental model mapping is a tool which scientists can use to face the dilemmas that arise when morality comes into conflict with property and power (Ravetz 2002). It can help them to build integrity, in that it exposes the different perceptions of a problem as well as of its solution. In this way scientists can live up to their obligation to educate stakeholders and public in order to enable them to judge the bearing of the information supplied (Birrer 1996). Thus mental model mapping can be an instrument for restoring public trust in science. 


\section{Method}

\subsection{Introduction}

The theoretical framework, presented in the previous chapter, has been developed to describe and analyse the process of decision making in persistent problems, with the purpose of offering methodological support. The present chapter is concerned with the operationalisation of the theoretical concepts that have been introduced in section 2.4 (frame) and 2.5 (mental model). The results will be used to design the research method used in our specific case study.

We start with Schön\&Rein (1994) who describe how different types of frames function in the decision making process, in a manner which we find useful for the analysis of our case. They do, however, not present a clear method for eliciting frames from the actors involved. For this very purpose we separated in our framework the mental models from the frame perspective types. In this way we can start our method with eliciting the mental models of actors involved in a decision making process. The mental models will show the causal network of conceptual elements that actors use to construct their argument. The other frame aspects like responsibilities and interests are dealt with in a subsequent phase of the analysis method, where five frame perspective types are used to characterize the position of actor on mutually contested elements of their mental models. This approach brings to light and separates the "facts" and the "opinions", which subsequently could be discussed in an attempt to construct a common mental model and to possibly overcome (some of the) frame differences present.

This chapter will first present a description of the frame reflection method of Schön\&Rein (1994). Next it will present five perspective types from literature that can be used to characterise frame perspectives. Subsequently it will describe general methods for mental model elicitation, and present more details on three of such methods. Finally, this chapter will present the research design that is based on the preceding descriptions of the theoretical framework and method.

\subsection{Frame reflection as a method to analyse persistent problems}

Schön\&Rein (1994) offer a method to analyse persistent problems. Central in their approach of controversies are the notions of frame, frame conflict and frame reflection. Section 2.4 described the role of frames in the decision making process. This section will analyse frames more in detail, and concludes with the definition of five frame perspective types that will be used to characterise actor frames. 
The relevance of Schön\&Rein (1994) for the present research is that these authors offer a method for the analysis of frames that we can also use to analyse mental models. For this purpose we need to identify the relationship between Schön\&Rein's frames and our mental models. Schön\&Rein's frames are composed of elements and relationships between them. Elements are selected objects or events from the real world $(: 26)$. In this sense frames have the characteristics of models. This description fits our definition of mental model presented in section 2.5. Schön\&Rein's definition of frames, however, contains other characteristics as well, which we will describe below. In the present research we separate these additional characteristics from the mental model and place them in the notion of frame that presented in section 2.4 and figure 2-5. Because our definition of mental model can be regarded as a subset of Schön\&Rein's definition, we regard their approach, guidelines and strategies to be applicable to mental model construction also. The specific distinction between mental models and frames made by us in this dissertation facilitates the analysis of the object of research: persistent controversies in a complex unstructured problem environment in integrated water management. This section will analyse the approach, guidelines and strategies for frame reflection presented by Schön\&Rein (1994) to solve this type controversies.

\subsubsection{Solving controversies using the method of frame reflection}

Schön\&Rein (1994:3) define controversies as policy disputes that are stubbornly resistant to resolution through the exercise of reason. These kinds of disputes cannot be settled by recourse to evidence to which all of the contending parties will agree. Controversies are immune to resolution by appeal to the facts $(: 4)$. According to Schön\&Rein the parties can dismiss the evidence adduced by their antagonists in two ways:

Depending on their views of the issue, the parties to a controversy can differ as to what facts are relevant $(: 4)$.

- Even when the parties focus their attention on the same facts, they tend to give them different interpretations $(: 5)$

The authors $(: 5)$ note that the parties have an astonishing virtuosity in "patching" their arguments so as to assimilate counterevidence and refute countervailing arguments.

In his dissertation, Van Koningsveld (2003) claims to improve the decision making process by using a rational approach which matches the mental models of knowledge generating scientists with those of information seeking coastal managers, where the mental model is limited to data concerning the physical system. Van Koningsveld's approach represents a post modern view on problem solving, in which the conceptual gap between scientists and decision makers is bridged by adding the lacking elements. This approach presumes that the construction of a common conceptual framework is possible. The work of Schön\&Rein shows that such a data focused approach can not by used to solve persistent problems, because the frames of actors are neglected. The frames of actors will, in such cases, prevent the construction of a common conceptual framework. To really solve such problems an approach is needed on a deeper, more fundamental level, which we present in this dissertation. 
Schön\&Rein hold the position that controversies are generated by frame differences. They consider frames and interests to be logically independent concepts, which interact with each other: interests are shaped by frames, and frames may be used to promote interests. This interaction is made visible in figure 2.6 trough the dotted lines labelled "meaning". It is the frames held by the actors that determine what they see as being in their interests and, therefore, what interests they perceive as conflicting. The frames are not free-floating but are grounded in the institutions that sponsor them, and policy controversies are disputes among institutional actors who sponsor conflicting frames. The frames represent mutually incompatible ways of seeing the policy situation (:29). According to Schön\&Rein there is no possibility of falsifying a frame in the traditional sense of the word. Observers are always connected to a frame and therefore not objective in the sense of frame-neutral. Those who construct the social reality of a situation through one frame can always ignore or reinterpret the "facts" that holders of a second frame present as decisive counterevidence to the first $(: 30)$. Therefore dealing with the frames that underlie controversies requires a new approach.

Schön\&Rein approach the problem of controversies using a design rationality. In their design rationality a designer creates an object under conditions of uncertainty and complexity, and in this process has to communicate with multiple individual or institutional actors which have their own interests, freedoms, and powers. They \&Rein conceived this design rationality to have three layers.

In the first layer the designer in a situation wants to create an object with materials available, under conditions of uncertainty and complexity. The meaning of many different, sometimes incompatible, values and variables involved in an object design shifts in local or global context. Continuing inquiry results in reformulation of both problem and solutions. The designing system consists of the designer solely (:166-167). This layer represents the technical frame perspective.

- In the second layer design is seen as a social process distributed among multiple actors, of which the designers are part. The designing system now contains individual or institutional actors, which may have cooperative or antagonistic interactions, and will have their own interests, freedoms, and powers. Together they form a coalition of actors, the integrity of which, according to Schön\&Rein must not been threatened by design moves. Reliable communication and mutual trust are important factors to sustain cooperative inquiry (:168-170). In this layer the other frame perspectives (organisational, personal, ethical and aesthetic) come into play.

- In the third layer issues arising from the actors' conflicting actions frames complicate the design process. The resulting controversy could, ideally, be dealt with using co-design, which calls for frame reflection by the actors $(: 170-171)$. In this layer a shared frame is build, ideally, through communication and learning processes between actors.

The process which Schön\&Rein call frame reflection now becomes their key process for solving intractable controversies. In the course of this process, the analysis of frames in use by the diverse actors makes them aware of the causes of the controversies. At the same time, however, this awareness can be experienced as an obstacle to step outside 
one's own frame, which makes the creation of a common shared frame even more difficult. They offer some strategies to overcome this difficulty. Only then can the building of a shared frame begin trough frame reflection. The process of frame reflection requires firstly that characteristics are available for identifying frames and frame conflicts, and secondly a procedure along which the frame reflections process can be conducted. These will be addressed in the next sections, respectively.

\subsubsection{Characterisation of frames}

In order to perform frame reflection we must first operationalise the notion of frames. Schön\&Rein (1994) introduced the notion of frames by referring to the stories told by actors about a troublesome situation. According to Schön\&Rein the elements and relationships within a frame are selected by the story told by the frame owner. Therefore, from this story the underlying frame of an actor can be constructed $(: 24)$. Stories are told by different groups and at different times $(: 25)$, each story serves diverse functions:

- To convey a very different view of reality and representing a special way of seeing,

- To select and name different features and relationship that become the "things" of the story,

- To places the features the story has selected within the frame of a particular context,

- To construct the story's view of social reality through a complementary process of naming and framing.

Things are selected for attention and named by a story in such a way as to fit the frame constructed for the situation by a specific actor. Together, the two processes of naming and framing construct a problem out of the vague and indeterminate reality. They carry out the essential problem-setting functions. They select for attention a few salient features and relationships from what would otherwise be an overwhelming complex reality. They give these elements a coherent organization, and they describe what is wrong with the present situation in such a way as to set the direction for its future transformation $(: 26)$. The functions are carried out through generative metaphors. A metaphor derives its normative force from certain purposes and values, certain normative images that have long been powerful in our culture $(: 27)$. Schön\&Rein believe that a small and constant number of generative metaphors underlie frames over long periods of time (:28). According to Schön\&Rein (1994), we can construct frames from the texts of debates and speeches or from the decision, laws, regulations, and routines that make up policy practice $(: 34)$.

Schön\&Rein detail their definition of frames by discerning three major conceptual elements concerning frames: 1 ) types of policy discourse; 2 ) types and functions of frames; and 3) levels of action frames (:31), which we will discuss briefly below. The policy discourse takes place in an institutional context, which may carry its own discourse characteristics, viz.:

- Perspectives and ways of framing issues,

- Roles, channels and norms for discussion and debate, 
- $\quad$ Policy forums that serve as institutional vehicles for policy debate. Each forum has its own rules. In the present case study these forums can be e.g. the Water Board, the Municipality, the Provincial councils, newspaper messages, television programs, the House of Representatives, the Ministry, the Administrative Jurisdiction Division of the Council of State. Discourse tends to conform to the norms of the forum in which it occurs.

The two different types of frames discerned by Schön\&Rein serve different functions. One or both types may be present in a policy story $(: 32)$ :

Rhetorical frames: serve the function of persuasion, justification, symbolic display (by linking to existing frames and associated norms of people) (:35). Are used to purchase legitimacy for a course of action actually inspired by different intentions, by hitching on a metacultural frame. In the present case study this type of frame can be found in the persuading actions performed during the decision process by the responsible authorities, and their legitimisation of the chosen course of action after the decision has been made.

- Action frames: serve the function of shaping of laws, regulations, allocation decisions, institutional mechanisms, sanctions, incentives, procedures, and patterns of behaviour, that determine what policies actually mean in action. In the present case study this type of frame can be found in the arguments that support specific solution alternatives.

Schön\&Rein note that frames implicit in the language used to "win the allegiance of large groups of people" often differ from the frames implicit in the agreements that determine the content of laws, regulations, and procedures (:32). When policy antagonists challenge one another's legitimacy, they may begin gaming, seeking deliberately to obscure the action frames that underlie their stated positions $(: 35)$. In the process of problem solving we expect to find the action frames to be predominantly visible in the first steps of the cycle, where the alternatives are generated. The rhetorical frames we expect to be more visible in the steps further down the cycle, where the alternatives have to be defended against opponents.

Action frames operate at three different levels of specificity $(: 33)$ :

At the level of policy action frame it is the single frame an institutional actor uses to construct the problem of a specific policy situation. In the present case this is the level of frames that directly justifies the preferred decision alternative of an actor.

- At the level of institutional action frame it is the more generic action frame from which institutional actors derive the specific policy frames. The institutional action frame is used to structure a wide range of problematic policy situations. Institutions possess characteristic points of view, prevailing systems of beliefs, category schemes, images, routines, and styles of argument and action, all of which inform their action frames. Institutional action frames tend to be complex and hybrid in nature, and consist usually of families of related frames. Moreover, the action frames held by individuals may be only loosely coupled to the action frames of the institutions of which they are members. Individuals' frames may represent selections from or variations of the institution's larger frame. Individuals at different levels in the organization may differ in their ways of 
interpreting the actions frames that prevail within the agency, or in the degree to which they conform to the agency's prevailing line of thought and action. In the present case study we therefore expect to find frames that different for the different functions and hierarchical positions in the organisation.

- Schön\&Rein also present the level of the metacultural action frame, which is the broad, culturally shared system of belief. An institutional action frame is the local expression thereof. The metacultural action frame is organized around generative metaphors, which was mentioned above, and is at the root of the policy stories that shape both rhetorical and action frames. In the present case an example is the call upon the notion of "danger", "protection" and "safety" by responsible authorities. An other example of metacultural frames is the appeal to "technical truth" and "waste of community money" by the opponents of the decision result.

In the case we expect to find evidence of all three levels of frames throughout the course of the decision process. It is our hope that the characteristics presented by Schön\&Rein (1994) can aid the prediction of a decision making process outcome.

\subsubsection{Approaches and strategies for frame reflection}

The process of frame reflections that is presented by Schön\&Rein as method for resolving persistent controversies requires two approaches to be applied consequently. The first is a frame-critical approach which recognizes the discrepant frames from which conflicting policy positions arise. The second is a frame-reflective approach which may resolve controversies through the adaptation of existing or generation of new frames $(: 57)$.

Common tasks in both approaches are:

- the construction of the frame conflicts involved in situated policy controversy,

- the exploration of the trajectories of frame conflicts,

- $\quad$ and the description of the practices through which frame conflicts are managed $(: 57)$.

Schön\&Rein note three conceptual obstacles for a frame reflective approach: 1 ) stalemate and pendulum swing, 2) the relativist trap, 3) selection among possible frames, and present strategies to overcome these. Furthermore, Schön\&Rein present some guidelines for inquiry into the process of frame reflection.

In the present study we will consider the approaches, strategies and guidelines of Schön\&Rein for their usefulness in analysing the decision making case. In relationship to chapter two their approach can be regarded as a method to deal with the unstructured problems described in section 2.3.1. Although the name "intractable problem" suggests the contrary, Schön\&Rein's method is devised to solve this type of problems, or at least to analyse and explain them. When appeal to facts cannot, by definition, resolve intractable problems, other strategies are needed. We will continue with the discussion of the strategies presented by Schön\&Rein to overcome the above three obstacles.

\section{Stalemate and pendulum swing}

According to Schön\&Rein the relationship between controversy resolution and frames is not straightforward for three reasons $(: 39)$. The first is that frame reflection may not lead 
to reframing, but may merely serve to reinforce stalemate or antagonism, because opponents may use the knowledge gained in the reflection process merely to strengthen the own positions. In this sense the work of spin doctors or image managers does not contribute to problem solving. When both parties follow this approach mutual paralysis may result. To escape this situation mutual trust is needed. Because of the common interests present in water management, we expect to find mutual thrust there, at least in some degree.

The second reason is that reframing may occur without frame reflection as a result of actions taken for other purposes.

The third reason is that policy controversy resolution may be logically independent of both frame reflection and reframing.

In order to make a reframing work Schön\&Rein propose the following strategy:

"policy makers must reflect on the old and new frames - accepting, in this

process, elements of the old frame which were recently delegitimized by their recent reforms. They must import elements of the old frame that stand in direct conflict with the new one, producing emerging frames through dialectical policy discourse $(: 40)^{\prime \prime}$.

This process in which the new frame is in need of elements from the old frame Schön\&Rein call the "pendulum swing" (:40).

\section{The relativist trap}

Schön\&Rein take their definition of the relativist trap from the field of sociology of knowledge. Relativism refers to the idea that what you see and know depends on who you are, when you are, and where you sit. All interpretations are necessarily conditioned society, historical period and social status. Therefore frame conflicts cannot be objectively resolved, because the frames themselves determine what counts as evidence and what interpretations of evidence are acceptable. The resolution is trapped in the relativism. Schön\&Rein (1994) present three strategies for escaping the relativist trap $(: 43)$ :

1. Looking for stubbornly resistant facts, which both may agree upon, through the lenses of one's own frame. The interpretation of the facts may still be controversial

2. Appealing to consensual, logically independent criteria for evaluating conflicting frames and choosing among them

3. Engaging in frame-mapping, or frame-translation, in order to understand one another's conflicting views (see also:46).

We note that the second strategy is, in fact, elaborated under the third obstacle.

\section{Selecting among conflicting frames}

Schön\&Rein (1994:44) presented the following independent criteria for a reasoned choice among the possible frames, the first three of which they took form March (1972):

Truth: the verifiability of the propositions implied by the premises contained in the argument of a frame.

- Beauty: the eloquence with which the argument is formulated, especially the parsimony of its chains of inference.

- Justice: connotes an ethical evaluation of the judgements of right or wrong to which the frame leads us. 
- Coherence: the extent to which our framing of the policy situation integrate a large number of disparate values and beliefs in a single, self-consistent perspective that "makes sense".

- $\quad$ Fruitfulness (utility): the extent to which our way of framing the situation suggests interventions that will plausibly achieve our purposes.

After the above conceptual obstacles for frame reflection have been dealt with, (Schön\&Rein 1994) also observe the existence of some practical difficulties in the construction of the frames that underlie an institutional actor's policy position $(: 35)$, which we summarise below:

1. Rhetorical frames (that shape the public utterances of policy makers) may be incongruent with the frames implicit in their patterns of action;

2. The same course of action may be consistent with quite different policy frames, conversely, the same frame can lead to different courses of action;

3. The meanings of policy made by a central governmental body in the early stages of policy formation may be transformed at local levels at the stage of policy implementation, and the policy frames espoused by state legislators may differ from the frames implicit in the discretionary judgments made by street-level bureaucrats (mind that Schön\&Rein describe the USA situation here);

4. It may be difficult to distinguish between conflicts within a frame and conflicts that cut across frames;

5. It may be difficult to distinguish between real and potential shifts of frame, because the potential may lie dormant because other reforms, essential to the activation of that potential, are not forthcoming. Conversely, even in the absence of formal deliberations and decision, policy may be reframed as a result of cumulative, incremental adaptations to a changing situation.

Schön\&Rein (1994) note that the above practical difficulties in constructing policy frames may be overcome, at least in principle, by carefully nuanced observations and analysis of the processes by which policy utterances and actions evolve over time and at different levels of the policy-making process. For this purpose Schön\&Rein propose the following criteria for sophisticated frame construction. Such construction should analyse $(: 36)$ :

1. Evolution over time;

2. Different levels of the policy-making process;

3. Differences between central and local policies;

4. Potential and actual changes of frame;

5. The rhetoric frames implicit in espoused policies and the actions frames implicit in policy-in-use (Argyris\&Schön 1974);

6. Formal policies and the policies implicit in the practices of street-level bureaucrats;

7. Visible shifts of policy and the cumulative effects of small changes of policy made in response to changing situations.

In conclusion, Schön\&Rein propose several approaches and strategies for the frame reflection process that may be helpful in solving intractable problems. In our research we will analyse whether these strategies are used by actors. The ideas presented by Schön\&Rein, however, do not offer a clear method for the preceding process of frame 
construction. According to Schön\&Rein (1994:34), "we must become aware of our frames, which is to say that we must construct them, either from the texts of debates and speeches or from the decision, laws, regulations, and routines that make up policy practice" (see also :56). This merely implies that we can use document analysis and interview as frame elicitation instruments, but does not offer a more specific method for this purpose their ideas need to be operationalised. Schön\&Rein, however, do give interesting points of analysis.

\subsubsection{Frame perspective types}

So far we have identified from literature the methods for frame analysis and frame reflection described, and the basic data from which frames can be constructed, being textual material. But we are still lacking a concrete method to perform the frame construction process. To bridge the gap between data and analysis method will draw upon one of the authors already mentioned in chapter 2 . For the purpose of the present research we will not elaborate on frame details, but limit the frame characterisation to the broad types described by Courtney (2001).

Courtney (2001:29) presents three main types of individual frame perspectives $(T, O, P)$, which he took from Mitroff\&Linstone (1993). These types are:

$\mathrm{T}$ : the technical perspective. The perspective of the scientist. A functional, rational and ordered orientation. Corresponds to Spranger's (1928) theoretical value which is based in the discovery of truth and knowledge in a rational and scientific way. Suitable for structured problems.

$O$ : the organizational perspective. The perspective of the senior manager of an interested organisation (organisational self-interest). A social and stable perspective. Can be extended to include societal elements - in a broader sense we can speak of a institutional perspective. Corresponds to Spranger's social value which incorporates an interpretive, philanthropic view - it seeks human interaction and considers the impact on the group or organisation as a whole. Relates to organisational responsibilities and role attitudes. Also relates to the history of the organisation and its company culture.

$\mathrm{P}$ : the personal (or individual) perspective. The perspective of a psychologist (from a person's needs perspective). A political and individualistic perspective. Corresponds to Spranger's political value which is concerned with prestige and power, often at the expense of others, and usually incorporates a critical and power-oriented view. Relates to educational background and personal character.

Courtney (2001:30) adds two more perspectives ( $E$ and $A$ ):

$\mathrm{E}$ : ethical. Relates to integrity and the way criticism is dealt with. Includes the individual stakeholder that will be affected by a decision. Also includes the environmental aspects. Corresponds to Spranger's religious value which aspires to make the world a better place, and is usually based on philosophical and interpretive views. Includes moral aspects, rules of behaviour and codes of 
conduct. The latter are often affected by larger questions of values, culture, tradition, religion, and ethnic contexts.

A: aesthetic. The beauty and harmony of a solution design. Corresponds to Spranger's aesthetic value which views the world from an artistic, interpretive view and seeks to find form and harmony in a given scenario.

Furthermore, Hall et al. (2003) discern a sixth perspective, which we will not use in our approach because it can be included in the first and second perspective:

M: economic. Corresponds to Spranger's economic value which arises from a functional, practical view and seeks usability and material goods.

Interestingly Hall et al. (2003) note that all these categories are not exclusive to individuals, because organisations exhibit the same types of values, although economic and political values are often predominant in business (apart from the traditional technical perspective). Therefore we will look for these categories at both the individual and institutional level. We assume that an actor (individual or institutional) will, in general, exhibit more than one type, but at different levels of dominancy. Schön\&Rein in their description of their frame reflection process focus on the institutional level. Our perspective typology approach, however, will allow us to start the reflection process at an individual level. We will use the above perspective types ( $T, O, P, E, A)$ to characterise the frames of individual actors. Using the theory of Schön\&Rein (1994) on types of frames, we try to relate the perspective types to the individual and institutional characteristics of the informant's job position.

\subsection{Mental models support frame analysis}

In the previous section the frame aspects like responsibilities and interests were dealt with by characterising them with five perspective types which are used to explain the opinion of an actor with regard to conflicting elements in the controversy. We will start the frame construction process, however, with the analysis of the mental models that are in use by the individual actors The mental model is based on the language an actor uses to describe the problem and reconstructs the arguments and reasoning of an actor. A description of the notion of mental models was given in the theoretical framework presented in chapter 2 . This section addresses the elicitation process of a mental model.

Mental models can be made visible with mapping techniques. A map is the researcher's conceptualisation of a subjects' mental model. Different kinds of mapping techniques exist in different disciplines (e.g. social planning and evaluation, business organisation design, knowledge analysis and structuring, see section 2.5.1). Different content and structure are contained in concept maps depending on the contexts for which they are generated. Consequently, maps having similar concepts can vary from one context to another and can be highly idiosyncratic.

The strength of concept maps lies in their ability to express a particular person's knowledge about a given topic in a specific context. Concept mapping provides a framework for making internal knowledge (of actors involved) explicit in a visual form 
that can easily be examined and shared. All methods and types of mental model mapping are considered (by their disciplines) to reveal individual and group differences in experiences, perceptions, assumptions, knowledge and subjective beliefs related to the problem, assess tacit knowledge, broaden the narrow understanding of a problem by confronting one stakeholders model with the models of others, make aware of alternative perspectives on the problem, encourage negotiation and help to reduce destructive conflict. The basic idea is to externalise a person's knowledge and consequently make it discussable. Mapping techniques can be suitable for changing the focus of decision makers from the actual decision-making to more early phases in the problem solution process. Mapping may assist those committed to a certain alternative to climb out the "certainty trough" by making visible new questions about the problem.

\subsubsection{Mental model structure and characteristics}

The idea of mental models is associated with the physical construction of the brain out of neuron and connecting dendrites (see figure 3-1). Learning, thinking, and remembering are considered as physiological, electrical and chemical processes.

\section{Mental model - physical}

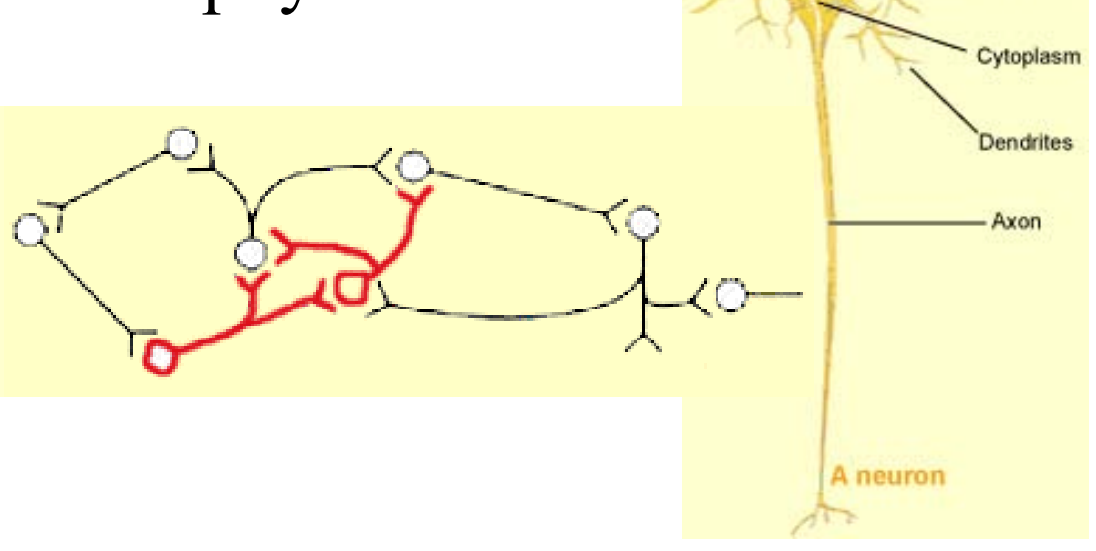

Figure 3-1: Learning is equivalent to growing dendrites. A neuron has a body and from this body many fibres called dendrites grow. Dendrites, with their tree-like branching structure, gather information and relay it to each neuron's cell body. Axons are generally very long, and each neuron has only one. This axon carries information away from the neuron's cell body toward other neurons, with which it makes connections called synapses. The brain has 100 billion neurons with up to $20 \mathrm{~K}$ synapses each. (Pictures copied from http://www.thebrain.mcgill.ca/flash/d/d_07/d_07_cl/d_07_cl_tra/d_07_cl_tra.html) 
When learning, a neuron grows dendrites that connects it to other neurons that are involved in the specific learning situation. Together these form a neural network that represents our memory and knowledge about the situation. For each new learning situation the brain is considered to construct a new neural network specifically for that object of learning. These networks are also called mental models.

The process of mapping a mental model produces an external visual representation of the internal neural network. Figure 3-2 gives a simple example for two situations. Doyle et al. (2001) note that mental models only exist in human memory, and should not be confused with the external visualisation products based on them. External diagrams and/or model maps are, according to Doyle et al., likely to be much more complete and complex than the internalised mental model that drives dynamic decision-making at a certain point in time. Furthermore, externalised models may also include information that was only held in a temporary state in working memory and was never fully learned. Internal mental models are subject to processes that externalised models are not, such as forgetting, interference, retrieval failure, and distortion. Mental model assessment test what is in memory at a particular point in time.
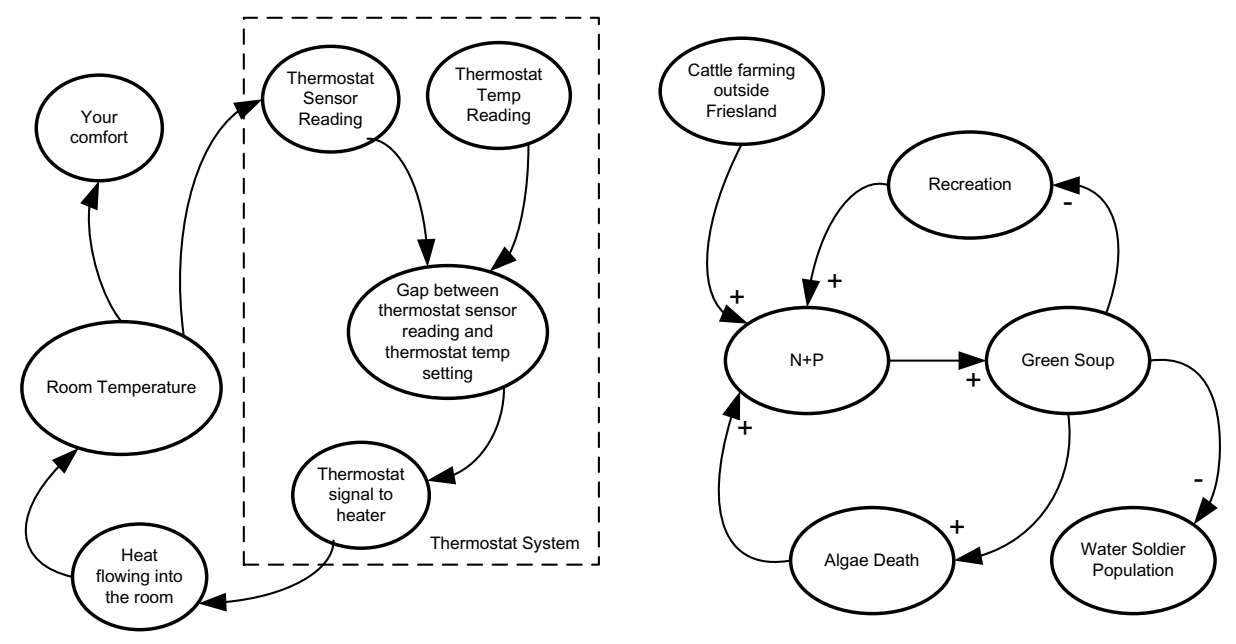

Figure 3-2: Example of simple informal mental model maps. Left of a room heating system, and right of an algae bloom system. A relationship arrow from A to B merely means "A causes B" or "B is influenced by $A$ ". The $+/$ - signs already introduces some formality in that the effect of the influence is indicated, and allow the detection of positive and negative feedback loops. 
In their overview of the use of mental models within system dynamics, Doyle\&Ford (1998) note that some general problems with mapping are information overload (e.g. what texts and experts to select) and time consumption (e.g. limited project resources) at the part of the researcher. Also they identify the existence more fundamental problems, which are related to characteristics of mental models. Doyle et al. (2001) present twelve characteristics of mental models for the discipline of system dynamics. Some examples are reproduced below because we consider them to be relevant for our case study:

1. "Mental models, particularly those of relative novices, are prone to errors and biases that result from biased information processing, unwarranted assumptions, overconfidence in one's knowledge base, and other barriers to learning."

2. "The boundaries of mental models are "fuzzy," that is, they are ill-defined and easily changeable. This is due to the structure of human memory, in which mental models are interconnected with other information in memory in a complex network of associations."

3. "Mental models often fail to incorporate important feedback mechanisms. Rather than adopting a closed- loop perspective in which decisions produce outcomes which feed back to inform and alter decisions, people tend to adopt an "openloop" perspective in which one event leads to another in a single causal chain that, because it follows a strict timeline, is unidirectional."

4. "Causation in mental models is generally represented in an overly simplified way. For example, people tend to seek simple, isolated causes for events rather than create networks of multiple, interrelated causes. They also show a preference for causes that are close in time and space to their effects (and occasionally confuse mere temporal correlation with causation). In addition, they tend to view causes as external to the system in question rather than see the structure of the system itself as an important causal factor."

5. "There are inherent time delays involved in changing mental models. When mental models are updated with new information, the old information is not instantaneously forgotten, but persists in memory alongside the new information, where it may still be recalled and influence decision making."

From their characteristics Doyle et al. (2001) conclude the following guidelines for mental model research:

1. "Capture the messiness, sloppiness, lack of completeness, and fuzziness that exists in the mental models (instead of producing neat, clean, complete representations of mental models)."

2. 2 "Mental models are easily influenced by, even seemingly subtle changes in, the ways knowledge is elicited. Therefore adopt methods that are as naturalistic as possible, that is, that correspond to the settings, tasks and question formats that people normally deal with when they think about dynamic system."

3. "The elicitation method should not impose a particular structure on the elicited information, but allow the structure to arise from subjects' responses." 


\subsubsection{Mapping methods}

The different techniques for eliciting mental models are appropriate for different classes of problems. Kremer (1997) presents an analysis of the historical foundations of mapping. Kremer remarks that mental model maps extend over a wide range of formality. This range is illustrated by figures 3-2 and figure 3-3. The informal maps are easy for people to create, because of the lack of constraints. They are therefore useful in education, in brainstorming, in the early stages of knowledge acquisition, and in any situation where the effort of conforming to a formalism may be too costly or time consuming. The formal maps are not as easy for humans to create and usually require some degree of expertise, but their formality allows them to be interpreted by computers, which enables various forms of computational support. For example, formal mental model maps are used to create expert systems or graphic forms of conceptual graphs or semantic nets. For human users, maps tend to make the structure of a body of knowledge much more salient than other forms of knowledge representation such as pure text and predicate logic. According to Cañas et al. (1999) the benefit of a mental model map above free textual descriptions (which are easy to input but hard to reason about) or formal rich structured representations (which are hard to input but support complex reasoning) is that mapping is a middle form between these two extremities. In the remainder of this section we will describe some methodological examples from literature.

In the method of DeTombe (2001) concepts and phenomena that are present in the mental model of a problem situation can be elicited in moderated group sessions with problem owner, experts and actors from the different fields involved. Explaining theories, hypotheses, assumptions, experiences, intuition are organised in knowledge islands, and the status knowledge is established. A semantic and, subsequently, a causal model of the problem behaviour is constructed based on the group information. The latter might also be implemented (by the facilitator) in a dynamic simulation model to check the concepts on internal logical consistency and external correspondence with observations. In the DeTombe method a conceptual model can be anything between the description of concepts and phenomena and a scooping level system dynamics simulation model. The method is directed at complex societal problems (like aids), but can also be applied at organisational problems.

Trochim (1989) presents a method that focuses on the starting point of elicitation of concepts. In this method individual statements are elicited in a brainstorm session (group or individual). Alternatively, the statements can be abstracted from text documents. The (at maximum) 100 most important statements put on cards and are sorted in similarity groups, and scored on a 5 or 7-point Lickert scale of importance. The results are mapped using multidimensional (often two-dimensional) scaling and cluster analysis statistical techniques. The maps are interpreted and discussed with stakeholder groups for the meaning of the clusters, which represent a concept on a higher level of aggregation, and may suggest a form of temporal order. The aggregate are given ratings. The method is applied in planning \& management problems in educational settings. 


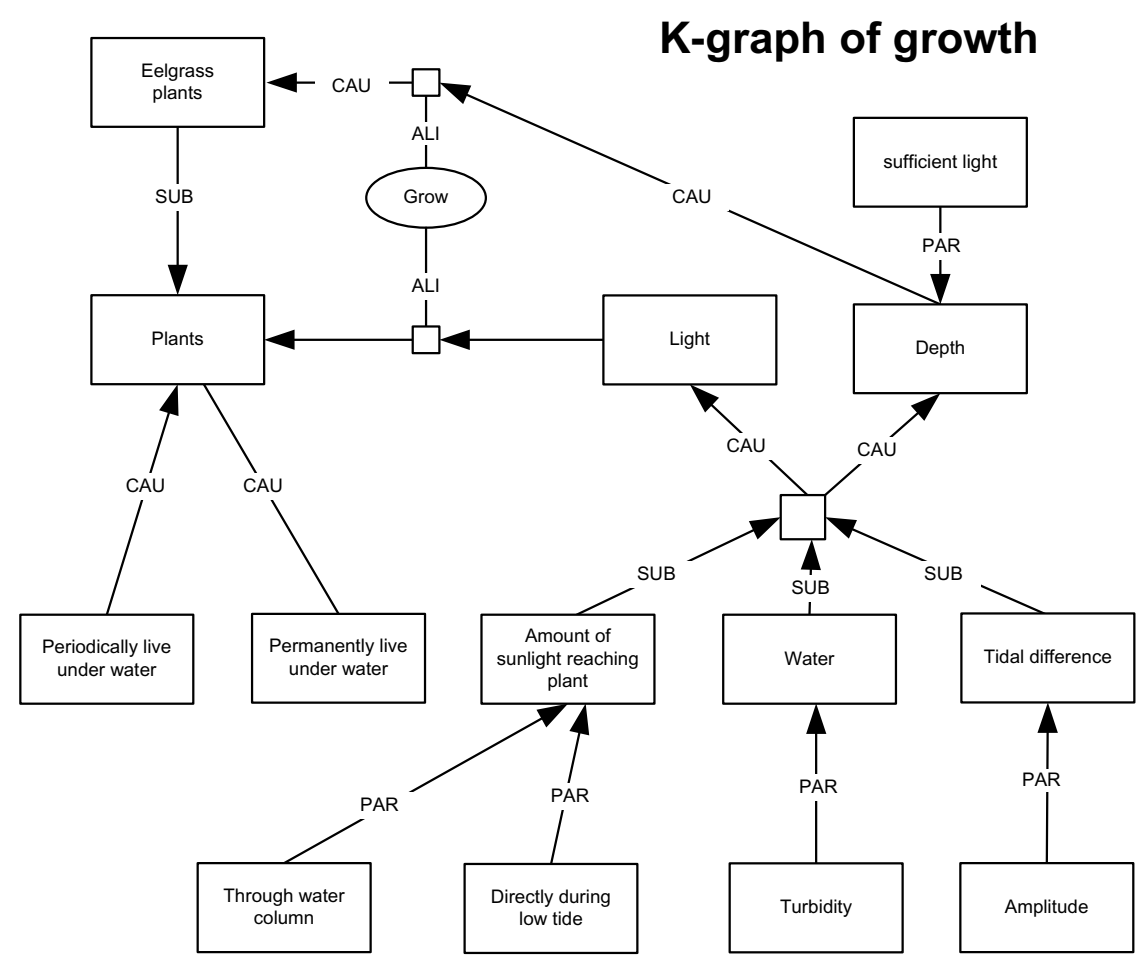

Figure 3-3: Example of a formal mental model map: a knowledge graph of a single text fragment from Van Koningsveld (1998). This type of map is highly formalised, in that the meanings of the relationships between the knowledge elements are strictly prescribed. Such a formalisation allows computational operations to be performed on a map. The text fragment reads (translation from Dutch):

"Plants need light to grow. For plants that periodically or permanently live under water, 3 factors play an important role: the amount of sunlight reaching the plant directly during low tide or through the water column, the turbidity of the water, and the amplitude of the tidal difference. These three factors together determine the depth to which enough light penetrates to enable the eelgrass plants to grow."

Meanings of the formalised relationships are taken from Kramer (1996:16). Starting from the bottom elements (including "enough light") are PAR relationships, the other unlabelled relationships in the figure are of the CAU type.

\begin{tabular}{|c|c|}
\hline EQU & :"Concept $\mathrm{A}$ is identical, equal to concept B" \\
\hline SUB & : $A$ is an inclusional part of $B "$ \\
\hline ALI & :"A is similar to B" \\
\hline DIS & :"A is different from $B "$ \\
\hline PAR & :"Exterior attributing of $\mathrm{A}$ to $\mathrm{B} "$ \\
\hline FPAR & :"Interior attributing of A to B (within a frame)" \\
\hline ASS & $\begin{array}{l}\text { :"A and B are different but associated with each other } \\
\text { (being part of the same frame" }\end{array}$ \\
\hline ORD & : $\mathrm{A}$ is ordered in comparison with $\mathrm{B} "$ \\
\hline CAU & :"A influences B" \\
\hline SKO & :"A is informationally dependent on B" \\
\hline AKO & :"concept A is an example of, a kind of, concept B" \\
\hline NFPAR & :"Interior attributing of A to B as a negation (within a frame)" \\
\hline POSPAR & :"Interior attributing of A to B as a possibility (within a frame)" \\
\hline NECPAR & :"Interior attributing of A to B as a necessity (within a frame)" \\
\hline
\end{tabular}


Van Koningsveld (1998) focuses on the construction of causal (and other) relationships between concepts from text, using a conceptual graph theory that allows for formal graph manipulation. The method can be used to identify overlap between en obvious omissions on the different concepts used by different parties. The method has been applied to a Eelgrass re-introduction project in the Dutch Waddensea. Figure 3-3 presents an example of his method.

A similar approach as DeTombe is used by Gill (1998) and Belt et al. (1998), but these focus more on the endpoint of constructing a simulation models using system dynamics. The resulting model explores the complexity of the problem and simulates some of the scenario's the group has developed. The model can be adjusted to new information as it becomes available. The methods are applied in integrated water management problems, to explore the effects of possible management alternatives.

Compared to DeTombe's over-all approach for problem articulation, Trochim, Van Koningsveld, and Gill add detail to specific steps.

The soft systems methodology (SSM, see e.g. Checkland 1981; Checkland\&Scholes 1991; Finegan 1994; Dick 1993; Dick\&Swepson 1994) develops conceptual models for business (re)design, integrating the technical production system, the information system and the human activity system (including roles, norms and values, see e.g. Kolkman 1993). SSM brings key decision-makers through a process of discovery that allows them to understand their problems in a new, more systematic light, linking their problem to other people and other problem areas, thus identifying new elements and relationships to be included in their model. The theoretical basis is learning theory. Like DeTombe, SSM addresses the problem articulation phase, but goes further by searching for and implementing solutions (action research). The application fields are business management and management of natural resources.

Based on the literature review the present research selected three mapping technique, viz. cognitive mapping, concept mapping and qualitative social research, to be potential useful in practical situations involving complex problems. These are described in the following sections.

\subsubsection{Mental models elicitation techniques}

Apart from the general literature overview presented in section 3.3.2, three methods have been investigated more in detail: qualitative social research, cognitive mapping and concept mapping.

Qualitative methods used in social sciences use as data source observation and participation, interviews and questionnaires, documents and texts, and the researcher's impressions. Myers (1997) mention as the main rationale for qualitative research that, when textual data is quantified, the goal of understanding a phenomenon form the point of view of the participants and its particular social and institutional context is largely lost. Qualitative research focuses on situations where data are not easily reduced to numbers. 
Often these data relate to the social world and the concepts and behaviours of people within it. Qualitative research seeks to construct representations of data that are based on in-depth, detailed knowledge of cases. Qualitative research starts with the analysis of existing theories in order to identify theoretical variables (also called or categories or factors) that may explain an observed situation. These variables subsequently are operationalised in concrete, measurable attributes. The actual value of the attributes is then measured by posing questions, in an interview or questionnaire. The resulting interview transcription is analysed on the appearance of the predefined attributes, a process called coding. Then the attributes composing a variable are aggregated into categories. Finally the expected relationship between the variables can be tested, and relationships can be visualised. In social science qualitative research relationships between attributes can be tested by different techniques, e.g. repertory grid, card sort, multidimensional scaling, cluster analysis. In exploratory social research, both concepts and links between them are generated by informants, on contrast to theory testing research, where concepts and links are predefined by the researcher. The present research is of the exploring type. However, based on theoretical considerations presented in the framework of chapter 2, general categories of concepts are identified for the domain of problem solving, and more specific categories for the domain of integrated water management. The results can be found in the list of probing questions presented in section 3.4.6.

The cognitive mapping method finds its base in the publications of Eden (1994) in the field of operations research, who base themselves on Axelrod (1976). These authors refer back to Kelly's theory of personal constructs (Kelly 1955). The cognitive mapping method was designed primarily for issue or problem structuring, in the context of action orientated strategic management interventions. To the qualitative researcher, cognitive mapping offers an alternative means of gathering and structuring data, as well as a means of structuring thinking about research issues, for example in project planning at the outset of a research. The method is aimed at understanding the client's perception of a problem, by structuring, analysing and making sense of client's accounts of the problem. The cognitive map provides structure for the client's accounts, through capturing the chains of argument and linking these together. The structure provides valuable clues as to the client's perceptions of the problem, and giving indication as to where the "nub(s)" of the issue may lie. The cognitive map allows identification and exploration of aims and objectives, and dilemmas, feedback loops and conflicts can be distinguished, explored and worked upon. A historical overview of cognitive maps can be found in Aissaoui et al. (2003).

The concept mapping method was introduced by Novak\&Gowin (1984). Their method is based on the theory of learning of Ausubel et al. (1978). Concept maps analyse the knowledge which a person (expert) has about a specific situation by unravelling the concepts used, thereby placing the knowledge in a situational context. For example "what factors influence the successful re-introduction of eelgrass in the Dutch Waddensea?". The focus is on knowledge. The knowledge could subsequently be used to construct actions, for example by converting the concept map into a causal relation diagram. The resulting concept map looks similar to the cognitive map. In both cases the relationships between concepts take the form of propositions. Propositions are two or more concepts 
linked by words to form a semantic unit. In its simplest form, a concept map would contain just two concepts connected by a linking word to for a single proposition. Concepts are labelled with descriptive text - a word or short phrase representing the concept, and the links are labelled (sometimes only implicitly) to express a relationship type. For an example see figure 3-4). For concept mapping the labelling of concepts and links is not restricted by any rules, cognitive mapping, however, favours bi-polar concepts. The map's vertical axis generally expresses a hierarchical framework for the concepts in which inclusive concepts are found at the highest levels, with progressively more specific, less inclusive concepts arranged below them. Canas et al. (2003) present an overview of mapping methods and software support tools, which focuses on the concept type of mapping in educational, expert knowledge elicitation and knowledge management settings. A combination of both the cognitive and concept mapping method has been presented by Aissaoui et al. (2003), with the aim of overcoming drawbacks present in each separate method.

Different content and structure are contained in maps depending on the contexts for which they are generated. Consequently, maps having similar concepts can vary from one context to another and can be highly idiosyncratic. The strength of maps lies in their ability to express a particular person's knowledge about a given topic in a specific context. Mapping provides a framework for making internal knowledge (of actors involved) explicit in a visual form that can easily be examined and shared. The three methods described above can be put in a hierarchical relationship: concept mapping describes the basic knowledge with regard to a decision situation, cognitive mapping describes the causal reasoning based on this knowledge, and qualitative research explains a situation in terms of aggregated concepts on a higher level of abstraction.

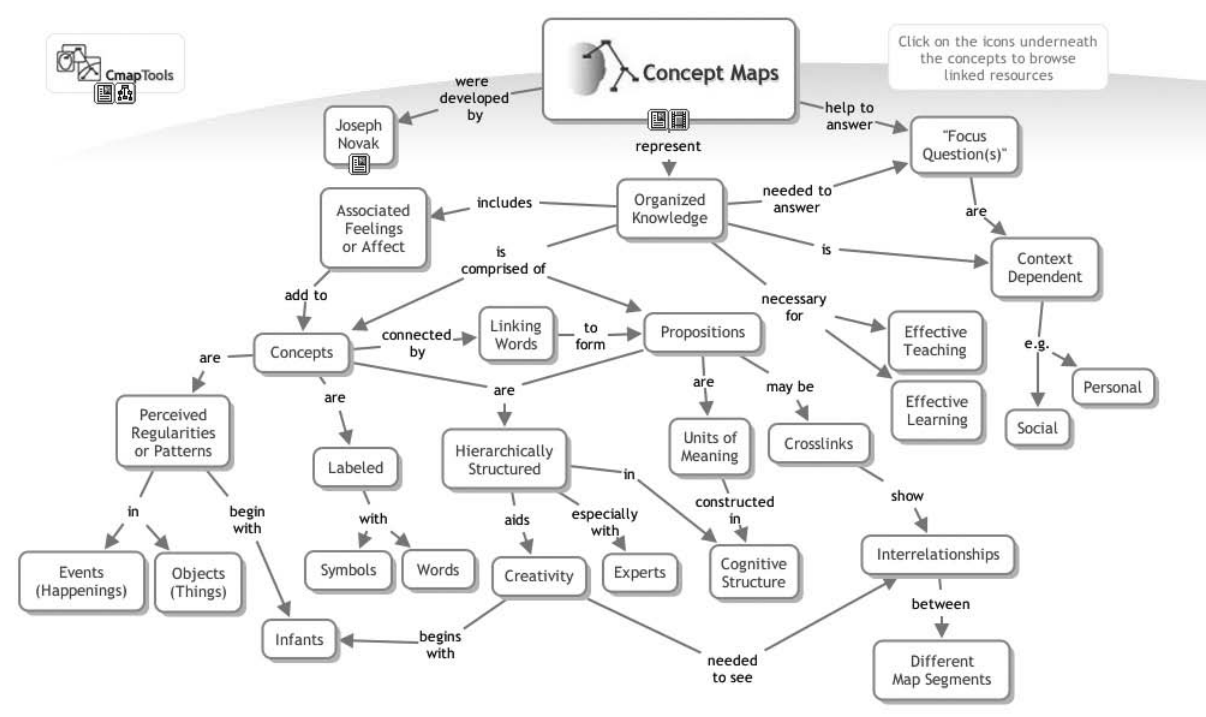

Figure 3-4: Concept map of the concept "concept map" (with permission copied from 
http://cmap.ihmc.us/). In comparison with the "knowledge graph" type of map, links are still labelled but without formality. The labels represent the words of the person whose mental model is elicited. Since the focus of the present research is on the use of information in complex decision processes, we will start using the concept mapping technique. Depending on the actual experiences within the case study, the use of the qualitative method is foreseen for the construction of an explanatory model of the case decision situation.

\subsubsection{Potential benefits of the use of mental models}

Schön\&Rein (1994:193) believe that policy researchers should seek first to understand policy practice - not to draw from it rules of effective policy making, but to describe and explain the kinds of inquiry in which policy makers engage. Literature on mental models puts forward that process of mapping mental models very well fits this opinion - mapping is considered to:

1. Reveal experiences, perceptions, goals, points of departure, assumptions, knowledge and subjective beliefs of stakeholders, experts and other actors.

2. Assess tacit knowledge,

3. Broaden the narrow understanding of a problem by confronting one stakeholders' map with the map of others,

4. Make aware of alternative perspectives on the problem, encourage negotiation, help to reduce destructive conflict,

5. Stimulate communication and learning.

Furthermore, literature claims that the produced mental model maps:

6. Exhibit the reasoning behind the decision maker's or expert's purposeful actions and they provide a way to structure and simplify thoughts and beliefs, to make sense of them, and to communicate information about them.

7. Can be used in the selection and interpretation of information,

8. Support information transfer and open communication between actors,

9. Can also identify blind spots in knowledge, give scientists clues they need to produce knowledge that fits into the frames of the diverse stakeholders in order that knowledge they produce can be of use to the stakeholders, enlarge insight in possible and desirable problem solutions, and support communication between actors,

10. Can reveal potential points of conflict by comparison of mapped mental models, decision process structure and actual use of knowledge.

Fischer (2001) defines the research discipline of policy epistemics as the discipline that analyses the interrelationships between the empirical and the normative inquiry, between the quantitative and the qualitative inquiry. According to Fischer (2001) it investigates the way interpretive judgments work in the production and distribution of knowledge. A particular goal of study would be

"the ways in which both experts and laypersons share background assumptions about the particular problem areas" (:20),

and a particular focus would be on

"the movements and uses of information" (:20).

According to Fisher (2001), policy epistemics would use new methods, the involvement of which could juxtapose the differing, often tacitly held, contextual perspectives and 
values, and directly compare the viewpoints and demand of experts, special interests groups and the wider public. Mapping mental models fits this description.

\subsection{Research design}

Chapter 1 showed how our research was preliminary focused on the development of a theoretical framework needed to describe the process of problem solving from the perspective of knowledge production and use. At the end of chapter 2 we used the framework to present a diagnosis for occurrence of persistent controversies. In the preceding part of chapter 3 we presented the elements that are to be used in the construction of a method to support decision making in a complex unstructured problem environment. This section describes the resulting method and research design that will test the hypothesis formulated at the end of chapter 2 .

\subsubsection{Research questions}

In order to investigate the central thesis in a specific case, we formulate the following research questions, each of which covers a different part of figure 2-5. The questions refer to a specific case of regional water management problems in the Netherlands. It is envisaged that the questions are equally valid for other regions, countries and decision making fields, because of the general applicability of the theoretical framework and methods.

1) In what way is the general decision making cycle specified in this particular case, and how is technical knowledge used therein?

This question will provide a description of the systems (both physical and human) involved, and of the course of the decision making process in terms of procedures and alternatives. Answers will be drawn from document analysis and details will be added from interviews. In general some sort of procedural rules will apply to a decision making process. For the water management cases studied here, the rules consist of the m.e.r. guidelines. These guidelines moderate the discussion and determine the way a solution is reached.

2) Which stakeholders are involved in the decision making process, and what is the general specification of their frame positions? On what elements can potential frame conflicts be expected? How do stakeholders (try to) exercise their influence in the diverse steps of the decision making process?

Stakeholders will be mainly identified from documents, frame positions from interviews mainly. The answers on the second question will specify the social-political context of the decision issue, in contrast to the mere technical context in the first question. The answers on the first and second question supply the information necessary to analyse the mental models of stakeholders.

3) What are the mental models of the stakeholders? Can mental models (and/or elements thereof) be related to the dominant perspective type of stakeholders? In 
what way do the position of the organisation in the decision arena, and the position of the individual within the organisation influence the dominant perspective type and the mental model?

The first sub question will be limited to a few technical and non-technical actor positions. The second sub question will be answered through the modification of mental model mapping techniques existing in other disciplines in such a way that they can be applied to our case in the field of integrated water management.

Based on the answers on the previous question, we now can put our hypothesis to the test:

4) Assuming that mental model found in the case are different, does the analysis of mental models and perspectives within actor frames explain the persistence of the controversies?

When such an explanation is found, differences between mental models and perspectives can have a predictive value with regard to the persistence of controversies.

\subsubsection{Unit of analysis}

In the present research we take as a the unit of analysis a decision making case. On different levels of aggregation the units of analysis are individual stakeholders that care to involve in the decision making process, their organisational units and their institutes. Together these form a "field of argument" (Willard 1996, in Fischer 2001:13). Argument is the polemical conversation, disagreement or dispute. Field of argument is the fields of inquiry (also called communities of inquiry) organized around particular judgmental systems for deciding what counts as knowledge as well as the adjudication of competing claims. Fischer (2001:14) describes such "policy communities" to consist of the network of scientists, policy experts, journalists, politicians, administrative practitioners, involved citizens who engage in and ongoing discourse about policy matters in a particular substantive area. (Fischer 1998:14) notes that, working with the same information, groups on both sides of an issue can easily construct their own alternative interpretations of the evidence. The constructs are visible through the vocabularies and concepts used to know and represent objects and their properties. Schön\&Rein (1994) use the notion of "frames" to explain the different interpretations. The present research uses the notion of "mental models" for the same explanation.

\subsubsection{Case reconstruction approach}

The overall research strategy is an explorative approach by comparison of a literature based theoretical framework with the result of a case study. In the case study, the individual researcher is in dialogue with a limited number of individual key stakeholders. Dialogue starts from the problem conception created by the researcher based on available written material, and then proceeds with semi-structured interviews to detail and modify this conception. The theoretical framework, to be developed first, guides the dialogue and is subsequently updated based on the results of the dialogue. Although presented in a sequential manner in this dissertation, the process of developing the 
theoretical framework, selecting the methods and analysing the results has in fact been an iterative one.

The case of the Zwolle storm surge barrier project in The Netherlands will be studied to investigate the practical applicability of the theoretical framework and hypothesis presented in the previous sections. This investigation will focus on a specific issue in regional water management, where knowledge is used in solving a complex unstructured decision problem. The issue is selected from available environmental impact assessment projects under the conditions that a decision has been taken that is sub-optimal from a technical perspective, it involves several actors, and uses scientific knowledge (including computerised calculation models). The case study will analyse the information used, and not used, in supporting the decision for building the barrier, the solution alternatives that have been considered, and the criteria that have been used to assess the impacts of these alternatives. After a description of the system in terms of the theoretical framework, the mental models of the major stakeholders involved will be reconstructed and analysed against their frame elements. We will especially look for those characteristics of mental models that differ between actors.

Mental models can be made visible with mapping techniques. A map is the researcher's conceptualisation of a subjects' mental model. Methods of mental model mapping are used, in various forms, in various disciplines outside the field of integrated water management. We will select and modify from these for application within the present research. All methods and types of mental model mapping can reveal individual and group differences in experiences, perceptions, assumptions, knowledge and subjective beliefs related to the problem, assess tacit knowledge, broaden the narrow understanding of a problem by confronting one stakeholders model with the models of others, make aware of alternative perspectives on the problem, encourage negotiation and help to reduce destructive conflict. The basic idea is to externalise a person's knowledge and consequently make it discussable.

\subsubsection{Method of data collection}

Data is collected by document analyses and interviews in depth with representatives of institutional stakeholders. The study starts with analysis of available documents, e.g. the environmental impact assessment report (EIA), and associated reports such as "Richtlijnadvies" and "Toetsingsadvies" of the EIA-commission, as well as research reports and publications. Documents from the earlier phases of the project are available to monitor the development of the conceptual model in time. Media messages (newspapers, internet) are used to detail stakeholders' concepts. Parallel to the document analysis, exploratory interviews with some of the stakeholders will produce additional documents and stakeholders. Representative stakeholders from the different institutions and organisational levels involved in the case are sought in order to cover the full range of frame perspectives and mental models. Reports or minutes of meetings, official protests, legal procedures, e.g. are used to detail the course of the decision making process. The use of scientific knowledge is detailed using research reports and publication referred to in the case project. 
In their analysis of a number of knowledge elicitation methodologies from different disciplinary traditions (judgement an decision making, human factors, cognitive science, expert systems), Hoffman et al. (1995) note that structuring an interview can help preventing getting side-tracked, making wrong assumptions about knowledge, getting a disorganised bundle of information. Structuring the interview can also reduce time spent relative to unstructured interviewing. According to Eden (2003) the amount and character of information elicited in an interview is considerably influenced by the structure of the interview and the skills of the interviewer. The structure can be obtained using domain-specific information, which results in a list of probing questions. These questions should cover a broad range of particulars within the domain and be carefully worded so as to avoid suggesting particular answers or imposing the categories or biases of the interviewer. Hoffmann et al. recommend that the researcher be bootstrapped into the domain prior to the elicitation of knowledge. Because the mapping of cognition is based on human communication in the form of a narrative (text or interview), the concept map is the researcher's conceptualisation of a subjects' mental model. Care should be taken in constructing interviews, because these are intrusive and involve researcher influence (Nelson\&Nelson 2000).

The domain-specific information is acquired trough prior analysis of the decision making c.f. problem solving domain. This analysis determines the general structure of the list, including a first version of more specific probing questions. Subsequent document analysis and exploring unstructured interviews result in a more detailed version of the list of focus points and probing questions.

The document analysis and exploring unstructured interviews also result in a description of the decision-making process and information used therein, in response to the first research question. The analysis also produces a list of stakeholders that will be interviewed. This completes the bootstrapping phase.

Before conducting the actual interviews with case stakeholders, the list of focus points and probing question is tested in a focus group session with experts familiar with the general problem field of integrated water management. In this test a different case is used as a discussion example, in order to prevent peculiarities of the Zwolle case to influence the list construction. The results are used to refine the list, and to produce additional information that the researcher can use to guide the interviews. The refined list is tested again in an interview with an expert from the specific case problem field (water management), resulting in minor changes of wording and a reduction of the number of probing questions.

The interview with a case informant has an open character as much as possible to stimulate the person interviewed to give is own facts, views and opinions. The interview tries not to impose a particular structure on the elicited information, but allow the structure to arise from informant's responses. Therefore mental model maps produced in the bootstrapping phase are not used as an aid for interviewing, and the list of focus points and probing questions is used as a checklist to elaborate on items introduced by the informant. Only when the informant does not address a specific topic from the list, 
the researcher will put forward these topic questions. Mental models and frame perspectives were elicited from a total of 14 stakeholders.

\subsubsection{List of probing questions}

Characteristics of the decision making cycle are used to construct an extensive list of questions that will elicit from informants information about every step in the cycle, and the possible influences therein.

The list is structured into several groups of questions, which start from a general level and gradually focus on the specific object of study. The list is intended to elicit as much as possible relevant aspects of the specific case, starting from a general problem description. The first group concerns the problem analysis and is intended as a general exploration of the case situation. The list then proceeds with a group concerning the actors involved, which is directed at a detailing of the social political context of the situation. The third group concerns the (physical) system, and is directed at eliciting system details. The fourth group of questions again concern the system, and is directed at the causal relationships that are used in the argumentation of the chosen problem solution. Finally, the fifth group concerns knowledge, and is directed at the use of knowledge in the argumentation process. The preceding groups actually serve to make the informant aware of his knowledge, experiences, and personal opinions.

A try-out of the list in a focus group session (see section 3.4.4) showed that the first version of the list was far to extensive, and also that several wordings had to be reformulated as not to influence the informant. The subsequent test of a shorter list in an expert interview showed that this new list performed well, except for some minor wording matters. The resulting short list (figure 3-5) covers a broad range of particulars within the domain and is carefully worded so as to avoid suggesting particular answers or imposing the categories or biases of the interviewer.

\subsubsection{Data analysis}

The interviews were transcribed into documents. A transcription was analysed on elements relevant for the construction of mental model maps and for frame perspectives. Mental model maps were drawn for some of the stakeholders, who stand as examples for the major frame perspectives. Mental model elements that were disputed between one or more stakeholders were collected in an data matrix. The specific opinion of a stakeholder on a disputed element was subsequently compared with his/her frame perspectives. The method used for data analysis will be discussed in detail in the next section. 
1. Problem phenomenon (general exploration)

- What issues are, in your opinion, involved in this problem?

- What examples make the issue tangible?

- How big or seriously is the issue?

- In your opinion, what is going on? What makes the issue to be a problem?

2. Stakeholders

- Which stakeholders are involved in this problem?

- How would you characterize the relations between the stakeholders?

- Which stakeholders did you contact directly on Barrier issues? (both formal and informal)

3. Broader context

- Into what broader context is the Barrier problem embedded?

- What other problems exist in that context?

- In what way are the other problems related to the Barrier problem?

4. Goals and boundary conditions

- What goals are mentioned? By whom?

- $\quad$ Are the goals formulated concrete or vaguely? What goals are present implicitly only?

- Which boundary conditions affect the problem? (Legal; Administrative; Financial; Temporal)

5. Solutions

- Which elements of the water system are important in the determination of a solution?

- What possible solution alternatives are mentioned?

- $\quad$ Are obvious solutions unmentioned? Which? Why?

6. Expectations with regard to the effects of solutions

- How does the solution make the problem phenomenon decrease or disappear?

- Which new problems are introduced by what solutions? Problems to whom?

- In what way are side effects of a solution taken into account?

7. Process of choice

- What aspects play a role in the decision process? (Between whom? When?)

- Which facts, knowledge and opinions ultimately were decisive?

- Which controversies arose?

8. Knowledge (dealing with knowledge in the chains of argumentation)

- On what subjects (insights, interpretations, opinions) discussion arose?

- Which knowledge aspects were involved in the decision process?

- In your opinion, was the available knowledge sufficient basis for a good decision?

9. Institutional boundaries

- In your opinion, do differences exist in the ways stakeholders deal with information, or the lack thereof?

- What hindrances did you experience yourself in the search for or application of information? How did you deal with that situation?

- Does the application of knowledge reveal the support of specific stakeholder interests?

- Did you find certain matters difficult to explain? Or difficult to convince? Which? To whom?

Figure 3-5: List of focal points and probing questions used in the case (translated from the Dutch). The list has been designed based on a literature study, and has been subsequently adapted using the results of a focus group session with experts on the field of integrated water management, and an interview with an expert on the hydrological aspects of the specific case issue. 


\subsection{Mental model mapping method design}

Starting from the methods described in section 3.3, we ultimately compared the mental models of informants by compiling an data matrix of the contested elements. In practice this approach offered considerable saving of time in the processing of the raw data. As an example the mental models of two informants (nos. 1 and 3 ) are presented. Because the relevant information of the mental models is present in the data matrix, maps of the other mental models have not been constructed (with the exception of informant 2). The research design described in the previous section will now be further elaborated with regard to the construction and analysis of mental models. The details of this part of our method are presented in figure 3-6 and are discussed below.

1. A transcription of the interview was made.

2. The transcription was structured by setting apart text fragments that deal with a single subject into the cells of a table. Next the important words and passages wore highlighted, and key words were marked in bold. On the same row of the column, in the adjacent cell, the text fragment was commented and the most important passages were copied into this cell to facilitate the production of the summary. All actions were performed with the Microsoft Word software.

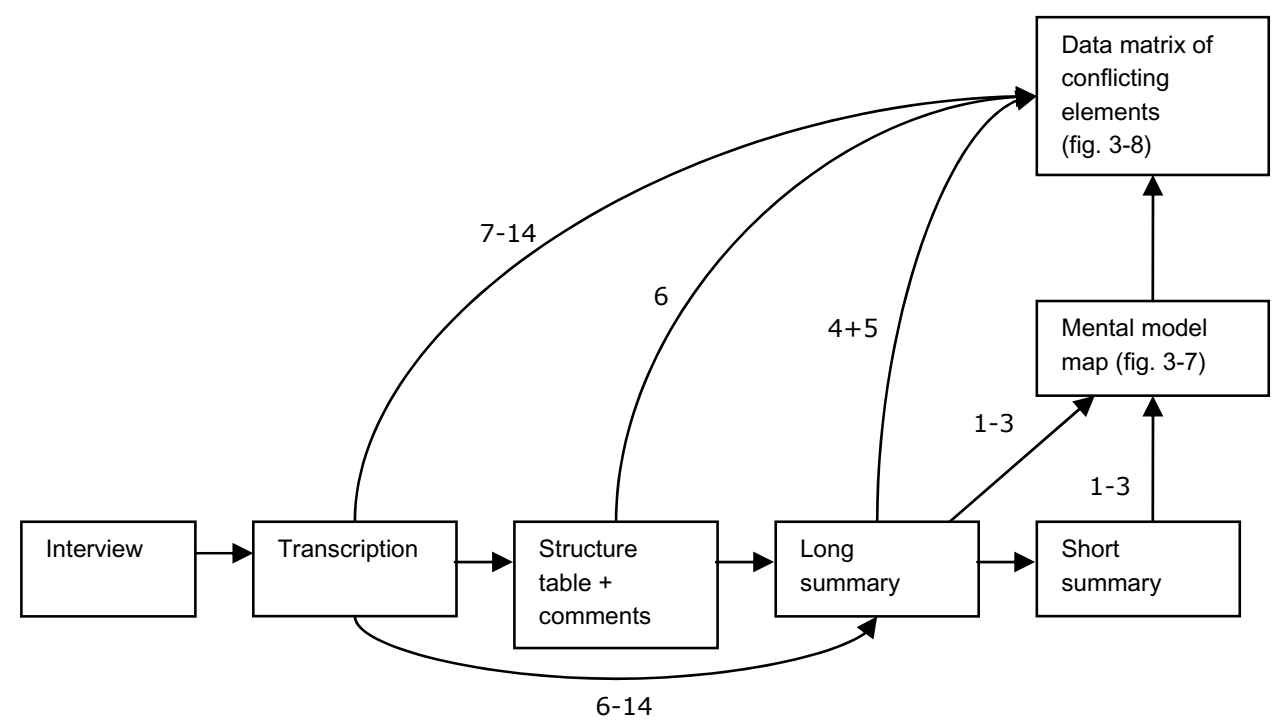

Figure 3-6: The procedure followed for the analysis of mental models. For successive informants (which are indicated by their code number) the procedural steps gradually were reduced in the production of the data matrix table. In order not to lose any information summaries have been made afterwards of every interview transcription. 
3. Subsequently a long summary was produced, based on the previous selected text passages. Next the long summary was further compressed into a short summary.

- Initially, the key words were collected and ordered in main and sub concepts in a list of key words. This was intended to be the basis for the construction of mental model maps. This procedure proved to be to laborious, in practice the construction of a mental model map on the basis of the summaries proved to produce better results. Therefore, starting from at the third informant, the list of keywords was discarded and the map was produced directly from the summaries.

4. Based on the summaries mental model maps were produced, using the CmapTools software package. Figure 3-7 and 3-8 provide two examples. Subsequently the short summaries are used to structure the map.

5. The mental model maps were subsequently analysed on model elements that conflicted with the maps of other informants, with the purpose of revealing controversies between informants. These specific elements were indicated in the map with ellipses. Conflicting elements were identified by different values on system parameters, different interpretations or opinions on the issue at hand. Also specific opposition against other informants or the general EIA opinion was noted.

6. In our study we are searching for barriers in the information flows between actors, and expect that these will become visible in the conflicting elements. In fact, we are searching for those parts of the maps that are not shared between all informants. Removing the shared elements from the maps would result in a set of maps that have minimal overlap, from which we intend to explain the course of the decision process in this case. In stead of performing the above operations in the maps, we collected all conflicting elements in a table, the data matrix, which makes them easier to process. The elements have been written down as bi-polar (or more) statements where possible (a method we copied from the cognitive mapping method described in section 3.3.3). This makes their meaning more clear compared to the mono-polar notation. Every pole represents a value that this specific element can take. Every time the analysis of the interview produced a new conflicting element, or a new value of an already existing conflicting element, its value was included in the list. The table keeps track of which informant uses which value of the conflicting element by writing down an indicator for the value in the table column of the specific informant. Also a reference is made to the corresponding time position (in minutes) in the interview. In this way, for each conflicting element the table shows the opinion of every informant on that subject. Table $\mathbf{3 . 1}$ presents an example of the data matrix.

The method described above to transcribe each interview is rather time consuming. In the course of our interview analysis we therefore devised a way to accelerate the analysis process without negatively influencing the intended final results. These methods are described below.

1. The first transcriptions represented the recorded interview text in full extent. This created in the researcher a detailed picture of the problem situation in the 
specific case. Using this detailed picture, later interviews were only transcribed with regard to new information, the other part of the recordings were summarized by means of keyword and sentences. The idea behind this approach was that, starting from a certain moment; subsequent interviews would not produce new information any more. This appeared not to be the case in our interviews. Although the parts of the interviews did indeed contain the same information, every informant appeared to produce original elements. The number of new elements, however, gradually decreased.

2. Mental model maps have been produced for the first three informants only. From these maps we concluded that informants mention many overlapping elements, which resulted in large correspondences between maps. Because our study focuses on map differences, we omitted the production of mental model maps starting from the fourth informant. For the $4^{\text {th }}$ and $5^{\text {th }}$ informant the conflicting elements were identified from the summaries that previously served the production of mental model maps.

3. After the fifth informant the list op conflicting elements appeared to grow less quickly, indicating that our list gradually became more complete. For this reason, starting from the $6^{\text {th }}$ informant the production of summaries was also omitted, and conflicting elements and their scores ware determined directly from the structuring table and added to the list.

4. Starting from the $7^{\text {th }}$ informant, also the structuring table was omitted, and the gained experience of the researcher now allowed the identification of conflicting elements directly from the interview transcription. In stead of in the structuring table, key passages, key words and comments have now been marked directly in the existing transcriptions, to facilitate the production of summaries.

5. Finally, we afterwards decided to produce the lacking summaries, in order acquire a better view of the opinions of all informants.

Figure 3-6 depicts the procedure followed in our method. The above described approach to accelerate the analysis will be able to efficiently produce a list of conflicting elements. Just like described for the development of the list of focal points and probing questions (see section 3.4.5), the researcher uses the information acquired in the early phase of his analysis to build an overview of the situation. From there the analysis can progressively be accelerated. 


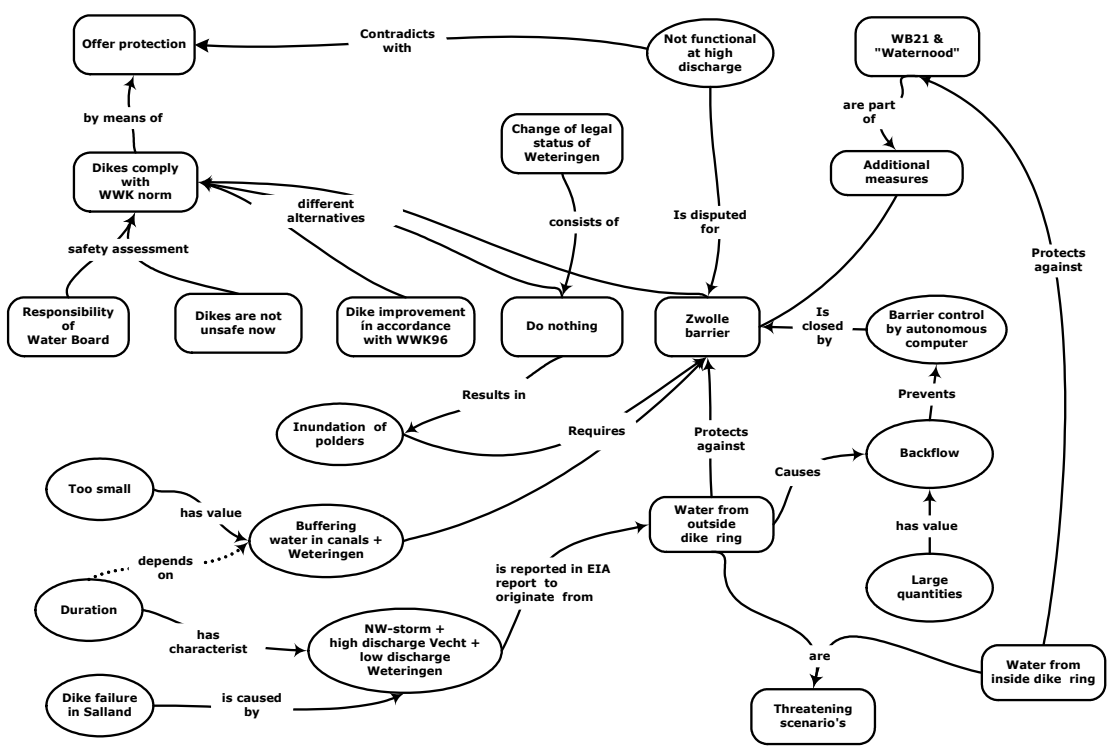

Figure 3-7/8: Example of the mental map of an O-type actor (above: part of the map informant no. 1) and a T-type actor (below: part of the map of informant no. 3). Ovals represent elements disputed by one or more other stakeholders. The full mental map is presented in Appendix C and D, where the original Dutch wording is retained to facilitate discussion of the maps with informants.

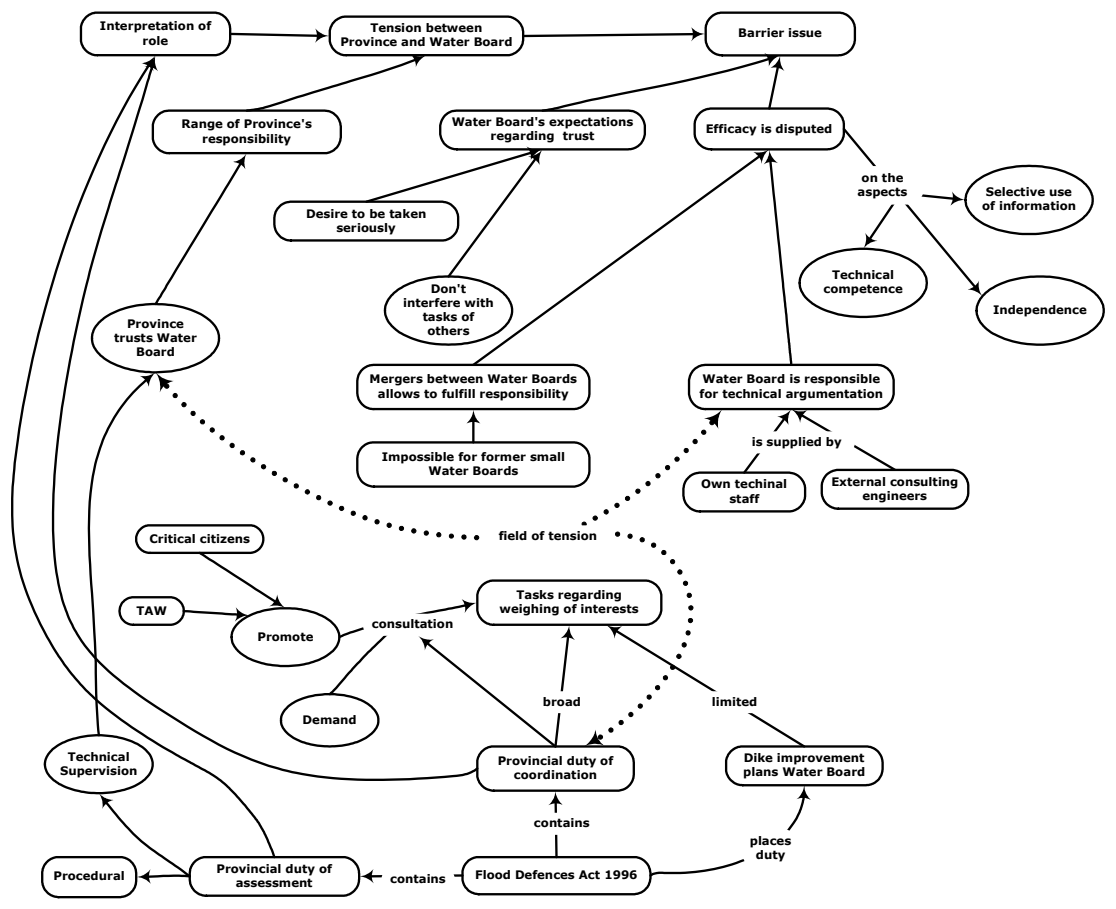


Tabel 3.1: Example of the data matrix, showing some relevant generalized disputed concepts with stakeholder scores. The full data matrix is presented in section 5.2.

\begin{tabular}{|c|c|c|c|c|c|c|c|c|c|c|c|c|c|c|c|c|c|}
\hline & $\begin{array}{l}\text { Disputed } \\
\text { element }\end{array}$ & Observations from interviews & Scores & 1 & 2 & 3 & 4 & 5 & 6 & 7 & 8 & 9 & 10 & 11 & 12 & 13 & 14 \\
\hline 2 & $\begin{array}{l}\text { Dike ring } \\
\text { principle }\end{array}$ & $\begin{array}{l}\text { Must be physically closed ...vs... } \\
\text { can have an open discharge canal } \\
\text { on condition that the safety norm } \\
\text { remains guaranteed. }\end{array}$ & $\begin{array}{l}\text { Closed (G), } \\
\text { Open }(O)\end{array}$ & G & O & G & $G$ & G & $G$ & 0 & $G$ & & & $\begin{array}{l}\mathrm{G}, \\
\mathrm{O}\end{array}$ & G & G & $\begin{array}{l}(\mathrm{G} \\
)\end{array}$ \\
\hline 16 & $\begin{array}{l}\text { Province } \\
\text { WWK } \\
\text { approval }\end{array}$ & $\begin{array}{l}\text { Province must dissociate and limit } \\
\text { to assessing the reasonability of } \\
\text { the EIA report contents ...vs... can } \\
\text { fully participate on contents } \\
\text { aspects also from the start of the } \\
\text { project }\end{array}$ & $\begin{array}{l}\text { Distance (R), } \\
\text { Involvement } \\
(\mathrm{M})\end{array}$ & R & M & R & ( & $M$ & $\mathrm{R}$ & & $\begin{array}{l}\mathrm{R} \\
*\end{array}$ & $\mathrm{R}$ & & M & & $\mathrm{R}$ & \\
\hline 33 & $\begin{array}{l}\text { Water } \\
\text { system } \\
\text { discharge } \\
\text { peaks }\end{array}$ & $\begin{array}{l}\text { Discharge peaks from the river } \\
\text { Vecht and the Sallandse } \\
\text { Weteringen do not coincide ...vs... } \\
\text { in the past the discharge peaks } \\
\text { were always observed to coincide }\end{array}$ & $\begin{array}{l}\text { Differ (N), } \\
\text { Coincide (S) }\end{array}$ & & S & & - & S & $\mathrm{N}$ & S & & $\mathrm{N}$ & $S$ & $-*$ & & & S \\
\hline
\end{tabular}

Concluding, the mental model mapping method described in this section will allow us to answer the first part of the third research question. The next section will continue with the construction of the method to analyse the relationship between perspectives and mental models.

\subsection{Frame perspective analysis method}

Having determined the contested issues in the problem situation in the previous section, we will try to use the TOPEA frame perspectives described in section 3.2.4 to explain an actor's score on such an issue, see (2) in figure 3-9. The dominant perspective will first be determined from an actor's institutional and personal context (1). This determination will be performed by the researcher based on the opinions and behaviour of the informant. The goal of the analysis of an actor's scores on the contested elements is firstly to explain the final position the actor takes with regard to the decision on alternatives (3). Furthermore, the analysis of score differences between actors is expected to reveal the frame conflicts described by Schön\&Rein (1994). Concluding, the analysis of perspectives in addition to mental models will produce the full answer on the third research question.

In order to find an answer to the fourth research question, we need to analyse the frame differences between actors. For this purpose we will use an extended version of the data matrix described in the previous section, which is our final framework of analysis, see table 3.2. Whether a controversy remains persistent will depend, we expect, on the possibilities an actor has to change his scores on conflicting elements with regard to his dominant perspective. 


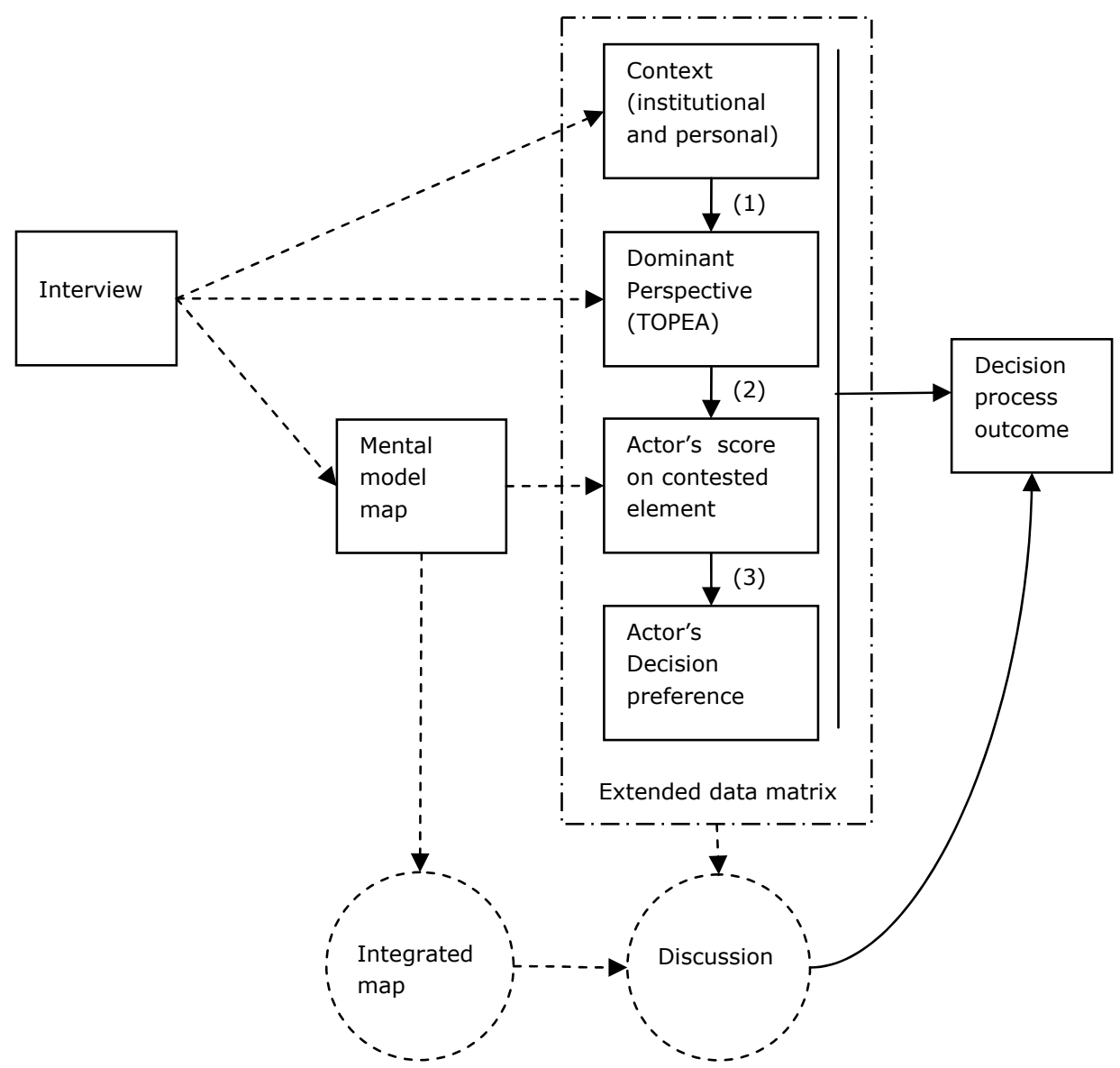

Figure 3-9: The basic principle of analysis for the case study. The circles denote possibilities for future use of the method. The dotted arrows indicate production, the full arrows explanation.

The method presented offers possibilities for future use, outside the scope of the present $\mathrm{PhD}$ research. The data matrix also provides a means of discussing the decision making arguments with informants. The scores could be discussed with informants, separately and in a group. Such a discussion would potentially offer clarity regarding background of the scores, and thus contribute to open communication. Also, based on his experience gained in the case analysis, the researcher may construct a common mental model map that integrates the elements of al informants. Such a map will reveal the relationships between the disputes elements, and offer a way to structure them into clusters. Subsequently this map, as well as the details of each disputed element, could be discussed with the actors involved in the problem. The result of such a discussion might offer an explanation for the decision process outcome. 
Table 3.2: The principle of frame analysis applied in the construction of an extended data matrix.

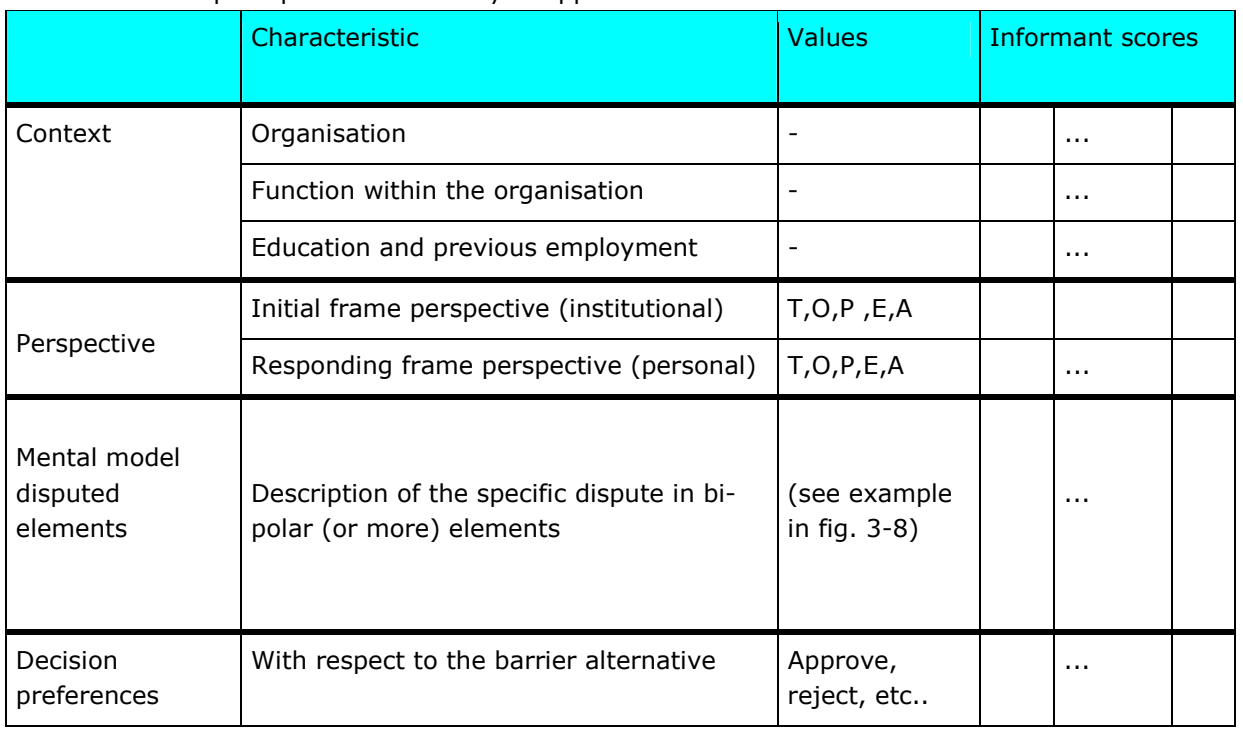

\subsection{Decision model}

The present study also set out to explain the decision ultimately taken in the case. An actor's institutional preference with regard to the decision in this case is presented in the bottom line of the extended data matrix. This preference does not, however, explain the decision ultimately taken. For this purpose we will analyse the interviews on what actors indicate to be the core issues of the argumentation. These core issues will be arranged in an explanatory model that can subsequently linked to the contested elements from the data matrix. 


\section{Case description}

The method developed in chapter three has been applied to a specific issue in regional water management. The issue was selected from available environmental impact assessment (EIA) projects. The object of research for this case study is the decision process by in which a storm surge barrier was selected from a range of other alternatives. The specific barrier is located in the city of Zwolle in the Netherlands. The case study will analyse the argumentation elements used in the EIA decision for building the barrier, the solution alternatives that have been considered, and the conflict issues that were raised during the decision process. Also this case study investigates the practical applicability of the theoretical framework presented in chapter 2 .

In this case the preferred solution is defended by the Water Board, by means of an EIA procedure, in response to critical remarks made by the public, other administrative institutions and experts. The goal of the Water Board is a timely implementation of the selected barrier alternative, for which purpose they need approval by the Provincial Executive Council ("Gedeputeerde Staten") of the Province and also, in this case, by the "Raad van State", the highest administrative court in the Netherlands, because of procedures started by protesting citizens.

The Zwolle storm surge barrier is located in one of the tributaries of the IJssel-Vecht delta (see figure 4-1) and will be one of the many barriers in this region ${ }^{1}$. The barrier, like all barriers of this type, is used in a river to reduce the effects of downstream windsetup and hence hydraulic loads by closing it when high water situations are anticipated. Closing the barrier will, however, also potentially increase the water level upstream of the barrier by blocking the discharge. This makes storage of the discharge in the river itself or in a detention basin, or the construction of a pumping facility a necessary collateral measure. In the Zwolle situation, the intended barrier will also convert the status of $42 \mathrm{~km}$ of primary flood defences in the hinterland from primary to that of secondary.

This chapter addresses the first and part of the second research questions (section 3.4.1):

1. In what way is the general decision making cycle specified in this particular case, and how is technical knowledge used herein?

2. (first part) Which stakeholders are involved in the decision making process, and what is the general specification of their frame positions? On what elements can potential frame conflicts be expected?

\footnotetext{
${ }^{1}$ The barrier construction is expected to be completed in the summer of 2005 .
} 
The case has been extensively described in the environmental impact assessment report (EIA-report 2001) and associated documents and media messages. This chapter summarises the relevant information.

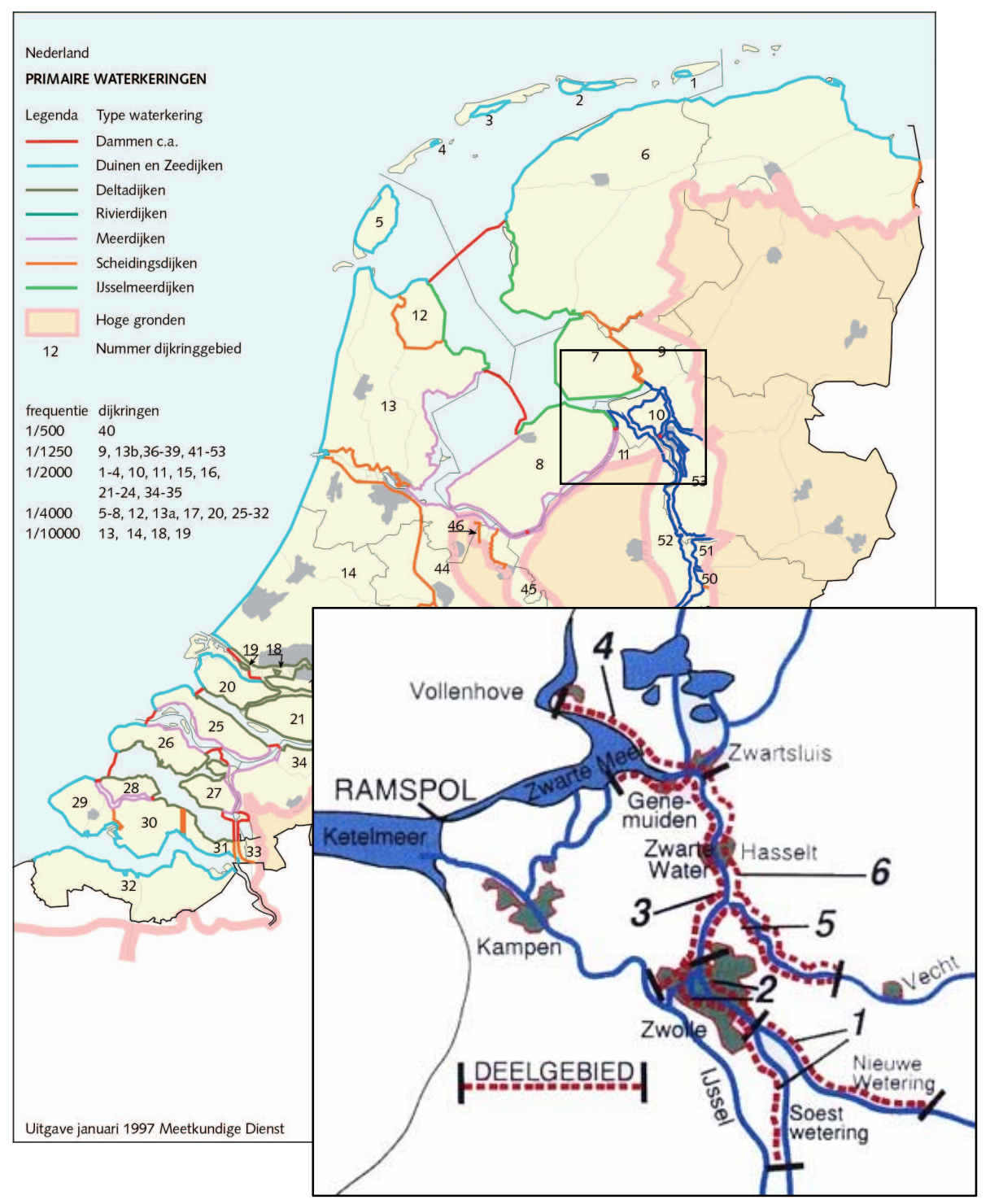

Figure 4-1: Map from appendix 1 from the "Wet op de waterkering", showing the dike-ring areas. The insert shows the case study area around the city of Zwolle (figure copied from the Groot-Salland water board website http://www.wgs.nl/ ). The case concerns the improvement of sections 1 and 2 of dike ring 53, as required by the act "Wet op de Waterkering 1996". 


\subsection{Characteristics of the selected case}

In general, the complex nature of large EIA-projects and the availability of documentation makes them suitable for the purpose of the present study. A further consideration is that EIA-studies often involve local issues (thus giving rise to involvement of local citizens and organisations), but are also concerned with jurisdiction, funding, responsibilities and interests on a national level.

The case was selected for analysis because of its unstructured, complex character, the involvement of various actors, and the use of scientific knowledge (including the use of computer based simulation models). The following aspects of the barrier system and the unstructured nature of related problems make this case especially suitable for the present study:

1. The physical system and its uses represent a multifunctional river basin including: city, shipping, agriculture, nature, cultural heritage \& landscape, recreation.

2. The barrier problem is interconnected with other problems in the same subsystem (water management and control in the hinterland of Salland) and in the larger water system (Zwarte Meer, Zwarte Water, Vecht, Dinkel, Regge).

3. The social context includes local and national political considerations including the balance of power between groups in society, policy statements, legal arrangements, pressure from interest groups, technical knowledge and skills, availability of funds, national attitudes and history, as well as a European framework of rules and regulations.

4. The problem involves a division of responsibilities between public authorities (national versus regional).

5. Conflicting opinions are present between the main actors involved (water board, province, public, the Netherlands EIA-commission).

6. An urgent decision is required by the "Wet op de Waterkering 1996" (WWK96).

7. The use of knowledge is disputed between and within actor groups (e.g. the risk of inundation is not confirmed by model calculations, and accompanying uncertainties are not explicitly dealt with).

8. The use of values/ norms is disputed (e.g. the applicability of safety standards).

These characteristics of the Zwolle barrier case also fit the definition of post-normal science by Funtowicz\&Ravetz (1993b), characterised by issues involving risk and environment, where facts are uncertain, values in dispute, stakes high and decisions urgent. The unstructured nature of the problems gives rise to discussion and discourse not only on a societal level, but also on the level of professional consultancy as well as that of applied science. 


\subsection{The Water system}

\subsubsection{Water system description}

The flood defences in along the rivers in the case area consist of primary and regional defences. Primary flood defences are, by definition, located along the large rivers and lakes, and the sea. Secondary flood defences are located along the smaller rivers and canals. The difference between the two is defined in the WWK96 (see figure 4-1). The insert in figure 4-1 shows the river Vecht which transfers into the Zwarte Water (at point no.3 downstream of Zwolle) and debouches into the Lake Zwartemeer. The Lake Zwartemeer is separated from the lake Ketelmeer (which is in open connection with Lake IJsselmeer) by the Ramspol storm surge barrier (Van der Schrier 2000). The Ramspol barrier is the first line of defence against storm induced high water threats (Ramspol 1995, 1998). The dikes behind Ramspol (nrs 1, 2, 3, 4, 5 and 6 on the insert in figure 41) are, at the time of the case and in the preceding period, subject to a process of improvement which should make them compatible with the legal guidelines according to the WWK96. Design flood levels (MHW's) are specified for the dikes along this system by the "Hydraulic Preconditions for Primary Flood Defences" ("Hydraulische randvoorwaarden", in Dutch, TAW 1996a), which are updated every five year. The presence of the Ramspol barrier reduces the MHW's upstream along the Zwarte Water that are required to reach the specified level of protection (which ranges from 1/1250 to $1 / 2000$ per year). Part of the WWK are the "Guidelines for safety assessment" ("Leidraad Toetsen op Veiligheid", in Dutch, TAW 1996b) which defines the framework to assess the safety conditions of a dike. When the resulting condition is not described as "good", a dike improvement process will be started according to the, at that time applicable, TAWdocuments Guideline for Designing River Dikes ("Leidraad voor het ontwerpen van rivierdijken", in Dutch, TAW 1985, 1989).

The case is concerned with two parts of the above water system: the Sallandse Weteringen and the canals in the Zwolle city centre (nos. 1 and 2 in the insert, respectively). The Sallandse Weteringen originally were brooks that discharged into the River IJssel, which have been gradually reconstructed into canals in the middle ages to drain the Salland region near the city of Zwolle into the Zwarte Water (Ramspol 1995:91). Reconstruction and improvement took place again in the period 1960-1970. The canals operate under free flow under all circumstances (Van der Schrier 2003a, personal communication), which means that there is no discharge sluice to prevent downstream water to enter the canals (like there is in polder discharge systems near the coast). The canals transfer into the Zwarte Water just downstream the Zwolle city centre, and join the Vecht (at point 3 on the insert in figure 4-1). Although the naming is confusing, the canals and their extension called Zwarte Water, are in fact a tributary to the river Vecht. The Weteringen and city canals are not real rivers because of their artificial construction, and have a comparatively small size, but nevertheless their flood defences are denoted in the WWK96 as primary. The latter fact makes them subject to the dike improvement process started by the WWK96. The safety assessment of the DAR-2 dikes in the city of Zwolle concluded that on some parts their height was below the required design level, and the assessment of the DAR-1 dikes along the Weteringen concluded that in many places these dikes were below the required design level (Grontmij_Projectbureau_DAR 1997a:16). 
Together the improvement of the six dike sections mentioned above comprise the "Dijkverbetering achter Ramspol" (DAR) project. Parallel to the construction of the Ramspol barrier (which was completed in 2002), the DAR project was started to improve the dikes upstream of Ramspol. Because of the Ramspol barrier, these dike improvements could be limited compared to a situation without the Ramspol barrier. The DAR project started in 1997 with the production of the "Nota van uitgangspunten" (Grontmij_Projectbureau_DAR 1997a) and the separate "Startnotities" for DAR1 and DAR2 (Grontmij_Projectbureau_DAR 1997b, c). Afterwards dike sections 1 and 2 were combined in a single project DAR-1 +2 , for which an environmental impact assessment (EIA) has been performed (EIA-report 2001).

The area of the Zwarte Water is a collection point of several catchments (besides the Overijsselse Vecht and the Sallanse Weteringen, also discharge from the Drente region joins further downstream). At times of high upstream discharges the water level in the Zwarte Water rises in order to realise the transport capacity required for further discharge down into Lake IJsselmeer. From there the water is discharged, through the IJsselmeer Enclosure Dike ("Afsluitdijk", in Dutch), into the Wadden Sea. The water level of the Lake IJsselmeer in this way influences the level in the Zwarte Water. Details of the Vecht catchment are described, for instance, in Van Slobbe (2002:159-161) and in the "Stroomgebiedsvisie" (2003). Table 4.1 specifies some characteristics of the stream reaches involved.

Table 4.1: Some characteristics of the catchments involved: the Overijsselse Vecht with its tributaries Sallandse Weteringen and Meppelerdiep. The rivers IJssel and Rhine are added for comparison.

\begin{tabular}{|c|c|c|c|c|}
\hline Stream reach & $\begin{array}{l}\text { Discharge } \\
\text { area } \\
(\mathrm{km} * * 2)\end{array}$ & $\begin{array}{l}\text { Stream } \\
\text { length } \\
(\mathrm{km})\end{array}$ & $\begin{array}{l}\text { Design } \\
\text { discharge } \\
(\mathrm{m} * * 3 / \mathrm{s})\end{array}$ & MHW-frequency \\
\hline Overijsselse Vecht & $3.7801)$ & $1671)$ & $4714)$ & $1 / 1250 \quad 5)$ \\
\hline Sallandse Weteringen & $4389)$ & 42 & $68 *$ & $1 / 100-1 / 1250 *$ \\
\hline Meppelerdiep & $9207)$ & ** & $112,58)$ & $1 / 18)-1 / 20010)$ \\
\hline IJssel & $2.2507)$ & $1287)$ & $2.5006)$ & $1 / 20005)$ \\
\hline Rijn & $185.0002)$ & $1.3203)$ & $16.000 \quad 2)$ & $1 / 1250-1 / 10.0005)$ \\
\hline $\begin{array}{l}\text { * These value } \\
\text { design freque } \\
\text { ** Not availat } \\
\text { 1) (Rijkswater } \\
\text { 2) www.verke } \\
\text { 3) http://rijno } \\
\text { 4) } \underline{\text { http://wwv }} \\
\text { 5) TAW (1996 } \\
\text { 6) http://wwv } \\
\text { 7) } \underline{\mathrm{http}: / / w w v} \\
\text { 8) http://proj } \\
\text { 9) Grontmij_P } \\
\text { 10) Provincie }\end{array}$ & $\begin{array}{l}\text { were under } \\
\text { cy for the ne } \\
\text { le, mainly art } \\
\text { staat et al., } 1 \\
\text { erenwatersta } \\
\text { otermijn.wlde } \\
\text { waterkeren. } \\
\text { ) habiforum.n } \\
\text { steunpunt.w } \\
\text { cten.nederla }\end{array}$ & $\begin{array}{l}\text { scussion be } \\
\text { situation ( } \\
\text { cial channe } \\
\text { 44) in (Slob } \\
\text { nl/ object/ } \\
\text {.nl/sum06 } \\
\text { info/nieuw } \\
\text { lata/public } \\
\text { eremissies } \\
\text { leeftmetwa } \\
\text { AR (1997b }\end{array}$ & $\begin{array}{l}\text { en the stak } \\
\text { report } 2001 \\
\text { the provin } \\
2002: 159 \text { ) } \\
=\text { nl\&tb=Obje } \\
\text { ef } \\
\text { ef/nbrwk } 0 \\
\text { hs/478 ontv } \\
\text { nema/augu } \\
24.530+\end{array}$ & $\begin{array}{l}\text { Iders. The value } 1 / 100 \text { is the } \\
\text { 5). } \\
\text { of Drente. } \\
\text { id=459 } \\
\text { tml\#03 } \\
\text { pweek.pdf } \\
\text { jn/GRW_2002_DON.pdf } \\
\text { WB21_Vecht_Zwarte_Water.pdf } \\
310 \text { ha }\end{array}$ \\
\hline
\end{tabular}


In the event that high discharges from the river Rhine through the river IJssel into Lake IJsselmeer continue for a long period, this can affect the water level in Lake IJsselmeer. Because of the (still) limited discharge capacity of the "Afsluitdijk" sluices, the water level in Lake IJsselmeer can rise above its design level and thus limit the discharge capacity of the Zwarte Water. Consequently higher water levels in the Zwarte Water, Vecht and Zwolle canals can result. In case a storm surge on the North Sea happens in this period, this situation is aggravated through the further limitation of Lake IJsselmeer discharge capacity and wind induced raise of water levels on the Zwolle side of the Lake IJsselmeer and Zwarte Water. The worst case scenario takes place when, added to the above two events, also a high discharge occurs on the river Vecht and the Sallandse Weteringen. In that case the water in the Zwolle city centre canals may reach high levels. Historically, such situations have caused flooding inconvenience in the city centre in e.g. 1825 (a major national flooding disaster), 1877, 1883, 1895 (CieMER 1998), 1916 (a national flooding disaster which initiated the planning of closure of the Zuiderzee), 1925, and 1930. After the closure of the Lake IJsselmeer with the "Afsluitdijk" in 1932, high water levels in 1954, 1956, 1960, 1965, and 1987 caused less flooding inconvenience.

The Zwolle city centre, however, does not fall under the protection of the WWK96, and no safety norm has been established for it (Grontmij_Projectbureau_DAR 1997a:9). As is indicated on the map in the appendix 1 of the WWK96, the dikes of dike ring 53 pass on both sides of the city centre, leaving it as an island surrounded by the city canals (see figure 4-2). Changes in water level on Lake IJsselmeer, and effect of rise of the water level due to wind action in case of NW storm show in the varying water levels in the city canal (in contrast to e.g. the city canals in Amsterdam which have a steady water level). Thus the Zwolle city centre legally lies outside the dike, which may have consequences for liability in the event of flooding damage. Remarkably, this legal status has not been changed after the construction of the Ramspol storm surge barrier. Rampsol effectively connects dike ring 10 and 7 and thus can be regarded to close the dike ring system, thus protecting the water lying behind it. Yet the Lake Zwartemeer, the Zwarte Water, the river Vecht and the Sallandse Weteringen maintain their primary status. This has been done from the practical argument that wind effects on these local waters may still cause dangerous water levels, and from the formal argument that the river Vecht is regarded by the water board as a "large river" as defined in the WWK96 (article 1).

The city of Zwolle was founded around 800 A.D. by Frisian merchants and troops of Charlemagne. The name Zwolle comes from the word Suolle, which means "hill". Zwolle was founded on a hill between the three rivers surrounding the city, IJssel, Vecht, and Zwarte Water. The hill was the only piece of land that would remain dry during the frequent flooding of the rivers. The oldest known written mention of Zwolle is from 1040 (Wikipedia 2004). Of old, the city of Zwolle has learned to cope with high water situations. Already in the early middle ages, a storm surge entering the Vecht river system from the former Zuiderzee would pass through Zwolle to find its way into the low lands of Salland. The old hanseatic town had a cunning water management policy. The low lands acted as a natural inundation area, and resulted in a relative lower ( 0.5 to 1 meter) water level in the city of Zwolle compared to e.g. the city of Genemuiden further downstream the Zwarte Water. 


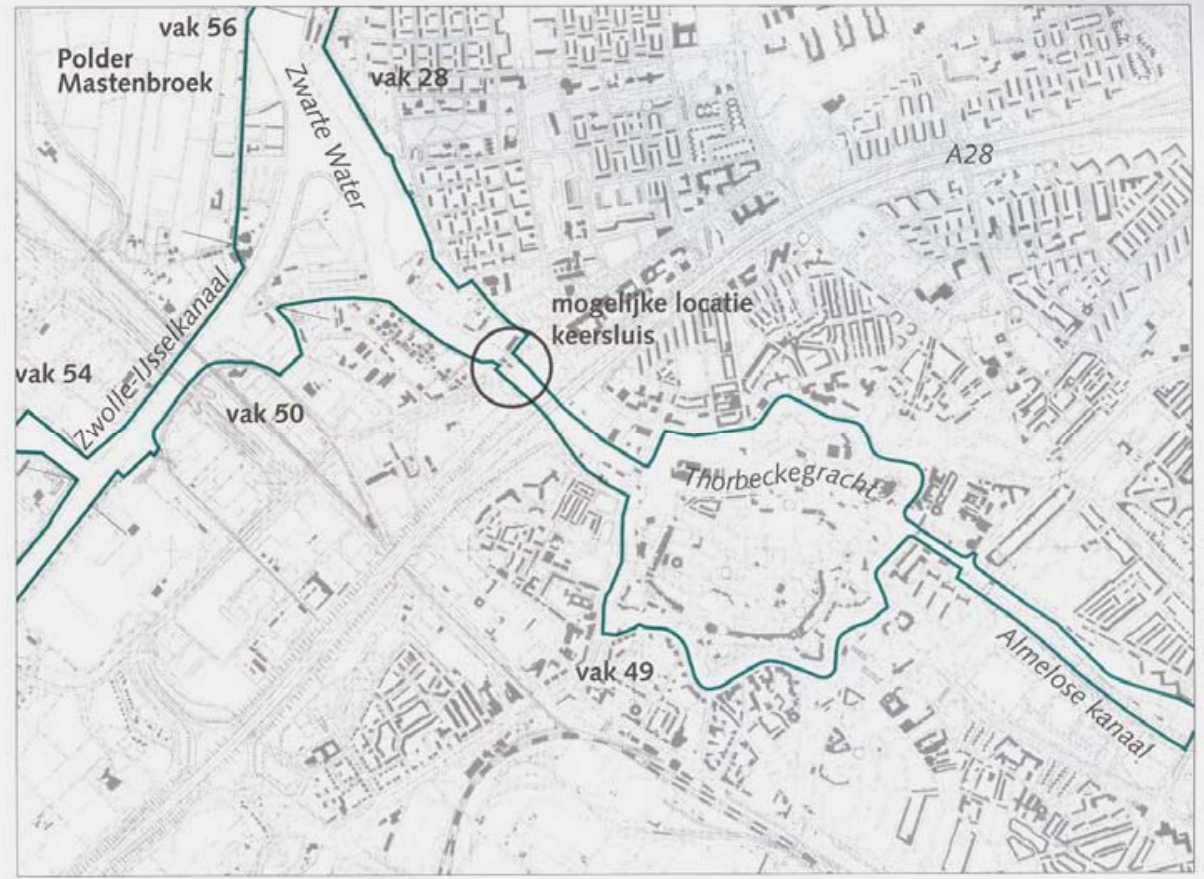

Figure 4-2: The Zwolle city centre canals and the course of dike ring 53. The canals are fed from the Weteringen on the right and discharge to the Zwarte Water on the left. Map copied from (Ramspol 1995: figure 4.1e "Tracé primaire waterkering in Zwolle"). Note that the city centre is situated outside the dike, and that in the alternative plans for the Ramspol barrier a possible barrier in Zwolle was already present.

The city of Zwolle has carefully maintained these inundation areas, even up to the $20^{\text {th }}$ century. In the second half of the $19^{\text {th }}$ century the railway tracks from Zwolle to the North and East were constructed on dikes in the low areas, and large openings were provided in these railway dikes to ensure unrestricted flow of the storm surge water. Until the closure of the Zuiderzee the dikes along the Weteringen were to resist these storm surges, and one polder (Sekdoorn) had an emergency spillway to mitigate the highest water level in the Weteringen by inundation of this polder, and, by a further emergency spillway, the adjacent polder Lierderbroek in case the Sekdoorn capacity was exceeded. More details of the water management history of Salland are described in the "Startnotitie DAR1" (Grontmij_Projectbureau_DAR 1997b:17-21), and historical details of the city of Zwolle are presented in the "Startnotitie DAR2" (Grontmij_Projectbureau_DAR 1997c:21-23).

Only after the closure of the Zuiderzee with the "Afsluitdijk" in 1932, this inundation principle was released, resulting in the major reconstruction of the area in the years 1960-1970. On this occasion, the emergency spillway along the Weteringen was removed. At the current time the former inundation areas are protected against high 
water by the dikes along the Sallandse Weteringen (see figure 4-3). But in extreme precipitation events they are at risk of being flooded again. The threat of the city of Zwolle being flooded does not so much result from a storm surge, but rather results from high precipitation events in the Salland en river Vecht region. The effects of a storm surge will be limited because of the protection offered by the Ramspol barrier. Calculations performed by (HKV_Lijn_in_water 1996b) show that the MHW in Zwolle is determined by the $1 / 1250$ per year discharge peaks on the river Vecht and Weterningen (:4). (HKV_Lijn_in_water 1999) calculated this MHW to be 1,75 m+NAP $(: 7,21)$. The lowest part of the Zwolle city canals quays lies at 1,65 m+NAP, which establishes the maximum allowable water level (HKV_Lijn_in_water 1996b:4).

(Grontmij_Projectbureau_DAR 1997c), in a description of the shortcomings within Zwolle compared to the WWK97 demands, proposes a $1 / 1250$ per year MHW of 1,80 m+NAP. At this level only limited parts at the edge of the city centre will inundate with insignificant water depth, and water hindrance there will be prevented by future municipal housing plans. At this proposed MHW no safety problems will occur in the city centre, but water hindrance in cellars and through sewer system backflow is possible $(: 18)$. (HKV_Lijn_in_water 1999), at a later time, mentions yet another maximum allowable water level in Zwolle of 1,40 m+NAP, without further argumentation (:7). The (EIAreport 2001), finally, mentions $1,75 \mathrm{~m}$ as maximum and $1,40 \mathrm{~m}$ as desirable target level (:19). The level of $1,40 \mathrm{~m}$ is substantiated in Annex I of (EIA-report 2001) because this was the highest water level measured after 1960 , on which occasion no damage was observed (:5).

The situation in Zwolle is unique with regard to the varying water levels due the open connection with Lake IJsselmeer and the Zwarte Water. But with regard to its location at the downstream point of a regional water system discharging into a larger stream, comparable situations exist in e.g. Den Bosch (Dieze into the Maas), Amersfoort (Eem into Gooimeer), Meppel (Mepperdiep into Zwarte Water).

\subsubsection{Water system model calculations}

The high water safety norm for dike ring 53 is 1/1250 per year (WWK96). (Grontmij_Projectbureau_DAR 1997b) presents the proposed MHW for Zwolle before $(2,55 \mathrm{~m}+\mathrm{NAP})$ and after $(1,90 \mathrm{~m}+\mathrm{NAP})$ the construction of the Ramspol Barrier. These values originate from a study performed in the context of the Ramspol barrier project EIA report (Ramspol 1995). The closure of the Ramspol barrier reduced the MHW in Zwolle. The calculated MHW's for Zwolle and the Weteringen are based on the physical maximum possible discharge over the Wijhe weir increased with the maximum pumping rates of all the pumping stations discharging into the Weteringen. This maximum discharge corresponds to a 1/100 per year event ((Grontmij_Projectbureau_DAR 1997b:9, 10, 82). Initially, a maximum Weteringen discharge of $99 \mathrm{m3} / \mathrm{s}$ was used for the calculations (HKV_Lijn_in_water 1996a:2). During the DAR1+2 project this maximum Weteringen discharge was adjusted to $68 \mathrm{m3} / \mathrm{s}$ (Annex I of EIA-report 2001:4). The corresponding MHW in Zwolle was recalculated to be 1,75 m+NAP (HKV_Lijn_in_water 1999:7). (Grontmij_Projectbureau_DAR 1997a:10) mentions that the proposed MHW's for Zwolle and the Sallandse Weteringen were not yet submitted to the Minister for approval. Grontmij_Projectbureau_DAR 1997b) adds that one of the reasons for this delay was the uncertainties in the model calculations $(: 9)$. 


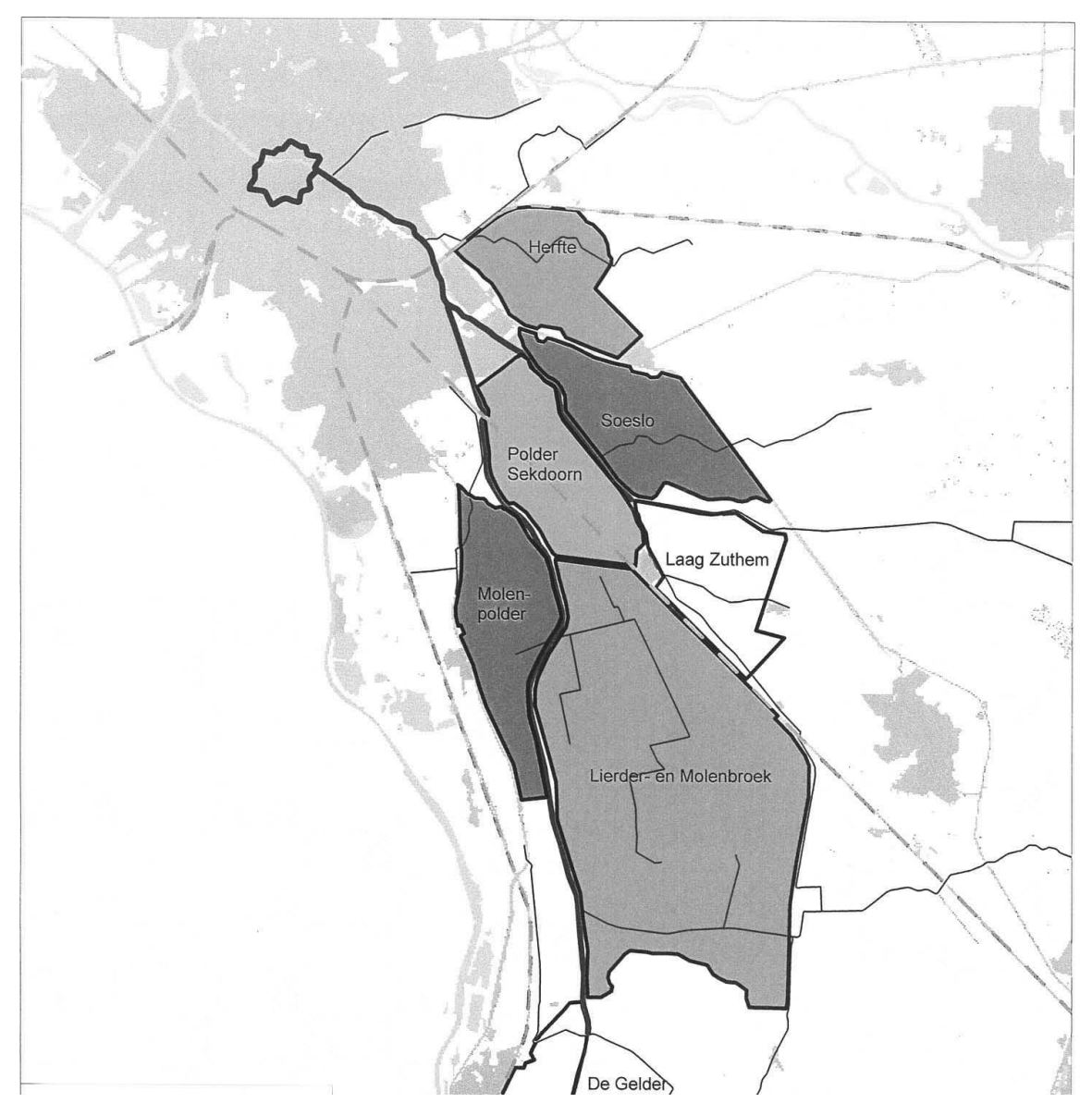

Figure 4-3: The marked five inundation areas of old are now protected against high water by the dikes along the Sallandse Weteringen. Within the EIA-project they were considered to perform this function again in several of the alternative solutions. (figure reproduced from (EIA-report 2001) Annex III "Waterberging in Salland").

According to the "Startnotitie Sallandse Weteringen" (Grontmij_Projectbureau_DAR $1997 \mathrm{~b})$, the current Salland water discharge system was designed to deal with a $1 / 10$ per year rainfall situation $(: 21)$. The maximum Weteringen discharge of $68 \mathrm{~m} 3 / \mathrm{s}$ corresponds, however, with a $1 / 100$ per year situation, according to (EIA-report $2001: 21,22,103)$. About $23 \mathrm{~m} 3 / \mathrm{s}$ of it originates from the pumping stations in the Salland polders, the rest originates from the higher parts of Salland (Annex II of (EIAreport 2001:4). Because of the artificial construction of the water system - limited capacity of pumping stations and the relatively small size of the Weteringen canals upstream the Wijhe weir - this maximum discharge cannot be exceeded. A 1/100 per 
year rainfall situation, however, will theoretically produce a peak discharge of $100 \mathrm{~m} 3 / \mathrm{s}$ just upstream Zwolle. The excess discharge will remain in the polders (a situation represented by one of the cover pictures), and will overflow from the Weteringen upstream the Wijhe weir into the adjacent area. In this way excess precipitation will cause local flooding in Salland, both in the lower and higher parts. For the same reason retention measures in the higher parts of Salland upstream the Wijhe weir will not necessarily reduce the actual peak discharge from the Weteringen (Annex I of EIA-report 2001:4). (Grontmij_Projectbureau_DAR 1997b) adds that water overflowing upstream of the Wijhe weir can partly find it way into other downstream areas along the Weteringen $(: 10)$, which will aggravate the water hindrance in the lower parts of Salland.

A closed Ramspol barrier will cause the upstream water level to rise in the Zwarte Water because of the blocked discharge (less, however, than an unprotected storm surge). Subsequently, water levels in the river Vecht and in Zwolle and on the Sallandse Weteringen will also rise. The maximum closure time of the Ramspol barrier is expected to be about 15 to 20 hours, related to the characteristics of an extreme $\mathrm{N}-\mathrm{W}$ storm event (Grontmij_Projectbureau_DAR 1997b:82). The calculated MHW's take the barrier closure into account (HKV_Lijn_in_water 1996b). The maximum closure time of the Zwolle barrier is estimated to be about 4 to 5 days, depending on the discharge peak on the river Vecht and a closure water level of 1,40 m+NAP, see Annex I of (EIA-report 2001:5). These closure times have been used in the model calculations performed in (HKV_Lijn_in_water 1999). In case of closure of the Ramspol barrier, the blocked discharge can be stored in Lake Zwartemeer and the Zwarte Water, and also emergency inundation are available on the Lake Zwartemeer side of dike ring no. 10 . in case of closure of the Zwolle barrier, storage in the Weteringen is very limited (calculations performed in (HKV_Lijn_in_water 1999) show a very quick rise of the water level in Zwolle even with low discharge conditions of $6 \mathrm{m3} / \mathrm{s}$ on the Weteringen), and inundation areas are not established.

High water level calculations have been performed for the Sallands Weteringen within the Ramspol EIA-project, using the model system SOBEK. The same model system has subsequently been used to quantify several high water scenarios for the DAR-project (HKV_Lijn_in_water 1996b). The appendix of the former report (HKV_Lijn_in_water 1996a) concludes that a closed Ramspol barrier will reduce high water levels in the DAR $1+2$ area to such a low level that the discharges of the river Vecht and the Weteringen now determine the $1 / 1250$ per year design water level. (HKV_Lijn_in_water 1996b:4) concludes that water levels above 1,65 meter +NAP in the city of Zwolle will very likely be caused by high discharge of the Weteringen. The same report also concluded that through the effect of wind higher $1 / 1250$ per year water levels may, in principle, occur in the Sallandse Weteringen and Zwolle than without wind, under specific (theoretically possible) combinations of boundary conditions. Because the uncertainty in the boundary conditions, however, no conclusion can be made with regard to the design water levels. For this purpose a probabilistic analysis of the interdependency between boundary conditions would be needed, according (HKV_Lijn_in_water 1996b:1). For example high discharge of the river Vecht may not occur simultaneously with a high $\mathrm{N}-\mathrm{W}$ wind episode and/or a high water level on Lake IJsselmeer. 
A subsequent study (HKV_Lijn_in_water 1999:10) concluded that the NW-storm scenario will produce lower high water levels in Zwolle (about 1,20 meter, see (:10 figure 4-1) than the maximum discharge scenario (1,75 meter, see (:7 table $3-2)$. The maximum discharge scenario presumes a co-occurrence of the discharge peaks of the river Vecht and the Weteringen $(: 6)$. The correlation between the high water boundary conditions is subject to discussion (:9) and therefore is one of the sources of uncertainty in the calculated high water levels, as was already indicated in (HKV_Lijn_in_water 1996a:4). Other sources of uncertainty are values of the boundary conditions (HKV_Lijn_in_water 1999:6), the model schematisation (:4), and the value of the wind hiding coefficient $(: 8)$.

Annex II of (EIA-report 2001) states that in the Weteringen a discharge wave with a peak of $68 \mathrm{m3} / \mathrm{s}$ will result in a water level corresponding to the proposed MHW's (:6). Annex II also states that the precipitation sequence resulting in such a discharge wave will have a frequency of occurrence less than $1 / 1000$ per year, which is in line with the MHW frequency of $1 / 1250$ per year.

Annex I of (EIA-report 2001) states that the maximum discharge precipitation sequence would theoretically result in a calculated peak discharge of $100 \mathrm{m3} / \mathrm{s}$, which can not be accommodated by the Weteringen and therefore will cause the Weteringen quays upstream to overflow in the adjacent area. (:4).

Annex II of (EIA-report 2001) uses a worst case scenario for the water levels in which the discharge peaks of the river Vecht en the Weteringen coincide $(: 6)$. Other considerations, presented in Annex IV of (EIA-report 2001) argue that the rapid reaction of the canalised Salland water system will result in Weteringen discharge peak which precedes the discharge peak of the river Vecht (:2). Annex IV of (EIA-report 2001) also suggests that there may be other worst case scenarios conceivable $(: 2)$, e.g. 1$)$ considerable $(300 \mathrm{~m} 3 / \mathrm{s})$ discharge on the Vecht and a NW-storm at a high level of the Lake IJsselmeer, 2) MHW (470 m3/s) discharge on the Vecht and lower discharge (20 $\mathrm{m} 3 / \mathrm{s}$ ) on the Weteringen, and 3) higher than MHW discharge on the Vecht (future scenario) at $40 \mathrm{~m} 3 / \mathrm{s}$ at the Weteringen.

(EIA-report 2001) states that the Weteringen design discharge is based on a frequency of $1 / 1$ (one or two days a year on average), resulting in a discharge of $49 \mathrm{~m} 3 / \mathrm{s}$ (:21). (EIAreport 2001) also states that the $1 / 100$ per year Weteringen discharge is about $68 \mathrm{~m} 3 / \mathrm{s}$ $(: 22)$. This discharge is the calculated maximum value that can be delivered by the Weteringen at the given boundary conditions (1/1250 per year MHW discharge of 470 $\mathrm{m} 3 / \mathrm{s}$ at the Vecht and a IJsselmeer water level on NAP $+0,28 \mathrm{~m}$ (which is a $1 / 10$ situation). The discharge capacity of the Weteringen is limited by the geometry of the Weteringen channels and weirs. (see also Annex I of EIA-report 2001:4).

The maximum measured discharge of the Weteringen was $45 \mathrm{m3} / \mathrm{s}$ in the 1998 high water episode (EIA-report 2001:26). The original reference to the Weteringen discharge is found in (HKV_Lijn_in_water 1996a) which refers to (Janssen 1993), who gives 55 $\mathrm{m} 3 / \mathrm{s} @ 1 / 10$ and $99 \mathrm{~m} 3 / \mathrm{s} @ 1 / 100$. 


\subsubsection{Conclusion}

Summarising, the high water safety issue in the Zwolle and Salland area is rather confusing due to inconsistent use of information, and complicated because of the combination of different, correlated sources of danger, viz. a N-W storm surge, a high water level in Lake IJsselmeer, a high discharge from the river Vecht, and a high precipitation runoff discharge from the Weteringen. Adding to this complexity is the manmade water management system of Salland, which at present cannot adequately deal with extreme precipitation events. Furthermore, the Zwolle city centre did not, at the time this case study was performed, come under the protection of the WWK96, which deprived the centre from a protection against flooding under the WWL96 ${ }^{1}$.

\subsection{Administrative and legal system and institutional stakeholders}

A description of regional water management from the perspective of policy development and plan development by provinces and water boards has been presented in Van Slobbe (2002:110-115). Figure 4-4 presents an extended general model of institutional parties and relationships involved in Dutch regional water management adapted from Slobbe's dissertation. General institutional parties are: National authorities, Province, Water Board, Municipalities, Citizens, CieMER. Furthermore, the province can install a CCD Advisory Group and the Water Board must install a Local Advisory Group. The EIA procedure identifies the institutional stakeholders involved in this specific case. In addition to to the general model the Water Board installed a Regional Advisory Group. Another institutional stakeholder is the external engineering company called Grontmij. The Grontmij project group already conducted the preceding dike improvement projects 3, 5 and 6 within DAR for the WGS. The applicable legal system governing the decision making process is mainly determined by the "Wet op de waterkering 1996" (WWK96) and its accompanying "Leidraad Toetsen op Veiligheid" (TAW 1996b) and "Hydraulisch Randvoorwaardenboek 1996" (TAW1996a). The "Randvoorwaardenboek" is updated every five years. Figure 4-1 shows the map from appendix 1 of the WWK that defines the dike-ring areas. Furthermore, several other acts are relevant for the process of permitting, mainly on the level of Municipality and Province. The "Nota van Uitgangspunten" (Grontmij_Projectbureau_DAR 1997a:19) lists a legal and administrative framework that contains 10 acts and regulations. In the following we will briefly describe the main institutional actors, and some of their stakes in the specific case of the Zwolle storm surge barrier project.

\footnotetext{
${ }^{1}$ By letter dated 6 July 2004 from the secretary of state of the ministry of V\&W informed Parliament of her decision to shorten dike ring 53 as a result of the construction of the Zwolle barrier. This decision was published in the "Staatsblad" 2004, 234. It brings the Zwolle City Centre within dike ring 53. At the same time the status of the Weteringen dikes and Zwolle quays has been changed from primary into secondary status.
} 


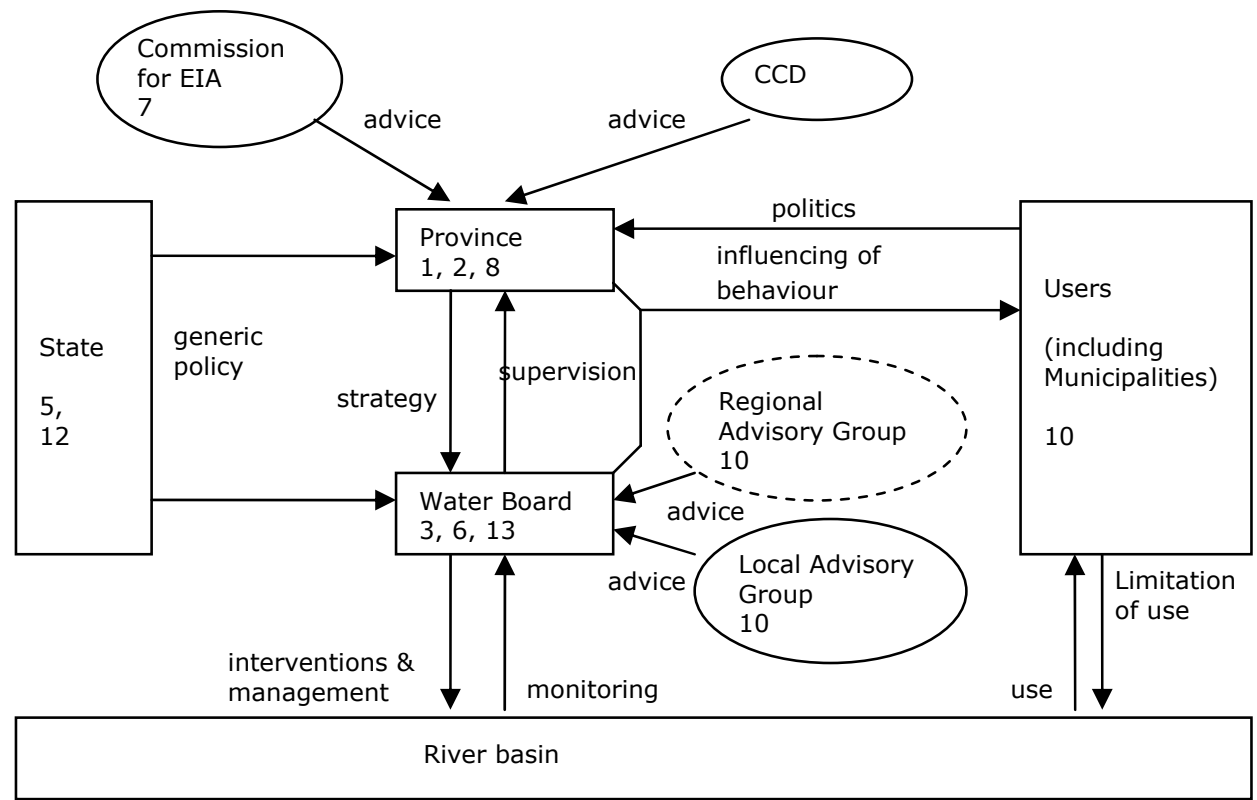

Figure 4-4: Model of parties and relationships involved in the control of regional water management, adapted after van Slobbe (2002:110). Compared to the original (blocks), several parties have been added (ellipses) that are related to the formal planning procedure for dike improvements. The code numbers of some of the informants (see table 4.3) have been added to their organisations.

\section{Ministry of V\&W}

On the national level, the ministry V\&W's primary role is policy development (e.g. the dike ring approach and establishment of safety norms). Further more, it is the third institution in the line of responsibility (super-supervisor). In the latter role it is responsible for a timely delivery of the dike improvement projects defined in the WWK96 before 1 January 2001. Also the State is directly responsible for water management issues that are of national importance, such as the dikes along the North Sea, the Wadden Sea, and the large rivers. Rijkswaterstaat (the Directorate-General of Public Works and Water Management) carries out the necessary work.

\section{Province of Overijssel}

Based on article 133 of the Dutch Constitution (Staatsblad 1983, no.70), and the "Waterschapswet 1992", the Province is supervisor to the District Water Board, and as such the second institution in the line of responsibility. In addition the WWK96 gives the Province a coordinating task. The coordination concerns the combined handling of all relevant permitting procedures (WWK article 17 and 19), but also the stimulation and, when necessary, demanding or even enforcing of the cooperation between stakeholders. Furthermore the WWK96 gives the Province a governing task, in that it must approve or reject the plans made by a Water Board (e.g. the storm surge barrier plan). Also the Province handles the financial flows from the National level to the Water Board. The Province of Overijssel requested, within the DAR-project, to evaluate the inundation risks of the Zwolle city centre for a water level corresponding to the $1 / 1250$ safety norm. The 
objective of this evaluation was to decide whether a safety norm was required for the Zwolle city centre (which was lacking at the time of the case, see section 4.2.1).

\section{District Water Board Groot Salland}

The District Water Board Groot Salland, as part of their water quantity task, is the first responsible institution for the maintenance and safety assessment of the dikes in the case area. It is the third layer of government. The District Water Board is organised in a General Council ("Algemeen Bestuur") consisting of elected members, an Executive Council ("Dagelijks Bestuur") consisting of members chosen from the General Council, and a chairman chairing both councils (the 'dijkgraaf' - the dike warden). The relationship between water board and province is governed by the "Waterschapswet" 1991. Starting from about 1992, the many small water boards existing up to that time were in the process of merging into larger scale water boards. These Water Boards new-style had, compared to the old situation, extended administrative and knowledge capacities, which are transferred from the National authorities and Provinces. The responsibility for some national waters is also transferred to the regional Water Boards (e.g. the river Overijsselse Vecht). Starting from 1992, the Water Boards have faced major changes of organisation and responsibilities. These changes required them to find a new equilibrium in their relationship with the Province. On top of this the high water episodes in 1993 and 1995 resulted in new legislation, the "Deltawet Grote Rivieren 1995" and the "Wet op de Waterkering 1996" on the national level, which forced them to start major, large scale dike improvement projects (most of which were already identified many years before but were not taken into execution because of time consuming administrative procedures. When a safety assessment reveals a dike section not to be up to the legal standard defined by the WWK96, a dike improvement procedure is started by the Water Board, which includes an EIA. According to the WWK96, dike improvements governed by it must be completed before January $1^{\text {st }} 2001$ (EIA-report 2001:8).

\section{Municipalities}

The municipalities played a role through their presence in the regional and local advisory groups. Furthermore, they are the responsible authorities for licensing the barrier building plans, together with any necessary change of the prevailing zoning plan. The municipality of Zwolle was visible in press publications concerning the barrier, mainly because the turmoil cause by questions asked by the VVD in the city council and their delay of the building permitting procedure.

\section{Permanent regional advisory group CCD}

In addition, in the province of Overijssel a separate "Coördinatie Commissie Dijkverbetering Overijssel" existed where the dike improvements are also discussed. This CCD was established already during the planning phase of the Ramspol barrier (Ramspol 1995:23).

\section{Regional advisory group}

The Regional advisory group ("klankbordgroep", in Dutch) is a regional committee which is established by the Water Board for all of the DAR-projects together, with the purpose of advising the Water Board from a regional perspective (Grontmij_Projectbureau_DAR 1997b:4). The regional advisory group operates on an administrative level. In contrast, 
the local advisory group operates on a public participation level. Both local and regional advisory groups are temporary. All municipalities involved in DAR participated in this advisory group, as wel als regional interest groups e.g. GLTO Overijssel, Natuur en Milieu, Kon. Schippersverenigng Schuttevaer, Bond Heemschut, Stichting Het Overijssels Landschap, Vereniging tot behoud van natuurmonumenten in Nederland.

\section{Local advisory group}

The Local advisory group ("adviesgroep", in Dutch) is a local committee which was established by the Water Board for each of the DAR-project separately

(Grontmij_Projectbureau_DAR 1997b:4). Its purpose is to supply local information and advise the Water Board on the presented alternatives (Grontmij_Projectbureau_DAR 1997b:3). Several local interest groups participated in the advisory groups, e.g. LTOHeino, LTO-Wijhe (these two represent the local farmers), Landschap Overijssel, Bond Heemschut, Vrienden van de Stadskern Zwolle, Bewonersverenigigng binnenstad (EIAreport 2001:97).

\section{Grontmij}

The consulting engineers firm Grontmij acted as DAR project manager and coordinated the production of the EIA report.

Table 4.2: List of institutional stakeholders involved in regional water management in the case, and their role.

\begin{tabular}{|l|l|}
\hline Organisation & Role in the case \\
\hline Ministry V\&W & $\begin{array}{l}\text { Legislation and issuing of regulations, } \\
\text { Super-supervisor: financial support and progress control. }\end{array}$ \\
\hline Province of Overijssel & $\begin{array}{l}\text { Supervisor: approve or reject the EIA report, } \\
\text { Coordination of concurrent administrative procedures, } \\
\text { Participation in EIA project team. }\end{array}$ \\
\hline Water Board Groot Salland & Manager of the water system, initiator of plans. \\
\hline Municipalities & Permitting with regard to spatial planning. \\
\hline Citizens & $\begin{array}{l}\text { Point of views to Water Board (apart from participation in the } \\
\text { advisory group), } \\
\text { Protests and objections to Province, } \\
\text { Appeal to court. }\end{array}$ \\
\hline CCD & $\begin{array}{l}\text { Permanent advisory group to the Province on dike improvement } \\
\text { issues }\end{array}$ \\
\hline Regional advisory group & $\begin{array}{l}\text { Advise to the Water Board from a regional perspective for all } \\
\text { DAR-projects }\end{array}$ \\
\hline Local advisory group & $\begin{array}{l}\text { Advise to the Water Board from a local perspective for this specific } \\
\text { DAR-project }\end{array}$ \\
\hline Grontmij & $\begin{array}{l}\text { Project leader and author of the ElA report for the Water Board, } \\
\text { Process manager }\end{array}$ \\
\hline
\end{tabular}




\section{CONTROVERSIES IN WATER MANAGEMENT: FRAMES AND MENTAL MODELS}

\subsection{Selection of informants}

Informants relevant for the case under investigation have been selected from the case documentation and preliminary interviews conducted within this $\mathrm{PhD}$-project (see section 3.4.4). The selection was, in fact, a kind of "snowballing" process, where one informant referred to one or several others. From the preliminary interviews a rather stable set of "key-players" resulted. These informants represent the institutional stakeholders that were identified earlier (in section 4.3). The informants have been questioned about the case in a semi structured interview (see section 3.4.5). The table 4.3 presents a list of selected informants and their characteristics. All 14 informants listed agreed to participate in this study. The interviews took place in the period 30 June -1 September 2004.

Table 4.3: List of informants interviewed and their institutional characterisation, which supplies informant details in addition to the general list of institutional stakeholders in table 4.2. Function lists the function at the time the informant was involved in the case.

\begin{tabular}{|c|c|c|}
\hline $\begin{array}{l}\text { Informant } \\
\text { code no. }\end{array}$ & $\begin{array}{l}\text { Organisational affiliation } \\
\text { (at the time of the case) }\end{array}$ & Function \\
\hline 1 & Province of Overijssel & $\begin{array}{l}\text { Civil servant, } \\
\text { policy employee water management }\end{array}$ \\
\hline 2 & Province of Overijssel & $\begin{array}{l}\text { Civil servant, } \\
\text { senior employee Water Boards and dikes }\end{array}$ \\
\hline 3 & Water Board Groot Salland & $\begin{array}{l}\text { Civil servant, } \\
\text { project leader dikes }\end{array}$ \\
\hline 4 & Grontmij consulting engineer firm & $\begin{array}{l}\text { Manager, } \\
\text { head Advisory group Soil and Water }\end{array}$ \\
\hline 5 & Ministry V\&W - RWS & $\begin{array}{l}\text { Civil servant } \\
\text { RWS headquarters }\end{array}$ \\
\hline 6 & $\begin{array}{l}\text { Water Board Groot Salland } \\
\text { 1995-2001 }\end{array}$ & $\begin{array}{l}\text { Manager, } \\
\text { head department dike improvement and } \\
\text { management }\end{array}$ \\
\hline 7 & RWS Zuid Holland & $\begin{array}{l}\text { Civil servant, } \\
\text { Technical expert on dike improvement }\end{array}$ \\
\hline 8 & Province of Overijssel Executive Council & Politician \\
\hline 9 & $\begin{array}{l}\text { University of Utrecht, } \\
\text { Water Board Hunze en Aa's }\end{array}$ & $\begin{array}{l}\text { Policy expert on water law, } \\
\text { Administrator ("dijkgraaf") }\end{array}$ \\
\hline 10 & retired (until 1990 Province Overijssel) & $\begin{array}{l}\text { Citizen, member of both the Local and } \\
\text { Regional Advisory Group, (former } \\
\text { director water management department) }\end{array}$ \\
\hline 11 & HKV lijn in water consulting company & Technical expert on high water statistics \\
\hline 12 & $\begin{array}{l}\text { Ministry V\&W - RWS/DGW (1990 - july } \\
\text { 2000) }\end{array}$ & $\begin{array}{l}\text { Administrator, Director of RWS } \\
\text { headquarters }\end{array}$ \\
\hline 13 & Water Board Groot Salland & Administrator ("dijkgraaf") \\
\hline 14 & Grontmij consulting engineer firm & Consultant \\
\hline
\end{tabular}




\subsection{The EIA procedure for dike improvement}

\subsubsection{The general EIA procedure}

Under the "Wet op de Waterkering 1996" (WWK96) the administrative procedure has considerably accelerated, at the same time giving due attention to environmental aspects by the obligation to perform an environmental impact assessment (EIA).

The EIA procedure is governed by the Dutch law on EIA, which was passed in 1987. In this law the Commission for Environmental Impact Assessment (CieMER) was given an important role in the EIA procedure (see e.g. (CieMER 2005). The CieMER advises decision makers - government ministers and provincial and municipal councils - on the environmental aspects of plans and projects. The Commission can draw on a pool of independent consultants to advise on the scope of EIAs (what are the relevant impacts and alternatives?) and prepare advisory reviews of the content of environmental impact statements (is all necessary information present and correct?). The Commission remains outside political decision making and does not express a preference for one alternative or another. It acts as an independent expert watchdog to improve the quality of the EIA's. In the Netherlands the Commission advises the government authority responsible for the decision, usually twice during the procedure. First the CieMER advises scoping guidelines (with regard to which topics should be covered in the EIA), second it performs an advisory review of the completed EIA (with regard to whether the essential environmental information for decision making has been presented).

The decision making cycle in the case situation is mainly described by the legal procedure along which the EIA is conducted. The procedure is described in the EIA-report (2001), a reproduction of which is included in appendix B. Important here are the time limits connected to some steps, e.g. the province ("Gedeputeerde Staten") has to decide on the acceptability of the EIA-report within three week after submission.

\subsubsection{Reconstruction of the chain of events}

This section presents an inventory of events and documents produced in the EIAprocedure, based on available documents. Appendix 7 of the EIA-report gives an overview, which has been detailed using available documents. We will distinguish between four major phases in the EIA-procedure. In the first phase solution alternatives were explored, presented to the public, and subjected to advise e.g. from the EIACommission. In the second phase research was performed on a few selected alternatives. In the third phase the EIA report was written, presented to the public, subjected to advise, and finally approved by the Province. In the fourth phase objections and appeal to court against the approval were made. Preceding the first phase, the dikes of dike ring 53 in Zwolle and Salland have been tested against the applicable TAW guidelines (Heidemij_Advies 1997a; b). This test established that the dikes failed to comply to the WWK96, and consequently a dike improvement procedure has been started, which includes the EIA procedure. Following the last phase, the implementation of the dike improvement plan was started, which included the construction of the Zwolle barrier. The four major phases are described below in more detail, indicating the relevant documents. 


\subsubsection{1 $1^{\text {st }}$ phase (exploration of alternative solutions):}

- At the start of the dike improvements behind the Ramspol barrier points of departure were established for all of the six DAR projects together. A first concept of the "Notification of intent" ("nota van uitgangspunten", in Dutch) was presented to the Regional Advisory Group and public reactions were included in the second concept dated 16 juni 1997. This second concept was presented to each of the DAR Local Advisory Groups separately. Public reactions are included in the final concept dated July 1997 (Grontmij_Projectbureau_DAR 1997a). The final concept was presented for approval to the two Water Boards involved, which approval was obtained from the Groot Salland Water Board on 14 August 1997. The approved report was the point of departure for the dike improvement planning process.

- $\quad$ For each separate DAR project an exploration of possible solution alternatives took place in consultation and dialogue with the Local Advisory Group and was reported in a first concept of the "Inception memorandum" ("startnotitie", in Duthc). The purpose of the "startnotitie" was to investigate which solution alternatives were promising and therefore were to be included in the IEA-report for further detailing. Official notification of the public on the intention of the dike improvement plans, and presentation of the concept version of the "startnotitie", took place on an information-evening on 20 May 1997. Starting from 19 November 1997 the final "startnotities" (Grontmij_Projectbureau_DAR 1997b; c) were made publicly available and reactions could be submitted for a period of four weeks. On 15 December 1997 a public hearing took place in Zwolle. Written reactions made by the public were collected by the Province, a total of 23 different reactions were submitted by private persons, interest groups, organisations and agencies.

- $\quad$ Following the public hearings and participation, the Province produced answers to the each reaction and gave an account of the ruling on their admissibility and response made with regard to the dike improvement plans in an "reactienota" (Provincie Overijssel 1998a).

- "Startnotie" and "reactienota" were submitted by the Province to the EIA Committee for advice on 11 November 1997. In their "Scooping Guidelines" ("Richtlijnenadvies", in Dutch) the EIA Committee addresses, in general, the nature, landscape and cultural heritage aspects of the dike improvement plans (Provincie Overijssel 1998a:6, 7). This advice was released on 23 January 1998 (http://www.eia.nl/mer/projectinfo/p918.htm) (Commissie_voor_de_Milieueffectrapportage 1998).

- $\quad$ On 2 February 1998 the Permanent Regional Advisory Group Overijssel (CCD) advised the Province about the dike improvement plans, including the public views and the EIA scooping advice. 
- Subsequently, the Province produced their guidelines for the DAR EIA projects. These were a single set of guidelines that were applicable to all DAR projects (Provincie Overijssel 1998b). At the same time the Province requested the Water Board to henceforth combine the up to then separated Zwolle and Weteringen plans in a single project, DAR $1+2$. Also the Province requested the Water Board to insert a separate phase into the dike improvement procedure, called intermediate phase ("Tussenfase", in Dutch), which had the goal of limiting the multitude of solution alternatives produced hitherto into a limited set within a reasonable period. The intermediate phase was also to present the results of research performed to the stakeholders involved for further consultation.

\subsubsection{2nd phase (detailed research on selected alternative solutions):}

The second phase, included on request of the Province, produced several research reports, which were included in the EIA-report (2001) under the titles "Annex I, II, III and IV".

- Annex I of (EIA-report 2001), with the title "Tussenfase: eindrapport beleidsmatige inperkingen van oplossingsrichtingen" is dated December 1998 and contains the conclusions of the research reported in the other annexes. It limits the solution alternative to two main solution directions. With regard to the scenario "shortening of the dike ring by means of a barrier" Annex I concludes that several very fundamental questions remain to be answered before this scenario can be put into effect $(: 21)$. These questions regard the additional measures needed to control the water level upstream the barrier in such a way that safety, water hindrance and economical damage remain within socially acceptable limits $(: 22)$. Annex I suggests a change of vision which no longer assume the $1 / 1250$ safety norm (:19). Annex I also states that the barrier alternative is feasible only under the condition that the safety of the inhabitants of the upstream region is not in dispute, and that a temporary water hindrance in the city of Zwolle and the lower parts of Salland is administratively acceptable because the water of the higher parts of Salland will collect there under the design conditions (:17).

- Annex II of (EIA-report 2001), with the title "Hydrologische en hydraulische modelberekeningen" and dated November 1998, contains model calculations performed with RAM en DUFLOW. The results were to establish the amount of detention area needed in case of a closed barrier. The results showed that both with and without barrier the 1/1000 water levels in the Zwolle city centre would keep below 1,60 meter + NPA, which is 15 centimetres less that the design water level (MHW) in Zwolle (:11).

RAM is the acronym for precipitation discharge module (RAM - Regen Afvoer Module) in DUFLOW. With the help of RAM it's possible to calculate the precipitation runoff to the surface water. RAM calculates the losses and delays that occur before the precipitation reaches the surface water. 
DUFLOW is a model that enables the water manager to calculate unsteady flow in networks of canals, rivers and channels. One starts with basic elements in the graphical network editor. With simply drag and drop the elements are put in place. River elements consist of 1-dimensional river flow. This 1-dimensional section simulates the full Saint-Vernant equations for river flow. With a fast numerical solver, the computation core calculates the results for water level, discharge and velocity (http://www.duflow.nl).

- Annex III of (EIA-report 2001), titled "Waterberging in Salland" and dated March 1999, presents a quick scan after the possibilities for detention, performed by the "Dienst Landelijk Gebied". It concludes that large areas are available (for up to $21 * 10^{\wedge} 6 \mathrm{~m} 3$ water, depending on the allowable water depth).

- Annex IV of (EIA-report 2001), titled "Verkenning inundatie bij bresvorming" (no date available), presents a calculation of the maximum water depths in the inundation areas. These depths vary between 0,95 aen 1,40 meter, depending on the inundation scenario used. The calculations have been performed with the DUFLOW model by Grontmij. Annex IV concludes that both with and without the barrier inundation will occur in case of failure of the Weteringen dikes, and that the presence of a barrier will produce a minor difference in damage only. Annex IV notifies, however, that the inundation scenario might in future become more unfavourable because of higher discharges of the river Vecht, and a time difference between the discharge peaks of Vecht and Weteringen $(: 3)$.

- The Provincial Executive Council, in their letter to the Water Board Executive Council dated 16 February 1999, notifies the Water Board that their reports on the "Tussenfase" meet the requirements of the Province.

- $\quad$ The reports of the "Tussenfase" have been sent by the Province Executive Council to the EIA Commission in February 1999 (see http://www.eia.nl/mer/projectinfo/p918.htm).

- New design high water levels for the Sallandse Weteringen have been calculated by HKV (1999). The new MHW in Zwolle is now 1,75 meter (EIA-report 2001) (:34). In their letter of 27 May 1999 the Water Board requested the Province to ask the Minster of V\&W to formally appoint these water levels. The Provincial Executive Council agreed to the new MHW's in their letter of 28 June 1999 (EIAreport 2001) (:34).

- $\quad$ On 17 June, 22 September, en 17 November 1999, the remaining two preferred solution alternatives were discussed in the Local Advisory Group. After extensive discussion about the related safety aspects the majority of the Advisory Group members voted in favour of the barrier. Two members, however, agreed to the exclusion of the Weteringen and Zwolle quays from dike ring 53, but claimed that the barrier would have no added value (EIA-report 2001:82). 


\subsubsection{3rd phase (production of the EIA report):}

- The previous research, arguments and choices were summarised in the EIA report. This report was presented for advise to the EIA Commission by the Province in their letter of 18 January 2001. Starting from 29 January 2001 the EIA report was available to the public for comment.

- After the closing of the public comment period, the EIA Commission was to produce her advice within five weeks. The advice concerns the completeness and quality of the EIA, and also takes into account any remarks and recommendations connected to the EIA report. The advice (called "toetsingsadvies" in Dutch) was released on 3 May 2001 (http://www.vrom.nl/pagina.html?id=9640).

- $\quad$ Anticipating the approval of the EIA report in a session of the Provincial Executive Council, written questions criticizing the argumentation were asked by a member of the Provincial General Council (mr. Bomhof, member for the VVD political party) (Bomhof 2001). The questions of Bomhof were answered by the Executive Council partly on 25 September 2001 (excluding questions 2 through 3C) and for the other part on 9 November 2001 (questions 2 through 3 C only).

- $\quad$ On 20 September 2001 the dike improvement plan for DAR 1+2 was approved by the Water Board.

- $\quad$ On 6 November 2001 the EIA and the attached dike improvement plan were approved by the Provincial Executive Council,

- In October 2001 the Province asked for two second opinions, in addition to the advise of the EIA Commission. Vermeer (2001) criticizes the model calculations performed in Annex II and IV and their conclusions, which he calls 'unusual' (:5) and 'astonishing' (:6). According to him the Zwolle barrier can be effective only in case of a robust use of retention and detention capacity for the full Weteringen discharge (:7). Van Hall (2001) concludes that no administrative nor legal or political or strategic arguments exist for the Provincial Executive to refrain from approving the EIA report.

- $\quad$ On 19 December 2001 the building permit is granted by the major and aldermen of the city of Zwolle.

\subsubsection{4th phase (objection and appeal):}

The building permit constitutes the last but one step in the EIA procedure. Wat is left are the possibilities for objection and appeal at the "Commisaris van de Koningin" and the "Raad van State". 
- On 6 November 2001, immediately after the approval, D.M. van der Schrier applied for nullification of the Executive Council approval, in an open letter to the "Commissaris van de Koningin".

- $\quad$ On 26 November 2001, D.M. van der Schrier used the public right to address the meeting of the Executive Council, and presented his opinion on the EIA report.

- In January en February 2002 several private persons appealed to the "Raad van Sate": hr. D. Van der Schrier, hr. P. Van Loo, hr. W.B.J. Hunneman + H.B. Hunneman.

- $\quad$ The "Raad van State" presented its ruling on 24 December 2002. The Court judged that the appeals were not admissible (because the appealing persons did not own any land within the dike improvement plan) or ungrounded (because the applicable procedures were not proven to be not complied with).

- The Provincial Executive Council takes s cognisance of the ruling on 24 February 2003 in (Provincie Overijssel 2003), and decides to ask the Minsiter of V\&W to take the initiative for a change in the definition of dike ring 53 (which requires an AMvB-decision by Parliament).

- $\quad$ The ruling of the "Raad van State" was commented in by Van Hall (2003), who also acted as informant no. 9.

- The barrier decision was subject of questioning in Parliament. Mr. Geluk (on behalf of the VVD) asked several questions which were responded to be the State Secretary M.H. Schultz van Haegen (Anonymous 2003).

\subsection{The issue}

It is not a single issue that was at stake in the Zwolle storm surge barrier case. For one there was the legal obligation to improve the dikes along the Sallandse Weteringen canals according to the WWK96. Every stakeholder, however, agreed that this would result in an unnecessary and intolerable intrusion into nature, landscape and farmer properties, and that an alternative was wanted. From a wide range of alternatives that had been considered at one time or another (including detention of water in inundation polders), the Zwolle barrier prevailed and was presented in the EIA-report against the original full-scale dike improvement plan. It was the argumentation for the barrier alternative that presented the source of diverse conflicts. Furthermore, the issue of dike improvement made another issue to enter the agenda, namely the issue of water management in the Salland region, see e.g. the advice given by the Dutch Commission for EIA. In order to fully comprehend the conflicting issues it is important to note that the storm surge barrier alternative defended by the EIA-report consisted of a combination of actions (EIA-report 2001:83): 
1. A change of legal status into "regional" for the quays along the Zwolle city canals and the dikes along the Weteringen up to the weirs at Langeslag and Wijhe;

2. Improvement of the inner bank of the dikes in the lower part of Salland over a length of approximately three kilometres;

3. Limited adaptation of water-retaining structures;

4. Construction of a retaining wall near to the hospital in Zwolle to reduce high water nuisance;

5. Adaptation of weirs and pumping stations in the main Salland drainage system in order to enable remote control from the Water Board main office location in Zwolle; additional water level gauges and flow meters will be placed at typical locations;

6. The formulation of an implementing program for the control of discharge under extreme rainfall conditions;

7. The legal registration of the regional dikes;

8. A plan for management- en maintenance which purpose is to maintain the current state, and to optimise it where possible.

Apart from the construction of the barrier, several additional changes to the upstream dike system and related discharge works had to be made. These included (no. 6) a study after the water management in Salland with the purpose of controlling the discharge under extreme conditions (this study also builds a computer model of the water discharge system). Anticipating to the results of this study the discharge pumps and weirs will be adapted for central remote control from Zwolle.

The issues present in the case are also visible from the many alternative solutions developed in the course of the decision process. In the next section we present an overview.

\subsubsection{Alternative solutions}

The complexity of the water system in the problem area resulted in a multitude of alternative measures to spring into existence. This section presents an overview of all measures presented in the different documents that were part of the EIA-procedure. Some additional information was acquired from one of the scientific background documents. The results are summarised in table 4.4.

In the "Nota van uitgangspunten" (Grontmij_Projectbureau_DAR 1997a:17) the question is raised whether alternatives should be considered in stead of a full scale dike improvement along the Sallandse Weteringen, because of the high costs of a full scale improvement and its expected limited effects on the existing water management problems of Salland. Four alternatives were mentioned, which were further detailed in the "startnotities". This report suggested looking for retention and detention options that fit into the long term water management plans for Salland $(: 23,24)$. With regard to the situation is the city centre of Zwolle it mentioned the application of less freeboard and the construction of a flexible barrier (:17). 
The report "Startnotitie DAR1" (Grontmij_Projectbureau_DAR 1997b) presents a large range of alternative solutions (:41-53). These are listed in table 4.4 , and are grouped in five scenarios:

A: full scale dike improvement according to WWK/TAW

$B$ : limited dike improvement to a lower height (without the freeboard)

$C$ : in addition to $B$ also reconstruction measures will reduce the discharge and thus the MHW's

D: large scale reconstruction of the area

$\mathrm{E}$ : Changing the legal status by shortening of dike ring 53.

From the 15 alternative measures listed in this "startnotitie", 10 are considered to be promising (:52). The measures are combined into four scenarios:

Scenario I: Full scale WWK-TAW dike improvement (A1).

Scenario II: Safety guaranteed by limited dike improvement (B), through a combination of water management alternatives $(\mathrm{C} 1+$ raising the upstream weirs $+\mathrm{C} 2+\mathrm{C} 3$ ) and a change of the assessment framework (B3).

Scenario III: Shortening of the dike ring by weirs (E1).

Scenario IV: Controlled inundation (D3) possibly in combination with a flexible barrier (E2).

In conclusion of the "startnotitie" five alternatives were constructed from the scenarios for inclusion in the EIA-report. The alternatives correspond to the scenarios, where scenario number 2 has been split into two alternatives: $\mathrm{C} 1$ only and a combination of $\mathrm{C} 1$ $+\mathrm{C} 2+\mathrm{C} 3+\mathrm{D} 3+\mathrm{B} 3$. These scenarios deviate from the two scenarios actually included in the EIA. Ultimately, the EIA-report limited the compared alternatives to A1 (full scale dike improvement) against E2 (barrier downstream Zwolle).

The report "Startnotitie DAR2" . (Grontmij_Projectbureau_DAR 1997c) mentions three alternatives $(: 39-43)$ that were already mentioned above:

- $\quad$ Full scale dike improvement (:39)

- Scenario A) Construction of a barrier downstream the Zwolle city centre (40).

- Scenario B) Lowering the MHW by reduction of the Weteringen discharge (40).

The separate introduction to the Annexes of (EIA-report 2001) concludes with regard to detention that the barrier alternatives, which were introduced having a fixed water level for closure, were no longer deemed to be realistic, because controlled inflow of excess discharge water into inundation areas would need substantial efforts. This introduction also concludes that taking no additional measures and accepting an uncontrolled inundation of areas behind a dike failure that may possibly occur would have consequences similar to controlled inundation.

In the scientific background document (HKV_Lijn_in_water 1999) the effect of a barrier downstream of the Zwolle city centre is investigated. When such a barrier is closed, the water levels in the centre will quickly rise above the level of the quays $(: 12)$. To prevent the Zwolle city centre from flooding a pumping facility and a detention reservoir in addition to the barrier (with fixed closure level) have been studied in $(: 14,16,21)$. These measures were identified in the "startnotities". Additional, this study analysed the new measure of lowering the bottom of the Zwarte Water. Also the existing situation has been calculated, in order to investigate the influence of the wind coefficient on the MHW calculations. Calculations show (see table 5-2 on page 14) that the buffering capacity of 
the existing Weteringen canals is far too small to buffer the discharge in case of closure of the barrier. As a result the water level in Zwolle will quickly rise to high levels and cause inundation. This study concludes that therefore a barrier without pumping or detention facilities is contra effective $(: 14)$.

Alternatives mentioned in the EIA-report (2001:2) as having been eliminated in the preceding research are:

- $\quad$ "Do nothing" (consequently the Weteringen dikes will not comply with the WWK96).

- "Adjusted safety norms". The WWK96 safety norm of $1 / 1250$ for dike ring 53 would be differentiated to include lower protection levels for selected dike sections. A dike failure in the lower part of Salland at MHW would be considered an acceptable risk.

- $\quad$ "Storm surge barrier accompanied by a pumping facility.

- $\quad$ "Storm surge barrier accompanied by a rerouting of discharge to the river Vecht or IJssel".

- $\quad$ "Storm surge barrier (closes at fixed level) accompanied by construction of detention areas to store the Weteringen discharge.

The alternatives analysed in the EIA report were 1 ) a full scale dike improvement (measure A1), and 2) a downstream barrier (closure on flow reversal) (measure 23) in combination with the creation of the possibility to minimise the discharge by shutting down discharge pumps and raising weirs (EIA:31). Alternative 23 also represents the "most environmental friendly alternative" ("meest milieuvriendelijke alternatief", in Dutch), which must be legally included in any EIA.

To complete the overview of alternative measures we added additional alternative solutions mentioned in by stakeholders in the interviews (see chapter 5 ). 
Table 4.4: A total of 25 different alternative measures were mentioned during the course of the decision making process. Considered in the "startnotities are the measures 1 through 15, which are grouped in different scenario's A through E. The measures 2 through 13 work within the primary status of the Weteringen to diminish the extension of the dike improvement, and include detention measures. Measures 1 through 5 take a dike construction perspective, measures 6 through 13 take a water management perspective, and measures 14 and 15 take an administrative perspective. The measures 14 and 15 introduce a barrier, from which measure 15 has been subsequently detailed in measures 16 and 17. Measure 18 was calculated upon initiative of HKV in their study, but has not been included in the EIA procedure. In the EIA report four new alternatives were presented (19 through 22). Furthermore, in the interviews some alternatives were mentioned that were not included in the documentation ( 23 through 25). Ultimately, the two measures 1 and 22 have been evaluated in the EIA report.

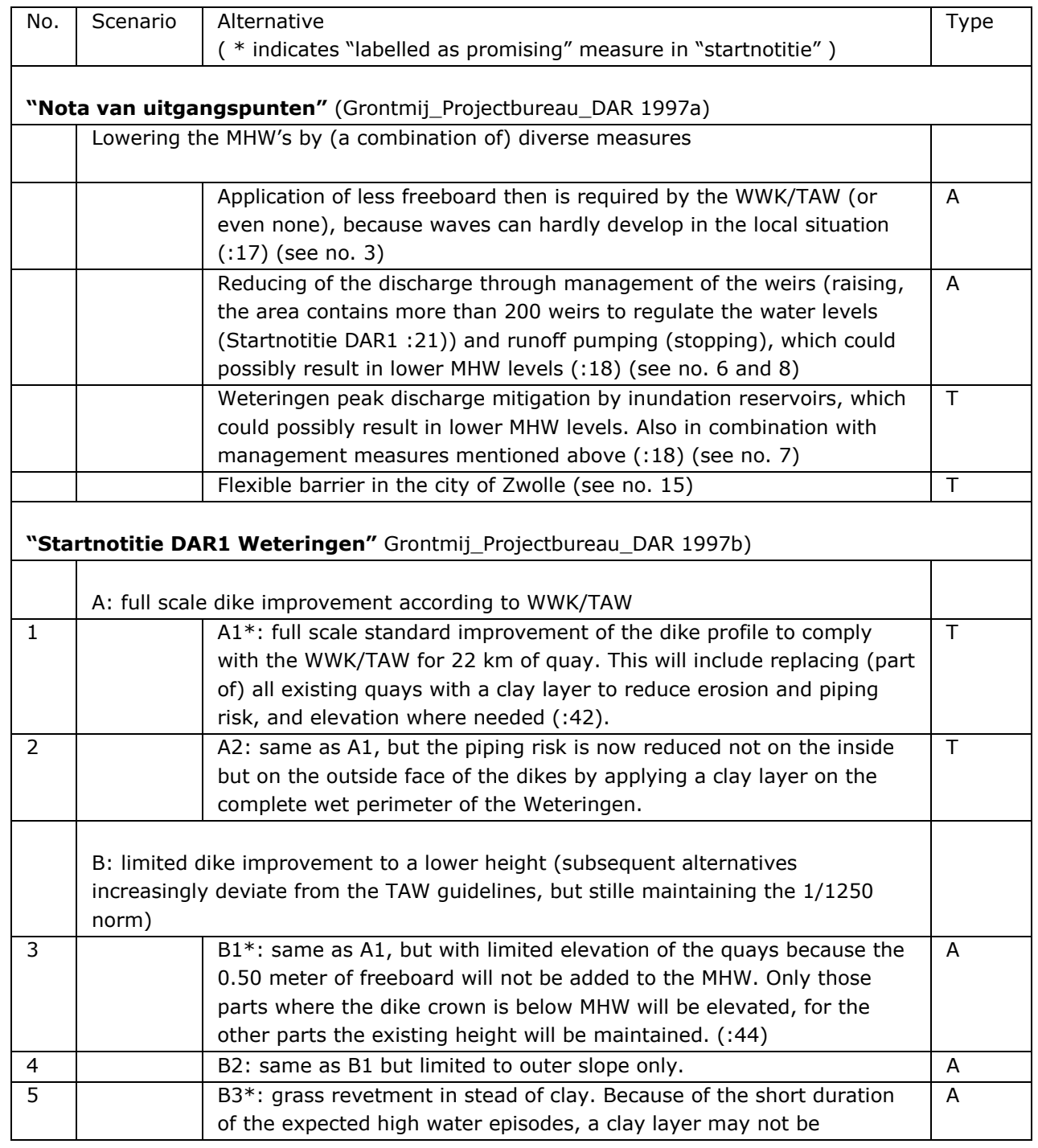




\begin{tabular}{|c|c|c|c|}
\hline & & $\begin{array}{l}\text { necessary in order to guarantee stability and erosion resistance. A } \\
\text { grass revetment might supply adequate safety, and eventual damage } \\
\text { could be repaired quickly or be even acceptable. This alternative will } \\
\text { need cooperation of the TAW for the deviation of their "Leidraad } \\
\text { Toetsen op Veiligheid". (:45) }\end{array}$ & \\
\hline & \multicolumn{2}{|c|}{$\begin{array}{l}\text { C: in addition to B also reconstruction measures will reduce the discharge and thus } \\
\text { the MHW's }\end{array}$} & \\
\hline 6 & & $\begin{array}{l}\text { C1*: Stopping the runoff discharge pumps in lower area. Because } \\
40 \% \text { of the maximum discharge is produced by the pumping stations } \\
\text { from the low areas, this will considerably reduce the discharge. } \\
\text { Stopping the pumps, however, will quickly cause local flooding in the } \\
\text { polders }(: 45) .\end{array}$ & A\# \\
\hline 7 & & $\begin{array}{l}\mathrm{C} 2^{*} \text { : The construction of an emergency spillway in the lower area } \\
\text { Weteringen dikes. This will fix the maximum water level to the height } \\
\text { of the spillway by storing the excess discharge in an inundation area. } \\
\text { This alternative makes a good combination with } \mathrm{C} 1 \text { (because pumping } \\
\text { out of inundated areas makes no sense). }(: 45) \text {. }\end{array}$ & $\mathrm{T}$ \\
\hline 8 & & $\begin{array}{l}\text { C3*: Local retention in the higher upstream areas (by stopping pumps } \\
\text { and raising weirs that separate it from the lower areas). In this way a } \\
\text { large part of the water can be locally buffered in the higher areas } \\
\text { before discharging it into the Weteringen. This requires reconstruction } \\
\text { of the area in relationship to a regional water management plan }(: 47) \text {. }\end{array}$ & A\# \\
\hline \multirow[t]{2}{*}{9} & & $\begin{array}{l}\text { C4*: uncontrolled discharge of the higher areas into the lower areas } \\
\text { to prevent discharge into the Weteringen }(: 47) \text {. This corresponds to } \\
\text { the current situation in which excess water, because lack of discharge } \\
\text { capacity, will take its natural course over land alongside the } \\
\text { Weteringen, and will be aggravated by C3 }(: 10) \text {. }\end{array}$ & A \\
\hline & \multicolumn{2}{|c|}{ D: large scale reconstruction of the area } & \\
\hline 10 & & $\begin{array}{l}\text { D1: broadening of the Weteringen channels by relocation of the quay } \\
\text { on one side of the Weteringen by about } 10 \text { to } 20 \text { meters. This will cost } \\
\text { a considerable amount of space, which, however, could be utilised for } \\
\text { nature development }(: 48) \text {. }\end{array}$ & $\mathrm{T}$ \\
\hline 11 & & $\begin{array}{l}\text { D2: reducing inundation damage by changing land use into less } \\
\text { vulnerable types }(: 48) \text {. }\end{array}$ & $\mathrm{T}$ \\
\hline 12 & & $\begin{array}{l}\text { D3*: controlled rerouting of the discharge of the higher parts into } \\
\text { designated inundation areas in the lower parts }(: 49) \text {. }\end{array}$ & $\mathrm{T}$ \\
\hline \multirow[t]{2}{*}{13} & & D4*: construction of an inundation area just upstream Zwolle (:49). & $\mathrm{T}$ \\
\hline & \multicolumn{2}{|c|}{ E: Changing the legal status by shortening of dike ring 53 (with a barrier). } & \\
\hline 14 & & $\begin{array}{l}\text { E1*: Closing dike ring } 53 \text { by means of one or two barriers just } \\
\text { upstream the Zwolle city centre }(: 50) \text {. }\end{array}$ & A by $\mathrm{T}$ \\
\hline 15 & & $\begin{array}{l}\text { E2: Closing dike ring } 53 \text { by means of a barrier just downstream the } \\
\text { Zwolle city centre. This alternative requires complete buffering of the } \\
\text { Weteringen discharge }(: 50) \text {. }\end{array}$ & A by $\mathrm{T}$ \\
\hline \multicolumn{4}{|c|}{ Expert report (HKV_Lijn_in_water 1999) } \\
\hline & \multicolumn{2}{|c|}{ Investigated the above scenario $\mathrm{E}$ for the downstream barrier } & \\
\hline 16 & & $\begin{array}{l}\text { Barrier (fixed closure level) + full pumping facility. A pumping } \\
\text { capacity corresponding to the full Weteringen capacity of } 68 \mathrm{~m} 3 / \mathrm{s} \text { is } \\
\text { needed in order to prevent the level in Zwolle to rise }(: 21) \text {. }\end{array}$ & $\mathrm{T}$ \\
\hline
\end{tabular}




\section{CONTROVERSIES IN WATER MANAGEMENT: FRAMES AND MENTAL MODELS}

\begin{tabular}{|c|c|c|}
\hline 17 & $\begin{array}{l}\text { D4: Barrier (fixed closure level) + detention reservoir behind an } \\
\text { emergency spillway in the Weteringen dike. Lowers the } 1 / 250 \text { level in } \\
\text { Zwolle to } 1,47 \mathrm{~m}+\text { NAP for a width of the emergency spillway of } 400 \\
\text { meter }(: 21) \text {. For an emergency spillway with a width in excess of } 100 \\
\text { meter or wider calculations show a flow reversal in Zwolle which } \\
\text { transports water from the river Vecht into the inundation area }(: 16) \text {. } \\
\text { For a spillway width of } 100 \text { meter and a spillway height of } 1.1 \text { meter } \\
+ \text { NAP the level in Zwolle reduces to } 1,62 \text { meter. }(: 16) \text {. (This } \\
\text { alternative is one optional specification of } 15 \text {, by means of } 7 \text {. Other } \\
\text { specification options are available in } 6+8 \text { which will produce similar } \\
\text { inundation results in the lower area). }\end{array}$ & $\mathrm{T}$ \\
\hline 18 & $\begin{array}{l}\text { Lowering the bottom of the Zwarte Water by dredging } 2 \text { meters. } \\
\text { Lowers the } 1 / 250 \text { level in Zwolle to values below } 1,40 \mathrm{~m}+\operatorname{NAP}(: 21) \text {. }\end{array}$ & $\mathrm{T}$ \\
\hline \multicolumn{3}{|c|}{ (EIA-report 2001) } \\
\hline 19 & 1: Do nothing & A \\
\hline 20 & 2: Safety norm differentiation within WWK96 & A \\
\hline- & 3: Storm surge barrier + pumping facility (see 16 ) & $\mathrm{T}$ \\
\hline 21 & $\begin{array}{l}\text { 4: Storm surge barrier + rerouting of discharge to the river Vecht or } \\
\text { IJssel }\end{array}$ & $\mathrm{T}$ \\
\hline- & 5: Storm surge barrier (fixed closure level) + detention areas (see 17) & $\mathrm{T}$ \\
\hline 22 & Barrier downstream Zwolle (closes at flow reversal) & A by $T$ \\
\hline \multicolumn{3}{|c|}{ Interviews } \\
\hline 23 & (g) Wadi-system N-O around Zwolle & $\mathrm{T}$ \\
\hline 24 & (h) A mere change of legal status & A \\
\hline 25 & $\begin{array}{l}\text { (i) New dikes on the upstream boundary of Zwolle (which would mean } \\
\text { a restoration of the historical natural polder detention system } \\
\text { function). }\end{array}$ & $\mathrm{T}$ \\
\hline
\end{tabular}

\# : needs upgrade of existing or instalment of new distance control facilities on all relevant pumps and weirs in the area. 


\subsubsection{Discussion of the alternatives}

The "Startnotitie DAR2 Zwolle" (Grontmij_Projectbureau_DAR 1997c) does not add new alternative measures, but discusses the implications of alternatives nos. 14 and 15 for the city of Zwolle with regard to discharge buffering.

The "Startnotitie DAR1 Weteringen (Grontmij_Projectbureau_DAR 1997b) concludes with three possible scenarios that are considered promising: scenario I "Verzwaring conform uitgangspunten rivierdijken" correspond to measure 1, scenario II "Beperkte kadeverbetering" corresponds to measure 2 through 9 (no reconstruction of the area), and scenario III "Verkorting dijkring" corresponds to the barrier measures 14 and 15 in combination with the detention measure 12. Scenario IV "Afleiding en buffering bovenstrooms water" corresponds to measure 11 and 12 and is presented as a possible addition to scenario III. Special attention is given in "Startnotitie DAR1 Weteringen" to a variant of scenario III which implies measure $15+12$ in combination with measure 6 (downstream barrier + full buffering by stopping the lower area discharge pumps and raising the higher area weirs).

Measure 17 - barrier (fixed closure level) + detention reservoir behind an emergency spillway - is one optional specification of measure 15 using measure 7. Other specification options are available in a combination of measures $6+8$ that will produce similar inundation results in the lower area (only with less inundation depth). Remarkably the EIA report (EIA-report 2001) does mention stopping discharge pumps (measure 6)+ raising weirs (measure 8 ) as a collateral measures to control the discharge (:57), but does not elaborate into the consequences of such measures. Consequences would be a "natural" inundation of local area's because precipitation excess runoff will not be discharged, and because of this the higher grounds in Salland would spill uncontrolled into the lower grounds causing even more inundation there. These consequences are covered by the statement that "".

The text in (EIA-report 2001:55) suggest that an argument in favour of the barrier measure has been "constructed", because a failure in the Weteringen dike is considered to precede flow reversal. This is a very remarkable order of argumentation, not previously exhibited in dike safety discussion. The purpose of closing the barrier would, in this argumentation, be to control the inflow of external water (from the river Vecht) in order gain time to allow evacuation. The inundation depth ultimately reached would not be less; it would only be reached at a later time.

Alternative 15 (barrier) is not new, already in the second Ramspol EIA-report (Ramspol 1995:61, 203, 218) a barrier north of the city of Zwolle is mentioned, to be constructed for the same purpose as the current barrier. And even before, in the first Ramspol EIAreport (Ramspol 1988:25, 144-1150), the Zwolle barrier was selected as the most environmental friendly alternative for the Ramspol barrier plans. The Ramspol EIA-report 1995 concludes (:218) that a barrier near Zwolle will not lower the extreme high water levels upstream of Zwolle, because the Ramspol barrier already takes care of storm surges, and the Weteringen discharge will dominate the water levels. The Ramspol EIA recommends further study after the Weteringen discharge in relationship to the 
effectiveness of a Zwolle barrier. This EIA-report 1995 also concludes (:203) that the original LNC-values of the Sallandse Weteringen have already been lost during the early reconstruction (1960-1970) of Salland.

Alternative measure 18 was presented before too, in the Ramspol EIA report (Ramspol 1988:70). In that report the dredging of a channel was proposed that stretched from the Lake IJsselmeer through the Ketelmeer into the Zwarte Meer. The alternative was rejected because of its large cost in relation to the limited mitigating effects expected.

The account for the blocked discharge problem given in the EIA appears to be:

- The barrier does not necessarily have to be closed.

- But in the event that the barrier is closed, the Weteringen discharge can be reduced to almost zero by stopping pumps and raising weirs, because of the complete artificial reconstructed character of the water system in Salland. This will prevent the city of Zwolle to be flooded by regional discharge water.

- The consequences of stopping pumps and raising weirs will be subject of future studies.

- The result of which could be implemented in the long term WB21 planning.

The alternatives can also be judged on the aspect of whether they represent an integrated solution, and whether they can be regarded as a Technical or an Administrative solution to the problem. The latter has been indicated in a separate column in table 4.4 .

- Alternatives 1,15 and 14 are standard ("normal" - see section 2.3.2) local technical solutions to the initial problem.

- $\quad$ Alternative 13 is also a standard ("normal") technical solution, but affects inhabitants (mainly farmers) of the polders.

- Alternatives $7+8+12,6+8,23$ and 25 are in good agreement with the WB21 philosophy, but require a broader regional approach affecting many stakeholders.

- $\quad$ Alternative 24 is a purely administrative measure that starts from the conviction that the current water system has an acceptable level of safety. This solution would require a fundamental change in the problem solving approach on several levels of the administrative hierarchy.

A common goal of all stakeholders was to prevent a major dike improvement along the Weteringen. Some of the alternative measures tried to directly withdraw the Weteringen dikes from the WWk96, i.e. alternatives $14+15$ and 24 . Alternative 24 is ruled out by a negative answer of the ministry (RWS) on a direct question of the water board whether a dike ring could have an opening (for discharge purposes) which can not be closed. This leaves, according to some actors, alternative 15 as the only feasible solution. Within the common goal, the multitude of alternative measures indicates the possibility of controversial opinions. The conspicuous absence of inundation measures in the IEA suggests that some of controversies are related to inundation and possibly might have been persistent and therefore have been removed from the scope of the EIA. The EIA argumentation will be subject of analysis in chapters 6 . Remarkably the single other alternative in the EIA, apart from the barrier, was the full scale dike improvement. This 
latter had already been rejected by all actors in the early phase of the decision making process. It was this alternative, in fact, that has initiated the whole discussion and dispute about a diversity of other alternatives. Although Annex I "tussenfase rapport" of (EIA-report 2001) suggests the inclusion of several other alternatives in the EIA (including an inundation alternative), none of these has in fact been included.

\subsubsection{Decision method and selection criteria used in the EIA}

Selection criteria (and assumptions) are specified in the EIA-report $(2001: 15,18,19,27$, $45,54,55,57,68$, etc.). The whole main EIA-report is, in fact, one big compilation of major and minor criteria, assumptions and effect scores, which are currently subject of study in another project (Reinshagen, 2005). The EIA-report (2001) mentions a the barrier alternative to be favourable in case it can prevent large scale dike improvements along the Weteringen, guarantees safety and protection against water hindrance, and creates a controllable and admissible situation for water management (:19). It also remarks that the most important bottleneck for the latter condition is constituted by the conflict between the discharge out of Salland versus the blocking of the discharge by a closed barrier (:19). Furthermore, it mentions as additional goals the reduction of water hindrance in the city of Zwolle, and the reduction of water hindrance in the lower parts of Salland caused by extreme rainfall events (:19). In a previous report "Startnotitie DAR1 Weteringen" (Grontmij_Projectbureau_DAR 1997b:54) the four scenarios mentioned in section 4.6.1 are all considered feasible. This report also asks special attention for the barrier alternative in combination with buffering. In the final EIA-report two alternatives are presented, none of which contains buffering. The concluding chapter of the EIAreport (:81 table 10.3$)$ presents a summarising qualitative overview of both alternatives (see reproduction below).

The EIA does not explicitly specify the use of a decision method. The method used appears to be descriptive in nature and somewhat resembles the score chart method from (Hellendoorn 2001:41, 45-53), in that information on alternatives is not processed using a decision method but merely presented "as is" in a table (see table 4.5), the table does not contain weights, and the table presents no judgement on the ranking of alternatives. The table is a structured presentation of qualitative scores of alternatives on criteria, with the exception of the costs which are quantified. In contrast with the score chart method, no qualitative ranking of alternatives for each of the criteria is given. For any further information on the meaning and consequences of the qualitative scores the reader must consult the text of the EIA-report and its annexes. 
Table 4.5: Table from the EIA-report (2001:81, translated from the Dutch) presenting the comparison of the alternatives that are considered in the EIA.

\begin{tabular}{|c|c|c|}
\hline \multirow[b]{2}{*}{ Decision criterion } & \multicolumn{2}{|l|}{ Decision alternative } \\
\hline & Maintaining primary status & Shortening of the dike ring \\
\hline $\begin{array}{l}\text { Safety against water from } \\
\text { outside the dike ring }\end{array}$ & $1: 1250$ & $1: 1250$ \\
\hline $\begin{array}{l}\text { Protection of lower Salland } \\
\text { against water hindrance }\end{array}$ & $\begin{array}{l}\text { By means of primary flood } \\
\text { defences }\end{array}$ & $\begin{array}{l}\text { By means of regional flood } \\
\text { defences, difference at water } \\
\text { levels above MHW }\end{array}$ \\
\hline $\begin{array}{l}\text { Consequences of dike failure in } \\
\text { regional defences (probability } \\
\text { less than } 1: 1250 \text { ) }\end{array}$ & $\begin{array}{l}\text { Water from the Zwarte Water } \\
\text { enters the dike ring }\end{array}$ & $\begin{array}{l}\text { No water from the Zwarte Water } \\
\text { enters the dike ring }\end{array}$ \\
\hline $\begin{array}{l}\text { Water hindrance by extreme } \\
\text { precipitation }\end{array}$ & Large & Large \\
\hline Water hindrance to City Centre & $\begin{array}{l}\text { Temporary reducible by } 20 \mathrm{~cm} \\
\text { at most }\end{array}$ & $\begin{array}{l}\text { In the long run more control } \\
\text { conceivable }\end{array}$ \\
\hline Management and maintenance & $\begin{array}{l}\text { Direct control; assessment } \\
\text { every } 5 \text { years }\end{array}$ & $\begin{array}{l}\text { Use and management not always } \\
\text { by the Water Board, regular } \\
\text { inspection of the maintenance } \\
\text { condition }\end{array}$ \\
\hline Future value & $\begin{array}{l}\text { Defences which can also } \\
\text { withstand higher water levels, } \\
\text { and guarantee discharge from } \\
\text { Salland, but the effect of } \\
\text { changes in MHW are unclear }\end{array}$ & $\begin{array}{l}\text { Clear separation, effect of } \\
\text { changes in } \mathrm{MHW} \text { immediately } \\
\text { result in clear responsibilities }\end{array}$ \\
\hline $\begin{array}{l}\text { LNC values and housing } \\
\text { conditions }\end{array}$ & $\begin{array}{l}\text { Occupation of area and } \\
\text { decline of vegetation values }\end{array}$ & $\begin{array}{l}\text { No large effects, limited to } \\
\text { barrier site only }\end{array}$ \\
\hline Cost & $24,500,000 \mathrm{Hfl}$ & $14,500,000 \mathrm{Hfl}$ \\
\hline Spatial feasibility & $\begin{array}{l}\text { Not optimal with regard to } \\
\text { agricultural interests }\end{array}$ & $\begin{array}{l}\text { Anticipates to future prospects in } \\
\text { spatial planning }\end{array}$ \\
\hline
\end{tabular}

\subsubsection{Conflicts between stakeholders}

In the present case of the Zwolle storm surge barrier, several events are present in the material analysed up to this point which indicate potential conflicts. During the first and second phase of the EIA procedure:

- The many alternatives in the first phase, technical as well as administrative, indicate a potential conflict between their inventors or "owners".

- $\quad$ The extensive and time consuming additional research performed in the second phase indicates that, based on the available information up to that time, a decision was not obvious.

- The rejection of administrative alternatives like differentiation of the legal norm or a mere changing of legal status into secondary, in favour of very few technical alternatives (only the barrier alternatives survived the selection process) may potentially raise resistance at the persons or groups that devised these alternatives.

- The limitation of alternatives to only those that fitted within the Water Board policy, in stead of a full argumentation that would also include other criteria (like technical), potentially raises resistance at the "owners" of those other criteria. 
- Media messages, e.g. in the "Zwolse Courant" and often mentioning Van der Schrier, speak of a "futile barrier".

During the third phase (writing of the EIA report) the following events are visible:

- The conspicuous absence of inundation measures in the IEA suggests that some of controversies are related to inundation and possibly might have been persistent and therefore have been removed from the scope of the EIA.

- The advise of the EIA Commission contains questions with regard the argumentation of the preferred alternative (details are presented below).

- The two second opinions that were performed on request of the Province indicate a conflict between the Technical and the Administrative perspective.

- The personal note of one of the technical authors in the report to the Provincial Executive Council indicates a submission of opposing technical arguments.

After the approval of the EIA report by the Provincial Executive Council the events listed in section 4.5.2.4 under the $4^{\text {th }}$ phase (objection and appeal) prove the existence of conflicts

The advice given by the Dutch Commission for EIA (CieMER) contains some remarkable aspects. In the first part of the advice the CieMER approved the EIA-report (CieMER 1999:2). In the second part of the advice, however, the CieMER made some critical remarks regarding the decisions made in the EIA-report, and advised to reconsider the barrier alternative by giving further consideration to the detention alternative $(: 4,5)$. The advice of the CieMer indicated some important controversies. Firstly, based on the EIA report the discharge from the Sallandse Weteringen in extreme high water situations can hardly ever be blocked (e.g. by a barrier), therefore the CieMER advised the Secretary of State to reconsider the principle that a dike ring must be closed. Secondly, the CieMER concluded that the construction of the barrier would have little effect on the factual situation with regard to water management, because water nuisance frequency in the low area of Salland will not decrease and because the built area in the Zwolle city centre may experience more water nuisance. Therefore, the CieMER advised to consider whether future water management plans for the area could by included in the barrier decision making process, especially the use of detention areas.

\subsection{Conclusion}

The case material analysed presents a very interesting picture of a decision process which resulted in a disputed choice. Disputes which were already present in the early case documents grew into intractable controversies which were never resolved during the course of the EIA project, but were contested up to the highest court in the Netherlands, the "Raad van State".

The question is now whether we can explain the decision process using the theory presented in chapters 2 and 3. Starting from the hypothesis presented in chapter 2, we will look for institutional role positions that can explain the different mental models used by the individual actors. 



\section{Case analysis}

\subsection{Introduction}

In chapter 3 we showed how persistent controversies can be caused by frame differences. In the present chapter we will analyse controversies in the Zwolle case using frames. We will look for changes in decision making positions and related changes in frames over time. These changes could indicate possible frame reflective processes having taken places in this case. For the purpose of detecting changes and reflection we will look for the appearance in the Zwolle case of frame characteristics and strategies for frame reflection described by Schön\&Rein (1994). This analysis includes an examination of influences on the decision making process by actors, their roles and their interactions, and the use of metaphors present in the stories used by actors in defence of their position. But first frame conflicts will be identified among the conflicting elements present in the mental models of informants. The different frame perspective types (see sections 2.4 and 3.2.4) connected to an institutional role position can lead to a clash of competences and interests. A strategy of one stakeholder to emerge as a winner in this clash can be the deconstruction of opponents, or, alternatively, a frame reflective strategy can be used to overcome the clash by constructing a common frame.

The Zwolle storm surge barrier case has been selected because of the controversies present (see section 4.6.4). These continue even to this date, despite the fact that a decision has been made and the construction of the barrier is now almost completed. Other theoretically possible outcomes of the decision process would have been a decision reflecting the consensus of the stakeholders, or no decision at all (e.g. postponing it in order to obtain further research). The start of the series of controversies was the WWK96, which obliged the Water Board to bring all their primary dikes up to standard before 1 January 2001. Throughout the history of the case we see shifts in frames (as evident, for example, in the different alternatives presented in section 4.6.1). We claim that the persistence of the controversies, and thus the continuing incompatibility of the frames can be traced back to the institutional positions of actors. These positions can be characterised by the perspective types, both on a personal and institutional level. The aim of analysing the controversies is to learn from them, and to determine if Schön\&Rein's frame reflection method could have mitigated the controversies.

This chapter begins by charting the actor positions, by analysing their mental models on conflicting elements, using the method described in section 3.5. Subsequently the actor positions will be characterised using perspective types, and the relationship between perspective type and institutional context will be analysed. The perspective types will be brought into relation with actors' positions on the conflicting elements (see section 3.6). In order to construct a decision explanation model for the case, the actor network will be analysed. 
This chapter will provide the answers to the third, second and fourth research questions:

3. What are the mental models of the stakeholders? Can mental models (and/or elements thereof) be related to the dominant perspective type of stakeholders? In what way does the position of the organisation in the decision arena, and the position of the individual within the organisation, influence the dominant perspective type and the mental model?

2. (second part) How do stakeholders (try to) exercise their influence in the diverse steps of the decision making process?

4. Assuming that mental models found in the case are different, does the analysis of mental models and perspectives within actor frames explain the persistence of controversies?

\subsection{Mental model analysis}

\subsubsection{Data matrix of conflicting elements}

Using the method presented in sections 3.4 and 3.5, this section presents the processed results of the interviews, see table in table 5.1. This type of table is also called a "data matrix". The table presents the aspects of the problem situation on which the opinions of the informants differ, or on which informants have an opinion differing from the viewpoints presented in the EIA-documents. In the following we will refer these aspects as "elements". The term "element" refers to the components that constitute the mental model of an informant. The elements listed in the table appear in the mental models of two or more informants. The table thus presents an overview of the different opinions that are present in the overlapping parts of informants' mental models. Not all elements are common to each mental model, the overlap is different for each informant (see figure 5-1). Below we will explain the layout of the table.

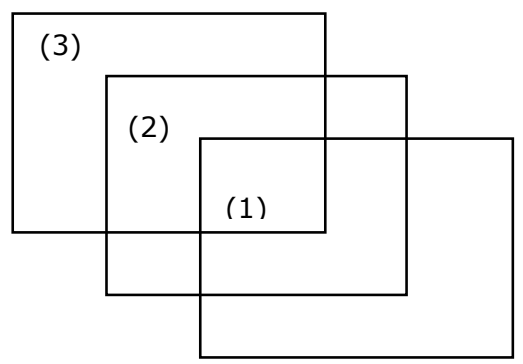

Figure 5-1: Overlap and differences between informant mental models. Element (1) is shared by all three informants, element (2) by only two informants, and element (3) is unique to its informant. 
The informants are listed across the table header of table 5.1 with a code number (see table 4.3 in section 4.4 ).

The first column in table 5.1 indicates the serial number of the disputed element.

The second column presents the generalized categories into which the contested elements have been grouped. Five clusters have been distinguished, namely WWK96, Province, Water Board, Water system, Barrier, and EIA. These clusters are described below.

- WWK96

This cluster contains the elements 2 through 12 . The elements represent the opinions of informants on different aspects of the WWK, like design, enforcement and interpretation. This cluster constitutes the administrative context for the barrier problem situation.

- Province

This cluster contains the elements 13 through 19. The elements represent the opinions of informants on the institutional tasks of the Province and their execution.

- Water Board

This cluster contains the elements 20 through 24 . The elements represent the opinions of informants on the institutional tasks of the Water Board and their execution.

- Water System

This cluster contains the elements 25 through 44 . The elements represent the opinions of informants about the flooding threats of the water system and their abatement. Different sub clusters are present for the WWK96 (like MHW and safety) and technical aspects (like flow reversal, the functioning of the water system and the resulting threats, and the additional measures required to make the barrier effective)

- Barrier

This cluster contains the elements 45 through 51 . The elements represent the opinions of informants about, for example, the barrier closing scenario and barrier effectiveness.

- $\quad$ EIA

This cluster contains the elements 52 through 68 . The elements represent the opinions of informants about the course of the EIA procedure, the relationship between actors, the decision criteria, the alternatives and the scientific knowledge used.

The third column specifies the characteristics of the dispute surrounding each element. The specification is based, as much as possible, on the original wording used by the informants. The specifications are presented as contradicting couples or triples of quotes (separated by the indicator "...vs..." ). In a few instances there is only one, or there are more, parts in a specification. 
The fourth column presents the values that are used to score the opinion of informants for the elements. The wording of the values has been derived from the dispute specification in the third column.

The subsequent columns, headed by the informants' codes, present the scores of informants 1 through 14, using the first letter from the fourth column. For some elements the difference in opinion does not follow from different scores, but from the single opinion presented by informants which derivates from the general prevailing opinion (as stated in the EIA). This is the case, for example, with element numbers 4, 7, $11,26,27,32,39,47$ in the table in table 5.1. In some instances a score has been derived from the interview by the researcher without an explicit statement from the informant, these indirect scores are noted between brackets (). When the score was not unambiguous both values were entered in the table. In the full data matrix references to the audio transcription have been noted in minutes. 


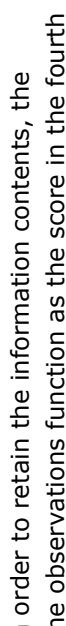

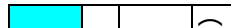

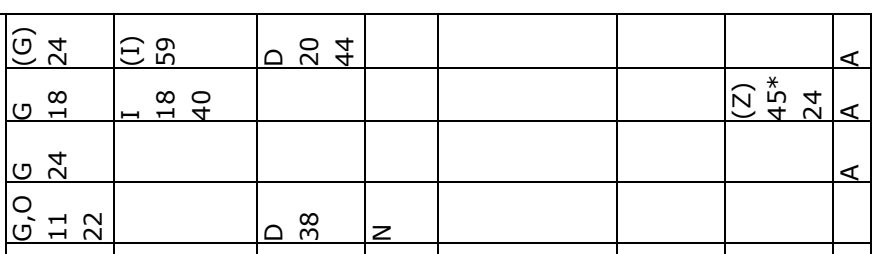
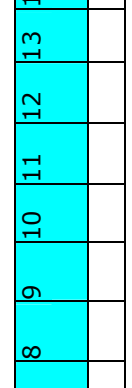

돈

도 है

$\dot{4}$

는 농

बृ

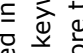

ه

部。

远

긍

४ 8

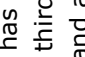

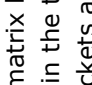

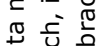

त

을

웡

온 넌

응 $\frac{1}{\bar{\pi}}$

离

安京

$\dot{x} \sum_{3}^{n}$

这

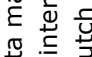

菭.

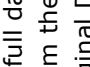

焉结

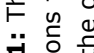

in

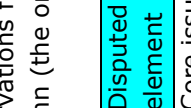

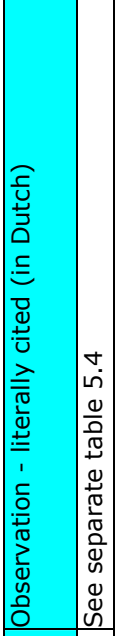

空

\begin{tabular}{|c|c|c|c|c|c|c|}
\hline & $\Delta \vec{m}$ & & 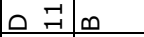 & us : & & م \\
\hline & & อ름 & $0 \approx$ & $n$ u : & $N \stackrel{F}{F}$ & \\
\hline ט & & & & & & \\
\hline $0 \stackrel{N}{ }$ & & & & $\ln \pi$ & & 0 \\
\hline
\end{tabular}
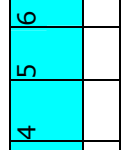

\begin{tabular}{l}
$m$ \\
$\sim$ \\
\hline- \\
\hline \\
0 \\
0 \\
0
\end{tabular}

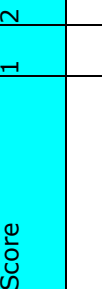

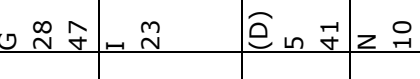

\begin{tabular}{l|l|l|l|l|l|l|l|}
\hline & $n$ & 1 & 1 & 0 & & $N$ & N \\
\hline & 1 & 0 & $z$ & 1 & & $\alpha$ & $\varangle$ \\
\hline
\end{tabular}

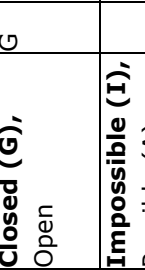

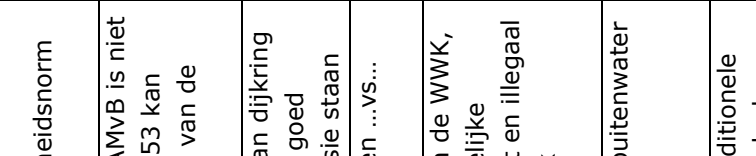

$\sum_{<}$ก

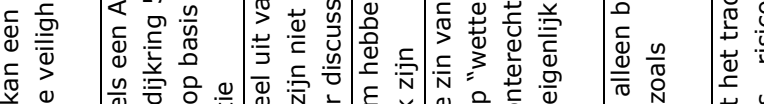

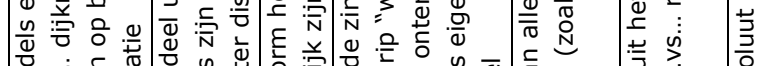

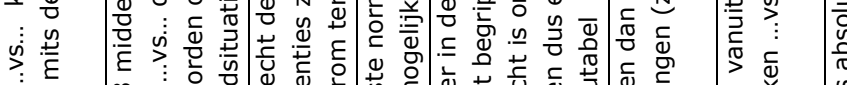

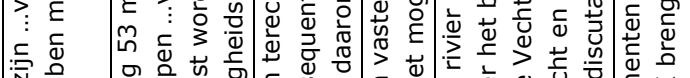

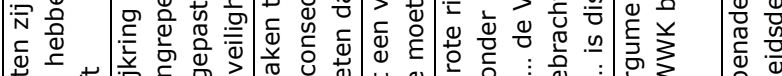

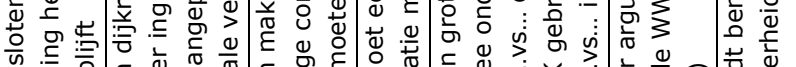

品

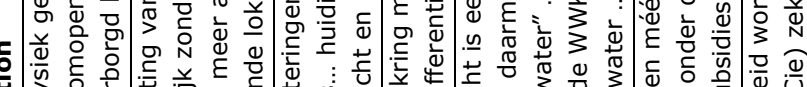

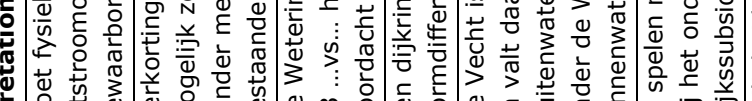

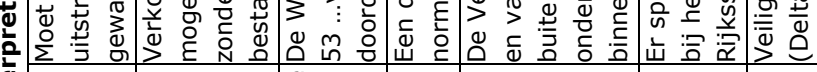

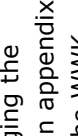

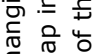
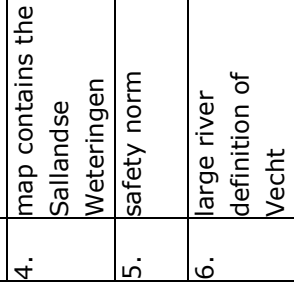

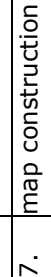




\begin{tabular}{|c|c|c|c|c|c|c|c|c|c|c|c|}
\hline I & n̂ & $\stackrel{\stackrel{n}{m}}{\stackrel{m}{I}} \stackrel{\infty}{\square}$ n & & & & & $\sum \stackrel{m}{q}$ & & & & \\
\hline$\stackrel{m}{r}$ & $\vec{a}$ & & & & & $>\tilde{\sigma}$ & $>\tilde{\sigma}$ & & $\simeq \tilde{\sigma}$ & 0 กี & ¿ ำ \\
\hline 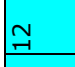 & in & & & $3 \%$ & & & & & & $\overrightarrow{\underline{\omega}}$ & \\
\hline 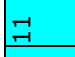 & & & & & & & m & -8 & $\Sigma R$ & & \\
\hline 욱 & $\stackrel{1}{2}$ ட & & & & & & 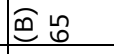 & , & & & \\
\hline a & & & & & & & $>\stackrel{\text { ஜ }}{q}$ & & $\propto$ n & (⿹ & \\
\hline$\infty$ & A & & & & & $\infty$ 亡ُ & & & $\underline{\alpha} \stackrel{*}{\underset{-}{-1}}$ & ш & $\sum$ ก \\
\hline$\wedge$ & 0 & & & & & & & & & & \\
\hline 6 & m & . & 1 & $3 \infty$ & & & $>$ Ln & ㄴ ம & 뜬 늇 & ш ᄂீ & 11 \\
\hline in & \pm 0 & & $\varangle$ & a & & & ब्र & 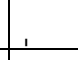 & $\Sigma$ & & 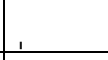 \\
\hline$\theta$ & & \pm & $\varangle$ & & & & & & $\underline{\Sigma}$ & & $z$ \\
\hline$m$ & & $I$ & & o & & & & & $\underline{x}$ & ט & $z$ \\
\hline$n$ & & & & 3 & & & $\infty$ & 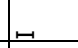 & $\Sigma$ & & $\sum$ \\
\hline$\rightarrow$ & & & & & & 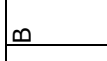 & $>$ & ㅇ & $\underline{x}$ & w & $>$ \\
\hline 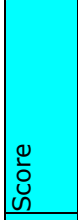 & 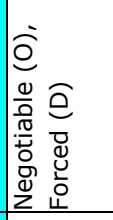 & 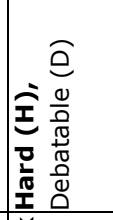 & 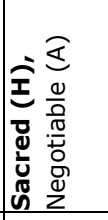 & 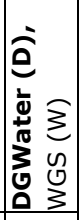 & & 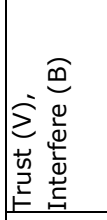 & 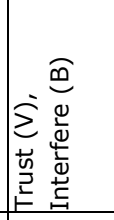 & 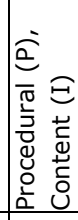 & 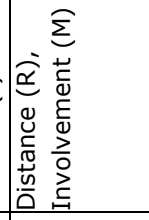 & 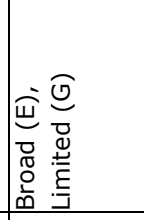 & 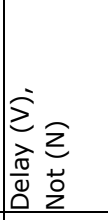 \\
\hline 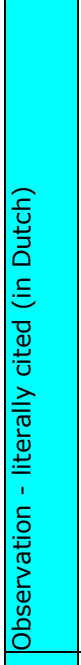 & 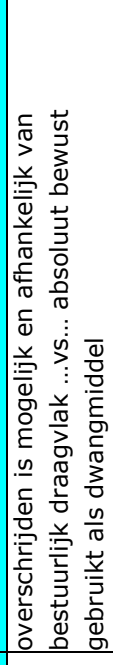 & 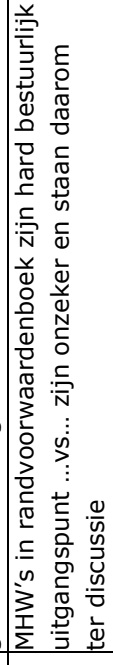 & 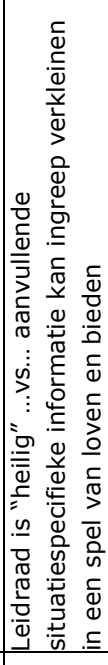 & 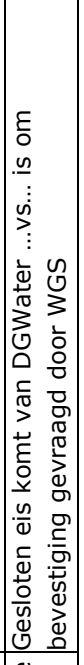 & 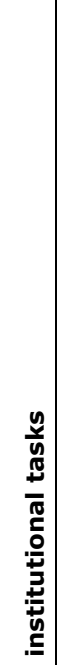 & 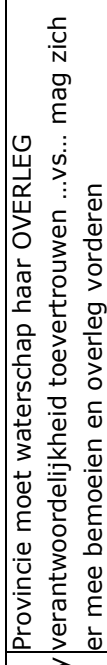 & 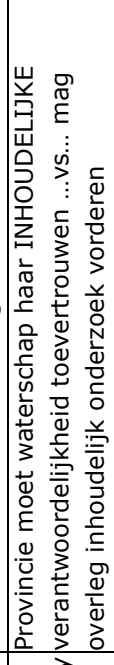 & 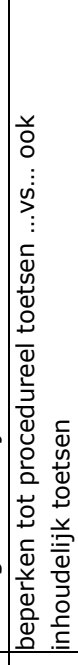 & 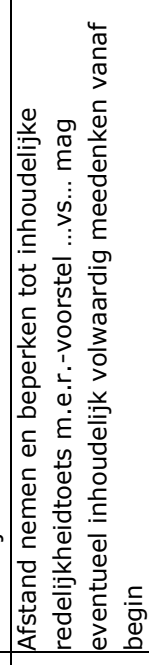 & 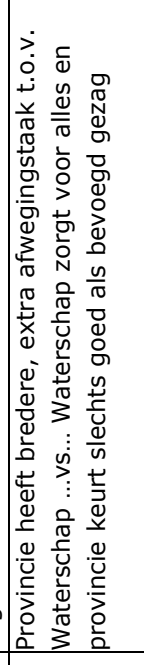 & 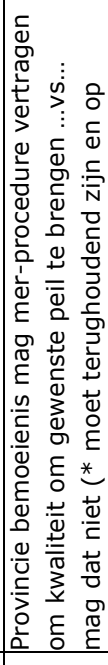 \\
\hline \multirow[t]{2}{*}{ 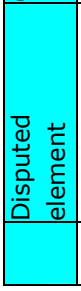 } & & 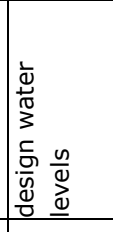 & 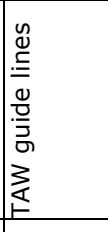 & 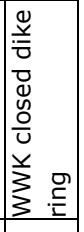 & 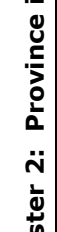 & 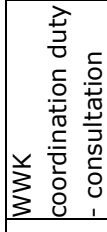 & 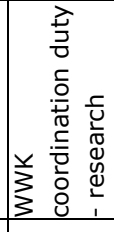 & $\begin{array}{l}\bar{\pi} \\
0 \\
0 \\
0 \\
0 \\
0 \\
0 \\
3 \\
3 \\
3\end{array}$ & 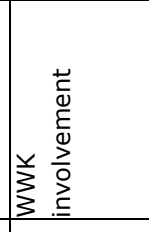 & $\begin{array}{l}0 \\
0 \\
\mathbb{J} \\
0 \\
0 \\
0 \\
0 \\
0 \\
\end{array}$ & 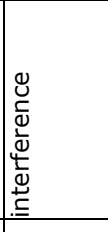 \\
\hline & & |ं & $\stackrel{-}{-}$ & & $\bar{U}$ & & & ก) & $\underset{-1}{0}$ & If & $\begin{array}{l}\infty \\
-1\end{array}$ \\
\hline
\end{tabular}




\begin{tabular}{|c|c|c|c|c|c|c|c|c|c|c|c|}
\hline I & & & & $\underline{x} \underset{q}{m}$ & lo & ○ & ๓ & & & & 0 ก \\
\hline$\stackrel{m}{-1}$ & & & & $\begin{array}{lll}0 & 0 & 0 \\
0\end{array}$ & & & ๓ & ט $\stackrel{\sim}{=} \sim \underset{\sim}{\sim}$ & & & \\
\hline$\approx$ & & & & & & & & อิำ & & & \\
\hline ت & & 08 & & 0 ำ $N$ & & & & 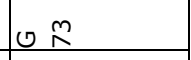 & & $-\curvearrowright$ & \\
\hline 웁 & & & & 0 음 & ¿ & & $\simeq \stackrel{\curvearrowright}{\sim} \infty$ & & & & \\
\hline a & & & & & & & ब्ञ m & & & & \\
\hline$\infty$ & & & & $\begin{array}{lll}1 & 0 & 0\end{array}$ & & & 赵合 & & & & \\
\hline$\Lambda$ & & & & & & & $\underset{\infty}{\stackrel{0}{-1}} \simeq \underset{\bullet}{0}$ & & & 18 & ○ ำ \\
\hline 6 & & & & §o응 & $\infty$ வ & & م & & & $\Perp \stackrel{n}{N}$ & \\
\hline nn & & & & 응 & & & $\underline{\underline{x}}$ & o & & $\Theta$ & \\
\hline o & & 1 & & $1 \quad 1 \quad 1$ & & & $\hat{y}_{\widehat{\omega}}$ & 0 & & $\mapsto$ & \\
\hline$m$ & & & & & & & $\infty$ & & & & \\
\hline$n$ & & $\vdash$ & & & & & $\underline{x}$ & a & & & \\
\hline-1 & & 0 & & 0 & $<$ & un & $\underline{x}$ & & & $\Perp$ & \\
\hline 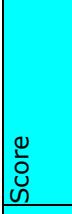 & & 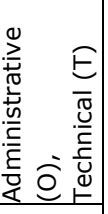 & & 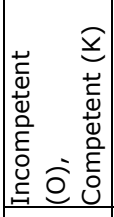 & 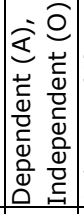 & 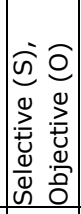 & 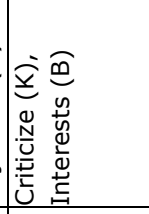 & 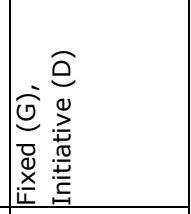 & & 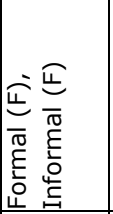 & 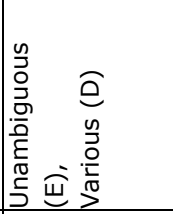 \\
\hline 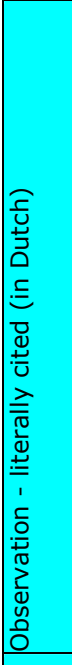 & 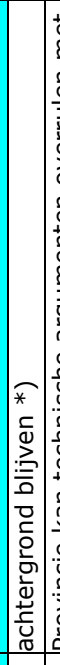 & 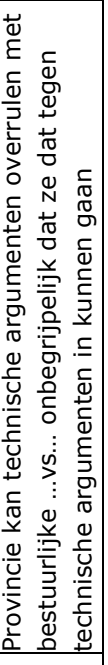 & 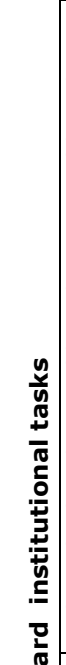 & 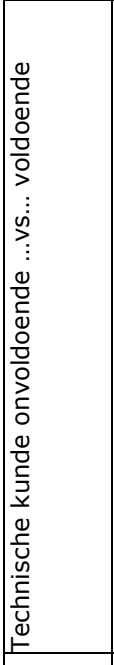 & 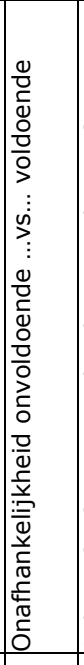 & 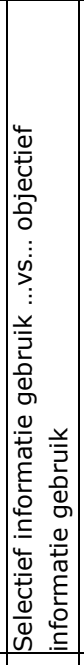 & 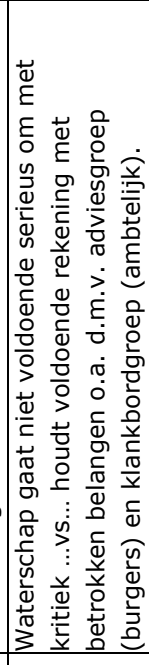 & 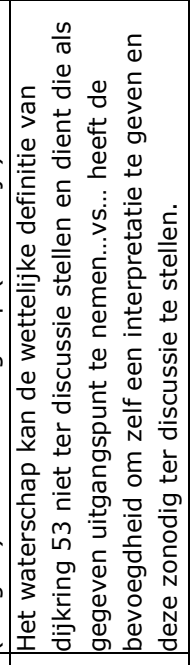 & $\underset{D}{\mathbb{D}}$ & 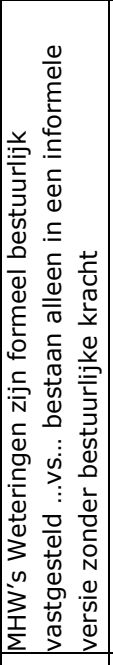 & 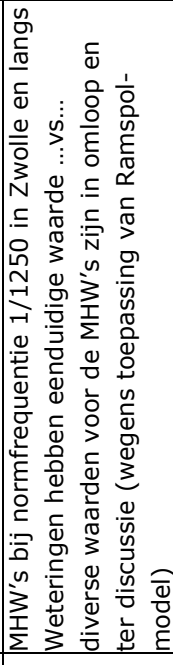 \\
\hline 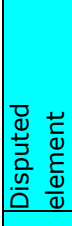 & & 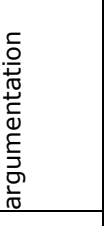 & 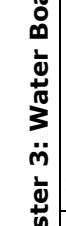 & 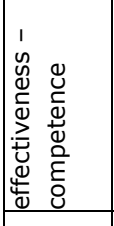 & 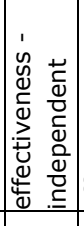 & 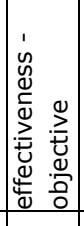 & 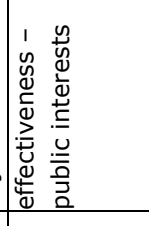 & 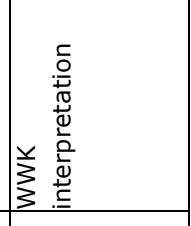 & 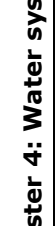 & 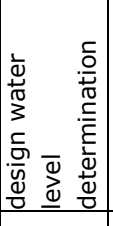 & 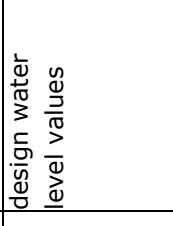 \\
\hline & & $\stackrel{\circ}{-1}$ & $\frac{n}{U}$ & & & & & & $\frac{n}{3}$ & & \\
\hline
\end{tabular}




\begin{tabular}{|c|c|c|c|c|c|c|c|c|c|}
\hline I & $\sum \approx \stackrel{\infty}{m}$ & & & อิ & & & n & 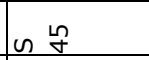 & 区ㄴํㄴ \\
\hline$\stackrel{m}{r}$ & & & & & & 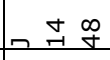 & & $\sum \underset{-}{m}$ & $\ll \stackrel{m}{-}$ \\
\hline \multicolumn{10}{|l|}{$\underset{+1}{\sim}$} \\
\hline$\stackrel{-}{ت}$ & & & $>\hat{m}$ & $\circ \stackrel{m}{\sim} \stackrel{\text { レ }}{\sim}$ & $z$ & & $\pi_{1} \quad 2$ & $n \underset{+}{-}$ & E $\stackrel{*}{*}$ న \\
\hline 욱 & & & $>\stackrel{\infty}{\circ}$ & & & & n $\begin{array}{lll}0 & 0 & 0 \\
& 0 \\
\end{array}$ & n & _t \\
\hline a & & & & & & & $z \stackrel{\infty}{0}$ & & \\
\hline \multicolumn{10}{|l|}{$\infty$} \\
\hline n & & & $>\stackrel{\infty}{-1}$ & & & & $n \stackrel{\infty}{-}$ & & \\
\hline 6 & 1 & I & 1 & & 1 & 1 & $z \&$ & & 1 \\
\hline in & 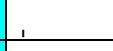 & & & & & 1 & n & & \\
\hline 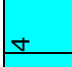 & $>$ & $\stackrel{\infty}{\infty}, \stackrel{\stackrel{N}{*}}{\circ} 0$ & & & & 1 & & & 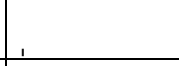 \\
\hline$m$ & $>$ & 욱 0 & 0 & & & & & & $\varangle$ \\
\hline n & & $\sum^{\pi} \times \stackrel{0}{0} 0$ & $>$ & 0 & $z$ & $z$ & $n$ & on & $\rightarrow$ \\
\hline \multicolumn{10}{|l|}{ - } \\
\hline 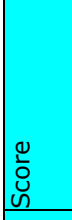 & 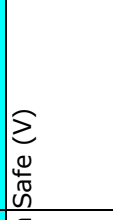 & 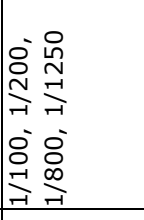 & 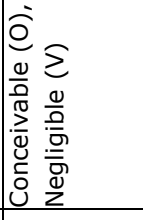 & 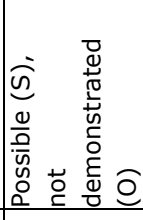 & $\begin{array}{l}\bar{z} \\
\overline{\bar{c}} \\
\overline{\underline{z}}\end{array}$ & 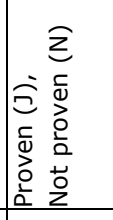 & 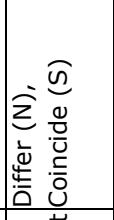 & 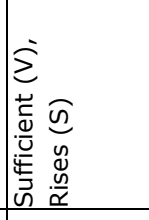 & 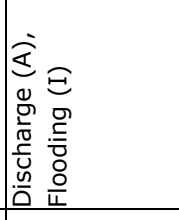 \\
\hline 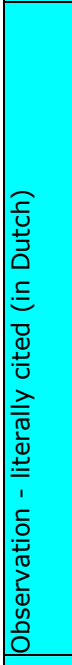 & 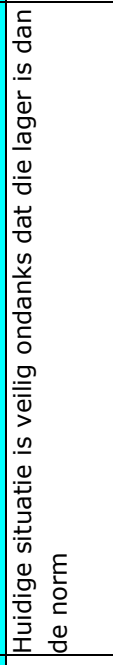 & 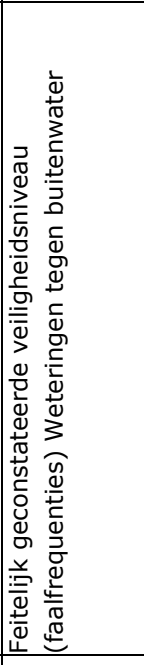 & 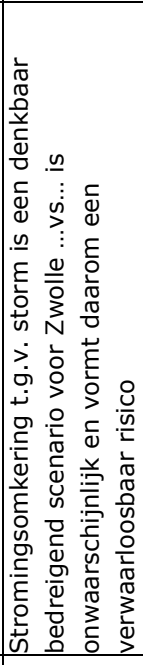 & 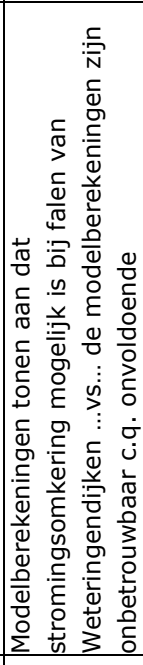 & 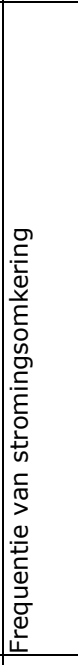 & 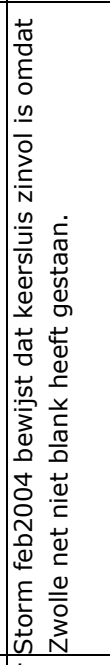 & 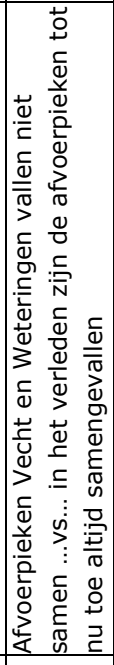 & 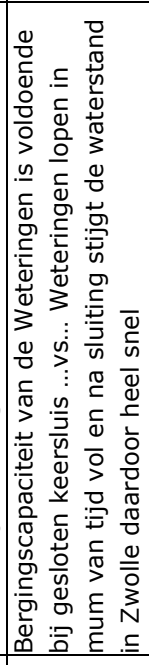 & 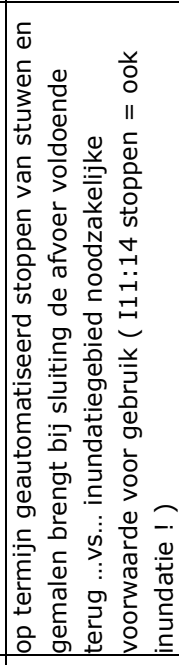 \\
\hline \multirow[t]{2}{*}{ 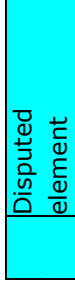 } & 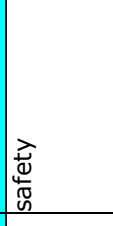 & 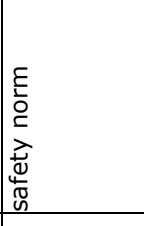 & \begin{tabular}{|l}
3 \\
0 \\
$\frac{3}{4}$ \\
$\frac{1}{0}$ \\
0 \\
0 \\
0
\end{tabular} & 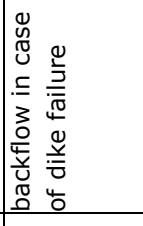 & 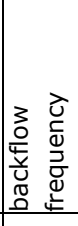 & 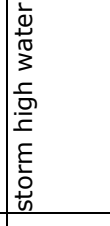 & 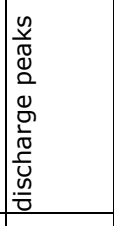 & 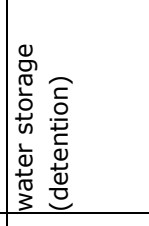 & 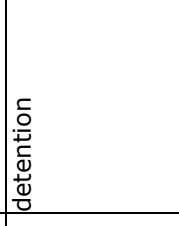 \\
\hline & $\stackrel{i}{a}$ & $\stackrel{\infty}{\infty}$ & กิ & i & $\dot{m}$ & $\stackrel{\dot{m}}{m}$ & $m$ & mं & in \\
\hline
\end{tabular}




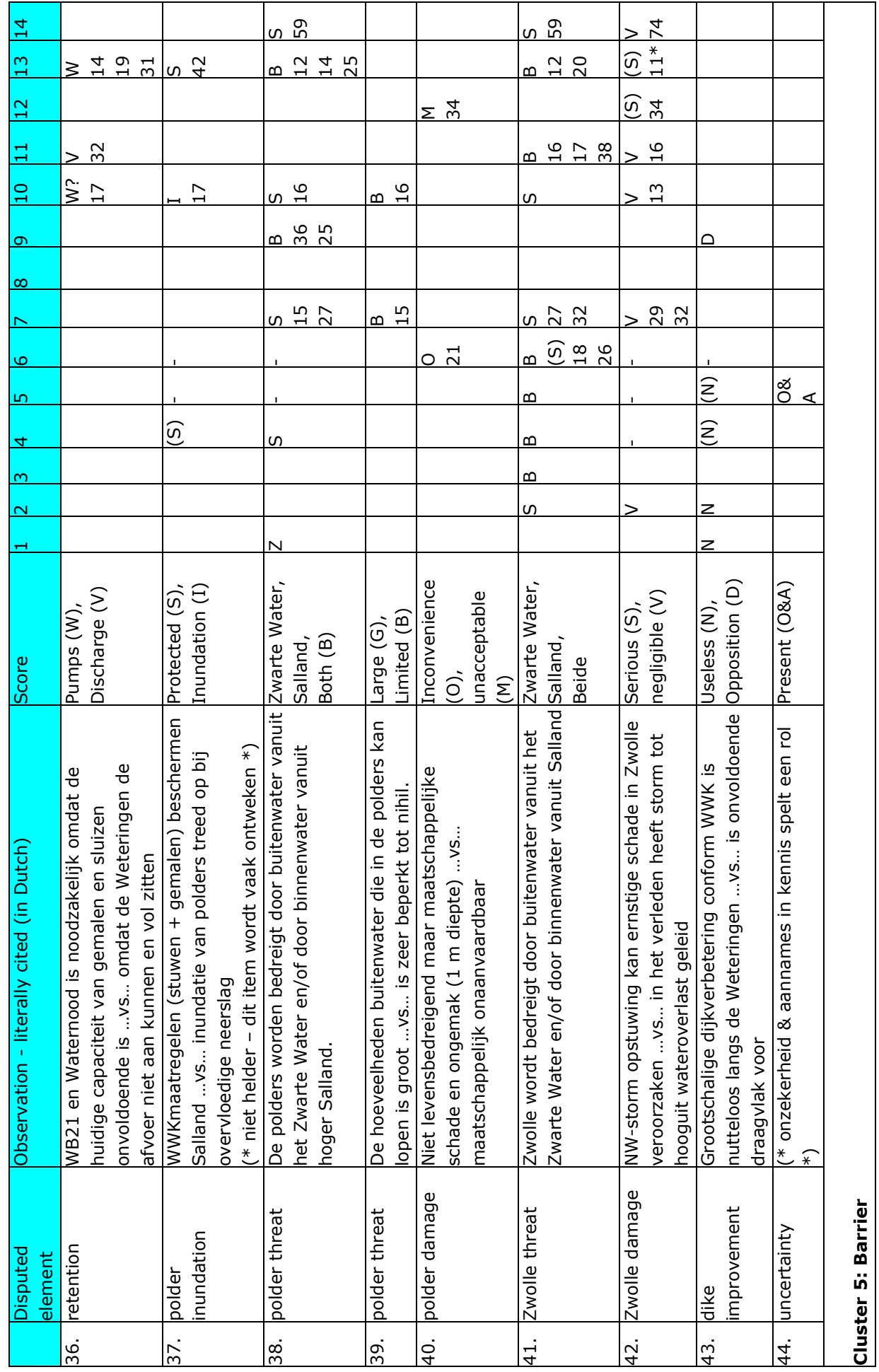




\begin{tabular}{|c|c|c|c|c|c|c|c|c|c|c|c|}
\hline A & & E्व & $\varangle \stackrel{\text { L }}{\sigma}$ & & & & & & & & 无字 \\
\hline$\stackrel{m}{m}$ & \pm ถ & $\frac{\vec{\sigma}}{\pi}$ & $\varangle \stackrel{m}{-1}$ & อล & & & & & & $z$ 엄 & \\
\hline$\underset{H}{N}$ & & & & & & & & & & & \\
\hline 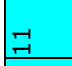 & & $0 \stackrel{m}{-}$ & & & & ш $\underset{\sim}{\sim} \underset{N}{N}$ & 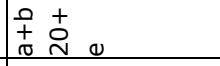 & & & $\frac{n}{n}$ & $z \stackrel{\text { L }}{+}$ \\
\hline 음 & & 욤 & & $\varangle \hat{m}$ & & & $\begin{array}{lll}0 & 0 \\
+ & 0 & 0 \\
\sigma & + & 0 \\
\end{array}$ & & & n & $z$ \\
\hline a & & & & & & & & & & & \\
\hline$\infty$ & & & $\varangle$ ते & ปั & & & & & & $n$ & 용 \\
\hline 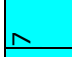 & & $\underset{\vec{\nabla}}{\sim} \stackrel{m}{\sim} \stackrel{\infty}{N}$ & & $\ll \tilde{m}$ & & & $\begin{array}{l}u \\
+ \\
+\end{array}$ & & & & \\
\hline 6 & 1 & $\underset{\sigma}{\infty}$ & 1 & ఏঙ $\stackrel{\infty}{+}$ & 1 & 1 & 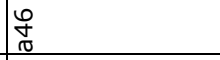 & & & & \\
\hline in & & 1 & & ב & & $z$ & مـ & & & & \\
\hline$\theta$ & & $\pi$ & 这 & 己 & 0 & . & $\begin{array}{ll}0 & 0 \\
+ & 0 \\
0 & +\end{array}$ & & $>$ & & \\
\hline$m$ & $u$ & $u$ & $<$ & \lrcorner & & نे & $\begin{array}{lll}+ & + \\
t & 0 & 0\end{array}$ & & & & \\
\hline$N$ & & ס & & $\ll$ & & ш & $\begin{array}{ll}+ \\
\pi\end{array}$ & & & & \\
\hline$\rightarrow$ & & & $\ll$ & & & ш & $\begin{array}{ll}+ \\
\pi\end{array}$ & & & & \\
\hline 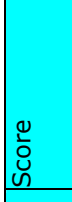 & 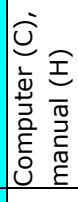 & & 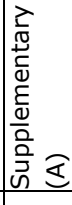 & 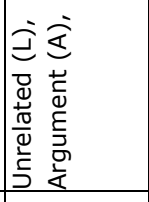 & 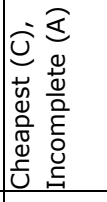 & 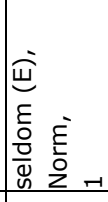 & & & 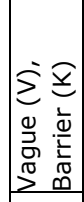 & 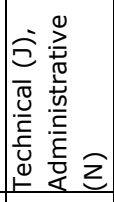 & 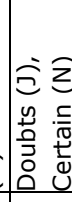 \\
\hline 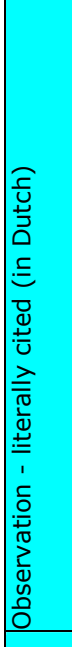 & 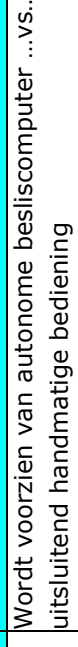 & 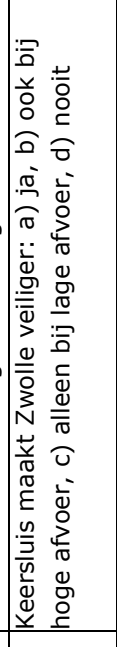 & 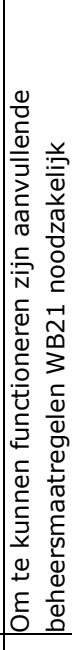 & 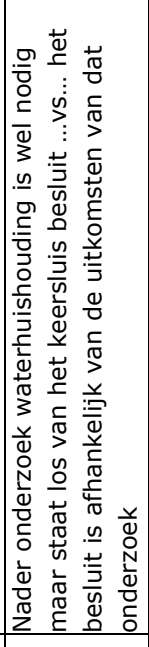 & 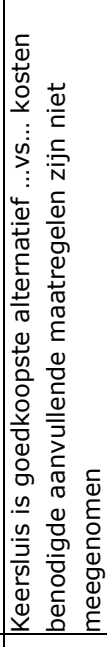 & 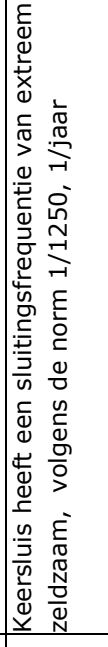 & 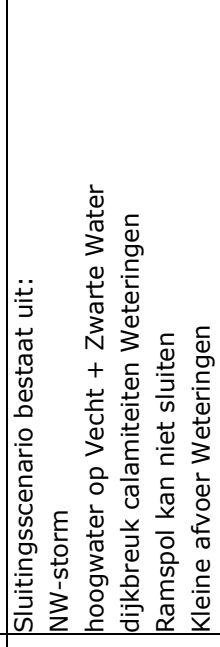 & & 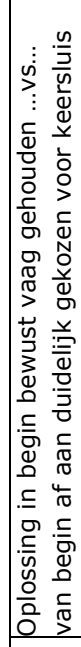 & 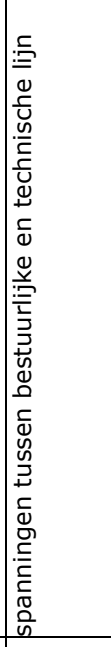 & 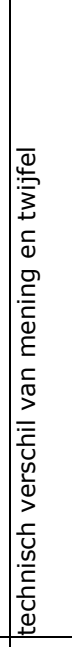 \\
\hline \multirow[t]{2}{*}{ 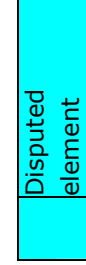 } & 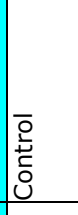 & 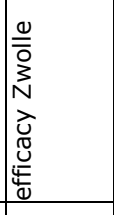 & 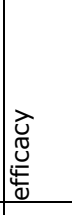 & 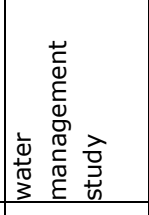 & 苍 & 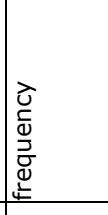 & 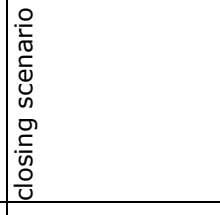 & \multirow{2}{*}{ 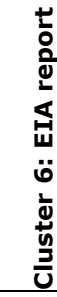 } & \multirow{2}{*}{ 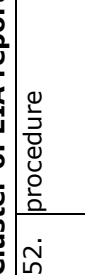 } & \begin{tabular}{|l}
0 \\
$\frac{0}{0}$ \\
$\frac{0}{3}$ \\
0 \\
0 \\
$\frac{1}{1}$ \\
\end{tabular} & 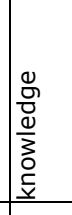 \\
\hline & ம் & 它 & $\dot{\gamma}$ & $\underset{\substack{\infty \\
+}}{ }$ & \& & io & in & & & & 苞 \\
\hline
\end{tabular}




\begin{tabular}{|c|c|c|c|c|c|c|c|c|}
\hline I & \begin{tabular}{l}
$\infty$ \\
\hdashline
\end{tabular} & & & & & & & 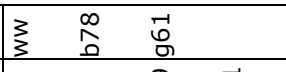 \\
\hline$\stackrel{m}{r}$ & & $3 \stackrel{0}{2}$ & ш & & 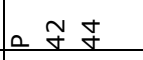 & $\ll \stackrel{-1}{\sigma}$ & & 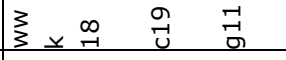 \\
\hline$\underset{\nearrow}{\mp}$ & & & س & & & & & \\
\hline$\exists$ & & & & & & & & \\
\hline 엄 & & $>\stackrel{\circ}{n}$ & & $\Sigma \stackrel{\sim}{\sim} \stackrel{\infty}{N}$ & & & & 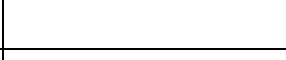 \\
\hline a & & & ш $\vec{\sigma}$ in $\infty$ & & & & & 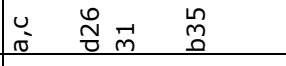 \\
\hline$\infty$ & ㅇำ $\stackrel{\sim}{\sim} \mathcal{7}$ & & & & & & & \\
\hline$\Lambda$ & & & & & & & & 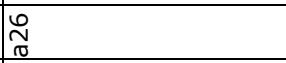 \\
\hline 6 & & & & $\underset{ت}{7}$ & ट्रे & & & 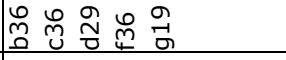 \\
\hline in & & $>$ & ш & & D & 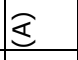 & & 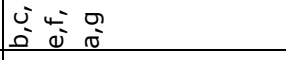 \\
\hline$\theta$ & & ш & & & $\supset$ & 1 & 1 & $\begin{array}{l}0 \\
0^{2} \\
0\end{array}$ \\
\hline$m$ & & & & & $a$ & $\ll$ & 0 & 芯 j。 \\
\hline$N$ & & & & & $\supset$ & & & \\
\hline 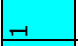 & & & & & & & & \\
\hline \begin{tabular}{|l}
0 \\
$\vdots$ \\
$u$ \\
\end{tabular} & & 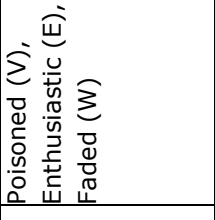 & 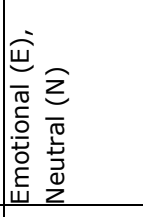 & 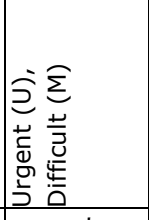 & 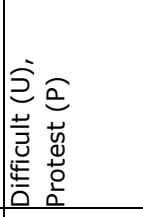 & 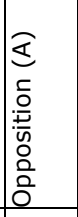 & 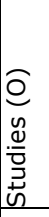 & \\
\hline 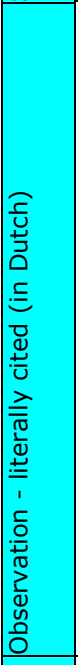 & & 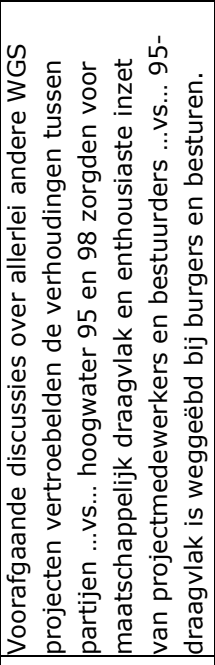 & 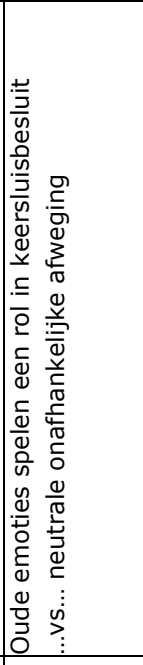 & 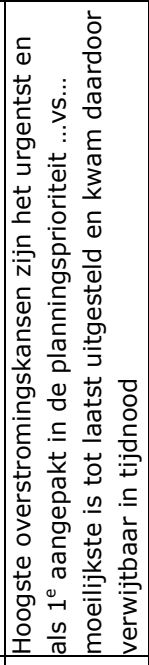 & 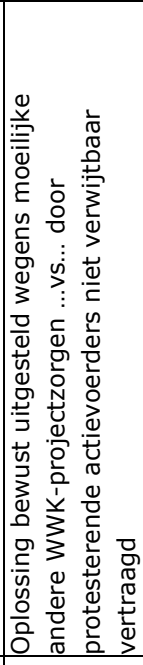 & 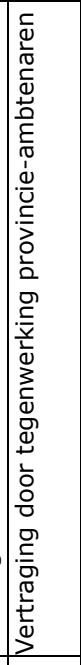 & 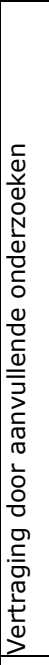 & 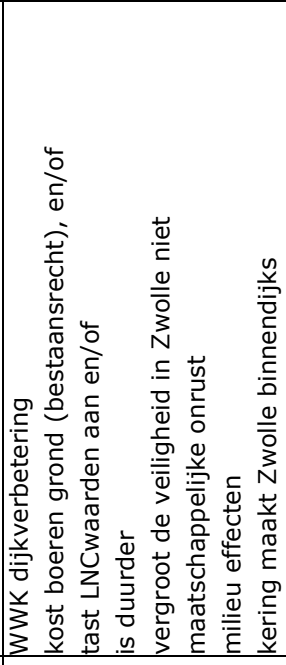 \\
\hline \multirow[t]{2}{*}{ 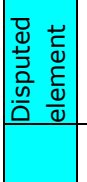 } & & 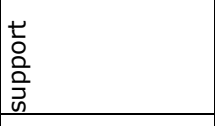 & 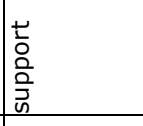 & $\frac{\pi}{0}$ & $\frac{\frac{\pi}{2}}{\frac{0}{0}}$ & $\frac{\frac{\pi}{2}}{\frac{\pi}{0}}$ & $\frac{\pi}{0}$ & 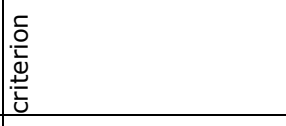 \\
\hline & & மn் & 它 & in & $\infty_{\substack{\infty \\
n}}$ & in & ठ் & 6 \\
\hline
\end{tabular}


144 CONTROVERSIES IN WATER MANAGEMENT: FRAMES AND MENTAL MODELS

\begin{tabular}{|c|c|c|c|c|c|c|c|}
\hline$\nexists$ & & & & 约 f $\stackrel{\infty}{+} \infty$ & & & 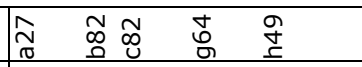 \\
\hline m & & & & & & & 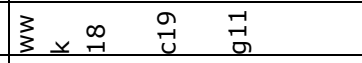 \\
\hline$\approx$ & & $\underset{⿱}{*}$ & & & & u & \\
\hline-1 & & & $\infty \underset{ت}{\Xi}$ & $\pi_{\pi}$ & & $\simeq ت$ & \\
\hline 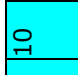 & & 육ㄱㄱ & & & & & 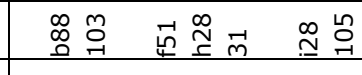 \\
\hline$a$ & & & & $\sum \dot{z}$ & & & \\
\hline D & & & & & $>\stackrel{m}{m}$ & & \\
\hline & \begin{tabular}{l}
$\infty$ \\
$\substack{\infty \\
\hdashline}$ \\
\end{tabular} & & & 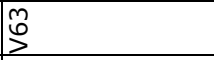 & & & \\
\hline 6 & $\begin{array}{l}0 \\
\sum_{z}^{\prime} \\
z\end{array}$ & & & & $0 \stackrel{0}{0}$ & $u$ & o \\
\hline$\underline{n}$ & & & & & $\varangle$ & $u$ & $i \quad j \quad 0$ \\
\hline+ & & & & & & نे & 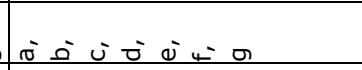 \\
\hline$m$ & & & & & & & \\
\hline & & & & & $\varangle$ & ـ & i $\quad$ c \\
\hline 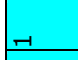 & & & & & & 0 & كَ \\
\hline 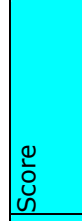 & 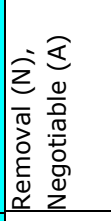 & 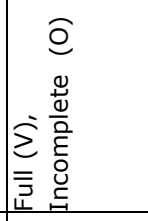 & 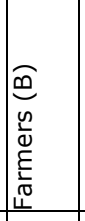 & 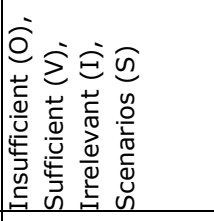 & 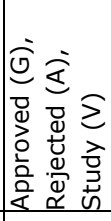 & & \\
\hline 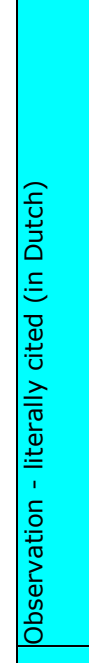 & 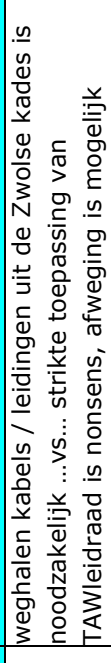 & 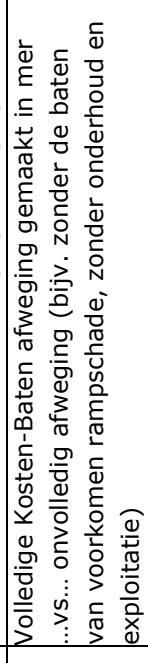 & 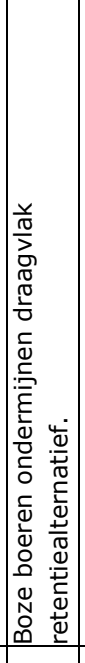 & 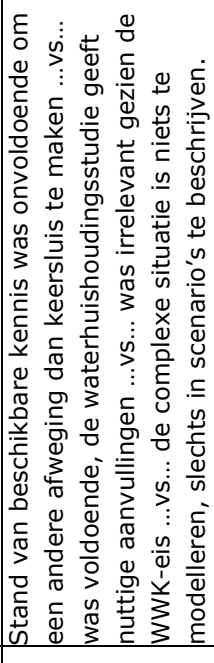 & 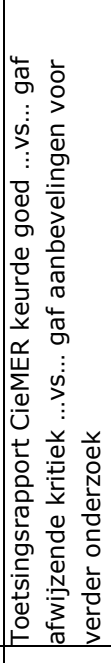 & 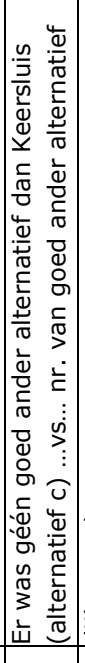 & 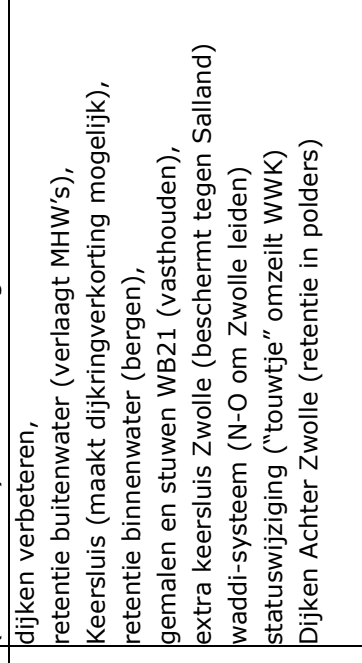 \\
\hline 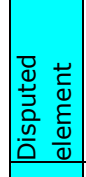 & & 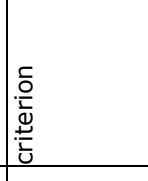 & 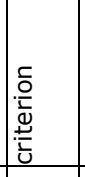 & $\mid \begin{array}{l}\frac{0}{8} \\
\frac{\sigma}{3} \\
\frac{0}{0}\end{array}$ & $\stackrel{\sqrt{\pi}}{2}$ & 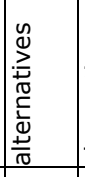 & 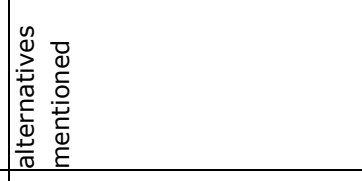 \\
\hline & $\begin{array}{l}2 \\
0 \\
0 \\
0\end{array}$ & חi & í & மூ & $\ddot{0}$ & $\dot{i}$ & 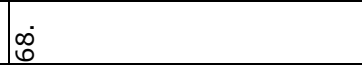 \\
\hline
\end{tabular}




\subsubsection{Analysis of controversies}

While all actors begin, in general, with the same understanding of the physical and legal systems, some crucial details differ between (groups of) actors. These details concern assumptions and uncertainties present in model calculations (e.g. MHW's, frequencies and inundation severity), and the reliability of historical data (e.g. on flooding).

Interpretations of data exhibit much more variation, e.g. on the following questions:

a) Does the WWK'96 inevitably prescribe a closed dike ring?

b) Can innovative concepts like a risk approach and norm differentiation be applied to dike ring 53 ?

c) How is the distribution of institutional responsibilities and accompanying expertise between Water Board, Province and Ministry to be interpreted?

d) Can the city centre of Zwolle be flooded by water from the river Vecht?

e) Is the city centre of Zwolle safe from flooding when the storm surge barrier is closed?

f) Would another decision outcome have been possible?

This section presents details on some of these important disputed elements in the case. It presents the opinions and interpretations of informants with regard to the administrative, legal and the physical systems that were described in section 4.2 and 4.3., and on alternative solutions. The analysis concentrates on elements that were regarded by the informants to be important for the development of the decision making process. These details were collected from the interview transcripts, and provide background information on some of the disputed elements identified in the data matrix.

\subsubsection{Administrative controversies}

Financial arguments for dike ring 53 (element no. 7)

Several informants (nos. 7, 9, 10) indicate that the inclusion of the Sallandse Weteringen in the definition of dike ring 53 can be considered rather peculiar from a technical perspective. They suggest financial motives to be the reason of the inclusion. Informant no. 9 states that both the former Water Board Salland and the Province of Overijssel have cooperated in obtaining as much financial support from the central government in Den Haag as possible, in order to minimise the cost to the local citizen. According to informant no. 9 all actors were, at that time, pleased with the inclusion of the Weteringen in the WWK96 [19:23]. The opinions of informant no. 7 confirm this statement. He added that the inclusion of the Weteringen in dike ring 53 was guided by whether or not a dike was included in the previous subsidy scheme from the national government [17:74]. Informant no. 10 mentions that in the 1968 reconstruction of the Salland water management system, the dikes along the Weteringen were given a height based on the influence of high water levels in Lake IJsselmeer. This informant also mentions that dike ring 53 has been fully based on information provided by the Province [I10: personal communications August 2004].

This historical information indicates that the inclusion of the river Vecht and the Weteringen in dike ring 53 does not mean that their presence on the map in appendix 1 
of the WWK96 denotes a high water safety problem of national importance. Local financial motives also played a role in designating them as primary water defences.

\section{Legal "buitenwater" and dike ring 53 (element no. 6)}

The city of Zwolle is located at the point on dike ring 53 where the Weteringen change name into the Zwarte Water. Several informants indicate that the function of the barrier is to protect the city of Zwolle and the lowlands of Salland against "buitenwater" in case the normal direction of discharge through the Weteringen should be reversed. Other informants indicate that the river Vecht is not a large river under the definition of the WWK96, nor do the Vecht or Zwarte Water represent "buitenwater", and therefore they consider the application of the WWK to the Weteringen and Zwolle to be inappropriate.

"Buitenwater" is a legal term from the WWK96 that denotes water outside a dike ring experiencing direct influence from storm and / or high water levels on the large rivers, Lake IJsselmeer, Lake Markermeer or the sea. The definition in the WWK96 (in article 1) does not mention explicitly the river Overijsselse Vecht or the Sallandse Weteringen. Before the construction of the Ramspol barrier, Vecht and Weteringen were under direct influence of the waters indicated in the WWK96. According to Van der Schier (2002:34) the influence of Lake IJsselmeer on the Zwarte Water extends to the point where the Vecht enters the Zwarte Water. The author demonstrates his claim with research that was performed in the preparation phase of the Ramspol Barrier (Ramspol 1995). For this reason, he argues that the water further upstream of this point (i.e. the Vecht, Zwarte Water and Sallandse Weteringen) do not meet the criteria of "buitenwater" according to the WWK96. Therefore the dikes along the Vecht and Weteringen, including the quays in the Zwolle city centre, should not be designated the status of primary dikes. In his opinion opponents of Van der Schrier's counteract his claim, by including the river Vecht as large river in the WWK96. He criticizes this change in law because it has not been approved by parliament (Van der Schrier 2003b). Informant no. 9, too, who is concerned with the perspective of water management law, questions the designation of the river Vecht as "buitenwater" [19:22], stating that the Ramspol barrier can be closed and therefore direct influence from Lake IJsselmeer or the river IJssel is not possible any more.

The opinions of informants thus reveal a dispute about the desirable legal status of the dikes along the Sallandse Weteringen and the Zwolle city canal quays. In the event of a primary status, the dikes and quays have to comply with the WWK96 requirements. In the event of a secondary status, they are the full responsibility of the Water Board, that can define its own levels of safety for these dikes. These levels will in general be much lower that the WWK96 levels for primary waters (Commissie-Integraal-Waterbeheer $2004: 10$ ). From a technical perspective, the designation of a secondary status appears to be obvious. From an administrative perspective, the map in appendix 1 of the WWK96 appears to be directive. The fact that no MHW's have been legally established for the Weteringen and part of the Vecht complicate the dispute surrounding this element.

Norm differentiation of dike ring $\mathbf{5 3}$ (element no. 5)

Alternative nos. 20 and 24 in table 4.4 (section 4.6.1) suggest a continuation of the existing situation (without a barrier or major dike improvement), and propose a change 
of legal status into secondary dikes, or at least a differentiation of norms under the existing primary status. The Water Board's reaction to this proposal can be found in the document "Reactienota op de zienswijzen" (Provincie Overijssel 1998a). From a broader functional perspective, the Water Board considered that a barrier to close the Weteringen downstream the Zwolle city centre was not necessarily obligatory, on condition that a safety norm differentiation would be applied to the lower part of Salland. The National authority RWS, however, in a letter responding to a request of the Water Board, indicated that it must be possible to close a dike ring, accordance with the dike ring principle. The Water Board prefers this latter interpretation, because it would create a clear distinction between primary and secondary dikes, and thus prevent vagueness in management and maintenance duties. Informant no.10 concludes from this reaction that the Water Board considers itself not competent to change status or differentiate norms of primary dikes, and that the main reason behind this opinion is that inundation, which could occur at lower safety norms, does not match with the WWK96 [110:106]. In the existing situation, however, differentiation of norms has been actually applied in that the proposed MHW's for the Sallandse Weteringen are based on a 1/100 per year high water situation (see section 4.2.2).

Informants nos. 10 [I10:11] and 14 raise another issue with regard to the WWK safety norms. The current principle of one single safety norm for a dike ring result in peculiar situations with different safety norms for dike rings on opposite sides of the same water body. In case of dike ring nos. 9 and 10 bordering the Zwarte Water, for example, dike ring no. 10 has a safety level of $1 / 2000$ per year, whereas dike ring no. 9 has a safety level of 1/1250. Because of the higher dikes of dike ring no. 10 the Zwarte Water will never present a safety threat to it - at extreme water levels dike ring no. 9 would overflow first. Therefore, at the Zwarte Water section of dike ring no. 10 a safety level of, say, $1 / 1300$ would suffice in practice. At the same time the existing situation raises the question of why the region within dike ring no. 10 should be protected more than the region within dike ring no. 9. To solve this problem, informant no. 14 suggests a different safety approach, which starts from the water body instead of the dike ring.

With regard to the interpretation of the dike ring principle in the WWK96, informant no. 11 mentions that the letter of the national authority RWS, indicating that a dike ring must be closed, can be seen as a formal indication from the minister to the Water Board, offering no room for interpretation at lower administrative levels [I11:73].

Although the risk approach to flood management, announced in the WWK96 (article 3.2), would allow differentiation of safety norms, we conclude that in the current case this approach has not been applied.

Zwolle city embankments (element no. 62)

The primary status of the Zwolle city canal embankments formally restricts the use of the embankment for trees, cables, piping and other foreign objects which might potentially reduce the strength of the dike. According to some (e.g. informant no. 6) the existing use of the embankments would have caused serious problems when upgrading the embankments to meet the primary requirements. The barrier would solve this problem. According to others (e.g. informant no. 7) the city embankments are more than adequate 
and up to their task, despite the presence of foreign objects, and an exception to the guidelines would have been easily negotiated.

\subsubsection{Controversies in the distribution of legal responsibilities (element no. 13 through 24)}

Disputed elements nos. 13 trough 24 concern the interpretation of the legal responsibilities and competences, and the distribution thereof between Province and Water Board.

According to informant no. 12 [I12:52] the EIA procedure provides the Province with adequate means to fulfil its legal tasks, and burdening the Water Board with additional research and other demands was unnecessary. In contrast, informant no. 1 states that the Water Board's General Council and the Provincial Executive Council have an obligation to represent the "vox populi", but ultimately failed to do so in this case. The Provincial Executive Council, for example, could have rejected the EIA and taken responsibility for the delay caused by additional research. This latter option is also mentioned by informant no. 9 [19:44]. A Water Board can take the initiative to devise an own, situation specific interpretation of the WWK and accompanying guidelines. This interpretation can be discussed with the National Authorities, and can be approved. This has been, in fact, successfully done by the Water Board WGS on the occasion of other preceding DAR projects (DAR $3+6$ and DAR 5, see section 6.1.3.1 for details).

Informant no. 1 [19:44] emphasizes the coordinating role which is designed to the Province in the WWK96. It presents the Province with the task, instruments and power to establish coordination between all applicable legal procedures and stimulate consultation between actors involved. The power includes the right to impose such a consultation in case other regulatory bodies fails to do so. The duty of the Water Board is to draft a dike improvement plan and submit it to the Province for approval, while considering of all interests present. According to informant no. 1 the Province has the additional task of deliberating the same interests within the broader context of the Provincial administrative framework. He regards competition between the Water Board and the Province on administrative responsibilities to be rather sensitive. This was also visible in earlier projects [11:17]. The task of the Province includes, according to informant no. 1 , an assessment to ensure the adequate representation of all interests, but also the assessment of the technical argumentation for the Water Board's dike improvement plans $[11: 17]$. He states that an intervention of the Province, even in the early phase of a Water Board project, is explicitly permitted.

The Province's concern with the interpretation of legal competences is not shared by informant no. 13. He considers the WWK96 to be quite clear, and reproached the Province for wanting an explicit interpretation of every phrase, in an attempt to strengthen their administrative position. The recent administrative changes (beginning in 1992) have created large and strong Water Boards, which, by the time of the DAR projects (around the year 1998), should have been given their due responsibilities by the Province [113:53]. His diagnosis of the friction between Water Board and Province is a historical one, in which the Province is reluctant to release the old structure of 
responsibilities. He claims that under the new structure it would be sufficient for the Province to approve the Water Board plans after they are finalised [113:62]. Informant no. 1 stresses that the relationship between Province and Water Board should be based on equivalence, and that this does not imply having the same knowledge at both institutions. He pleads for a complementary approach, in which both partners trust the ability of the other to fulfil their responsibilities [I1:35].

In conclusion, the chain of legal responsibilities for dikes and barriers runs from the Water Board, through the Province, to the national Government. The distribution of responsibilities and division of labour involved is been, according to informants, a matter of dispute throughout all DAR projects and culminated in the days of DAR1+2. The information and opinions regarding this issue given by the informants appears to be controversial. Especially in the case of the barrier, this is considered unfinished business for the Province. Section 5.5 will examine this issue in more detail.

\subsubsection{Technical disputes}

Barrier effectiveness (element nos. 46, 47, 50)

The main conflict concerns the effectiveness of the Zwolle barrier. According to several sources, (EIA-report 2001:82; Van der Schrier 2002) and informants nos. 2, 7, 10, 11 the barrier will, upon closure, quickly result in flooding because of the lack of discharge storage capacity in the Weteringen and Zwolle city canals, and because no collateral measures like detention basins or a pumping facility exist. Therefore the need for a storm surge barrier at the intended location can not be argued from the physical / technical point of view. According to others informants (no. 13) this situation is only temporary, because the long term water management reconstruction plans will provide measures that will reduce the Weteringen discharge to almost zero, by stopping upstream drainage pumps and raising upstream weirs from the central barrier control unit. Moreover, in the event this situation should occur, despite the prevailing predictions, the barrier can be quickly lowered within 20 minutes to release the blocked discharge.

Barrier closure (element nos. 29, 31)

The barrier should be closed at the moment of flow reversal. According to the EIA-report (2001:31) and informants nos. 4, 6, 13 this will provide adequate safety. Others $(2,7$, $10,11,14$ ) claim that flow reversal is unlikely to occur. Observations made during the recent high water situation in February 2004, where high discharge coincided with a storm surge (local wind force 6), showed, according to informant no. 2, that under these conditions the Weteringen still vigorously discharge towards the Zwarte Water. For them this would indicate that indeed flow reversal is unlikely. Annex II of the EIA-report (2001:11) states that the likelihood of closure of the barrier is less that $1 / 100$ per year. The website of the Groot Salland Water Board (http://www.wgs.nl/, accessed on 17 November 2004) and informant no. 3 mention an expected closure frequency of once a year.

Dike failures in Salland (element nos. 29 through 33)

The short term justification of the Zwolle barrier is, according to some informants (e.g. nos. 6 and 13), the protection of the lower parts of Salland against inundation with legal 
"buitenwater" from the river Vecht, in case the dikes along the Weteringen will fail at several locations at the same time, a position also taken by the authors of the EIA-report (2001:77). Informants nos. 10 and 11, and Van der Schrier (2002) claim that such a worst case scenario is highly improbable. Furthermore, these opponents claim that a dike failure at one or two places along the Weteringen will not be sufficient to cause backflow of Vecht water into the Weteringen.

Risk (element nos. 41, 42, 51)

According to informants nos. 1, 2, 3, 7, 10 and 11, the risk of the worst-case flooding scenario for the city of Zwolle without a barrier is extremely rare (e.g. less than $1 / 10000)$. They therefore consider this an acceptable risk. According to informants nos. 3,12 and 13, however, the risk is much higher and the Zwolle barrier will close at a frequency of possibly once a year or once every 10 years.

MHW (element no. 26)

The Design Flood Level (MHW) has, according to informant no. 11, been calculated using models that were not suitable for this task, and informants nos. 7, 10 and 14 claim that the MHW values are debatable. According to others (e.g. informant no. 13) the worst case boundary conditions used in their calculation are uncertain and therefore a cautious safety approach is preferred.

Discharge capacity in case of extreme precipitation events (from documents) Related to the MHW issue is the confusion that exists among stakeholders about the discharge capacity of the Weteringen, as became apparent from the case documents. Maximum discharges of $43 \mathrm{m3} / \mathrm{s}$ (measured), $68 \mathrm{m3} / \mathrm{s}$ (calculated maximum channel capacity) and $100 \mathrm{~m} 3 / \mathrm{s}$ (probable discharge based on an extreme precipitation event) are mentioned, based on the various numbers circulating. In case of an extreme precipitation event the lower parts of Salland may potentially regain their former natural inundation function, due to the physical limitation of the discharge system. The long term water management reconstruction programme in Salland in the context of WB21 addresses this issue outside the limits of the current case. That program includes the development of a model to simulate discharges and storm surges.

Flow reversal (element nos. 29, 30, 31)

The worst case high water scenario for the City of Zwolle raises the issue of the exact timing of the high water discharge peak in the river Vecht and the Weteringen canals. According to informant no. 10 available data and earlier research performed by RWS in 1992 (see Van der Schrier 2003) shows that these peaks will arrive at the Vecht Zwarte Water confluence (no. 3 on the insert in figure 4-1) at the same time. Some claim, however, that the possibility exists that the Weteringen peak occurs early (Annex IV of the EIA-report 2001:2), and therefore the Vecht peak may theoretically threaten the city of Zwolle by flowing back into the city because of a low Weteringen level. As the Vecht is legally designated "buitenwater" by the WWK96 (a designation which is contested by informant no. 10), this backflow would be an argument to resist claims, by, for example Van der Schrier (2003), that the Weteringen never can be reached by "buitenwater" after the construction of the Ramspol barrier and therefore should be removed from the WWK96. 
The proposed reconstruction of Salland under the WB21 programme intends to retain excess precipitation water in the local area for a longer period. These measures would delay discharge peak that is currently considered to be early compared to the discharge peak on the river Vecht (Annex II of the EIA-report 2001:12).

\subsubsection{Disputes on alternative solutions (element no. 68)}

Alternative solutions mentioned in by stakeholders in the interviews are (the numbers in parenthesis refer to the alternative numbers in table 4.3):

a. (1) Full scale dike improvement (in accordance with WWK'96 and TAW),

b. (13) Routing of "external backflow water" into designated inundation polders (to lower the MHW's, somewhat like the historical situation but in extreme situations only),

c. $(14,15,23)$ Storm surge barrier (resulting in a lower protection level of the upstream dikes),

d. $(7,8,12)$ Detention of local runoff discharge water in existing polders (local detention in lower areas),

e. $(6,8)$ Stopping runoff pumps and raising upstream weirs (local retention, also in higher areas),

f. (14) 2 nd barrier upstream of Zwolle (protection against high discharge),

g. (23) Wadi-system N-O around Zwolle,

h. (24) Change of legal status (a mere lowering of the protection level),

i. (25) New dikes on the upstream boundary of Zwolle (restoration of the natural polder system function).

Alternatives a through $\mathrm{f}$ were mentioned in the documents discussed in section 4.5.1. Alternatives $\mathrm{g}, \mathrm{h}$ and $\mathrm{i}$, however, have not yet been documented and will be described below.

Chronologically, these alternatives were introduced in the discussion in the following order, according to informants: dike improvement $(a)$, inundation of polders $(b+d)$, barrier (c) and status change (h). The other alternatives could not be located exactly in this time sequence, but the stopping of pumps (e) was suggested to occur in response to criticism of the barrier, and subsequently the $2^{\text {nd }}$ barrier appeared in the barrier discussions ( $f$ ). The wadi system ( $g$ ) and new dikes ( $\mathrm{i}$ ) appear to be ideas that have not been taken into account seriously, although they represent solutions to the problem.

Originally alternative c) was defined in accordance with conform with alternative no. 5 from the EIA-report (see table 4.4 in section 4.6.1). But, according to some informants, because of the social disturbance to local residents and expected costs of construction of inundation areas the inundation part has been dropped from this alternative to create alternative $\mathrm{c}$ ). The problem of storing the retained discharge would, according to this new definition, be resolved by the closure of the barrier at a lower level, at the immediate instance of flow reversal (which assumes that such a reversal will take place at water levels considerably lower than MHW). 
According to informant no. 4 [14:99], by the time the end of the decision process was reached, the newly developed WB21 water management policy would have permitted a postponement of the barrier decision. This corresponds to alternative no. 19 identified in section 4.6.1 table 4.4.

\subsubsection{Conclusions}

As predicted (in section 2.7), the controversies among stakeholders mainly concern disputes between the administrative and the technical perspectives. Added to this are disputes on the distribution of responsibilities among various institutes, involving persons of both perspectives. These disputes have historical roots, which is illustrated, for example, by informant no. 9 [19:25]. This informant recalls from the period that he was working with the former Water Board Salland that the Water Board already struggled in the eighties with technical problems of the Sallandse Weteringen. The WWK96, according to him, just made the problem more acute. One informant mentioned that the friction between Water Board and Province has been present as long ago as the Ramspol barrier project (which started about 1988). The next section concentrates on an explanation of the disputes using the notion of frame.

\subsection{Frame perspectives}

Following the procedure described in figure 3-9 of section 3.6, this section continues with the analysis of actors' frame perspectives. The aim is to analyse the relationship between the scores on disputed elements and the frame positions, with the purpose of explaining the scores. To achieve this we first have to determine the perspective types of the individual informants. We will do that on a high level of abstraction.

An informant's frame perspective is determined using the description of the TOPEA characteristics in section 3.2.4. The determination is based on the opinions and behaviour of the informant. The researcher selects the most appropriate perspective type(s) for each informant. As suggested in section 3.2.4, more than one single perspective type appears to fit an informant, and informants changed their perspective types over time. The results are presented in table 5.2.

- In the early phase of involvement of an informant, he appears to act in accordance with his profession. The function within the organisation and specific role in the case project appear to determine the perspective type. This type was predominantly one of the subset TOP. When we combine the O+P types (see section 3.2.4) into the term Administrative perspective type $(O+P)$, the other initial perspective type is the Technical $(T)$. The two consultants form an exception in that they take an Ethical perspective (E) which can be explained from their specific tasks. The consultants appear to balance between professional integrity, criticism on the other two main perspective types, and the various interests of actors (including LNC-values). Very illustrativly, the project manager, informant no. 4, described his role as "religion management" [14:80].

- $\quad$ From the interview it appears that after the initial phase of providing argumentation - both pro and con- for the diverse alternatives in order to 
determine their feasibility, a second phase could be identified in which a different perspective type dominates. This second phase appears to involve, for some informants, personal integrity (an Ethical perspective type) which threatens to be jeopardized in the course of the decision making process. For other informants their position in the political playing field becomes threatened which causes a Political $(P)$ perspective type to dominate. For some informants the dominance of the Ethical and Political perspective types becomes quite explicit, and motivates them to vigorously oppose the opinions and actions of opponents.

- $\quad$ Ultimately the behaviour of some informants with regard to the disputes appears to be restricted by personal interests (a Political perspective type) in relation to institutional structures of power, or a resignation to established social and political structures. This is indicated in table 5.2 as the third perspective type. This third type is not included in the extended data matrix (table 5.3), because it does not, according to our observation, influence the disputes. After the final decision was made the third type describes the motivation of an informant to give up his resistance.

- For most informants Aesthetic matters also exerts influence on their behaviour, in that they consider large scale dike improvements to be in disharmony with the local landscape (LNC-values). According to our observation this perspective type is present in the background during the entire decision making process and has no effect other than everyone's rejection of the full scale dike improvement alternative. We therefore do not include it in table 5.3.

The initial perspective type, ruling the behaviour and perspectives of informants, appears to be based on their function in their organizations, viz. their institutional responsibilities. The subsequent perspective type appears to indicate the manner in which informants deal with their responsibilities viz. initial perspective type. This second perspective type seems to be responsible for the greater part of the delays in the decision making process, because it explains the stubbornness with which informants defended their positions. The moment at which a change of perspective type occurred differed for each informant and appeared to be related to the moment the informant became frustrated by practicing his initial perspective type.

Literature identified in section 1.3.3 (Schön\&Rein 1994; Fischer 2001) indicates that frames are grounded in the institutions that sponsor them. We therefore will analyse the interviews for characteristics that could support this claim. We look at organisation, function, specific role of the informant in the case, education and employment history. The informant's functions within organisations can be described, based on the interviews, as follows:

Administrator: concerned with the social and political network within and outside the institution, with interests and image, with legal responsibilities, and project progress (which will be forced if necessary). Their statements appear to be beyond dispute (e.g. informant no. 13).

- Manager: concerned with the people that have to do the job, with technical feasibility and social / political support. Sometimes also concerned with integrity (e.g. informant no. 4). 
- Public administration staff (civil servants): concerned with the correct implementation of the procedures, with distribution of legal tasks and responsibilities (e.g. informant no. 1).

- Technical staff (civil servants), which can be divided in two types: (i) dike builders concerned with the traditional approach of building large and solid dikes that comply to the TAW guidelines (see, for example, the discussion about the dike improvement along the river Vecht). (ii) water managers concerned with the hydrology of the region and the other function of the dike. They will question benefit and necessity of traditional dike improvement plans (e.g. informants nos. 2, 10, and 14).

- Experts: will discuss the validity of their knowledge, think about probabilities and uncertainties, and are careful in their assertions (e.g. informant no. 11).

The overview in table $\mathbf{5 . 2}$ presents the findings of this analysis. A more rigorous analysis of the relationship between frame perspective types and personal and institutional characteristics lies outside the scope of the present research.

The relationship between scores on selected disputed elements and frame perspective types is presented in table 5.3. For each informant the primary and secondary perspective type are entered in two lines at the top of the data matrix. This relationship is not clear for all scores. Details of the institutional and personal context are sometimes needed to explain the score. The separate scores on disputed elements constitute the argumentation for the ultimate position taken by an informant with regard to the barrier alternative. This position is indicated in the bottom line of table 5.3. One informant changed his position during the decision making procedure. Two others mentioned in the interview that they have changed position since its completion.

Table 5.3 results from the application of the method of analysis (see section 3.6 ) to the case. This method, however, does not explain the decision finally taken. In the process of building the framework, we came across several possibilities for the way the final decision was reached. In the next section we will analyse the informant's transcripts with reference to opinions and interpretations with respect to the construction of the final decision. 
Table 5.2: Frame perspective types of informants, in relationship to organisation, function, and specific role of the informant in the case, education and employment history. Previous involvement indicates in what ways an informant has previously gained knowledge of the water system and the actor network. Most informants have a civil engineering education $(2,4,5,7,10,11,12)$ or engineering education $(3,6,14)$. A non-technical education is present only with informants no. 1 (public policy), 9 (law) and 13 (economy, social science, philosophy).

\begin{tabular}{|c|c|c|c|c|c|c|c|}
\hline \multirow[t]{2}{*}{$\mathrm{Nr}$} & \multirow[t]{2}{*}{$\begin{array}{l}\text { Organisational } \\
\text { affiliation }\end{array}$} & \multirow[t]{2}{*}{$\begin{array}{l}\text { Institutional role in the } \\
\text { case }\end{array}$} & \multirow{2}{*}{$\begin{array}{l}\text { Specific } \\
\text { personal role in } \\
\text { the DAR } 1+2 \\
\text { case }\end{array}$} & \multirow[t]{2}{*}{$\begin{array}{l}\text { Previous } \\
\text { involvement }\end{array}$} & \multicolumn{3}{|c|}{$\begin{array}{l}\text { Perspective } \\
\text { development }\end{array}$} \\
\hline & & & & & $1^{\text {st }}$ & $2^{\text {nd }}$ & $3^{\text {rd }}$ \\
\hline 1 & $\begin{array}{l}\text { Province of } \\
\text { Overijssel } \\
\text { (since 1991) }\end{array}$ & $\begin{array}{l}\text { Supervisor: approve or } \\
\text { reject the EIA report. } \\
\text { Coordination of } \\
\text { concurrent administrative } \\
\text { procedures. } \\
\text { Participation in EIA } \\
\text { project team. }\end{array}$ & $\begin{array}{l}\text { Project team } \\
\text { member, } \\
\text { administrative } \\
\text { matters }\end{array}$ & $\begin{array}{l}\text { Water Boards } \\
\text { reorganisation, } \\
\text { All DAR projects }\end{array}$ & 0 & $E$ & \\
\hline 2 & $\begin{array}{l}\text { Province of } \\
\text { Overijssel }\end{array}$ & $\begin{array}{l}\text { Supervisor: approve or } \\
\text { reject the EIA report. } \\
\text { Coordination of } \\
\text { concurrent administrative } \\
\text { procedures. } \\
\text { Participation in EIA } \\
\text { project team. }\end{array}$ & $\begin{array}{l}\text { Project team } \\
\text { member, } \\
\text { technical } \\
\text { matters }\end{array}$ & $\begin{array}{l}\text { Water Boards } \\
\text { technical liaison, } \\
\text { All DAR projects }\end{array}$ & $\mathrm{T}$ & $E$ & $P$ \\
\hline 3 & $\begin{array}{l}\text { Water Board } \\
\text { Groot Salland } \\
\text { (since 1994) }\end{array}$ & $\begin{array}{l}\text { Manager of the water } \\
\text { system, initiator of plans. }\end{array}$ & $\begin{array}{l}\text { DAR } 1+2 \text { project } \\
\text { since } 2000\end{array}$ & None & $\begin{array}{l}\mathrm{T}+ \\
\mathrm{O}\end{array}$ & & \\
\hline 4 & $\begin{array}{l}\text { Grontmij } \\
\text { consulting } \\
\text { engineer firm } \\
\text { (since 1997) }\end{array}$ & $\begin{array}{l}\text { Project leader and author } \\
\text { of the EIA reports for the } \\
\text { Water Board }\end{array}$ & $\begin{array}{l}\text { Process } \\
\text { manager, } \\
\text { project team } \\
\text { member }\end{array}$ & $\begin{array}{l}\text { Leader of all the } \\
\text { DAR projects }\end{array}$ & $E$ & 0 & \\
\hline 5 & $\begin{array}{l}\text { Ministry V\&W - } \\
\text { RWS }\end{array}$ & $\begin{array}{l}\text { Legislation and issuing of } \\
\text { regulations. } \\
\text { Super-supervisor: } \\
\text { financial support and } \\
\text { progress control. }\end{array}$ & $\begin{array}{l}\text { Explaining State } \\
\text { policy to } \\
\text { Provincie and } \\
\text { Water Board }\end{array}$ & $\begin{array}{l}\text { "Deltaplan Grote } \\
\text { Rivieren", } \\
\text { All DAR projects }\end{array}$ & 0 & $P$ & \\
\hline 6 & $\begin{array}{l}\text { Water Board } \\
\text { Groot Salland } \\
(1995-2001)\end{array}$ & $\begin{array}{l}\text { Manager of the water } \\
\text { system. } \\
\text { Initiator of plans. }\end{array}$ & $\begin{array}{l}\text { Project team } \\
\text { member }\end{array}$ & $\begin{array}{l}\text { Dike improvement } \\
\text { projects (IJssel, } \\
\text { Kampen, } \\
\text { Ramspol), } \\
\text { All DAR projects }\end{array}$ & $\mathrm{T}$ & 0 & \\
\hline 7 & $\begin{array}{l}\text { Member of the } \\
\text { CieMER on } \\
\text { personal title } \\
\text { (RWS Zuid } \\
\text { Holland) }\end{array}$ & $\begin{array}{l}\text { Advice to the Province on } \\
\text { the legal acceptability of } \\
\text { an EIA }\end{array}$ & $\begin{array}{l}\text { Assessing the } \\
\text { DAR } 1+2 \text { EIA } \\
\text { report, writing } \\
\text { the advise }\end{array}$ & $\begin{array}{l}\text { "Deltaplan Grote } \\
\text { Rivieren", } \\
\text { State financial } \\
\text { support for dike } \\
\text { improvement to } \\
\text { Provnice } \\
\text { Overijssel }\end{array}$ & $T$ & $E$ & 0 \\
\hline
\end{tabular}




\section{CONTROVERSIES IN WATER MANAGEMENT: FRAMES AND MENTAL MODELS}

\begin{tabular}{|c|c|c|c|c|c|c|}
\hline 8 & $\begin{array}{l}\text { Province of } \\
\text { Overijssel } \\
\text { Executive } \\
\text { Council (up to } \\
\text { 2002) }\end{array}$ & $\begin{array}{l}\text { Supervisor: approve or } \\
\text { reject the EIA report. }\end{array}$ & $\begin{array}{l}\text { Portfolio Water } \\
\text { management } \\
1999-2002 \\
2^{\text {nd }} \text { authority } \\
\text { responsible }\end{array}$ & $\begin{array}{l}\text { Member of } \\
\text { Executive Council } \\
\text { since } 1991 \\
\text { (Portfolio } \\
\text { Environment, } \\
\text { agriculture, nature } \\
\text { en landscape) }\end{array}$ & $P$ & $P$ \\
\hline 9 & $\begin{array}{l}\text { University of } \\
\text { Utrecht, } \\
\text { Water Board } \\
\text { Hunze en Aa's }\end{array}$ & $\begin{array}{l}\text { Expert on water law } \\
\text { policy }\end{array}$ & $\begin{array}{l}\text { Second opinion } \\
\text { on MER }\end{array}$ & $\begin{array}{l}\text { Secretary-director } \\
\text { of the former } \\
\text { Water Board } \\
\text { Salland (1983 - } \\
\text { 1991) }\end{array}$ & $\mathrm{O}$ & $P$ \\
\hline 10 & $\begin{array}{l}\text { Citizen, retired } \\
\text { (up to } 1990 \\
\text { director water } \\
\text { management } \\
\text { department } \\
\text { Province } \\
\text { Overijssel) }\end{array}$ & $\begin{array}{l}\text { Provides opinions to the } \\
\text { Water Board (apart from } \\
\text { participation in the } \\
\text { advisory group). } \\
\text { Protests and objections to } \\
\text { Province. } \\
\text { Appeal to court. }\end{array}$ & $\begin{array}{l}\text { Member of both } \\
\text { the Local and } \\
\text { Regional } \\
\text { Advisory Group. }\end{array}$ & $\begin{array}{l}\text { Dike improvement } \\
\text { and water } \\
\text { management in } \\
\text { Overijssel since } \\
1963, \\
\text { Ramspol planning } \\
\text { phase, } \\
\text { All DAR projects }\end{array}$ & $\mathrm{T}$ & $E$ \\
\hline 11 & $\begin{array}{l}\text { HKV lijn in } \\
\text { water } \\
\text { consulting } \\
\text { company }\end{array}$ & $\begin{array}{l}\text { Expert on high water } \\
\text { statistics and flooding } \\
\text { damage }\end{array}$ & $\begin{array}{l}\text { Second opinion } \\
\text { on MER }\end{array}$ & Ramspol & $\mathrm{T}$ & $\mathrm{O}$ \\
\hline 12 & $\begin{array}{l}\text { Ministry V\&W - } \\
\text { RWS }\end{array}$ & $\begin{array}{l}\text { Legislation and issuing of } \\
\text { regulations. } \\
\text { Super-supervisor: } \\
\text { financial support and } \\
\text { progress control. }\end{array}$ & $\begin{array}{l}3^{\text {nd }} \text { authority } \\
\text { responsible }\end{array}$ & $\begin{array}{l}\text { "Deltaplan Grote } \\
\text { Rivieren", } \\
\text { All DAR projects }\end{array}$ & 0 & $P$ \\
\hline 13 & $\begin{array}{l}\text { Water Board } \\
\text { Groot Salland }\end{array}$ & $\begin{array}{l}\text { Manager of the water } \\
\text { system, initiator of plans. }\end{array}$ & $\begin{array}{l}1^{\text {st }} \text { authority } \\
\text { responsible }\end{array}$ & $\begin{array}{l}\text { "Deltaplan Grote } \\
\text { Rivieren", } \\
\text { All DAR projects }\end{array}$ & 0 & $P$ \\
\hline 14 & $\begin{array}{l}\text { Grontmij } \\
\text { consulting } \\
\text { engineer firm } \\
\text { (since 1997) }\end{array}$ & $\begin{array}{l}\text { Project leader and author } \\
\text { of the EIA report for the } \\
\text { Water Board, Proces } \\
\text { manager }\end{array}$ & $\begin{array}{l}\text { Writing the EIA } \\
\text { report on } \\
\text { DAR } 1+2\end{array}$ & $\begin{array}{l}\text { Project leader and } \\
\text { writing the EIA } \\
\text { report on DAR6 }\end{array}$ & $E$ & $\mathrm{~T}$ \\
\hline
\end{tabular}




\begin{tabular}{|c|c|c|c|c|c|c|c|c|c|}
\hline$\vec{I}$ & ш & $\vdash$ & (E) & & & $n$ & $>$ & D & نa \\
\hline$\stackrel{m}{-}$ & 0 & a & 0 & $\propto$ & ن & & $\stackrel{n}{2}$ ○* & $\sigma$ & $a$ \\
\hline$\underset{\sim}{\approx}$ & 0 & a & ט & & ш & & $\stackrel{n}{-}$ & & a \\
\hline$ت$ & $\vdash$ & $\circ$ & نे & $\Sigma$ & & $\stackrel{*}{*_{1}}$ & $>$ & ס & un \\
\hline 윽 & $\vdash$ & ш & & & & $n$ & $>$ & ס & $u$ \\
\hline$a$ & 0 & $a$ & & $\simeq$ & $\smile 0 \frown$ & $z$ & & & a \\
\hline$\infty$ & $a$ & a & ט & $\propto *$ & ш & & & & 20 \\
\hline$\wedge$ & $\vdash$ & ш & 0 & & & $n$ & $>$ & ס & $u$ \\
\hline 0 & $\vdash$ & 0 & $\cup$ & $\propto$ & ш & $z$ & 1 & $\sigma$ & $a$ \\
\hline in & 0 & a & 0 & $\Sigma$ & , & $n$ & , & . & $z$ \\
\hline$\theta$ & ш & 0 & $\cup$ & $\smile \Sigma \frown$ & , & . & , & 巴0 & $\varangle$ \\
\hline$m$ & $\vdash$ & $\mathrm{I}$ & 0 & $\simeq$ & 0 & & & $u$ & $a$ \\
\hline$N$ & $\vdash$ & ш & 0 & $\Sigma$ & & $n$ & $>$ & ס & $u$ \\
\hline$\rightarrow$ & 0 & ш & 0 & $\propto$ & ш & & & & $a$ \\
\hline 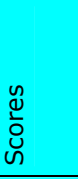 & 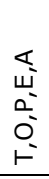 & 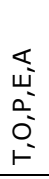 & 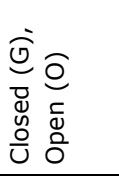 & 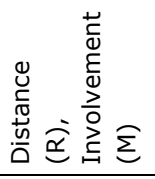 & 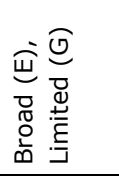 & 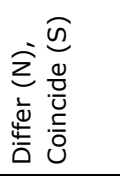 & 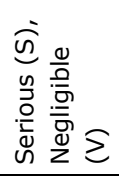 & $\begin{array}{l}0 \\
0 \\
0 \\
0\end{array}$ & $\begin{array}{l}n \\
z \\
i \\
u \\
0 \\
0\end{array}$ \\
\hline 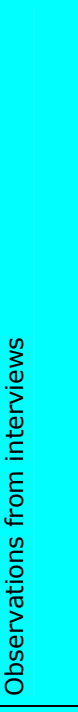 & 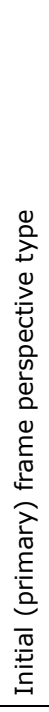 & 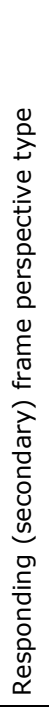 & 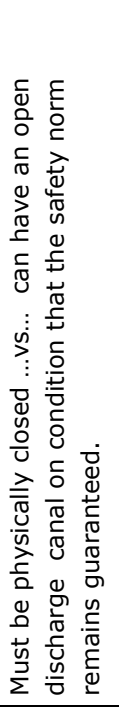 & 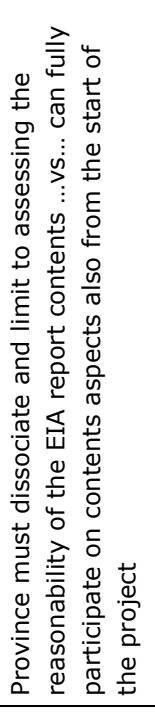 & 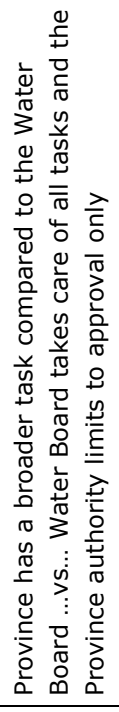 & 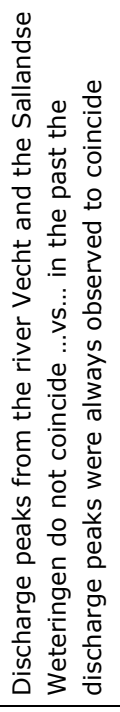 & 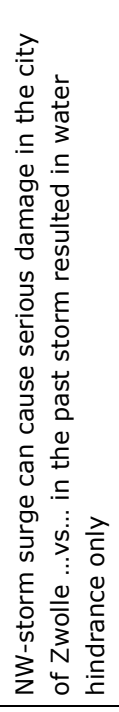 & 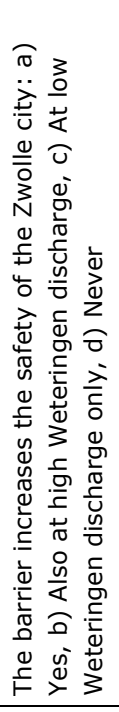 & 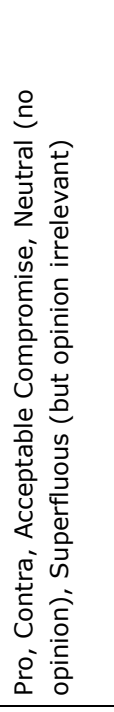 \\
\hline 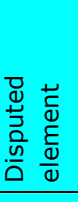 & & & 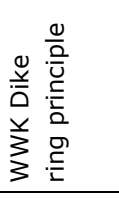 & 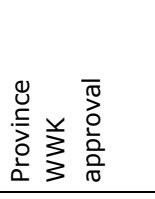 & 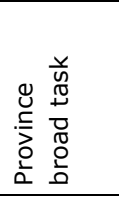 & 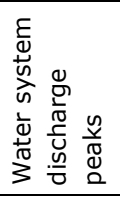 & 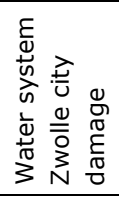 & 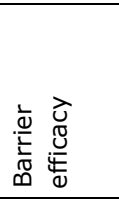 & 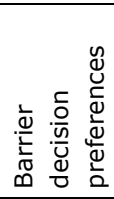 \\
\hline & & & $N$ & $\underset{-1}{0}$ & ન & $\stackrel{m}{m}$ & $\stackrel{\mathcal{F}}{*}$ & $\mathscr{t}$ & \\
\hline
\end{tabular}




\subsection{Analysis of the actor network}

In order to appreciate the relationship between the frame perspective types and the informant's scores on disputed elements, and to construct an explanation for the decision finally taken, this section looks into the interactions in the actor netword reported by the informants. The perspective types presented in the previous section are only a part of such an explanation. This section presents opinions and interpretations of informants regarding the division of labour and the relationships. These were described in section 4.3 in a general way.

\subsubsection{Actor network interactions}

The actor network of the Barrier case is presented in figure 5-2. This section will comment on several of the institutional relationships presented in this figure. Section 5.4.2 will focus on personal relationships.

\section{Province - National authority}

The Province had to deal with the various policy cultures within the national government. Informant no. 12 mentioned, for example, the difference between the ministries of RWS/V\&W and VROM. RWS would give the feasibility of policy much attention, and had an organizational structure that was adequate for this pragmatic approach. The regional chief engineer-directors and Water Board Chair Persons ("dijkgraven", in Dutch) frequently visited national headquarters to discuss practical matters. VROM, on the contrary, did not have such an open consultation structure and, in the opinion of informant no. 12, therefore generated policies with a high theoretical quality but not usable at the level of Water Boards and Municipalities [I12:17]. The Province therefore had to deal, within coordinated decision procedures, with a wide range of responsible authorities. Where RWS could be expected to take quick pragmatic decisions, VROM might be acting quite the opposite way. Because the Water Board only had to deal with RWS, Informant no. 12 suggested that this might explain some of the friction between the Water Board and Province.

\section{Water Board - National authority}

Informant no. 1 stated that civil servants from the national level have frequently visited the Province, and made comments on and became involved in the way in which the decision process was run [113:41]. Informant no. 6 mentioned how Province and Water board together had visited RWS to talk about the DAR1+2 controversies [16:55].

\section{Province - Water Board}

Informant no. 9 was of the opinion, from personal experience, that the relationship between Province and Water Board was a very hierarchical one. Instead of working together on a problem from the beginning, he characterized the relationship as checking the correctness of the Water Board work. As an example he mentioned the strict adherence to the procedure by the Province [19:97]. Criticism from the Water Board of the Province for interfering with their work should be seen in this light, according to informant no. 10. The above picture is in contradiction with the intensive involvement of 
provincial civil servants, stated by informants no. 1 and 2 , in the project team right from its start. Informant no. 1 indicated that the strict adherence to the procedure was prompted by earlier experiences where the procedure of the Province has been criticized by the "Raad van State". Their careful attention was meant to protect the Water Board from unnecessary appeals to the court [11:46]. Informant no. 2 added another example, related to the procedure for transfer of the river Vecht from national to regional authorities [I2:16]. Informants nos. 12 and 13 characterised the relationship between Province and Water Board as a problematic one for many years, not only at the civil servant level, but also at the administrative levels, starting with the Ramspol project and continuing to the DAR projects [112:62], [113:39]. One other source even called the relationship completely spoiled.

Informant no. 3 saw the relationship as a purely functional, where the Province was involved in organizing public participation and the Water Board supplied the expert knowledge. He also mentioned that, for the larger part, the Province manages the national financial contribution to Water Board projects [13:30]. Informant no. 2 had a different opinion on the relationship. He considered his contribution in the project team that prepared the EIA as providing technical expertise in the development of alternatives within the DAR dike improvement program. For this purpose he, and his provincial colleague, informant no. 1 , had frequent meetings with the Water Board, up to once a week. Formally the Province acted as the competent authority for the EIA, had to be informed of all aspects of the project, and had to comment on all documents, in full detail [I2:09]. Informant no. 2 had his doubts about whether the Water Board always appreciated his actions, and referred to another DAR project (DAR5 Vecht dike revetments) where the initial plans of the Water Board had also been changed also because of the Province [I2:12].

Informant no. 3 placed the relationship between Province and Water Board in a historical perspective, by referring to the situation before the merger of the small historical Water Boards into the large Water Board of Groot Salland. In those old days, the small Water Boards used to consult the Provincial Water Management Department for almost every activity, and had to do so because of lack of both capacity and technical expertise. This historical situation has changed completely with the formation of the new Water Board that has full technical and administrative capacity [11:33]. According to informant no. 1 this change has resulted in tension between Province and Water Board, especially on the level of civil servants [I1:64]. These persons, especially those at the Province, in his opinion, had difficulties in defining the new division of tasks. He also noted that the Water Board, as a result of the attitude of the Province, did not feel they were taken seriously, and not recognized in their new legal situation. As a result the Province might be seen by the Water Board as an annoying power. This seems to apply to the other DAR projects, and Ramspol, also [I1:65, 71]. Informant no. 3 defended the Provincial position by pointing at their intermediate role, in which they had to deal with criticism on the DAR project from both TAW experts and citizens who felt ill treated by the Water Board [I1:65]. He interpreted the tension between Water Board and Province as a struggle about the shaping of the coordinating task of the Province. This task, according to him, obliged the Province to take valid arguments from participating citizens into due account, even if this displeased the Water Board. Another part of the tension, according to 
informant no. 1, originated form different, broader technical insights, which for the Province not only included dikes and water management but also e.g. nature preservation and cultural heritage [11:67]. According to informant no. 1 the root of the dispute lay in the conflict between a technical perspective which regarded the barrier to be non-effective, and an administrative perspective which granted the Water Board its responsibilities as the legal initiator of the dike improvement project [I1:82].

Informant no. 5 referred to the emotions that played a role in the relationship between Province and Water Board. Earlier discussions that took place concerned the grass revetments along the river Vecht, dike improvement in the city of Kampen, and problems with the Ramspol barrier construction. All these projects required considerable attention to such an extent that, at the time of the Zwolle Barrier, the relationship was rather overstressed and old emotions surfaced [15:26].

\section{Citizens - democratic representative bodies}

According to informant no. 9 the Water Board Groot Salland had a very open organizational attitude, both internally and towards citizens of the region. But informant no. 9 also suggested that the water management policy field, especially the Water Boards, had always operated under the protection of the administrative process, because the general public was convinced of the danger flooding. Also because farmers made up $80 \%$ of the representatives in the Water Board's general council, once the farmers agreed, a decision was secured. In the new organisational structure of the merged Water Boards this situation had changed, and the new Water Boards now had to learn to deal with social opposition from other citizen parties. According to informant no. 9 the water management policy field could profit from experiences in the field of spatial planning, where this learning process towards interactive decision making was further advanced [19:96].

Informant no. 10 has raised his voice right from the start of the DAR projects, and continued voicing his concerns in the specific DAR $1+2$ project. At the first opportunity he already shared his opinion with the Water Board and Province in both the local and regional advisory group. During the official citizen participation in the EIA procedure he delivered his point of view, which he also did in informal contacts with Water Boards and Province. After the approval of the EIA by the Water Board General Council and, later on, by the Province Executive Council informant no. 10 used every legal route possible to protest and ask for a nullification of the provincial approval. The Zwolle city council approved the necessary permits by the narrowest margin in spite of his effort to convince them of the contrary, because of the personal effort of the alderman who stressed the importance of a good relationship with Province and Water Board and pointed out the inevitability of the approval, albeit by provincial force [I10:49]. In the procedure for approval by the Province's Executive Council informant no. 10 also mobilised his political contacts and questions were asked by the Province General Council about the intended decision. Under pressure by the Water Board, the Provincial Executive Council approved the EIA. Thereafter informant no. 10 asked the "Commisaris der Koningin" to use his administrative powers to reverse the approval, but the request was not granted. At this point informant no. 10 appealed to the "Raad van State", who considered his appeal not admissible because he did not own any property on the dike. Informant no. 10 finally 
brought his case under attention of a member of parliament who posed a formal question to the minister of Transport, Public Works and Water Management about the approval of the EIA and its possible consequences. The answer pointed out that the regional responsibility regarding the EIA had been well taken care of by the Province and the Water Board. And subsequent informal contact revealed that the ministry considered the matter to be of to small an importance to make a fuss [I10:49].

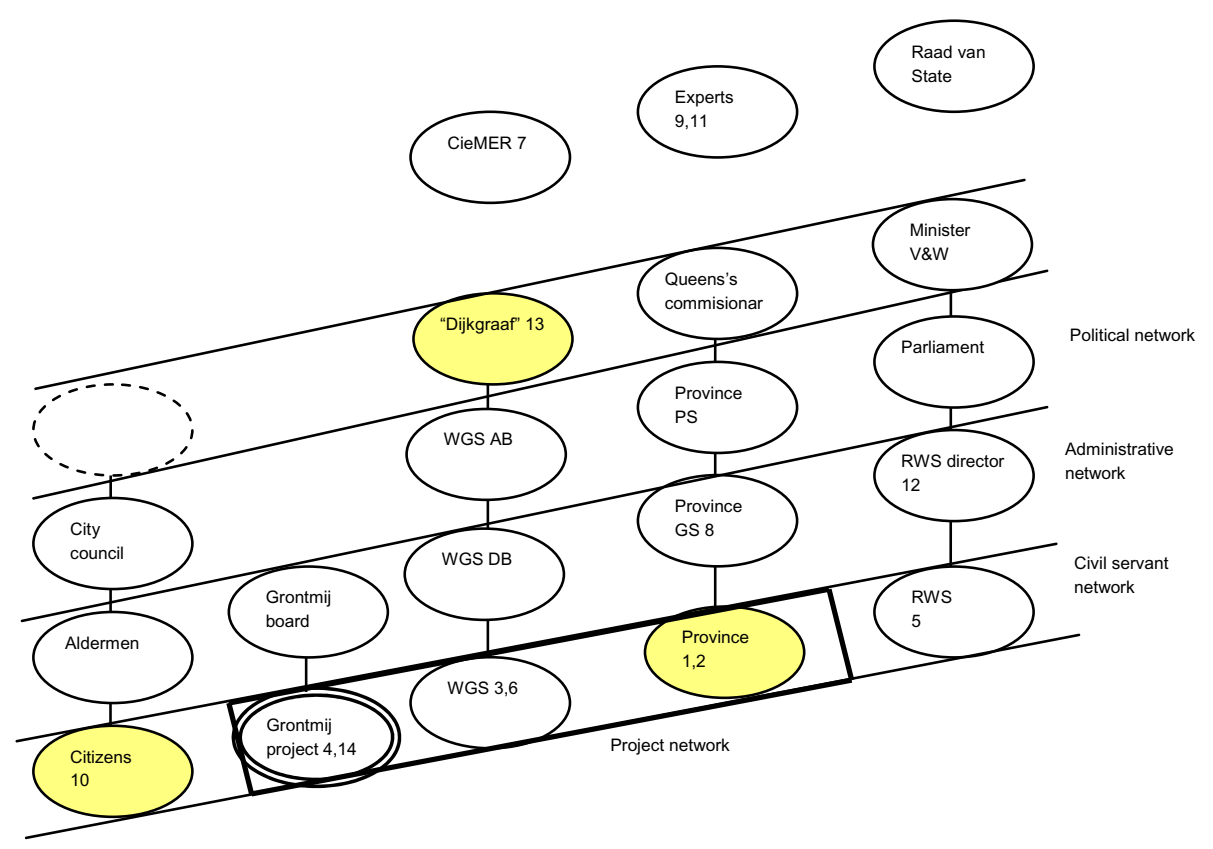

Figure 5-2: The actors involved in the case can be located on diverse hierarchical levels in their institutions, and cover almost the full range of administrative organisations in the Dutch society. Their involvement is based on their appearance in documents and interviews. The horizontal dimension indicates how institutions operate on different spatial scales. The vertical dimension indicates the hierarchical relationship within and between institutions. The "layers" indicate the various networks that appear from the interviews. The positions of the informants are indicated in this figure with their code numbers. The marked informants appear to have had a relatively large influence on the decision making process. 


\subsubsection{The influence of individual persons within the network}

The persistence of the controversy was explained by informant no. 9 from the obstinacy with which the actors, especially the "leaders", of both the Technical (informant no. 10) and the Administrative (informant no. 13) position persevered in their arguments. Especially the opposition of informant no. 10, who had a great deal of knowledge both about the water system and the administrative system from his previous employment, against his former employer caused resentment [19:57]. In the opinion of informant no. 9 the EIA would probably have been accepted without problems without the opposition of informant no. 10 [19:38]. At the same time, informant no. 13 had proven to be a rock solid negotiator in earlier project difficulties, e.g. with contractors in the Ramspol and Kampen dike improvement projects [19:85]. Informant no. 3 considered the role of informant no. 13 to be "the sand in the machine" of decision making, who, with his criticism, stimulated other to resist the EIA preferred alternative [13:81]. This opinion was also put forward by informant no. 9, who added that the role of informant no. 13, in his opinion, caused subjective animosity between the actors [19:42]. Remarkably, other informants stress the good working and personal relationships between the actors in general, and noted how in this specific case working relationships were put under pressure.

Informant no. 7, too, stressed the influence of individuals and their different emphases [I7:100]. Informants nos. 4 and 12 confirmed the importance of individuals in the decision process. In the opinion of informant no. 4 institutions did not control the flow of information. Individual persons, however, sometimes used their organization as an excuse to promote their personal opinions and preferences [14:70]. Informant no. 12 mentioned personal character, interests, positions, and opportunities to win as important aspects. He considered the circle of acquaintances to be of more importance for the course of the decision process than knowledge [I12:64]. He considered unsolvable controversies to be a result from conflicts between persons, and the tension that existed between Province and Water Board for years might have played, in his opinion, a dominant role [112:65].

The provincial Executive, informant no. 8, was described by informants as a person strongly aimed at harmony and consensus. He was faced with the different Technical and Administrative opinions on the alternatives from within the province, including two different second opinions. The Water Board urged him not to follow the advice of his own critical civil servants, but to thrust the expertise of the Water Board [I1:73]. His hesitation to follow the Technical advice was heavily criticized by persons with a technical perspective, e.g. informant no. 10 [I10:63]. Persons with an administrative perspective, e.g. informant no. 13, also criticised his hesitation, and exerted great pressure on him to approve the alternative presented by the Water Board in the EIA [I13:39]. The dilemma the provincial Executive faced upon rejection of the MER was an appeal by the Water Board to the National authority RWS or the "Raad van State".

With regard to the two second opinions, the responsible informants no. 1 and 2 both considered "their" expert opinion to produce convincing evidence. In fact, informant no. 1 explained his concern that a technical expert opinion might win the case for the Technical 
perspective, so he called for an administrative expert to provide counterbalancing Administrative evidence [I1:73].

Informant no. 13 expressed his anger about the delay in the EIA procedure caused by the provincial interference, and his concern about a possible intervention from the national authority in relation to the exceedance of the legal deadline for dike improvement (1 January 2001) presented by the WWK96 [I13:41]. Also informant no. 5 considered the Province to be one of the causes of the long duration of the procedure. From the perspective of a Water Board he considered the extra time claimed by provincial civil servants to perform additional research and discussion to be complicating. He explained the need for this delay from the uncertainty raised by the technical opponents. In his opinion, the province could have taken a quick decision early in the EIA procedure [I5:65]. Informant no. 9 confirmed the urgency of the decision with relation to the WWK96 deadline, and mentioned earlier delays at the Ramspol and Kampen projects [19:42].

One informant pointed at the role of the Zwolle Council in delaying the permitting procedure.

\subsubsection{Conclusion}

The actor network involved in dike improvement in Overijssel appeared rather stable, starting from the early days of the Ramspol barrier planning in the eighties, which was also confirmed by informant nr 13 [113:03]. Frequent informal contacts existed within this network. There appear to have been extensive informal contacts involving the Provincial Executive, the "Commisaris der Koningin", and the "dijkgraaf" at the administrative level, and at the civil servant level involving Water Board, Province and RWS. At the citizen participation level informant no. 13 mobilised persons in the Zwolle city council, the Province General Council and Parliament to promote his interests. Formal contacts within and between institutions existed along every available hierarchical connection, where the local visit of the CieMER and the use of expert second opinions were quite remarkable. All things considered, the full range of administrative organisations in the Dutch society have been involved in this case.

The two major institutional stakeholders, represented by persons of the water board WGS and province Overijssel, collaborated right from the beginning in the DAR $1+2$ project group that was directed by the external engineering company called Grontmij. We mention the Grontmij project leader as the third major stakeholder, because of the interests such a company in general has with these kind of projects. Although the Grontmij project leader was supposed to follow the ideas of his principal the Water Board Groot Salland, his philosophy and leading and guiding capacities were of great influence on the project development, according to informants nos. 4 and 14. The Grontmij project group already conducted the preceding dike improvement projects 3, 5 and 6 within DAR for the Water Board Groot Salland, in changing team compositions depending on the exact nature of the specific project problems, but with always with the same major actors included. There had been, in fact, a build up during the DAR projects of a multitude of common experiences and emotions. 
Opinions on the personal relationships differed greatly between informants and other observers, ranging from a good personal relationship that was under persistent functional stress in the DAR $1+2$ case, to a completely spoiled relationship already from the Ramspol project. Part of the relational stress was attributed to the change in distribution of both legal and informal responsibilities between Province, Water Board and National authorities after the introduction of the new large Water Boards starting from 1992. The Water Board expected their expertise to be taken seriously by the Province, and the Province had to give their technical and administrative expertise a new role in their broader responsibilities compared to the narrower water management and flooding safety responsibilities of the Water Board.

\subsection{Decision explanation model}

The analysis in the previous sections presented an overview of conflicting elements and the behaviour of actors in their institutional and personal social network. In this section we will construct an explanatory model for the decision finally reached.

Which decision is finally preferred by each informant is presented at the bottom line in the extended data matrix in table 5.3. The scores of an informant on the conflicting elements represent details of their argumentation. The explanatory model, however, is mainly based on the informant answers on a separate interview question that was not included in the data matrix of conflicting elements, but is presented in table 5-4. This was the first question in the list of focal points and probing questions (see section 3.4.5 figure 3-5), which resulted in a broad range of 28 different answers. These answers have remarkably little overlap between the informants. The informants indicated in their answer what they considered to be the most determining argument for the course of the decision process. Many informants returned to this question at the end of the interview, on their own initiative, to reflect on and summarize their opinions. It was these answers that prompted the construction of the decision explanation model, which is presented in figure 5-3.

The model can also be regarded as a problem tree. It presents the arguments (in rectangles) against and in favour in the barrier plan controversy, and their causal relations (the arrows). It decomposes the central controversy into several layers of sub problems. The model elements can be related to elements in the data matrix. For example, the elements 2, 3, 4, 6, 9, 10 and 12 connect to the WWK96 argument. The ovals do not represent sub problems, but indicate the initial barrier plans (which are a solution to previous problems) that initiated the central controversy, and the solutions finally taken. Below we will discuss some aspects of the model based on informants' statements. These descriptions have been used to develop the decision explanation model in figure $5-3$. 


\begin{tabular}{|c|c|c|c|c|c|c|c|c|c|c|c|c|}
\hline \multicolumn{13}{|c|}{ 舀 } \\
\hline$\stackrel{m}{r}$ & & & & \multicolumn{3}{|l|}{$\stackrel{9}{m}$} & & & & \multicolumn{3}{|c|}{ 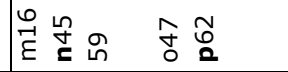 } \\
\hline \multicolumn{13}{|c|}{$\underset{\sim}{\sim}$} \\
\hline 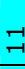 & \multicolumn{3}{|c|}{$\frac{m}{i}$} & & & & & & & & & \\
\hline 운 & \multicolumn{3}{|c|}{ 움 } & \multicolumn{3}{|c|}{ 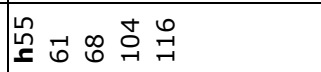 } & \multicolumn{3}{|c|}{ 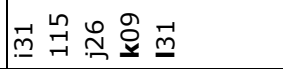 } & & & \\
\hline \multicolumn{13}{|c|}{$a$} \\
\hline$\infty$ & & & & $\widehat{0} \approx$ & Oि & & & & & 히 & & \\
\hline$r$ & $\stackrel{m}{m}$ & & & $\begin{array}{ll}\infty & 0 \\
\infty & \stackrel{-}{0} \\
\end{array}$ & & & $\vec{I}$ & & & & & \\
\hline 6 & ס & & & & & & .- & & & & & \\
\hline I & & & & $\stackrel{4}{*}$. त्र &.$\widehat{હ}$ & & & & & & & \\
\hline$\dot{\theta}$ & ס & & & & & & & & & & & \\
\hline m & 0 & & & & & & & & & & & \\
\hline$\sim$ & ـ & & & & & & & & & & & \\
\hline$r$ & | & & & $\Xi$ & & & & & & & & \\
\hline 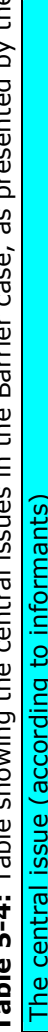 & 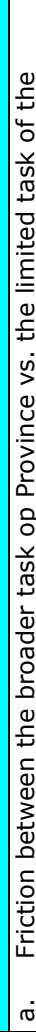 & 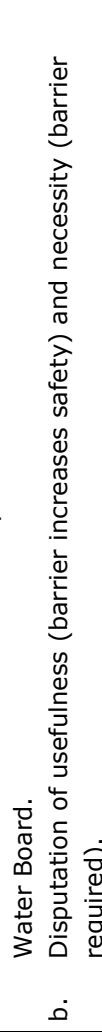 & 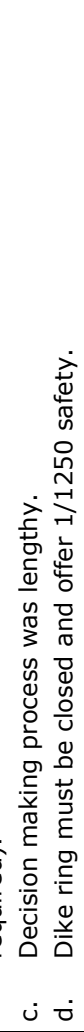 & 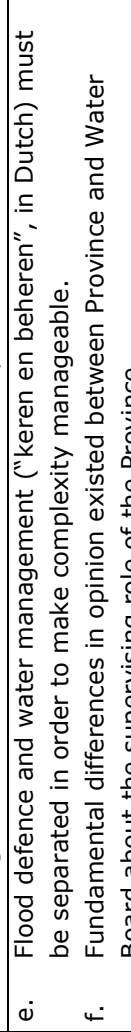 & 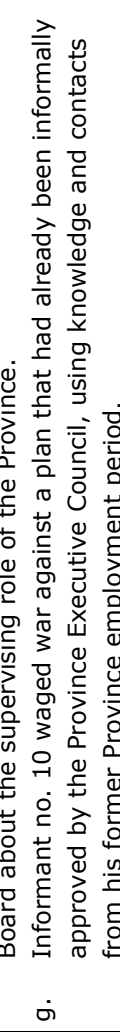 & 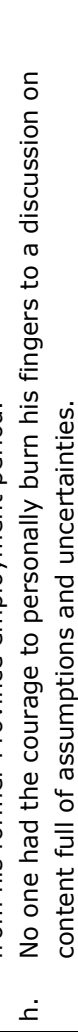 & 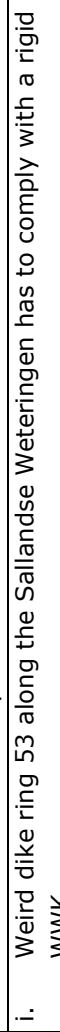 & 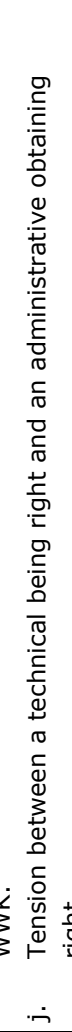 & 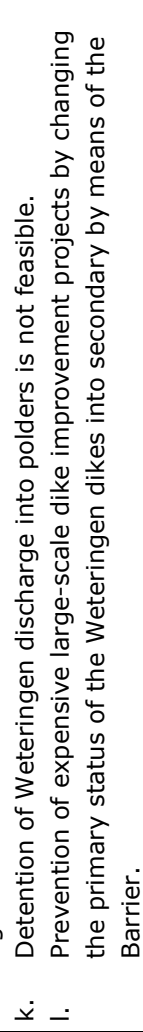 & 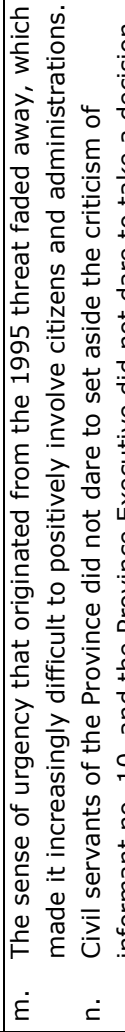 & 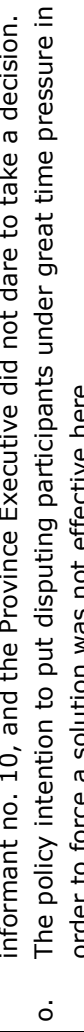 & 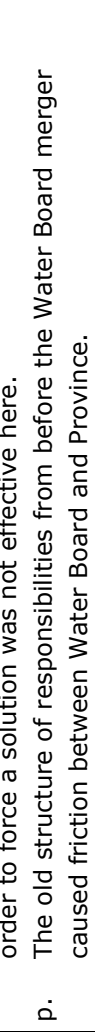 \\
\hline
\end{tabular}




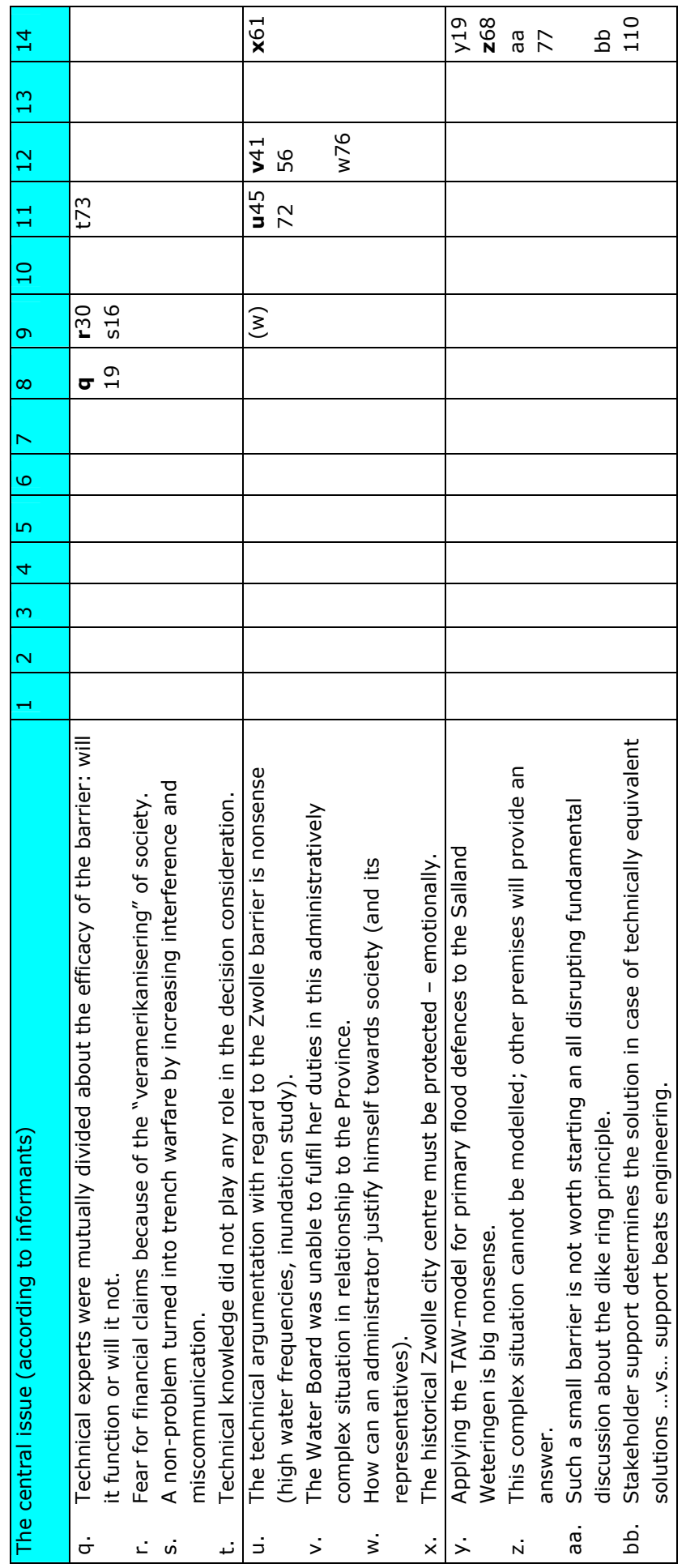




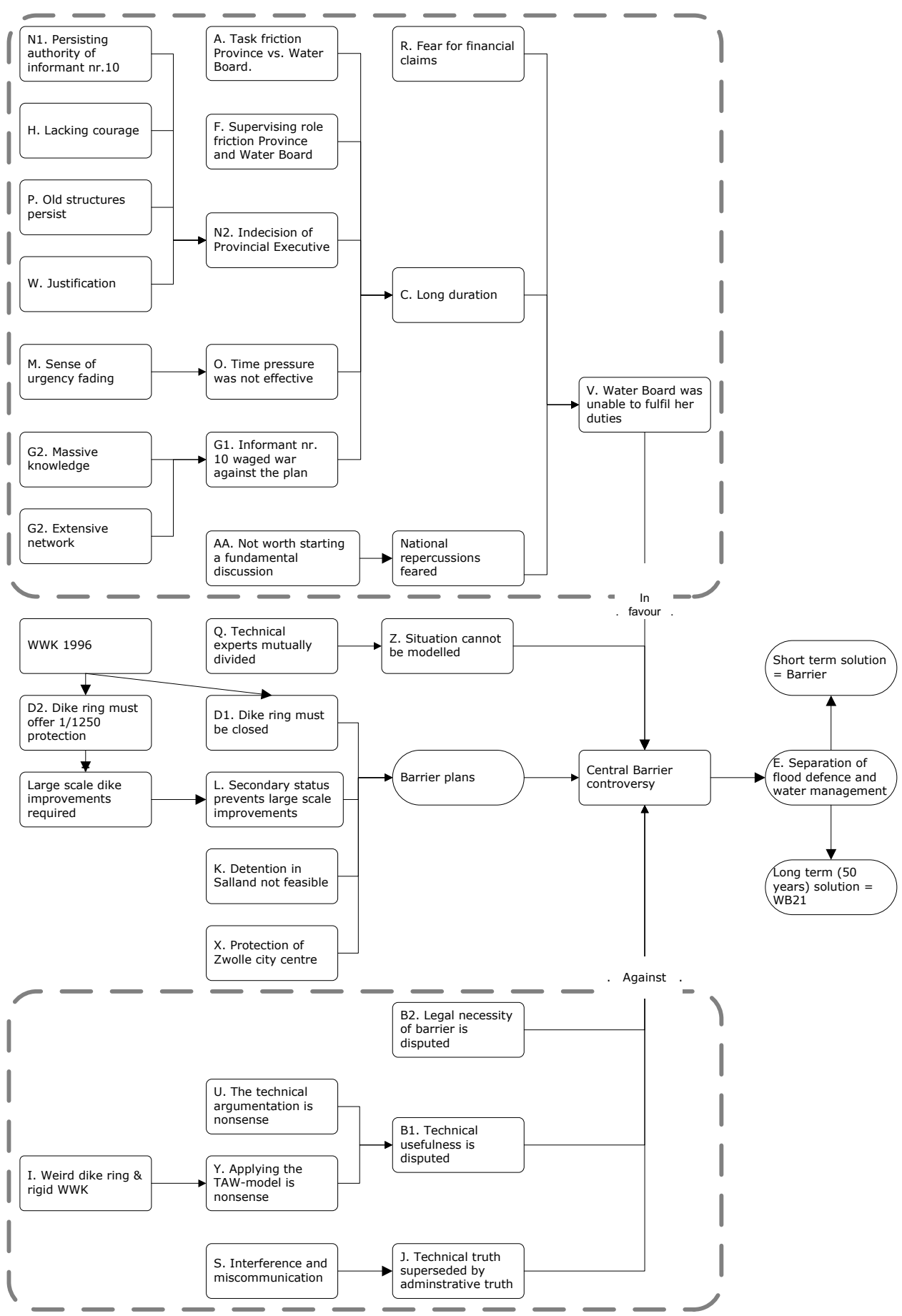

Figure 5-3: The causal decision explanation model decomposes the central controversy into several layers of sub problems. The model elements can be related to conflicting elements in the data matrix. 
In the end the issue appears to involve regional support and acceptability, as well as the distribution of responsibilities between Water Boars and Province. Informant no. 9 noted the opposition of the local farmers against the construction of inundation areas, which would have resulted in tremendous social pressure and resistance. In contrast, much less opposition would be expected from the urban areas, but the initiative of informant no. 10 raised opposition here also [19:26]. The same informant also noted that the Water Board considered the behaviour of the Province to obstruct their responsibilities. Informant no. 13 confirmed this with this remark that the Water Board would have asked for a directive from the national authorities when the EIA should have been rejected, and perhaps even a decision from the "Raad van State" [I13:41].

Another important element in the explanation model is the delay of the EIA procedure caused by the discussions about diverse contested elements. In the opinion of informants nos. 9 and 13 the Province was not decisive enough in their role as approving authority [19:57]. According to other informants, e.g. nos. 1 and 2, the delay was necessary to deal with the different opinions just because of this role [I1:73]. Some informants indicated that the minister would not accept much more delay in the EIA procedure (e.g. [19:66].

The role of technical arguments has, according to some informants, been limited to the project level of civil servants, at the administrative level these arguments were considered to be not relevant (e.g. [I11:50, 74]).

Support and acceptability also played a role at the level of national authorities. According to informant no. 10 several solution alternatives have been rejected because these would cause a need for reinterpretation of the WWK and the dike ring principle by the minister of V\&W. This opinion is confirmed by informant no. 12, who also expressed the concern within RWS for questions in Parliament that might harm the political position of the minister in case of a local (dike ring 53) subsidence of the WWK96 demands and possible future negative consequences thereof [112:69]. According to informant no. 9 an exception made for dike ring 53 would have created a precedent for opponents of dike improvement project in other dike rings, or for civil servants that could use it to lower their budgetary demands, e.g. along the large rivers. The letter produced by REW clearly indicates that, at a national level, there was no willingness to change the appendix of the WWK with regard to the inclusion of the Weteringen in dike ring 53 without a strict adherence to the dike ring principle that a dike ring must be closed and have a uniform protection level [19:67].

Also an important aspect was the legal liability for flooding damage. According to informant no. 9 current social developments, starting from the high river levels in 1995, tend to hold the authorities responsible for any flooding damage that might be inflicted on citizens, and justice tends to honour their claims more and more. This caused Water Boards to be very cautious regarding any alternative solution that is not clearly based on the WWK96 [19:28]. Remarkably the Water Board considered the Province to lack courage to approve their EIA and dike improvement plan [113:39], where, at the same time, the Water Board did not want to use their administrative possibilities to construct 
their own interpretation of the WWK96 and accompanying guidelines. According to informant no. 9 a court, in a liability suit, will ultimately judge whether the decision arguments, including model calculations, are reasonably defendable. Any other criterion therefore would be irrelevant for the decision makers [19:53].

Remarkably actors with a Technical perspective not only presented their technical arguments against the effectiveness of barrier alternative, but also presented arguments to refute the arguments for its legal necessity presented by actors with an Administrative perspective. It seems that, where possible, the conflicting elements with regard to the WWK96 have been interpreted by the Administrative actors in such a way as to create as much a necessity for the barrier alternative as possible (see the bold marked elements from nos. 2 through 12 in the data matrix in table 5.1). The technical aspects appear to be countered with an appeal to uncertainty ("experts divided" and "complex situation cannot be modelled").

\subsection{Conclusion}

\subsubsection{Issues \& controversies}

Our analysis of the case reveals the following picture. In the period preceding the case problem (which started in 1997) a major dike strengthening operation in the DAR region (see figure 4-1) had been prevented by the construction of the Ramspol storm surge barrier. The administrative effect of the barrier was a lowering of the MHW's for the upstream region, according to the new WWK96 TAW-guidelines, compared to a situation without the Ramspol barrier. After the adoption of the WWK in 1996 the Water Boards were required to make a safety assessment of all dikes within their administration and, when needed, realise the required improvements before the deadline of 1 January 2001 .

The dike safety assessment performed by the Water Board Groot Salland revealed (not unexpectedly) the problem of major shortcomings with respect to the WWK-TAW guidelines (Heidemij_Advies 1997a; b). The Water Board initiated a dike improvement procedure to remediate the shortcomings, using standard technical solutions according to the TAW guidelines. Immediately after the start of the procedure, the dike improvement plans appeared to lack support among all stakeholders involved. The safety of the dikes along the Sallandse Weteringen and the Zwolle city canals was not considered to be a major problem. Much more a problem was the local water management in the Salland system, the design of which is not adequate to deal with extreme precipitation events. At the same time the applicability of the WWK to the dikes along the Sallandse Weteringen was questioned. In this starting phase of the problem solving process the problem definition was broadened from the WWK demands for protection against water from outside to the more general problem of the water management in the Salland system.

In the eary phase (see figure 2-5) a broad range of alternatives was generated (in the advisory group and project team) which tried to find an integrated solution for the external high water ("buitenwater") threat and the local precipitation runoff discharge ("binnenwater") problems. The alternatives ranged from technical measures for decreasing the extent of legally required dike improvement (including both dike 
construction principles to comply with the TAW guidelines in a minimal way, and detention and inundation schemes to lower the MHW's) to administrative measures to remove the legal obligation for dike improvement, and are categorised as such in table 4.4 (section 4.6.1). In the intermediate phase, additional research projects were performed (with regard to MHW water levels and inundation depths) to investigate the feasibility of some of the technical alternatives. This research raised a multitude of further questions regarding details of alternatives. Additional research would be needed to solve these (see the list of questions mentioned in report of the intermediate phase in Annex I of the EIA-report (2001). At this stage of the problem solving process various conflicts arose between Technical and Administrative perspectives. The T's accused the A's of opportunistic argumentation to force a politically desired solution; the A's accused the T's of lacking insight into the complex administrative situation that supported their arguments. At the end of the intermediate phase the problem solution space was limited to those alternatives that were in accordance with the Water Board policy.

The problem solution process was, by now, taking much time, which was considered by the Water Board Groot Salland to be a problem because of the legal deadline of 1 January 2001. Furthermore the Water Board perceived the uncertainties present in the calculated lower MHW's resulting from some of the alternatives as insufficient guarantee for adequate safety. One of the major sources of uncertainty was the definition of the worst case high water scenario. the Water Board, in their role as first authority responsible, decided to choose a solution which with certainty would conform to their legal WWK obligations: a storm surge barrier downstream the Zwolle city centre. It is a technical measure that allows a subsequent administrative measure of changing the legal status of the Weteringen dikes from primary into secondary. This solution is presented in the environmental impact assessment (EIA-report 2001) against the alternative of the original full scale dike improvement. The other part of the problem, being the water management in the Salland area, would be dealt with in a long-term approach under WB21/KRW.

The controversies between the Technical ( $T$ ) and Administrative ( $A$ ) solution appeared to be irresolvable. The technical as well as administrative arguments of the T's were not accepted by the A's, and the administrative arguments of the A's were regarded as invalid by the T's because the T's could refute each of them as arbitrary interpretations of the WWK. All the way through the dike improvement procedure A's and T's have tried to convince each other and the first (the Water Board Groot Salland), second (Province Overijssel Executive Council) and third (Ministry of V\&W) authorities responsible, using every available means. The power of the first administrator responsible ultimately forced a decision in favour of the barrier. This decision was subsequently contested by a single citizen stakeholder at the level of Province and Parliament, and brought before the highest Dutch administrative court, the "Raad van State" by several citizen stakeholders and interest groups. This court ruled the objections against the decision to be not admissible and unfounded. Subsequently the construction of the Zwolle barrier was started, and will be completed before summer 2005.

The objective of the barrier solution was to prevent flooding in the city of Zwolle and the polders in Salland. Ironically, the water management situation in Salland 1998 A.D. will 
already cause rural flooding in case of $1 / 100$ per year extreme precipitation events (see "Startnotitie Weteringen") (Grontmij_Projectbureau_DAR 1997b:10), and Annex I of (EIA-report 2001:4). This flooding is a result of limited pumping capacity in the lower areas, and limited discharge capacity in the higher areas. Furthermore, excess runoff from the higher parts will cause flooding of the lower parts. The short term measures accompanying the barrier (stopping pumps and raising weirs) will aggravate the rural flooding. In the short term, the barrier, when closed, appeared to protect the inhabitants of the city of Zwolle at the expense of the inhabitants of the Salland polders. In the long term the WB21 reconstruction plans are to extend the local storage capacity. Currently some reconstruction projects are already in progress. The adequacy of the created extra storage, however, has yet to be calculated in a modelling project that was already announced as part of the barrier alternative and is currently under way.

The worst case external high water scenario for the WWK is a 1/1250 per year event. When the dikes along the Weteringen are not reinforced and raised up to the $1 / 1250$ norm in accordance with the WWK guidelines, and the barrier would be absent, the lower parts of Salland could be flooded in a storm surge event in case water levels exceed the current $1 / 100$ per year level of the Weteringen dikes. This could be the result of overflow of the existing dikes, or of a possible dike failure along the Weteringen. From a regional point of view such a flooding is considered acceptable, and emergency overflow sections could be constructed to guarantee dike integrity under such circumstances and mitigate the effects of the $1 / 1250$ per year external event. Forcing an inundation by means of an emergency spillway in the Weteringen dikes would lower the MHW in the Zwolle city centre to an acceptable level (of 1,60 m+NAP, see Annex II of EIA-report 2001). Such an approach, however, would be against the WWK96 directives.

Salient controversies presented in the case include the following:

1 The barrier is unnecessary from an administrative point of view because the inclusion of the Weteringen dikes in dike ring 53 is both administratively disputable and technically unnecessary, and alternative administrative solutions exist in a risk approach within the context given by the WWK96.

2 The arguments for including the Weteringen dikes in dike ring 53 are based on financial considerations.

3 Water from outside the dike ring, in the sense of the Flood defences Act 1996 ("buitenwater", in Dutch) is supplied by the river Overijsselse Vecht.

4 Foreign objects in the broad quays of the Zwolle city centre are not permissible.

5 Norm differentiation for the dike sections along the Weteringen is not possible.

6 The barrier is ineffective from a technical point of view because the barrier closing scenario has a negligible frequency of occurrence.

7 The discharge of the Weteringen can be stopped by upstream measures to such an extent that the water level causing flooding of the Zwolle city centre will not be reached if the barrier is closed.

8 Multiple dike failures in rural Salland may cause backflow of Vecht water into Salland.

9 A Province may interfere on a technical level with a dike improvement project of the Water Board and associated Environmental Impact Assessment.

10 A Province may give due attention to procedural matters within an EIA also when this delays the EIA procedure. 


\subsubsection{The use of research information}

In the initial stage of the decision making process the advisory group was heavily involved, together with the project team, in finding alternative measures for a full-scale dike improvement of the Weteringen and Zwolle. In an intermediate stage the water board removed all solution alternatives which included inundation as a means of lowering the MHW's in the Weteringen, because of its administrative complications (of norm differentiation) and the uncertain effect on the MHW reduction (of technical measures). The same arguments also ruled out the alternatives with diminished dike improvement. Since a full scale dike improvement was considered not to be a feasible alternative, only a single alternative was left for consideration, viz. the barrier including accompanying measures to reduce the Weteringen discharge from the higher parts of Salland in the event of closure of the barrier. Fundamental questions remained, however, with regard to the safety of the Weteringen dikes, the damage resulting from a possible dike failure, and the socially acceptable inundation depths.

Remarkably, research performed in the initial project phase did consider the inflow of and inundation with water from the river Vecht to be unacceptable because of the $1 / 1250$ safety norm (EIA-report 2001) and (see (Grontmij_Projectbureau_DAR 1997b:20). At the same time, however, it selected an alternative which implied the possibility of inundation with local Weteringen discharge and precipitation water. The report of the intermediate phase stated that a barrier downstream the Zwolle city centre would need administrative and social acceptance of water inconvenience in the lower parts of Salland. This could be regarded as the application of the "not in my backyard" principle to the city of Zwolle at the expense of the Salland rural area.

The reported low probability of flooding in the Zwolle city centre appears to contradict the barrier decision. At the same time, rejection of inundation alternatives in favour of the barrier is reported to hardly change the calculated damage of flooding in the Salland rural area. For both the safety of the Zwolle city centre and the Salland rural area, in case of a dike failure along the Weteringen, the presence of the barrier makes no difference.

The example of the Zwolle barrer case shows how our method is capable of surfacing contradictions in the decision making argumentation. The question now remains why actors, using this same expert information, reach a different decision outcome. The statement from the Administrators that they have a legal obligation to prevent water from outside ("buitenwater", in Dutch) entering the dike ring indicated a specific frame and which can be regarded as an explanation. The driving force for the entering process is a low water level on the Weteringen. This low level could result, in cases of higher Weteringen discharge, from the above mentioned dike failure. In this case the barrier, however, is reported not to be effective with regard to inundation damage. But the low level could also result from a low Weteringen discharge. The argument presented by the Administrators is that in combination with a high "buitenwater" level flow reversal could possibly occur. A low Weteringen discharge in combination with a high Vecht discharge 
is, however, contradicted by available research from the earlier Ramspol project (Burgdorffer 1992).

\subsubsection{The decision process}

The central Technical issue in this case seems to concern retention and detention in Salland, from either extreme precipitation or storm surge, but not the Zwolle storm surge barrier. The central Administrative issue seems to be the presumed "closed dike ring" principle. This controversy has not been resolved in the case. The barrier solution ultimately allows and facilitates a further development of the Salland water management plans and their implementation over the next fifty years.

The actors involved in the case can be located at diverse hierarchical levels in their institutions, and cover almost the full range of administrative organisations in Dutch society. At the time of the case an earlier contest over the distribution of legal responsibilities between Province and Water Board culminated and was decided in favour of the Water Board. This complicated the discussion on the issues.

Although the decision making process can be described as rather turbulent, several years after this process ended (with the ruling of the "Raad van Sate" in 2002) almost all actors claim to be content with, or at least to acquiesce in, the decision outcome (the Zwolle storm surge barrier). One actor (taking a Technical perspective), however, maintains his opposition, because the storm surge barrier will never be closed as long as the need for discharge of the Sallandse Weteringen is not provided for by other means (like an alternative discharge route or detention in the polders). Some other actors, representing the Technical point of view, share his opinion but ultimately consider the Administrative arguments to be acceptable or inevitable. Most civil engineers agree that inundation will take place anyway, regardless of the operation of the barrier at the design event, because of the nature of the water system in Salland. The recently initiated longterm reconstruction of the Salland water system can alleviate this problem by retaining the precipitation locally. The presence of the barrier has allows a legal change of status to secondary of the Weteringen dikes and Zwolle quays, and consequently allows a very much reduced improvement of the dikes and quays that will not affect the LNC-values. Also the barrier has allowed the Weteringen dikes to be incorporated in the regional longterm WB21/KRW plans. 



\section{Discussion of results}

\subsection{Reflection on the theoretical framework}

The previous chapter analysed the case in terms of frames. In this chapter we will reflect upon elements of our theoretical framework that were presented in chapter 2 .

\subsubsection{Complex unstructured problem situations}

With regard to the characteristics of complex, unstructured problem situations presented in section 2.3.1 (figure 2-3) we will show that the Zwolle storm surge barrier case exhibits all characteristics of such a problem situated in a multifunctional system, where knowledge is uncertain and values are disagreed upon. We will check the aspects of such problems for occurrence in the frames analysed in the previous chapter.

Debated values in the case are, for example, the legal level of protection to be offered to the region of Salland and the Zwolle city centre, the restrictions placed on the discussion of the dike ring approach, the disregard of technical-scientific objections against the chosen barrier alternative, and ,finally, the ruling of non-admissibility by the "Raad van State" on the citizen appeals against the barrier by residents who do not own land directly on the dike.

Uncertain knowledge (as experienced by one or more stakeholders - this does not correspond to a scientifically underpinned uncertainty) is present in, for example, the frequency of the worst case high water scenario (ranging from $1 / 1$ and $1 / 10$ to $1 / 1250$ and 1/10000), the calculated MHW's in the Weteringen, the co-occurrence of peak discharge flows in the water system at the point where the Vecht debouches into the Zwarte Water and the related possibility of backflow into the Weteringen, the possibility of dike failure along the Weteringen, the effect of closure of the Zwolle barrier on the upstream water levels, and the extent of the mitigating effect of inundation areas. Knowledge about the administrative system depends on the interpretation of laws, guidelines and their explanations by the national authorities. Current uncertainties regarding this type of knowledge become apparent through the objections brought forward in the EIA procedure and the court cases, as occurred in all DAR projects.

Complex interactions in the systems are, for example, the interaction between storm surge and high runoff discharge water levels in the regional surface water network, the relationship between regional precipitation patterns and the discharge levels of the rivers Weteringen and Vecht, and the multiple relationships within and between diverse layers in the administrative political system. The physical complexity of the Salland region was also illustrated by informant no. 10, who explained how the layout and capacity of the discharge channels was designed for average situations only. In such a situation the 
upper part of Salland will discharge through the Raalte-Deventer canal and the pumping station at the city of Deventer into the river IJssel. In wet situations, however, the excess water will be spilled into the Weteringen and add to the discharge there. In dry situations, the Deventer pumping station will reverse direction and will supply additional water [110:131].

Multifunctional aspects are, for example, the use of agricultural land for inundation purposes and nature development, the use of agricultural land and land with significant landscape, natural and cultural heritage values for dike improvement, the urban use of land (the Zwolle city centre) that may potentially be flooded because it is located outside the dike ring.

The technical problems present in the case are the dike improvement according to WWK guidelines, the flood protection against external water entering dike ring 53, and the mitigation of water hindrance in case of extreme precipitation. These technical problems have to be coped with in a social context, which consists of the triple relationship between authorities on national, Provincial and Water Board levels, of diverse stakeholders like farmers, citizens, nature and cultural heritage protection groups, companies such as the energy production plant and shipping enterprises, and mayors of municipalities involved.

On the other hand social problems exist such as flood damage responsibility and related potential financial claims, and feelings of insecurity among residents because of (supposed) flooding threat. This latter aspect diminishes as the high water episodes from 1993, 1995, and, especially for the Salland region, 1998, fade from memory. These social problems have to be dealt with in a technical context of dike improvement, water management and WB21. This is precisely the situation in which integrated problem solving operates, as mentioned in section 2.6.

\subsubsection{The decision making cycle}

With regard to the decision making cycle presented in section 2.2.1 (figure 2-1), the cycle was described for the EIA situation by the procedure in Appendix B, and was detailed in section 4.5. The focus of the EIA procedure, as it was actually performed in the case, was on the steps of Problem definition and Solution space generation, which were described in separate documents, the "Startnotities" (Grontmij_Projectbureau_DAR 1997b; c) and the Annexes to the EIA-report (2001). The latter also described a first selection and analysis of alternatives, and effects were predicted using high water level and inundation models. In the conclusion of Annex I "Rapportage tussenfase" in (EIAreport 2001) the alternatives were further reduced, and in the EIA report only two alternatives ware fully analysed (the Zwolle barrier and the full scale dike improvement). The EIA did not perform new research but referred to research already done in the previous steps. The weighing of benefits and costs was performed in a qualitative way, with the exception of a quantification of the costs. Also some of the earlier performed model calculations were used to support qualitative argumentation. An EIA is meant, by definition, to prove by the first responsible authority (the Water Board) that their argumentation for the preferred alternative is valid. This argumentation was ultimately accepted by the second responsible authorities (the Province). Implementation of the 
barrier is currently under way; the barrier construction will be finished in May 2005.

Evaluation of possible environmental effects will take place afterwards (see appendix $B$ of this dissertation and (EIA-report 2001:89).

The scientific knowledge used in the decision making cycle consisted of TAW guidelines for dike improvement (TAW 1985; 1989; 1996b), river discharge and storm wind frequency distribution models (HKV_Lijn_in_water 1996b), the MHW level calculation model SOBEK (HKV_Lijn_in_water 1996a; b; 1999), a hydrological and hydrodynamic water level calculation model DUFLOW (Annex II and IV of EIA-report 2001), an inundation depth and GIS based damage calculation model (Annex III of EIA-report 2001).

The influences exerted by actors on the decision making cycle were described on an institutional level in figure 4-4, and were detailed in section 5.4 (figure 5-2). In the initial steps (during the "startnotities" en "Tussenfase") the Water Board supported the initiatives of the EIA project team and Advisory group to perform research on alternative solutions, albeit grumbling because of the extra financial costs and the delay of the project. But at the end of the "Tussenfase" the Water Board rapidly directed the decision process towards the barrier alternative, using their specific interpretation of the WWK (both with regard to dike improvement as well as to distribution of responsibilities), of the model calculations, of observation data and of future scenario's.

The most important opponent against the barrier alternative, representing a technical perspective, assisted cooperatively in the search for alternatives in the initial project phase. But after the approval of the EIA by the Water Board General Council this opponent applied every means available to express his arguments against the decision and to get the decision revoked. The opposition started in the Zwolle city council, continued in the Provincial General Council, was followed by a request to the "Commisaris der Koninging" to overrule the decision of the Province Executive Council, and culminated in the appeal to the "Raad van State". Up to the decision of the Provincial Executive Council some civil servants representing the Technical perspective, in diverse institutions, also opposed the barrier decision. Their arguments followed the same line of reasoning as the aforementioned opponent, but were overruled by the decision of the Provincial Executive Council, which at the same time terminated their opposition. The official document that prepared the Provincial Executive Council decision contained a personal policy opinion of the opposing civil servant [12:73].

From an Administrative perspective the broader legal responsibilities of the Province were defended against the limited responsibilities of the Water Board. The Provincial concern for participatory aspects of the EIA procedure were, by them, considered to legitimise project delay. The issue of distribution of technical responsibilities was ultimately decided in favour of the Water Board by the Province Executive Council (Provincie Overijssel 2003). 


\subsubsection{Construction of knowledge}

\subsubsection{Actor network structured as post-normal fora of decision making}

Section 2.3.2 (figure 2-4) described the post-normal fora of decision making. In this section we will restructure the actor network presented in section 5.4 (figure 5-2) as trajectories of the problem solving process through the diverse fora of discussion. The results are presented in figure $\mathbf{6 - 1}$. The arrows more or less denote the flow of time and hierarchy. The different actors use different problem solving strategies that are typical to their community. These trajectories of inquiry are plotted in the three concentric communities of knowledge construction or discussion arena's introduced by Funtowicz\&Ravetz (1993b). Each community has it own problem solving approaches and paradigmatic rules. The entries have not been ordered on the systems uncertainties or the decision stakes axes, but have been merely put into the appropriate community.

The communities of applied sciences are involved through the calculation methods used, e.g. dike improvement guidelines, river discharge and storm wind frequency distribution models, MHW levels calculated with the SOBEK model, water levels in the Weteringen and inundation depths in the polders calculated with the hydrological and hydrodynamic DUFLOW model. In a later phase of the project disciplinary expert were called upon to provide a second opinion, from a technical and an administrative perspective, respectively. The protesting citizen (informant no. 10) made an attempt to involve the TAW and the Delft University in order to change the applicable guidelines and WWK96 interpretations through an advice to the parliament, but did not succeed.

The Grontmij Company represents the communities of professional consultancy involved in the case, together with the project executive civil servants of the Water Board and the Province. In this community expert judgment and "courage" is demonstrated through the resistance against the full scale dike improvement and the creative use of TAWguidelines. For example a 1/200 dike height along the Weteringen was considered to offer adequate protection. At this level also the statement was made that the construction of the Salland water system will always result in flooding problems in case of extreme precipitation events, and that in such cases water from the higher parts of Salland will discharge into the lower polders outside the Weteringen canals. On the other hand the relationship with the Water Board management required a delicate balancing process between technical insights and administrative needs.

The social-political arena is represented by a diversity of actors. The network interactions described in section 5.4 illustrate how different solution preferences were fiercely defended by actors in this community, using every available means. Opportunity of arguments is visible in the choices made regarding e.g. the WWK96 interpretation (compliance with the legal norm versus offering flooding protection, norm differentiation and risk approach, strictness of deadline, distribution of responsibilities), and the related re-definition of problem and goals. Also local interests interfered with the problem solution alternatives. Ethical aspects became visible through the passion that actors from the project team displayed in the defence of their perspective. Technical actors opposed the dismissal of their technical arguments against the barrier, and administrative actors championed a new distribution of responsibilities between Province and Water Board. 


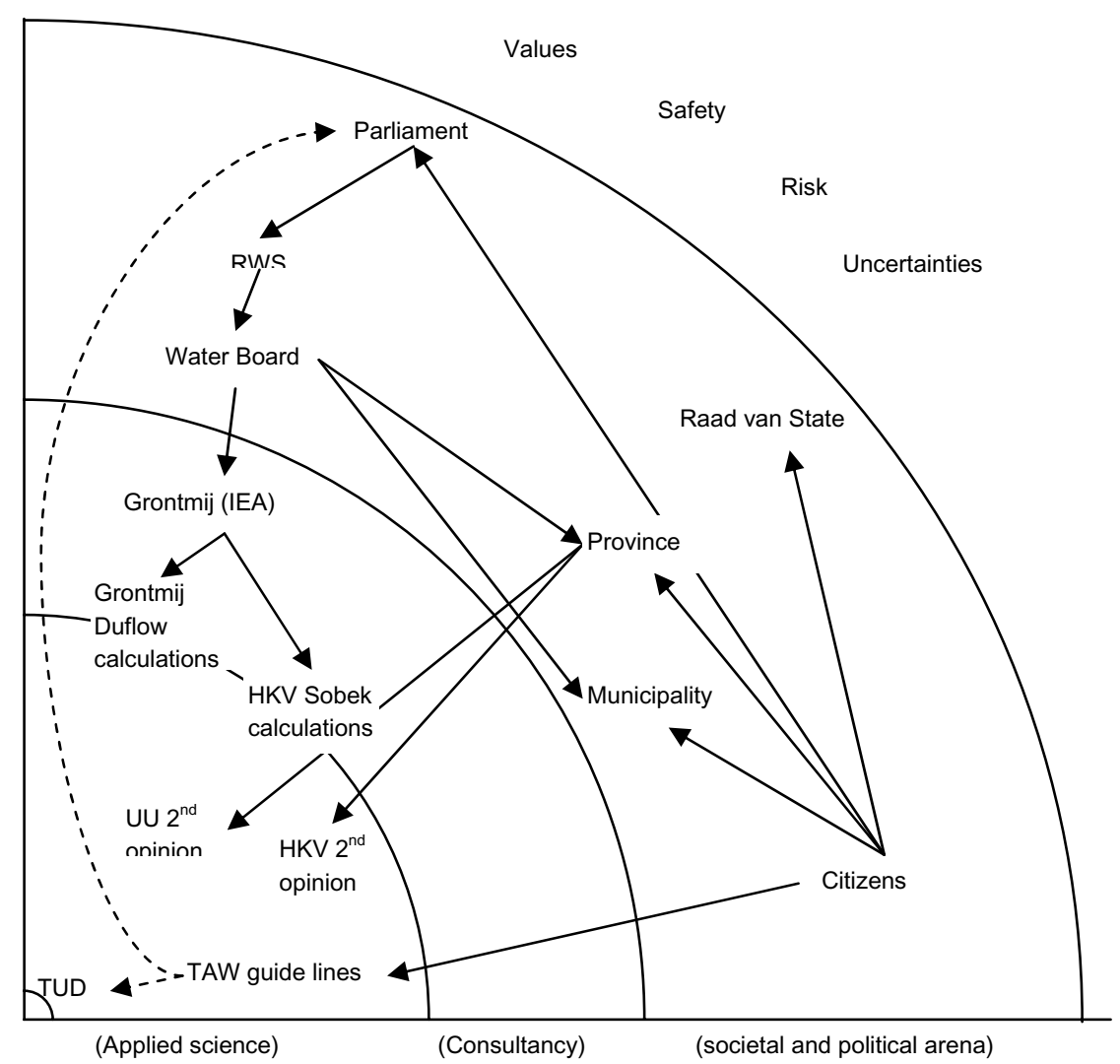

Figure 6-1: The trajectories of inquiry resulting form the controversies raised around the "Zwolle Barrier" issue. The trajectories are plotted in the three concentric communities of knowledge construction / discussion arena's introduced by (Funtowicz\&Ravetz 1993b).

Figure 6-1 also contains the different administrate levels that were previously identified in figure 5-2, and that were already indicated in figure 2-6. In complex unstructured problem situations, interactions between these levels would be expected to provide an adaptive solution process. Our case shows communication and thus flow of information between all levels involved, partly through the documents produced in the EIA procedure, partly through personal contacts in the actor network. Yet the problem definition ultimately has only been changed marginally in adhering to the original WWK96 problem interpretation. Therefore second order learning (defined in sections 2.4 and 2.6.2) appears not to have taken place in the DAR $1+2$ EIA project. This is remarkably because informants told about changes in policy that did take place in the other DAR projects. For example, in DAR $3+6$, according to informant no. 14, the dike improvements along the Zwarte Water were minimized by the personal efforts of Grontmij employees. These 
convinced the traditional dike builder type of persons also involved in the project of several ways to prove the strength of the existing dikes, thus preventing the TAW guidelines to be applied without consideration for the specific local situations. These efforts required considerably time and additional investigation of existing dike strength, which was allowed by the supervising authorities on the Water Board and Provincial level. Another example is the DAR 5 project. Here the personal efforts of individual employees on the executive and management levels prevented a major dike improvement conform the TAW guidelines (which required a layer of clay on the dike surface), by proving that a grass revetment would have sufficient effectiveness for the same purpose as the clay layer. This change in policy required all levels of authority to cooperate in a change of the TAW guidelines, which indicates that the original policy was adapted and a second order learning process took place in this project. Surprisingly, the comparable efforts of employees (e.g. informants nos. 2, 4, 10) within the DAR $1+2$ project did not succeed in changing the dike ring policy application on dike ring 53. On the contrary, their efforts now induced substantial resistance from e.g. informant 13.

The three different cases mentioned above exhibit different characteristics with regard to the specific nature of the problem, which might explain why in the DAR $1+2$ project a change was not effectuated. In the other two projects the discussion concerned technical aspects, whereas in the DAR $1+2$ the discussion also involved administrative aspects. In DAR 3+6 the "dike builders" had to be convinced of alternative implementations of the TAW guidelines. The learning process concerns the recognition of alternative ways to comply with the guidelines, which constitutes a first order learning process involving a single level of authority. In DAR 5 also the higher levels of authority had to actively participate in the change. Informant no. 4 mentioned how managers had to be convinced to cooperate, in this specific Vecht situation, against the "delta dike perspective" on dike construction at that time. Additional research was funded (and caused a delay in the project) and the resulting technical arguments proved sufficient to cause an extension of the TAW guidelines with grass revetments. The similarity between these two projects is that the discussion involved technical matters only. Apparently such a technical discussion succeeded in a feedback loop trough all levels of authority and a second order learning process occurred that changed the common frame. In DAR $1+2$ technical opinions interfered with opinions on institutional responsibilities and interpretations of the WWK96, and ultimately the discussion was decided on the basis of non-technical arguments (see the decision explanation model in section 5.5). Apparently, when nontechnical arguments enter the discussion a feedback loop is less likely to be established. Potential learning points available in such a loop could have been the interpretation of WWK96 (allowing for a norm differentiation and a risk approach), the integration of defence against high outer water with the management of regional water. Also the legal definition of external water ("buitenwater") in the Overijsselse Vecht delta system, and the admissibility of citizen complaints against dike improvement plans when the complaining person lives within the dike ring but does not actually own land on the dike, could have been clarified, as was indicated by Van Hall (2003) in his comment on the ruling of the Raad van State. 


\subsubsection{Examples of knowledge construction}

The way knowledge or meaning is constructed depends on the (different) interpretations of available information by the actors. This construction process was described in sections 2.4 (on frames) and 2.5 (on mental models). In section 1.1 .3 and 2.6.5 we noted that social construction takes place within the available uncertainty ranges of the information. Deconstruction of opponents takes place within the same boundaries. In our case several examples of construction and deconstruction can be found. These are presented in the present and the next section.

\section{Uncertainty in the interpretation of the WWK96}

In the interpretation of the "Wet op de Waterkering 1996" (WWK96) the Water Board made several choices that had consequences for the course of the decision making process. These choices concerned elements nos. 2, 3, 5, 6, 9, 10, 11 and 12 in the data matrix (table 5.1). These choices appeared to have played a decisive role in that they ruled out many alternative solutions. Common for these choices is that they called upon a higher authority to produce irrefutable arguments to make the barrier alternative inevitable. Some non-Water Board informants questioned the legitimacy of the argumentation because they considered these choices to be the own responsibilities of the Water Board and considered other valid choices to be possible.

For example, informant no. 5 (a civil servant on the national RWS level) noted that in the past the Weteringen dikes have been specified as primary dikes following the then existing administrative arrangements. The course of dike ring 53 has not been re-reexamined since. This, in the opinion of informant no. 5 , would have been possible. But is the the Water Board who has to take the initiative for such a change, which they did not [I5:36]. The chain of responsibility is from Water Board to Province and ultimately to the National authority. Therefore the national level cannot, and will not, prescribe how a specific problem situation must be solved. Informant no. 5. considered the Water Board to be fully capable of dealing with the problem and their approach fitted the dike ring philosophy $[15: 38,63]$. According to informant no. 5 situations have occurred in the Netherlands where a dike improvement was postponed e.g. to harmonise it with other activities under the condition of no imminent danger and the availability of emergency measures. But stopping the barrier alternative EIA in favour of a further search for a possible more optimal solution has never been considered. The Water Board just claimed to follow their legal responsibilities with regard to dike ring 53 [I5:78]. In the opinion of informant no. 5 the "Raad van State" could have asked for further research to be performed, but this court refrained from entering into technical and administrative details of the matter [15:81]. According to informant no. 5 the "dijkgraaf" of Water Board Groot Salland was very concerned about the Provincial opinion against the barrier, because it opposed his responsibilities, and therefore invoked the higher authorities to convince the Province (see the letter of RWS in the appendix of the EIA report [I12:42, 45].

In contrast to the opinion of informant no. 5, informant no. 13 (the "dijkgraaf") stated that the discussion about the removal of the Weteringen dikes from dike ring 53 with or without the Zwolle barrier was decided by the national authorities who stated that such a removal needed a barrier [I13:18]. 
Informant no. 12 (also on the national RWS level) put the matter in perspective. According to him the barrier serves low frequency events, and will not be closed otherwise. The barrier was, in his opinion, legitimised by the large damage which an extreme event would cause without barrier, its frequency of occurrence, and the feeling that the social acceptation of flooding damage diminishes [I12:35].

Our analysis of the interpretation of the WWK in the case reveals a situation where the authority on the national level adopts an Administrative perspective and puts the responsibility for the barrier alternative at the local level first responsible authority, and confirms the local views.

\section{Uncertainty in calculation models (physical as well as statistical)}

Important aspects of model calculation uncertainty in the case were:

- The MHW's could not be calculated with certainty, because the boundary conditions for the calculation of the maximum discharge scenario are subject to discussion. The scenario presumes a co-occurrence of the discharge peaks of the river Vecht and the Weteringen. Other sources of uncertainty are values water level at Lake IJsselmeer, the discharge rates, the model schematisation, and the value of the wind hiding coefficient.

- The hydrological and hydraulical situation of the Salland water system has not been modelled adequately yet. The effects of closing the barrier on the hinterland were explored, but still have to be studied in detail in a modelling project that is currently under way.

- The possibility of flow reversal could not be entirely excluded,

- $\quad$ Future developments with regard to climate change and land use were uncertain, and might result in larger discharges then currently estimated.

These uncertainties were used by some actors to legitimize their choices.

Informant no. 13 drew a parallel between the Zwolle barrier and the Ramspol barrier. Ramspol will close approximately once a year in a storm situation. After closure the upstream water level will rise because of the buffering effects. When the upstream water level exceeds the downstream storm water level at the outer side of the barrier, the barrier will be lowered again. Thus the buffering process will only work when the Ramspol barrier closes at a relatively low water level. High water levels at Lake IJsselmeer before the storm will diminish the available water storage upstream the Ramspol barrier. The Lake IJsselmeer level, however, appeared to be an uncertain factor, and closure of Ramspol did already occur at higher levels than expected. When Ramspol is closed the river Vecht discharge will also raise the water level in the city of Zwolle. The Zwolle barrier is, according to informant no. 13, to offer protection for this situation, especially in times of high river Vecht discharge. Depending on the initial water level on the Zwarte Water at the moment of closure, the Zwolle barrier will open when the water level in the city of Zwolle exceeds the downstream level [113:21, 27]. Also informant no. 12 referred to uncertain future scenarios, which he considers, at some point in the future, to legitimize the Zwolle barrier [I12:38]. Both informant nos. 12 and 13 represent an administrative perspective. Informants from the technical perspective, on the other hand, considered the discharge in Zwolle to be always of such a magnitude that, given the very 
limited storage capacity of the Weteringen canals, the Zwolle barrier would never be closed.

Informants representing the technical perspective also pointed at historical data. Informant no. 10, for example, claimed that historical floods proved the dikes along the Weteringen to be safe. And informant no. 11 explained that the chance on a flow reversal in Zwolle is extremely small [111:37]. This information, however, is disregarded by informant no. 13. This informant claimed that historical data are not valid any more because of recent changes in the water system, and that extensive, not quite unproblematic model calculations confirmed the potential danger for the city of Zwolle I13:27, 33].

Although informant no. 13 suggested, on the on hand, that the Water Board judged the situation from a risk perspective; the actual decisions were made from the traditional safety perspective. Informant considered the use of large safety margins to be a good approach [113:24,45]. He also doubted the reliability of the applied probability models in the MHW calculations. The 1998 extreme precipitation episode proved how a 80 to 90 $\mathrm{mm}$ in 24 hours rainfall event in the river Vecht basin (including the German part), in combination with an already saturated soil, could produce much more water hindrance that previously expected [113:30]. The high water in Zwolle in February 2004 was, in the opinion of informant no. 13, a narrow escape that proved his argument. When the wind force had not been the force six measured then, but instead force eleven, the city of Zwolle would have been flooded [113:48].

Informant no. 3, a Water Board civil servant, used the theoretical small probability on occurrence of the worst case scenario, in which several dikes along the Sallandse Weteringen fail and water from the river Vecht was calculated to enter the Salland region, to defend the Zwolle barrier decision [13:13].

\subsubsection{Examples of deconstruction of adversaries}

Effective risk communication depends on the trust and credibility of the communicators (Zaruk 2004), and Schön\&Rein (1994) consider of mutual trust to be an important factor of successful frame reflection. The absence of trust in the case is illustrated by several examples in which adversaries try do deconstruct each others arguments.

For example, informant no. 10 expressed fierce opposition against the arguments of the Water Board, in both advisory committees, public participation events, the local press, procedures of objection at the Province and appeal to court, and questions asked in Parliament to the responsible minister. This opposition can be regarded as an attack on the reliability and credibility of especially the Water Board, but also of the Provincial and the National authorities. In response, the Water Board claimed that the barrier would really improve flooding safety and would close once a year, and that the worst case event already had a narrow escape. Response to specific arguments of informant no. 10 was very limited. Only at a general level the Water Board stated that the necessary storage capacity upstream the Zwolle barrier would be realised in future. Future measures included the stopping of runoff discharge pumps in the polders and landscape 
reconstruction in the context of WB21 and "waternood" (which were already identified as alternative solutions in the early phase of the EIA procedure, see chapter 4). Research into the effectiveness of such measures was announced already in the EIA report, but the modelling project started only after the barrier decision had been made. Several informants representing the Technical perspective doubted the effectiveness and are still eagerly awaiting the modelling results, which must prove a reduction of the Weteringen discharge to almost zero to be feasible in case of closure of the Zwolle barrier. In the opinion of informant no. 10 the future measures will boil down to the same effect that the worst case scenario tries to avoid, that is the flooding of the Salland polders. The only difference being that these are now not officially designated as emergency detention areas.

An other example is the critical comment expressed in the second opinion report by informant no. 11, who considered the calculations performed by the Water Board using the DUFLOW model not to be valid. Remarkably the technical informants presented their criticism in a very gentle manner, as was also the case in the EIA evaluation report coauthored by informant no. 7. The latter, in his advice to the Province, suggested to reconsider the barrier alternative and try to find a more integrated solution for the problem. Informant no. 13 did not consider this advise, for him the approval of the EIA was the only aspect relevant. Also remarkably was the disregard bij the Water Board of earlier research on the Vecht and Weteringen discharge performed in 1992 (Burgdorffer 1992). This report concludes a coincidence of Vecht and Weteringen discharge peaks.

The persistent opponents of the barrier alternative, informants nos. 2, 7, 10, and 11, all had a civil engineering education and a function that involved them in the technical aspects of the problem. Their opponents were marked by an administrative function in their organization, and informants with a management function sooner or later gave way to the administrative point of view, irrespective of their educational background. The arguments of the barrier opponents have been invalidated or declared irrelevant by the barrier proponents.

For example, informant no. 13 stated that informant no. 10 was the one and only opponent, and suggested that this sole source of opposition made it suspect. According to informant no. 13, no tensions were otherwise present between the administrative and the technical line of thinking [113:09]. This opinion is contradicted by several other informants, like nos. 2, 7, 11 and 14, who did experience conflict between those two lines of thinking.

Another example of the deconstruction of opponents was the remark of informant no. 13 that, although informant no. 10 had a fabulous historical consciousness and knowledge to draw upon in the discussions, this informant did not recognize that his environment had changed in the past fifty years, like the funnel-shaped entrance to the Ramspol Barrier resulting form the land reclamation projects in Lake IJsselmeer. Therefore his memories could not always be considered to be valid anymore [113:10]. This opinion of informant no. 10 is contradicted by recent publications of informant no. 13 (Van der Schrier 2002, 2003b). Moreover, informant no. 13 initiated the Ramspol barrier plans, and was very well aware of the resulting situation upstream the Ramspol barrier (see e.g. Ramspol 
1988). Also other informants contradicted the opinion of informant no. 13. For example informant no. 9 regarded him, based on his personal experiences since 1983, to be a very competent person, without any self-interest, and a great loyalty towards society [19:16].

On an administrative level, informant no. 13 considered the way the Provincial executive in charge of the dike improvement handled the situation to express an attitude of indecision, and a lack of courage to dismiss the technical arguments of informant no. 10 [113:45]. In general, informant no. 13 complained about the lack of knowledge of the provincial civil servant, and the weak administration of the Provincial executive. His main complaint seemed to be that, where all over the country dike rings were being closed and reinforced, the delay in Overijssel was intolerable [I12:25].

The situation of persistent controversies in the DAR $1+2$ project is in sharp contrast with the course of the earlier DAR projects. In those projects controversies also existed, and were heavily debated, but research resulted ultimately in a common solution. E.g. the limited dike improvements along the Zwarte Water (DAR 3,6) and the use of grass revetments along the river Vecht dikes (DAR 5).

\subsubsection{Public participation}

The post-normal principle (section 2.7) involves an open communication about the problem. One aspect of communication is the participation of stakeholders, which is addressed in this section. According to (Pröpper\&Steenbeek 1998) the level of openness is an indicator for the distribution of influence between the project initiator and the other participants. More openness corresponds to wider opportunities to exercise influence.

The chain of events in the EIA procedure has been described in section 4.5. In this chain we discern four major phases: an initial phase (where the problem was analysed and many alternative solutions were devised), an intermediate phase (were some alternatives were detailed using model calculations and a selection was made), the EIA report production phase (where the selection was narrowed down to the barrier against the full scale dike improvement alternative, and including the approval by the Provincial Executive Council), and the phase of appeal and protest.

A remarkable difference in the level of public participation appeared between the first and the third phase, the second phase denoting a kind of changeover. In the first phase the level of participation was relatively high, and was organised in the advisory groups, the public participation events prescribed by the EIA procedure, and in informal contacts. Parallel to the official EIA procedure, a more informal technical scientific discussion took place between actors in this case. Mainly within the project group at first, and subsequently in the advisory group [114:06]. The stakeholders participating in the advisory group have discussed the concept (working) documents that were being produced by the project group for the formal procedure. These discussions had a very lively character, some of the aspects discussed resulted in additional research, which accounts for some part of the project delay [14:06]. In this way the advisory group had direct influence on the EIA-report [14:100]. Informant no. 7 described the atmosphere 
as remarkably open, and rules were creatively bended in favour of meaningful measures [17:86]. The advisory group requested the search for solution alternatives against a large scale dike improvement, a possibility that was already indicated in the "Nota van uitgangspunten" (Grontmij_Projectbureau_DAR 1997a). The "startnotitie" concludes that such an alternative necessarily must be sought in a change of the legal status of the Weteringen dikes, and suggests to find such in solution in a more regional approach trough a combination of DAR1 an DAR2 (Zwolle) (Grontmij_Projectbureau_DAR 1997b:35, 36).

The participation of public stakeholders within the advisory group had been difficult to arrange, because of lack of public interest. One of the participants, after some urging from the project leader, was informant no. 10 on behalf of the "Bond Heemschut" (a society for cultural heritage). Other participants were "Natuur en Milieu Zwolle" (a nature interest group) and the "LTO" (an agricultural organisation), and many others covering a broad range of local interests. To the opinion of some persons, few of the participants were seriously involved with the dike improvement problem, many were just guarding their own interests. The advisory group had been involved right from the start (already in the production of the "startnotities"), and had been consulted before the important decision events, especially at the selection between alternatives (EIA-report 2001:1, 119 and figure $B$ 7.1). At the end, all but two participants of the advisory group agreed to the barrier alternative (EIA-report 2001:82). The exceptions, who claimed the barrier would have no functional value for the high water protection, were both civil engineers from profession [I10]. The input of the engineers made in the advisory group were not been seriously responded to, in their opinion [I1, I10].

This event marks the starting of the third phase. Informant no. 7 pinpoints the moment of changeover to be located between the intermediate advice given by the Commission EIA and the final EIA report [17:66]. In this third phase the participation was limited to protest, objection and appeal, and the processes of construction and deconstruction described in the previous sections became dominant.

The limited participation in the later phases is in agreement with an earlier analysis made by Vogelezang (2002), who concluded that the problem solving style ultimately applied in the Zwolle storm surge barrier project (in the production of the EIA-report) should be labelled as "consultative", which is rather low on the participation ladder of Pröpper\&Steenbeek (1998) and Pröpper (1999). In contrast the early style of participation (in the production of the "startnotities" and "tussennotities" can be labelled as "active cooperation and discussion and initiation of research", which is higher on the ladder.

\subsection{Schön\&Rein's frames}

In section 3.2 we described the method of Schön\&Rein (1994) to analyse persistent controversies using frames. In this section we will compare their method with our case and will look at frame differences and frame changes present within our case. Our case exhibits almost the full range of frame aspects described by Schön\&Rein (1994). Several processes of frame reflection took place in the case, but did not result in a commonly 
shared decision. The controversies remained notwithstanding the existence of an integrating inundation alternative.

Schön\&Rein (1994:29) claim that controversies are generated by frame differences. Examples of frame conflicts found in the Zwolle barrier case are mainly based on differences between a Technical and several Administrative frames. The technical frame contains the knowledge about the water system and the related uncertainties. The different administrative frames contain the legal responsibilities (e.g. visible in the controversy between informants no. 2 and no. 1 within the Province, and between the Province and the Water board), the legal liability for flooding and construction damage (e.g. visible in the controversy between the Province and informant no. 13), the financial arguments with regard to National support (e.g. the controversy between civil engineers opposing the inclusion of the Weteringen dikes by the administrators). Other frame differences concern a short term (e.g. WWK96 compliance and upstream water storage) versus a long term (e.g. WB21) perspective, and a norm following (e.g. TAW guidelines) versus a situation dependent practical (e.g. historical proven dike strength) approach.

The case shows several examples of an evolution of frames over time. For example, the development of the Sallandse Weteringen discharge system started in the early middle ages, and has always used the low areas upstream the city of Zwolle for inundation purposes. The construction of the "Afsluitdijk" in 1932 changed this policy, and the change was effectuated at the 1960-1970 reconstruction. Dikes along the Weteringen were to prevent inundation. Only recently, within our case, inundation re-entered the perspective of water managers because of the limitations of the current water system to accommodate extreme situations. Another example of change over time is the development of the administrative institutions. In the nineties national tasks were decentralised, the Provincial water boards were abolished, and new large Water Boards took over their tasks. These changes required the institutional frames to be adapted in relation to distribution of responsibilities. In the same period the legal framework changed and the "Deltawet Grote Rivieren 1995" and the "Wet op de Waterkeringen 1996" were adopted. Different perspectives competed in these changes: a civil engineering perspective (strong and safe dikes) versus the inclusion of other interests (like nature, landscape and cultural heritage). A last example is the change from the prior motivation to include the Weteringen in dike ring 53 for financial reasons into a perspective that considers this inclusion questionable from a technical perspective. This change appears to be initiated by the consequences of the WWK96 [19:23].

Different levels of the policy-making process can be observed in the case, which is illustrated by figure 6.1. The National level establishes the WWK96 safety norms and the TAW guidelines to put these norms into concrete dike design specifications. The Water Board applies the norms and guidelines, and interprets the guidelines for the specific local situation. This interpretation also contains local interests. The Province monitors and approves the Water Board plans, but at the same time guards its own, broader interests and responsibilities. The municipalities have to grant building permits and changes in zoning plans with their local political and social context, but eventually can be forced by the Province to cooperate with the Water Board Plans. Citizens were found to be active at every level, see also the social map in figure 5-2. They try to oppose the plans of 
authorities for reasons of technical integrity, unbalanced individual disadvantage or possible financial profit.

Also a difference between central and local policies is visible in the case. The National authority uses the dike ring philosophy to determine the protection level against external water ("buitenwater"). But the Water Board has to integrate this national philosophy with their other water management tasks, notably the precipitation runoff discharge, and has to find an optimal solution within the given national framework. Their concern is an optimal use of the WWK96 for local purposes.

The rhetoric frames implicit in espoused policies differ from the actions frames implicit in policy-in-use. For example the Water Board publicly communicates to build a barrier that will protect the city of Zwolle against high water once a year. Technical reality, however, prohibits the closure of the barrier, a fact that the Water Board will undoubtedly be aware of. Also the Water Board's claim that the barrier is the only alternative left by the National authority's directive differs form the statements on the national level that a Water Board is responsible for, and therefore can create, their specific interpretation of the WWK96. Finally the announced careful weighing of all interest involved differs from the way the Water Board forced the decision at the level of the Provincial Executive.

Formal policies in the case also differ from the policies implicit in the practices of streetlevel bureaucrats. Several civil servants and consultants identified implementation margins in the WWK and TAW guidelines, and tried to use these in their creation of alternative solutions. Changes in policy were initiated at a personal level (e.g. by informants nos. $1,2,4,6,10,14)$. In our case these initiatives did not succeed. In the other DAR projects, however, policy indeed changed as a result of personal initiatives.

Visible shifts of policy and the cumulative effects of small changes of policy made in response to changing situations in the case are, for example, the insight that a full scale dike improvement was technical unnecessary and lacked social support. This insight made the actors aware of the unforeseen adverse consequences of their earlier institutional efforts to have the Weteringen dikes included in dike ring 53. In their search for alternative solutions the (history based) detention principle at first seemed to be promising, but appeared to lack support from the local farmers. Subsequently the barrier alternative was devised, but this lacked support from the civil engineers based on the working of the water system. Ultimately the long term WP21 approach was used to reconcile the different perspectives, but did not succeed in this purpose, since the opposition against the barrier continued. A potential change of frame was present in the possibilities offered by the use of detention areas. But this potential could not be used because of perceived political, legal and financial responsibilities conflicting with it (as is illustrated by the decision explanation model in figure 5-3).

Schön\&Rein (1994) suggested several strategies for escaping persistent frame conflicts. The first is looking for stubbornly resistant facts, which opponents may agree upon, through the lenses of their own frames (see section 3.2.3). Such facts are present in the case. For example, all actors agree that the Weteringen dikes should not be submitted to a full scale WWK96 improvement. All actors agree that the application of the WWK96 to 
the Weteringen dikes as part of dike ring 53 is senseless (e.g. [14:28]). Other facts are recognised but their interpretation is still controversial. For example the location of the Zwolle city centre outside the dike, historical data on water levels, discharge flow direction, dike strength and flooding, and precipitation statistics. The second is an appeal to consensual, logically independent criteria for evaluating conflicting frames and choosing among them. In the case such criteria might have been found in the risk approach offering a new interpretation of the WWK, and in the application of norm differentiation within a single dike ring. Both approaches would have fit in the WB21 philosophy. The third is a frame-translation, in order to understand one another's conflicting views. Some of these frame translations appear to have taken place in the case. For example, informant no. 10 stated (in the interview) that the Water Board and the Province hardly had any other choice, given the situation at the National level. Informant no. 7 stated that in hindsight he now was able to fit his technical perspective within the broader administrative framework. Informant no. 14 stated that, afterwards, the barrier alternative could be considered the best alternative when the goal was preventing a full scale dike improvement in Salland. Informant no. 13 stated that the tense relationship between Water Board and Province could be explained from the historical institutional developments that changed the Water Board from a small institute guided by the technical and administrative power at the Provincial Water Management Department into a full scale independent and autonomously operating institute having adequate knowledge and power for itself.

Three different major frames appeared to have been constructed in the end of the EIA procedure: a technical frame (containing the water system knowledge), an administrative frame (containing the distribution of responsibilities), and a legal frame (containing liability matters). About the same situation different stories can be told from different perspectives, each story conveys a very different view of reality and represents a special way of seeing. Through the process of naming and framing, the stories make the "normative leap" form data to recommendations, from fact to values, from "is" to "ought" (Schön\&Rein 1994:26). The technical details end up in the story told by the decisionmaker-in-chief to shape public consciousness about the issue and to convince his audience. Several stories are told by actors about the physical aspects of the case situation. For example:

- $\quad$ About the NW storms that quickly raised the water level in the Zwolle city canals and the Sallandse Weteringen within a period of two hours as a result of wind effects blocking the discharge.

- About historical floodings of the Zwolle city centre, and how people used to seal up their door posts using clay to keep the water out [I13:11].

- $\quad$ About the reducing effect the old inundation areas in Salland used to have on the water levels in the Zwolle city centre, and how the same principle could be used again in modern times.

- About the design of the Salland water system and how the low areas are bound to flood in extreme situations regardless the barrier, and even more so when such a barrier would be closed.

Also stories are told about the administrative and legal context:

About how the WWK96 forces the minister to either improve the Salland dikes full scale or build a barrier. 
- About the impossibilities of local relaxation of the WWK because such would cause a precedent for other projects.

- $\quad$ About the national funding of dike improvement projects that might be lost when the Water Board not timely complies with the WWK96.

- $\quad$ About the need for adequate high water protection in the city of Zwolle.

- About the prevention of decline of nature, landscape and cultural heritage values.

- About how possible inundation damage causes societal disturbance in the farmer communities in Salland.

According to Schön\&Rein (1994:26) the "normative leap" proceeds through generative metaphors that are contained within the stories. Metaphors guide the decision making process on a high level of abstraction, by comparing the issue at hand with a issue on a more general level. In our case we found several metaphors to be operative. For example:

"Dike ring 53 is like a polder with a scouring sluice" (EIA-report 2001:54) [I7:14]. This draws a parallel with the low polders in the West and North of the Netherlands, which in the past years frequently have been afflicted by flooding through extreme rainfall. This metaphor is, however, not correct because the Salland Water system operates under free flow discharge in all situations. Only in rare occasions (with a very low frequency of occurrence - lower than the existing safety norm) the Zwolle barrier would close [I10:8].

- $\quad$ "The Weteringen are just like any normal tributary that has limited discharge when the water level in its main river rises" [17:24]. This suggests that, like any other tributary of the large Dutch rivers, the Weteringen do not fall under the definition of a dike ring.

- $\quad$ "The Zwolle city centre is located outside the dike". This is factual true, but hardly recognisable on the spot. The metaphor activates the memories of the citizens with the picture of flooded areas like in the river forelands, and stimulates their feeling of insecurity. The metaphor also suggests that such a situation badly needs protection, and any argument against the barrier would than be against the personal safety of Zwolle citizens also. In this way the Zwolle barrier becomes a symbol for safety, irrespective the technical opinions against it [I10:84].

- $\quad$ "The beautiful ancient Holland river landscape with its meandering dikes needs protection". This general picture is not applicable to the Salland Weteringen dikes, because these are all very recently (1960-1970) constructed straight canals.

- $\quad$ "The EIA represents the struggle between dike building technocrats versus LNCvalues protecting administrators". This metaphor suggests the Zwolle barrier to be an elegant solution serving both camps.

- $\quad$ "We must be prepared for an uncertain future where the sea level rises and extreme precipitation increases". This metaphor suggests these conditions to be scientific facts that might already influence the current generation of Zwolle and Salland inhabitants. According to informant no. 7 this scenario might perhaps come true in say 500 years. 


\subsection{Reflection on case results}

In section 1.1 we concluded from literature the following claim:

The solution of complex, unstructured problems in integrated water management is faced with controversy and dispute, unused en misused knowledge, project delay and failure, and decline of public trust in governmental decisions.

With regard to our case, the dispute ${ }^{4}$ is visible in the debates between the Technical and the Administrative perspective, e.g. the technical arguments presented by informants nos. 2, 7, 10 and 11 .

Controversy ${ }^{5}$ is visible in continuous separate efforts of Province and informant no. 10 to decide the conflict in accordance with their opinions. Unused knowledge is e.g. the unused data and research reports on high water peak discharges, and the estimated frequency of closure of the barrier. The presentation of a closure frequency of once a year, the disregard of the principle causes of inundation in Salland, and the specific interpretation of the distribution of responsibilities by the Water Board can be regarded as examples of misused knowledge. Project delay is cause by the additional research and deliberation started in the initial phase of the EIA project, the delay of the permitting procedure by the Zwolle municipality, and the objections and appeal to court by informant no. 10 and other citizens. Project failure is a matter of perception, but from the Technical perspective the barrier can not be closed currently, and the effect of future land reconstruction projects for discharge reduction is doubted. Decline of public trust in governmental decisions is visible in the publications of informant no. 10, the personal policy opinion of informant no. 2, the resignation of informant no. 7, and the careful criticism of informant no. 11. In the case the civil engineers, after having used every available means to oppose the administrative arguments, ultimately resigned in the primacy of the administrative (organisational + political) perspectives. In the remainder of this section we will analyse the success and failure of the problem solution more in detail.

\subsubsection{Has the unstructured problem been solved?}

Complex unstructured problem situations require an interaction of the problem solution with the larger context, changing the definition of problem (see sections 2.3.1 and 2.3.2). Below we will analyse the case on these aspects.

The initial problem of the DAR-1 and DAR-2 projects concerned the legal obligation for dike improvement along the Sallandse Weteringen and in the Zwolle city centre, respectively. In the course of the EIA project DAR $1 \& 2$ have been repeatedly joined and

\footnotetext{
${ }^{4}$ Dispute $(\mathrm{m}-\mathrm{w})$ : to engage in argument : DEBATE; especially : to argue irritably or with irritating persistence. transitive senses $1 \mathrm{a}$ : to make the subject of disputation $\mathrm{b}:$ to call into question <her honesty was never disputed $>1:$ a discussion marked especially by the expression of opposing views.

5 Controversy (m-w): 2 a : bitter sometimes violent conflict or dissension <political strife> b : an act of contention : FIGHT, STRUGGLE )
} 
separated. The final decision implies a disconnection of the legal protection against external high water ("buitenwater") from the management of regional discharge high water, and marks a separated solution.

The quays in the city of Zwolle presented minor problems only. These problems concerned a few locations where the heigt was insufficient, and the use of the quays for cables and pipes and trees. The latter, although it had not been regulated, was considered not to present a real problem by experts [17:80]. It was, however, administratively used as an argument in favour of the barrier, by claiming that all foreign objects would have to be removed from the quays. With regard to flooding damage legal liability would pose no problem because the city centre is located outside the dike.

The situation for the Weteringen dikes was different from Zwolle. The WWK96 demands on dike improvement would result in an enlargement of the dike body that was considered to be technically senseless and lacking social support. The Water Board, however, would be liable for flooding damage (mainly agricultural) when the dikes were not brought up to their legally required "delta" strength. This possible flooding damage has been problemised. For one by the farmers who claimed financial regulation in case of development of inundation areas. Remarkably, an other potential financial claim originated from a local electricity production plant, who had an existing agreement that their high tension masts should always accessible with heavy equipment, also in case of inundation.

The above exploration of the initial problem resulted in the generation of many alternative solutions in the initial project phase, see section 4.6.1. At the end of the second project phase the Water Board decided for the barrier alternative, which would allow a withdrawal of the problematic dike sections from dike ring 53 and thus a change of legal status from primary into secondary.

A change of status would, in Zwolle, prevent a discussion about the installation of foreign objects tolerated for many years without any administrative control with regard to the primary status of the quays. Also the construction of a barrier would provide the Zwolle city centre with legal protection against flooding with water external to the dike ring. Remarkably, the probability of such flooding was estimated by expert to be lower than the $1 / 1250$ per year level required by the WWK96 in the situation without barrier.

Moreover, the barrier will not, and legally need not, protect the Zwolle city centre from flooding with regional discharge water.

A change of status would, along the Sallandse Weteringen, prevent full scale dike improvement. The dike can now be improved to comply with the regional demands of e.g. 1/100 per year. The barrier is considered to protect Salland against high discharge levels from the river Vecht in combination with a NW storm. The worst case scenario will occur when, under such conditions, several dikes along the Weteringen will fail and the Weteringen discharge will completely be diverted through the dike failures. In such event the water from the river Vecht may, according to model calculations performed by the Water Board, enter Zwolle and Salland, and the barrier will provide the legally required protection against "buitenwater". The same calculations show, according to technical experts, that the amount of damage will hardly change by the presence of a closed barrier. Furthermore the technical experts claim that the probability of flow reversal in Zwolle his highly unlikely. The flooding damage will be caused by regional discharge 
water, for which the Water Board is not liable, and has a probability of occurrence of $1 / 100$ per year. The 1998 extreme precipitation event is an example of such an $1 / 100$ per year event.

The above consequences of the barrier solution present new problems as well as considerable opposition. This is in accordance with the characteristics of complex unstructured problems, where problems and their solutions appear to be connected to the broader context. With regard to Zwolle we are now confronted with a barrier which can not be closed because of the lack of upstream discharge storage in the Weteringen. An additional solution is constructed through the integration of the storage problem into the long term WB21 land reconstruction projects. On the short term distance controlled shutdown of polder pumping stations and raising of weirs is considered to offer a first alleviation of the storage problem, in combination with a low closure level of the Zwolle barrier. New problems, however, lie ahead because model calculations have yet to prove the adequacy of this set of measures, which is already doubted by technical experts. Also with regard to Zwolle, the barrier wil hardly ever close because the frequency of occurrence is estimated by technical experts to be very low. This argument is opposed with reference to climat change effects (sea level raise and extreme rainfall increase), which might change the frequency model. According to informant no. 7 such change would make a barrier inevitable in say 500 years from now. Before constructing a barrier, however, this informant considers the enlargement of the Zwarte Water storage basin area a preferable alternative.

With regard to the Sallandse Weteringen water system, the local storage in land and ditches is insufficient to allow shutdown of polder pumping stations and raising of weirs without local flooding. WB21 "Waternood" measures will only offer temporary relief, once the soil is saturated and the ditches are filled, the water will again discharge (under free flow or with pumps into the Weteringen) or, alternatively, cause flooding. For the higher parts of Salland, at such occasion the raised weirs will cause the water to flood the land adjacent to the Weteringen, and the flood will continue its natural course into the lower areas of Salland.

We can conclude that the case situation poses an example that exhibits many characteristics of complex unstructured problems, also with regard to the embedding of the problem in its context. The initial problem formulation changed several times until it became a problem integrated in both its broader physical and administrative context. An integrated solutions has, however, not been reached within the EIA project.

\subsubsection{Each actor constructs its own truth}

The Technical perspective stated that the Zwolle barrier, conceived as a solution for the WWK96 dike improvement obligation, is not useful from a technical point of view because its closure in the worst case scenario would aggravate the damage. Also they claim that from an administrative point of view the WWK does not make the barrier inevitable, because the WWK96 does not prescribe a closed dike ring, but prescribes a safe control of high external ("buitenwater") levels. In this way the Technical perspective threatened to bring down the administrative arguments for a technical effective and and legal necessary barrier. 
The Administrative perspective counteracts the above opposition by using several specific interpretations of the WWK96. In the data matrix (table 5.1) these interpretations of concerned disputed elements (nos. 2, 3, 5, 6, 9, 10, 11, and 12) are marked in fat. These elements show how the Water Board influenced the decision process by pronouncing their institution specific interpretation as the truth, which inevitably resulted in the barrier decision. This interpretation, however, is disputed. Several other informants, also from authorities at a higher administrative level institution, produced scores which differ from the Water Board. This deviation can be regards as administrative manoeuvring space or uncertainty, which in our case has deliberately not been used by the Water Board to reach other available alternative decisions.

The Water Board is the first responsible authority for the WWK96, and has considerably freedom for its interpretation. On request of the Water Board the national authorities produced a letter stating that a dike ring must be closed, and that a change into secondary status of the Weteringen dikes can only be reached by the construction of a barrier. According to informant no. 11 this letter can be regarded as a formal directive to the Water Board, which subsequently can claim to have no other options and produce the EIA accordingly. According to this informant the technical arguments did not play any role whatever [111:74].

The above analysis of our case fits the description of Schön\&Rein (1994) who noted $(: 30)$ :

"Observers are always connected to a frame and therefore not objective in the sense of frame-neutral. Those who construct the social reality of a situation through one frame can always ignore or reinterpret the "facts" that holders of a second frame present as decisive counterevidence to the first (:30)."

Also, Schön\&Rein (1994) claim that (:36):

"Any given construction of a policy frame can, however, be tested against relevant data - for example, the texts of policy debates or the artefacts and routines of the policy-making process. Frame-critical analysts can and should ask whether these constructs fit the data, exploring, for example, whether these constructs account adequately for:

- $\quad$ The things and relationships the frame sponsor singles out for attention or selectively ignores,

- $\quad$ The way in which the frame sponsor's policy story executes the normative leap from facts to recommendations."

What a "frame sponsor singles out" is, in our case, made visible in the data matrix (table 5.1 ) by the scores of the informants. The elements for which scores are present apparently have informant's attention; other elements are disregarded (consciously or unconsciously). Therefore, a detailed analysis of the data matrix offers an instrument for Schön\&Rein's process of critical frame analysis.

Informant no. 9 [19:75] suggested that an explanation for the behaviour of the individual actors could possibly be found in the "distance" of the actor to (his perception of) the problem. This "distance" could be a measure for the amount of decision freedom an actor has, or perceives to have, with regard to his position. In this way "distance" would be 
equivalent with "objectivity". On the one hand, a larger distance would imply more freedom and objectivity to reach a genuine problem solution. On the other hand a larger distance would offer the freedom to include interests of other, possibly more nearby actors in the solution. In both cases the decision strategy of an actor would depend on the distance to the problem.

In response to this suggestion we note that, in the case of the Zwolle barrier decision process, the notion of "distance" appears to be rather complex and not easily defined. For instance, almost every informant presents a different answer to the question what he thinks to be the "root of the issue". The decision explanation model presented in section 5.5 (figure 5-3) structured these answers. When we define the notion of "distance" as the interest an actor has in the issue, and we define interest to be "that what is closest to an actor", that every actor has his own closest interest. An actor will act from his own positions in order to defend his own responsibilities and interests, both institutional and personal, as is visible form the perspective types ( $T, O, P, E, A)$ in section 5.3. Conclusively, arguments are valid only locally to the actor, and the institutional and informal social network power will determine the outcome of the decision process. In our case only the civil engineers appeared to be able to withstand the argumentation of the administrative perspective and to prove their own arguments. Other participants appeared to be, more or less easily, yield to the administrative argumentation.

The arguments from the technical perspective are used by the administrator-in-charge to derive elements for his story, because he wants to refrain from presenting technical figures. According to informant no. 12, the story is the decision maker's ultimate account the society [112:76].

\subsubsection{Actor integrity}

Several informants made statements regarding personal integrity. According to informant no. 4, for example, no player has been dominating the decision game. This, in his opinion, had always been a group process with group responsibility. For some actors such a group responsibility offered safety compared to personal responsibility [I4:74]. In contrast, according to informant no. 13, it was the attitude of individual persons that decided the course of the decision process [113:57]. Informant nr 7 indicated having had at one time a problem dealing with his personal conviction, objectivity and independency in the decision process, and ultimately decided that administrative considerations might very well balance the technical arguments without him being able to oversee the total picture [17:92].

Informant no. 9 illustrated the powerful position of technical advisors, because administrators are not in a position to judge the expert and therefore have to thrust his opinion. An administrative advice could be questioned and brought before court for a ruling to solve it, but the disregard of technical advice might have serious adverse effects which a court cannot decide upon. Therefore administrators can only function when trusting the integrity of technical advisors [19:85]. 
Another element of integrity is mentioned by informant no. 10, who stated that, once a decision has been taken within a certain group, a person is expected not to display doubts or even criticism in public, afterwards [I10:141]. In his opinion all resistance was in fact futile from the moment the Water Board Council approved of the EIA [I10:143].

\subsection{Conclusions}

The Zwolle barrier case exhibits all characteristics of a complex unstructured problem situation. These characteristics caused the decision making process to become problematic. Both scientific uncertainty and debated values played an important role. The different argumentations produced by the actor groups from the Technical and the Administrative perspective can be positioned at opposite ends of the available uncertainty range. Not only with regard to technical uncertainty, but also with regard to administrative interpretation of the WWK and TAW guidelines. In the "battle" of arguments examples are present of personal deconstruction of adversaries and of rhetorical presentation of selected information to support the decision finally taken. Different actors tell different stories to defend their position (see section 6.2). The trajectories of inquiry through the different communities of knowledge construction and related problem solving strategies (see Ravetz 1999) have been visualised in figure 6-1.

Our theoretical framework was well capable of describing the decision making cycle and its influencing processes in the case situation, and succeeded in revealing assumptions, limitations, uncertainties, interests, opinions, and expose difficulties in the application of knowledge (as was our claim in section 1.3).

The major frame conflicts present in our case concerned the differences between the Technical and Administrative frames. Within the latter we can distinguish between distribution of responsibilities, legal and political liability, and funding issues. The frames of different actors evolved over time, in that more details were accommodated, and insight into both the physical and administrative systems grew. The frame differences, however, were not overcome and the decision was ultimately forced by the decision maker-in-charge. The decision model (figure 5-3) explains how his decision was reached.

Our case presents an example of how the solution of complex, unstructured problems in integrated water management is faced with controversy and dispute, unused en misused knowledge, project delay and failure, and decline of public trust in governmental decisions. Although a decision was finally reached several years after the intended deadline, an integrated problem solution was not reached. The solution was limited to the well structured part of the problem by deliberately separating in form it broader context. This limitation can, in our opinion, be contributed to the lack of possibilities to search for an integrated solution involving all levels of authority, and discussing the additional problems that were raised by the integrated approach in the initial phase of the EIA project. The notion of "truth" appears, in our case, to be relative to the position of an actor within the actor network (presented in figure 5-2). The persistence of the disputes in our case shows that open communication alone is not enough to prevent decision making barriers. Apparently institutional and personal perspectives ultimately play a dominant role. 


\section{Conclusions}

\subsection{Introduction}

The challenge of learning to live with risk of floods (and other risks) implies three activities: becoming aware of extreme events and their risk (sources of risk), estimating the effects of extreme events, and building resistance or resilience against extreme events. For the latter, a shift from pure engineering towards a more integrated (flood management) approach is needed. Such an approach can only work when it is embedded in a theoretical framework that can adequately describe the problem situation from an integrated perspective. An integrated approach demands not only integration between scientific disciplines, but also integration between the diverse steps of the problem solving cycle (e.g. problem analysis, plan preparation, decision making and implementation) in close cooperation with other relevant land use functions and their associated stakeholders. Dealing with multiple stakeholders in a multifunctional system also means dealing with unstructured problem situations, where values are debated and knowledge is uncertain. These elements should therefore be included in the theoretical framework. In addition to the theoretical framework methods are also needed to analyse the elements of the framework and to promote integration of instruments for flood damage reduction. Such methods should stimulate awareness of the different frames of perception in operation by the stakeholders, offer techniques for frame reflection and the construction of new common frames, and should recognise institutional and personal barriers for integration. In our research we drew upon knowledge from the social and cognitive science disciplines to promote communication and learning between individuals and their organisations through frame reflection.

Traditional problem solving approaches are directed at control and remediation, identifying acceptable protection levels, and management of uncertain risks. In contrast to these "end of pipe" approaches, an integrated problem solving approach aims at finding new, less hazardous alternatives to reach the intended principal goals, in order to prevent risk when possible. Integrated problem solving consists of gathering, synthesising, interpreting, and communicating knowledge from various expert domains and disciplines, and is aimed at helping responsible decision makers and participating stakeholders to think about a complex problem and to evaluate possible solutions. The early phases of problem articulation and system analysis are especially important to guide the process towards a truly integrated problem solution. The philosophy behind integrated problem solving is that transparent and open communication about the problem from all perspectives involved can result in a decision that is more optimal than the solution attained from the perspective of a single actor. The research presented in this dissertation looks upon integrated problem solving as a process of production, transfer and interpretation of information. Interpretation in complex problem situations takes place from different perspectives. These perspectives might limit the possibilities of 
turning the available information into usable knowledge, and cause controversy and dispute, disregard and misuse of knowledge, delay and failure of projects, and decline of public trust.

The overall claim of this dissertation is that the analysis of mental models will identify communication barriers, by revealing the experiences, perceptions, assumptions, knowledge and subjective beliefs that a "mental model user" draws upon to reach his conclusion about some issue. Mental model analysis assesses tacit knowledge, broadens the narrow understanding of a problem by confronting one decision maker's, stakeholders' or scientist's map with the map of others, brings to light alternative perspectives on the problem, encourages negotiation and helps to reduce destructive conflict. The basic idea is to elicit a person's knowledge and consequently open it up to discussion. The results will be useful for helping decision makers, but also for scientists and stakeholders.

\subsection{Conclusion regarding the theoretical framework}

We started our research with a preliminary focus on the development of a theoretical framework for the description and analysis of integrated problem solving from the perspective of knowledge production and use. The description and analysis of the Zwolle barrier case using the theoretical framework developed in chapter 2 (see figure 2-5) confirms the usability of our framework in this specific case. The usefulness of figure 2-5 as a general model that is valid for different situations of problem solving is proposed based on literature from the three different theories that are integrated in this figure (problem solving, frames, and mental models). The case represents a complex unstructured problem situation, indeed. It contains debated values, uncertain knowledge, complex system interactions and multifunctional system use. The extension of Hisschemöller's (1993) two-dimensional representation with a third dimension "system complexity" (see fig. 2-3) provides additional insight. The actor network in the case is structured in terms of the post-normal fora of decision making described by Funtowicz\&Ravetz (1993b) (see fig. 2-4). The trajectories of inquiry resulting from the controversies raised around the "Zwolle Barrier" issue are plotted in the three concentric communities of knowledge construction or discussion arenas (see figure 6.1). The postnormal fora of decision making fit into the front side of figure 2-3 in its description of the types of interaction between scientific knowledge and value aspects of unstructured problems. The final framework (see fig. 2-6) allows us to place the mental models of actors involved in the problem in a central position of our analysis. It allows visualising the interactions between the mental models of decision-makers, stakeholders and disciplinary experts. Conflicting elements in these mental models are revealed by our method of analysis, and indicate "gaps" between the frames of decision makers, scientists and stakeholders. The meaning of the available information for a specific actor is the result of an interpretation and valuation process that occurred within the frame of perception of this actor, as is shown in the data matrix in table 5.1. The frames of the different actors guide the construction of the meaning of information, and thereby shaped decision positions and feeds controversy. The frame determines the boundaries of the problem solution space for each actor, and their preferred alternatives. 


\subsection{Conclusions regarding the research method}

Schön\&Rein (1994) propose several approaches and strategies for the frame reflection. They do not, however, offer a clear method for the preceding process of frame construction. According to them "we must become aware of our frames, which is to say that we must construct them, either from the texts of debates and speeches or from the decision, laws, regulations, and routines that make up policy practice" (:34). This merely implies that we can use document analysis and interviews as frame elicitation instruments, but no other more specific method. In our research we developed a method to elicit the frames of Schön\&Rein (1994), by separating mental models from the frame of reference (see fig. 2-7). In this way we can begin by eliciting and analysing the mental models of actors involved in a decision making process, without explicitly making reference to the more sensitive frame aspects of responsibilities and interests. These aspects are dealt with in a subsequent phase of the analysis method, where five frame perspective types are used to characterize the position of the actor on mutually contested elements of their mental models. The method is visualised in figures 3-6 and 3-9 and table 3.2. The approach brings to light and separates the "facts" and the "opinions", which subsequently could be discussed in an attempt to construct a common mental model and to possibly overcome (some of the) frame differences present. This last step, however, was not a part of our research. With regard to the case our research ended with an explanatory model of the barrier decision.

More than one single perspective type appeared to fit our informants, and the dominance of the types appeared to shift over time. The initial perspective type, ruling the behaviour of informants, appeared to be based on their function in their organizations, viz. their institutional responsibilities. The next perspective type appeared to indicate the manner in which informants deal with their responsibilities viz. initial perspective type. This second perspective type seems to be responsible for the greater part of the delays in the decision making process, because it explains the stubbornness with which informants defended their positions. The moment at which a change of perspective type occurred differs for each informant and appeared to be correlated to the moment the informant became frustrated in the practicing of his first type. Ultimately the behaviour of a few informants appeared to be restricted by personal interests in relation to institutional structures of power, or a resignation to established social and political structures.

With regard to Schön\&Rein's method for frame reflection, several aspects of their method can be recognised in our case. But, although the many discussions between actors did enhance insight into the technical functioning of the water system, the actors did not succeed in constructing a common frame between Technical and Administrative actors. Stubbornly resistant facts (a term introduced by Schön\&Rein 1994, see section 3.2.3) were disregarded by Administrative actors, or interpreted at the far end of the available uncertainty range. At the level of the individual actor, some Technical actors appeared to have incorporated Administrative and Political frame aspects into their Technical frame, because they ultimately accepted the barrier decision. Acceptance does not, however, imply that these Technical actors abandoned their technical arguments, but that they accepted the ultimate power of administrative arguments. The Administrative actors' stories used to defend their barrier decision contain metaphors to place their decision within a generally accepted set of norms with regard to flood protection and LNC-values. 
Local, regional, and national levels of decision making are present in the case, as well as differences between national and regional policies. Developments over time affected the decision making process, and almost postponed the barrier decision.

The data matrix method used in our research is suitable to analyse disputed concepts. The mental model analysis revealed assumptions and interpretations implicitly present in the various alternative solutions, and identified barriers to the construction of a common frame. The different actor perspectives were related to various opinions on contested elements of mental models. An argumentation model has been constructed that succeeded in explaining the outcome of the decision process.

\subsection{Conclusions regarding the research questions}

Our theoretical framework (see chapter 2) and method (see chapter 3 ) were applied to the Zwolle barrier case. The case concerns the decision making process about the improvement of sections of of dike ring 53, which was initiated by the Flood defences Act ("Wet op de Waterkering 1996" - WWK96). The Zwolle storm surge barrier case exhibits all characteristics of a complex, unstructured problem situation in a multifunctional system. It contains debated values, uncertain knowledge and complex interactions (see section 6.1.1). Elements of the mental model and perspective types were elicited from 14 stakeholders. Interviews were processed into mental maps and a data matrix table. A total of 68 disputed map elements were identified. The main map elements were processed into a causal decision explanation model.

In response to our first and second research question, we conclude from chapter four that the steps in the decision making cycle in our case are specified by the environmental impact assessment (EIA) procedure. The influences on the decision making cycle are specified for one part by the procedural participation advisory groups and events, and for an other part by the informal actor network. The use of technical knowledge is visible in the research reports delivered in the course of the EIA procedure, which partly refer to earlier research reports.

Stakeholders involved cover almost the full range of administrative organisations in Dutch society, and were situated at diverse hierarchical levels in their respective institutions. Based on the analysis of the field of actors and their interactions prior to the case, frame conflicts could be expected on the issues of compliance to the TAW guidelines, distribution of legal tasks and responsibilities, and citizen's protests. From the analysis of the case documentation, the main conflicts appear to be the difference in opinion between the Technical and the Administrative perspectives with regard to the preferred solution alternatives. The limitation of alternatives to only those that fit within the Water Board policy, instead of a full argumentation that would also include other criteria (like technical), raised resistance among the "owners" of those other criteria. The approval advice given by the Dutch Commission for EIA contains some critical remarks regarding the choices made in the EIA-report, and advises reconsideration of the barrier alternative by giving further consideration to water detention. The case analysis reveals that some of the disputes, which were already present in the early case documents, grew into intractable controversies that were never resolved during the course of the EIA 
project, but were contested up to the highest administrative court in the Netherlands, the "Raad van State". Other disputes, like those on the distribution of legal tasks and responsibilities, were settled in the course of the EIA project.

In response to our second and third research question, we conclude from chapter five that actors tried to exercise their influence in all steps of the decision making process using every available means and with great personal dedication. This not only included the procedural opportunities, but to a large extent also an actor's informal network. The mental models in use among the informants interviewed contain many elements that directly relate to their institutional functional positions, a relationship that was revealed by the analysis of informants' perspective types.

There was more than a single issue at stake in the Zwolle storm surge barrier case. First, there was the legal obligation to improve the dikes along the Sallandse Weteringen canals according to the Flood defences Act. Every stakeholder, however, agreed that this would result in an unnecessary and intolerable intrusion into nature, landscape and farmer properties, and that an alternative was needed. From a wide range of alternatives that have been considered at one time or another, the Zwolle barrier prevailed and was presented in the EIA-report in comparison to the original full-scale dike improvement plan. It is the argumentation in favour of the barrier alternative that presented the source of various conflicts. Furthermore, the issue of dike improvement entered another issue onto the agenda, namely that of water management in the Salland region. Disputes between frames are apparent in the list of disputed mental model elements (See the data matrix in section 5.2.1). Salient controversies that are present in the case are specified in section 5.6.1. The central Technical issue in our case appears to be water detention in Salland, from either extreme precipitation or storm surge, and not the Zwolle storm surge barrier. The central Administrative issue appears to be the "closed dike ring" principle. Throughout the dike improvement procedure proponents of both perspectives have tried to convince each other and the first (WGS), the second (GS of Overijssel) and third (Ministry of V\&W) authorities responsible of their arguments. This controversy was not resolved in the case. The barrier solution ultimately allows and facilitates a further development of the Salland water management plans and the implementation thereof, over the next fifty years.

In response to our fourth research question, we conclude from chapter five that, in the specific case analysed, the method developed to analyse mental models and perspectives that comprise the frame of an actor does indeed explain the persistence of controversies. It appears that the root of the issue lies in the unacceptability of the deployment of inundation areas for extreme high water events outside dike ring 53, where at the same time these inundation areas are effectively already operational for storage of excess local drainage water. The issue involved all levels of administration, from local residents (mostly farmers in the lower parts of Salland and inhabitants of the Zwolle city centre) up to the responsible Minister of Transport, Public Works and Water Management. A complicating factor was the uncertainty in the chosen worst case scenarios and in the calculated MHW's and expected inundation depths. The example of the Zwolle barrier case shows how our method is capable of surfacing contradictions in the decision making argumentation. In the end, the controversies in the Zwolle barrier case appear to involve 
regional support and acceptability, as well as the distribution of responsibilities between the Water Board and the Province. The opposition of the local farmers to the construction of inundation areas cautioned the Authorities to the existence of social pressure and resistance. In contrast, much less opposition was expected from the residents of urban areas, but the initiative of a single person also raised opposition there.

Despite the risk approach that was recently introduced in the State policy (the Flood defences Act 1996, in article 3.2, already allows for replacing the MHW safety norm by a probability on flooding caused by dike failure), in the present case a traditional safety approach was applied, based on the probability of water level exceedance. Dealing with uncertainties appears to coincide here with a "maximum safety" approach within the given legal framework, in order to secure responsibilities regarding the Flood defences Act and flooding liability.

\subsection{Conclusions regarding the post-normal hypothesis}

The hypothesis for this dissertation puts at the root of persistent controversies the differences in perspectives between actors. After the first development of our theoretical framework, however, we started from a different hypothesis. We hypothesised, based on the literature (that lead to the first two diagnoses, see section 2.7), that transparent and open communication is needed in order to construct a common mental model between actors, from which a common problem solving framework can be constructed to solve the problem. We called this the "post normal principle". We hypothesised that in cases where persistent controversies exist, this type of communication is malfunctioning because of perspective driven barriers.

Yet, while building the case description and analysing the documentation and interviews, we found a surprisingly well-organised and well-functioning communication occurring between the decision makers, experts and public. But in contrast to this communication, and although a decision was ultimately taken, the controversies which showed themselves in the early phase of the decision making cycle remained unresolved for several issues. This observation falsified our first hypothesis, because good communication according to the post-normal principles apparently did not result in a solution without controversy. Because our general goal (see section 1.3) is to develop a method that contributes to the improvement of decision making, we searched for a different diagnosis and adapted our hypothesis.

As a result of our observations in one specific case, we must now conclude that we disagree with the literature which states that open communication (of values, choices, assumptions, limitations and difficulties that underlie the use of knowledge), explicit recognition by scientists of complexity, unpredictability, and the uncertain nature of natural systems (including exposure of difficulties, exploration of alternative approaches and assumptions across disciplinary boundaries), and the involvement of stakeholders (e.g. in an "extended peer review" process, which includes a discussion of applicable norms and values) are sufficient to produce a commonly supported integrated solution in complex unstructured problem situations. In our case, we found a very open and deliberate communication in the first phase of the decision making process (see section 
6.1.4). Scientists addressed the complexity of the physical system and revealed the uncertainties in their predictions. Many stakeholders have been involved in a rather high (for this type of decision making) level of participation, and discussed the problem and its alternative solution in detail. The persistence of the disputes in the later phases of the decision making process shows that open communication alone is not enough to prevent decision making barriers. Apparently institutional and personal perspectives ultimately play a dominant role. These perspectives determine the way in which actors deal with details that were exposed using the post-normal-principle communication. These details are, for example, declared irrelevant (like a new interpretation of the Flood defences Act, distribution of responsibilities, and need for further research), or are not explicitly answered (e.g. the necessity of detention, and the low frequency of occurrence of the worst case scenario).

Our research began with the notion of communication gaps between decision makers, scientists and stakeholders, and the goal of developing a model based method that would be useful in bridging these gaps. In developing our theoretical framework we identified mental model analysis as a method that could possibly facilitate the bridging of the gaps. Reflecting on the results of our research, we must now conclude that some gaps appear unbridgeable. Despite intensive communication between actors in this case, their different frame perspectives maintained different mental models and therefore different preferred solutions. Yet the knowledge of the problem situation appears to have expanded considerably, through the efforts of the EIA project team, several research projects and critical members of the advisory group.

We conclude that, based on the results of our case research, our claim in section 1.2.4, developed from the literature, has to be adjusted with regard to communication:

A frame includes an actors' assumptions, interests, values and beliefs, and determines what he sees as being in his interests and, subsequently, what interests he perceives as conflicting. A frame guides interpretation of information, and thereby shapes decision positions and contributes to controversy. It is within the frames that information is judged and synthesised into a problem solution. The frame determines the boundaries of the problem solution space, and the allowable alternatives. Frames are influenced by the personal cultural and educational background. Frames are also grounded in the institutions that sponsor them, and institutional characteristics cause frame differences between actors that cannot be bridged by communication and will result in persistent controversy with regard to the preferred solution. 


\subsection{Recommendations}

The theoretical framework showed how the problem solving cycle for a complex unstructured situation is influenced by the different frames of stakeholders involved. Within the stakeholder network the struggle between frames determines the decision process outcome. Therefore frame analysis can support integrated problem solving by mediating the construction of a common frame, or at least revealing the underlying assumptions and interests of conflicting frames. Our case analysis showed that a frame can be analysed by separating it into a mental model and perspective types. A map of the elicited mental model revealed which elements and relationships were part of a stakeholder's argumentation, and conflicting elements between maps of different stakeholders revealed controversies. The analysis showed how controversies became persistent when the opinion of a conflicting element was shaped by different perspective types. Such a perspective type was, in turn, shaped by the personal and institutional context of the individual stakeholder. Each stakeholder constructed a preferred solution alternative within his perceived range of uncertainties, which were both technical and administrative in nature. Open communication appeared to be an insufficient condition for resolving controversies. Also needed, but lacking in this case, is the individual willingness to change existing regulations or their interpretations, to break through institutional communication patterns and distributions of responsibilities, in order to creatively redefine the problems on a higher level of aggregation and to find new solution spaces.

Discussion of the elicited mental model maps may, in future, promote communication and learning between individuals and their organisations involved in the case.

Construction of a common mental model map of the problem situation (e.g. by the researcher) would allow the structuring of conflicting elements of diverse argumentation chains without immediately resolving the controversies, and may surface assumptions, interpretations and uncertainties (both technical and administrative) involved. The nature of the controversies could be discussed using the perspective types and their rooting in institutional and personal contexts. It is hoped that a means can be devised for overcoming frame differences also at the more abstract levels of national policy in the early stages of the problem solving cycle, where the problem is defined and the solution space determined. The data matrix also offers a way of discussing the decision making arguments with informants. The scores could be discussed with informants, separately and in a group. Such a discussion would potentially offer clarity on the meaning of and rationale of the scores, and thus contribute to open communication.

Truth is relative to the frame in operation and therefore cannot be objective. Integrity, in the sense of Ravetz (2002), means recognizing the uncertainties in knowledge and the social and political construction of values. An integrated approach means a critical dialogue about conflicting interests and perceptions of both problem and solution. Frame reflection by mental model analysis can contribute to this goal. 


\section{Bibliography}

Anonymous (2000). Protocols for Water and Environmental Modeling. Bay-Delta Modeling Forum Ad hoc Modeling Protocols Committee, BDMF 2000-01. Richmond, CA.

Anonymous (2003). Tweede Kamer der Staten-Generaal, Vergaderjaar 2002-2003, Aanhangsel van de Handelingen, KVR17753. 's-Gravenhage, Sdu Uitgevers: 2627-2628.

Ackof, R. L. (1979). "The future of operational research is past." Journal of the Operational Research Society 30(2): 93-104.

Aissaoui, G., D. Genest, et al. (2003). "Cognitive Map of Conceptual Graphs : A Graphical Model to Help for Decision." International Conference on Conceptual Structures (ICCS 2003), Conceptual Structures for Knowledge Creation and Communication LNAI 2746: 337-350.

Arnstein, S. R. (1969). "A ladder of citizen participation." Journal of the American Institute of Planners 35(4): 216-??

Ausubel, D., J. Novak, et al. (1978). Educational Psychology: A Cognitive View (2nd Ed.). New York, Holt, Rinehart \& Winston.

Ausubel, D. P. (1968). Educational Psychology: A Cognitive View. New York, NY, USA, Holt, Rinehart and Winston.

Axelrod, R. (1976). The cognitive maps of political elites. Structure of Decision. R. Axelrod, ed. Princeton, NJ, Princeton University Press.

Barker, P. (1999). Mental models and network pedagogy. ENABLE99 - Enabling NetworkBased Learning, EVITech Helsinki University of Technology, Espoo, Finland, June 2 - 5.

Beck, M. B. (1998). "Applying systems analysis in managing the water environment: towards a new agenda." Water Science and Technology 36(5): 1-17.

Belt, M. v. d., L. Deutsch, et al. (1998). "A consensus-based simulation model for management in the Patagonia coastal zone." Ecological Modelling 110(1).

Beychok, M. R. (1995). Fundamentals of Stack Gas Dispersion.

Bezuijen, C. (1996). Evaluatie van het REGIWA-project Nannewijd, Stageverslag opleiding van Hall instituut bij afdeling Watersystemen, Waterschap Friesland.

Birrer, F. A. J. (1996). De sociocybernetische uitdaging in een democratiesche samenleving. 7e Sociaal-wetenschappelijke Studiedagen, Amsterdam.

Boersma, S. T. K. and T. Hoenderkamp (1988). Simulatie : een moderne methode van onderzoek. Den Haag, Academic Service.

Bomhof, L. (2001). Schriftelijke vragen ex. Art. 53 Reglement van Orde.

Brighton, P. W. M., A. J. Byrne, et al. (1994). "Comparison of heavy gas dispersion models for instantaneous releases." Journal of Hazardous Materials 36(3): 193208.

Brunner, R. D. (1996). "Policy and global change research." Climatic Change 32(2): 121147.

Burgdorffer, M. (1992). Berekening van de extreme hoogwaterstanden voor de Overijsselse Vecht en het Zwartewater, Rijkswaterstaat RIZA.

Canas, A., R. Hoffman, et al. (2003). A Summary of Literature Pertaining to the Use of Concept Mapping Techniques and Technologies for Education and Performance 
Support. In: Final report to CNET. Pensacola, FL, Institute for Human and Machine Cognition.

Cañas, A. J., D. B. Leake, et al. (1999). Managing, Mapping and Manipulating Conceptual Knowledge. AAAI Workshop Technical Report WS-99-10: Exploring the Synergies of Knowledge Management \& Case-Based Reasoning., AAAI Press, Menlo Calif, (July 1999): Accessed at January 4th 2004 at http://www.ihmc.us/users/acanas/Publications/AAAI99CmapsCBR/AAAI99Cmap sCBR.html.

Checkland, P. (1981). Systems thinking, systems practice. Chichester:, Wiley.

Checkland, P. and J. Scholes (1991). Soft systems methodology in action. Chichester, Wiley.

Churchman, C. W. (1971). The Design of Inquiring Systems: Basic Concepts of Systems and Organisation. New York, Basic Books.

Churchman, C. W. (1982). Thought and Wisdom. USA, Intersystems Publications.

CieMER (1998). Advies voor Richtlijnen voor de milieueffectrapporten Dijkverbetering achter Ramspol; deelgebied Sallandse Wateringen, deelgebied Zwolle.

Commissie voor deMilieueffectrapportage.

CieMER (1999). Toetsingsadvies over het milieueffectrapport Dijkverbetering Achter Ramspol Zwolle; Sallandse Weteringen en Zwolle. Commissie voor deMilieueffectrapportage.

CieMER (2005). Website of the Netherlands Commission for EIA. Utrecht. 2005.

Commissie-Integraal-Waterbeheer (2004). Water in Beeld 2004 - Voortgangsrapportage over het waterbeheer in Nederland, Ministerie van Verkeer en Waterstaat in samenwerking met de partners in het Landelijk Bestuurlijk Overleg Water.

Courtney, J. F. (2001). "Decision making and knowledge management in inquiring organizations: toward a new decision-making paradigm for DSS." J.Decision Support Systems 31: 17-38.

Craik, K. (1943). The Nature of Explanations. Cambridge, Cambridge University Press.

De Blois, C. J. (2000). Uncertainty in large-scale models for decision support in water management - an approacht to effective and consistent modeling. Civil Engineering and Management. Enschede, University of Twente: 250.

De Groot, R. S. (1992). Functions of Nature - Evaluation of environmental functions as a tool in planning, management and decision-making. Groningen, WoltersNoordhoff.

De Groot, R. S. (1994). Evaluation of environmental functions as a tool in planning, management and decision-making. Wageningen, Landbouwuniversiteit.

De Jonge, V. N., M. J. Kolkman, et al. (2000). Need for new paradigms in integral coastal policy making. 10th International Wadden Sea Symposium, 31 October - 3 November, Groningen, The Netherlands.

De Roode, F.J. (1998). De kwaliteit van afwegingsmethoden, Een onderzoek naar kwaliteitscriteria voor het gebruik van afwegingsmethoden voor integraal Waddenzeebeheer. Publicatie van de Universiteit Twente. ISBN 90-365-1639-0. $\mathrm{v}+89 \mathrm{p}$.

Dee, D. P. (1993). Validatie van Complexe rekenmodellen met behulp van meetgegevens. Proceskennis en statistiek in bodem en water (Lezingendag 21 januari 1993), Rapporten en Nota's No. 30 van de CHO-TNO. 
Dee, D. P. (1995). A pragmatic approach to model validation. Quantitative Skill Assessment for Coastal Ocean Models, American Geophysical Union, Washington, DC.

DeTombe, D. J. (2001). "Compram: a method for handling complex societal problems." European Journal of Operational Research 128(2): 266-281.

Dewey, J. (1916). Democracy and education : an introduction to the philosophy of education. New York: Macmillan.

Dick, B. (1993). You want to do an action research thesis? Available on line at http://www.scu.edu.au/schools/gcm/ar/art/arthesis.html.

Dick, B. (2000). Soft systems methodology. Session 13 of Areol - action research and evaluation on line. Available at http://www.scu.edu.au/schools/gcm/ar/areol/areol-session13.html.

Dick, B. and P. Swepson (1994). "Appropriate validity and its attainment within action research: an illustration using soft systems methodology. Available at http://www.scu.edu.au/schools/gcm/ar/arp/sofsys2.html." Resource papers in actions research.

Doyle, J. K. and D. N. Ford (1998). "Mental models concepts for system dynamics research." System dynamics review : the journal of the System Dynamics Society 14(1): 3-30.

Doyle, J. K., D. N. Ford, et al. (2001). Mental models of dynamic systems.

Eden, C. (1994). "Cognitive mapping and problem structuring for system dynamics model building." System Dynamics Review 10(2/3): 257-276.

Eden, C. (2003). "Analyzing cognitive maps to help structure issues or problems." European Journal of Operational Research Article in Press, Corrected Proof.

Edwards, P. N. (1996). "Global comprehensive models in politics and policy-making." Climatic Change 32(2): 149-161.

EIA-report (2001). Dijkverbetering Acther Ramspol, Projectnota/MER, Sallandse Weteringen - Zwolle, deelgebied 1-2. Grontmij_Projectbureau_DAR. Zwolle, Waterschap Groot Salland.

Findeisen, W. and E. S. Quade (1985). The methodology of systems analysis: an introduction and overview. Handbook of Systems Analysis - Overview of Uses, Procedures, Applications, and Practice. H. J. Miser and E. S. Quade. New York, Elsevier Science Publishing Co. Inc. 1: 117-149.

Finegan, A. (1994). "Soft Systems Methodology: An Alternative Approach to Knowledge Elicitation in Complex and Poorly Defined Systems. Available at http://www.csu.edu.au/ci/vol01/finega01/." Complexity International 1.

Fischer, F. (1998). "Beyond empiricism: Policy inquiry in postpositivist perspective." Policy Studies Journal 26(1): 129-146.

Fischer, F. (2001). Citizens and Experts in Participatory Inquiry: Facilitating Discursive Practices. the 2001 Annual Meeting of the American Political Science Association,, San Francisco, August 30-September 2, 2001. (Draft version, cited with author's permission ffischer@andromeda.rutgers.edu).

Ford, D. T. (1991). Getting someone to use the systems: lessons from HEC. Nato Advanced Research Workshop on computer-aided support systems for water resources research and management, Ericeira (Portugal), Springer-Verlag, Berlin 1991. 
Ford, K., A. J. Cañas, et al. (1991). "ICONKAT: an integrated constructivist knowledge acquisition tool." Knowledge Acquisition 3.

Forrester, J. (1971). Counterintuitive behavior of social systems. Collected Papers of J. W. Forrester. Cambridge, MA, Wright-Allen Press, Inc.: 211-244.

Forrester, J. W. (1968). Principles of Systems. Cambridge, USA, Wright-Allen Press Inc. Forrester, J. W. (1994). Learning through System Dynamics as Preparation for the 21st Century. Systems Thinking and Dynamic Modeling Conference for K-12 Education, Concord Academy, Concord, MA, USA, Sloan School of Management, Massachusetts Institute of Technology.

Fuglseth, A. M. and K. Grønhaug (2002). "Theory-driven construction and analysis of cause maps." International Journal of Information Management 22(5): 357-376.

Funtowicz, S. O. and J. R. Ravetz (1990). Uncertainty and quality in science for policy. Dordrecht, the Netherlands; Norwell, MA, U.S.A., Kluwer Academic Publishers.

Funtowicz, S. O. and J. R. Ravetz (1993a). The emergence of post-normal science. Science, politics and morality - Scientific Uncertainty and Decison Making. R. v. Schomberg. Dordrecht [ ], Kluwer academic publishers. 17: 85-123.

Funtowicz, S. O. and J. R. Ravetz (1993b). "Science for the Post-Normal Age." Futures 25(7): 739-755.

Funtowicz, S. O. and J. R. Ravetz (1994). "Uncertainty, complexity and post-normal science." Environmental Toxicology and Chemistry 13(12): 1881-1885.

Funtowicz, S. and J.R. Ravetz (1999). "Editorial: Post-Normal Science - an insight now maturing." Futures - Special Issue on Post-Normal Science 31(7): 641-646.

Geldof, G. D. (2001). Omgaan met complexiteit bij integraal waterbeheer. Civil Engineering. Enschede, University of Twente: 186.

Gill, R. (1998). Integrated Environmental Policy Planning and Development Assessent: The IdeaMaP Toolbox. Available at http://www.une.edu.au/cwpr/NEEEG/Devel.html. Armidale, NWS, Australia, New England Ecological Economics Group, Centre for Water Policy Research, University of New England Armidale.

Goffman (1974). Frame Analysis. Harmondsworth, Middx., Penguin books.

Goldsborough, D. G. and M. J. Kolkman (1999). Mimicking real life problem solving by integrating simulation modelling and role-play. International Seminar of the SEFI Working Group on Curriculum Development: "What have they learned?" Assessment of Student Learning in Higher Engineering Education, 22-23 April, Delft University of Technology, Delft, The Netherlands.

Goodman, N. (1978). Ways of Worldmakng. Inianapolis, Hackett.

Grant, W. E. and P. B. Thompson (1977). "Integrated ecological models: simulation of socio-cultural constraints on ecological dynamics." Ecological Modelling 100: 4359.

Grimberg, Rinus (1999). De 'Saptial Modeling Environment' als concept en technologie voor de ontwikelling van landschap simulatie modellen - Een gevalstudie naar een hydrodynamisch module voor een marien ecosysteem model. Afstudeerrapport 19 april 1999, Universiteit Twente.

Grontmij_Projectbureau_DAR (1997a). Nota van uitgangspunten. Zwolle, Waterschap Groot Salland, Waterschap Wold en Wieden.

Grontmij_Projectbureau_DAR (1997b). Startnotitie Sallandse Weteringen (DAR 1). Zwolle, Waterschap Groot Salland. 
Grontmij_Projectbureau_DAR (1997c). Startnotitie Zwolle (DAR 2). Zwolle, Waterschap Groot Salland.

Haag, D. and M. Kaupenjohann (2001). "Parameters, prediction, post-normal science and the precautionary principle-a roadmap for modelling for decision-making." Ecological Modelling 144: 45-60.

Halffman, W. and R. Hoppe, Eds. (2004). Science/policy boundaries: a changing division of labour in Dutch expert policy advice.". Scientific Expertise and Political Decision Making (Sociology of the Sciences Yearbook). Dordrecht, Kluwer.

Hall, D., Y. Guo, et al. (2003). Developing a Value-Based Decision-Making Model for Inquiring Organizations. 36th Annual Hawaii International Conference on System Sciences (HICSS'03) - Track 4 January 06 - 09, 2003, Big Island, Hawaii.

Heidemij_Advies (1997a). Dijken Achter Ramspol, Grondmechanisch hoofdonderzoek, Deelgebied 1.

Heidemij_Advies (1997b). Dijken Achter Ramspol, Grondmechanisch hoofdonderzoek, Deelgebied 2.

Hellendoorn, J. C., Ed. (2001). Evaluatiemethoden ex ante : een introductie. Den Haag, Sdu Uitgevers.

Hendricks, V. F., A. Jakobsen, et al. (2000). "Identification of matrices in science and engineering." Journal for General Phylosophy of Science 31: 277-305.

Hisschemöller, M. (1993). De democratie van problemen: de relatie tussen de inhoud van beleidsproblemen en methoden van politieke besluitvorming. Amsterdam, Universiteit van Amsterdam: 254.

HKV_Lijn_in_water(1996a). Aanvullende analyse waterstanden achter Ramspol. K. Vermeer, D. Klopstra, J. M. van Noortwijk and H. J. Barneveld, Rijkswaterstaat Riza en Waterloopkundig Laboratorium, PRO16.

HKV_Lijn_in_water (1996b). Maatgevende waterstanden achter de Ramspolkering. D. Klopstra and K. Vermeer, Rijkswaterstaat RIZA, PRO 50.

HKV_Lijn_in_water (1999). Berekeningen waterstanden Sallandse Weteringen. D. Klopstra, D. G. Meijer and A. P. P. Termes, Waterschap Groot Salland, Rijkswaterstaat RIZA.

Hoffman, R. R., N. R. Shadbolt, et al. (1995). "Eliciting Knowledge from Experts: A Methodological Analysis,." Organizational Behavior and Human Decision Processes 62(2): 129-158.

Holling, C. S., R. Sando, et al. (1997). Science and Policy Partnership for Sustainability, Draft Case Statement.

Hoogerwerf, A. (1989). Overheidsbeleid: een inleiding in de beleidswetenschap. Alphen aan de Rijn, Samsom H.D. Tjeenk Willink.

Hoppe, R. and G. Grenstad (1999). Report on ECPR workshop 'Plural Rationality and Policy Analysis. ECPR Mannheim Joint Sessions of Workshops 1999, Workshop 25: Plural rationality and policy analysis, Mannheim.

In 't Veld, R. J. and A. J. M. Verheij (2000). Willens en wetens: Over de verhouding tussen waarden, kennisprodutie en kennisbenutting in het miliuebeleid. Willens en Wetens: De rollen van kennis over milieu en natuur in beleidsprocessen. P. d. R. J. In 't Veld. Utrecht, Lemma: 157.

Jäger, J. (1998). "Current thinking on using scientific findings in environmental policy making." Environmental Modeling and Assessement 3: 143-153. 
Janssen, M. H. M. (1993). Onderzoek naar kansen op dagafvoeren van de Vecht en het Zwartewater. Werkdocument 92, 134X, Rijkswaterstaat RIZA.

Janssen, P. H. M., W. W. Slob, et al. (1990). Gevoeligheidsanalyse en Onzekerheidsanalyse: een Inventarisatie van Ideeën, Methoden en Technieken. Bilthoven, RIVM.

Janssen, R., M. v. Herwijnen, et al. (2000). BOSDA voor Windows. Een computer programma voor de ondersteuning van complexe keuzevraagstukken. (Programmatuur en handleiding). See also http://130.37.129.100/english/o_o/instituten/IVM/research/bosda.htm. Den Haag, SDU uitgevers.

Jasanoff, S. (1990). The Fifth Branch, Science Advisers as Policy Makers. Cambridge, Mass. [etc.], Harvard University Press.

Johnson- Laird, P. (1983). Mental Models: Towards a Cognitive Science of Language, Inference and Consciousness. Cambridge, MA, Harvard Univ. Press.

Jonassen, D. H. (2003). "Using Cognitive Tools to Represent Problems." Journal of Research in Technology in Education 35(3): 362-381.

Jørgensen, S. E. and G. Bendoricchio (2001). Fundamentals of ecological modelling. Amsterdam [etc.], Elsevier.

Kelly, G. A. (1955). The psychology of personal constructs. New York, Norton.

Kinnear, J. (1994). What Science Education Really Says about Communication of Science Concepts. 44th Annual Meeting of the International Communication Association, Sydney, New South Wales, Australia, July 11-15, ED372455 (ERIC Document).

Klinge, M., C. M. Lorenz, et al. (2000). Ecologisch Herstel Zuidlaardermeer. Resultaten met het compartiment (1996 t/m 1999) en evaluatie ten behoeve van het toekomstig beheer, Waterschap Hunze en Aa's en Witteveen \& Bos.

Kolkman, M. (1993). Problem Articulation Methodology. BIK. Enschede, Univertity of Twente: 305.

Kolkman, M. J., F. J. de Roode, et al. (2000). Assessing quality of decision methods. 10th International Wadden Sea Symposium, 31 October - 3 November, Groningen, The Netherlands.

Kolkman, M. J., Kok, M., \& Veen, A. van der (2005). Concept mapping as a new tool to visualise the use of information in decision-making. Physics and chemistry of the earth, incorporating part $A, B$, and $C$. (in press).

Kramer, M. (1996). Knowlegde graphs making career in politics - A study of the applicability of knowledge graphs as a tool for analysis and comparison of texts. Applied Mathematics, University of Twente.

Kramer, N. J. T. A. and J. d. Smit (1991). Systeemdenken. Leiden, Stenfert Kroese.

Kremer, R. (1997). Constraint Graphs: A Concept Map Meta-Language. Department of computer science. Calgary, Alberta, The university of Calgary: Available at http://www.cpsc.ucalgary.ca/ kremer/dissertation/index.html.

Kuhn (1964). Postscript to the second edition of The Structure of Scientific Revolutions, Cited in Schön\&Rein $1994: 34$.

Lasswell, H. (1971). A pre-view of the Policy Sciences. New York, Elsevier. Cited in (Schön\&Rein $1994: 11$ ).

Luna-Reyes, L. F. (2003). Model Conceptualization: A Critical Review. 2003 System Dynamics Research Conference, New York, NY, July 20-24, System Dynamics Society, Albany, NY. 
March, J. G. (1972). "Model Bias in Social Action." Review of Educational Research 42: 413-29.

Mitroff, I. I. and H. A. Linstone (1993). The Unbounded Mind: Breaking the Chains of Traditional Business Thinking. New York, Oxford Univ. Press.

Molen, D. v. d. (1999). The role of eutrophication models in water management, Landbouwuniversiteit Wageningen.

Morgan, G. M. and M. Henrion (1990). Uncertainty - A Guide to Dealing with Uncertainty in Quantitative Risk and Policy Analysis. New York, USA, Cambridge University Press.

Myers, M. D. (1997). "Qualitative Research in Information Systems." MIS Quarterly 21(2): 241-242.

Nelson, K. M. and H. J. Nelson (2000). Revealed causal mapping as and evocative method for information systems research. 33rd Hawaii International Conference on System Sciences 2000 (HICSS-33), January 4-7, Maui, Hawaii.

Nieuwkamer, R. L. J. (1995). Decision support for river management, Technische Universiteit Twente.

Norman, D. A. (1983). Some observations on mental models. Mental Models. D. R. Gentner and A. L. Stevens. Hillsdale, NJ:, Erlbaum.: 7-14.

Novak, J. D. and D. B. Gowin (1984). Learning How to Learn. Cambridge, England, Cambridge University Press.

Oreskes, N., K. Shrader-Frechette, et al. (1994). "Verification, Validation, and Confirmation of Numerical Models in the Earth Sciences." Science 263(February): 641-646.

Parson, E. A. (1997). "Informing global environmental policy-making: A plea for new methods of assessment and synthesis." Environmental Modeling and Assessment 2(4).

Peirce, C. S. (1877). Fixation of belief. Writings of Charles S. Peirce: a chronological edition. E. C. Moore, et al. Bloomington, Indiana University Press. 1986, 3: 2420257.

Petersen, F. and P. Zandbergen (1995). The role of scientific information in plicy and decision-making. The Lower Fraser Basisn in transition: A symposium and workshop, Kwantlen College, Surrey, BC, Canada, Resource Management and Environmental Studies, University of British Columbia, Vancouver, BC.

Piaget, J. (1962). Play, dreams, and Imitation in Childhood. New York, Norton.

Pidd, M. (1998). Tools for Thinking, Modelling in Management Science. Chichester e.a., John Wiley \& Sons.

Pidd, M. (1999). "Just modelling through: a rough guide to modelling." Interfaces 29(2): 118-132.

Pidd, M. (2003). Tools for tinking: modelling in management science. Chichester, England, John Wiley \& Sons.

Priddy, R. (1999). BEYOND SCIENCE: On the nature of human understanding and regeneration of its inherent values., Robert Priddy, Oslo 1999. 2002.

Pröpper, I. and D. A. Steenbeek (1999). De aanpak van interactief beleid : elke situatie is anders. Bussum, Coutinho.

Pröpper, I. M. A. M. (1999). Interactieve beliedsvoering: de binnenkant van het proces. Dan Haag, VNG Uitgeverij. 
Pröpper, I. M. A. M. and D. A. Steenbeek (1998). "Interactieve beleidsvoering: typering, ervaringen en dilemma's." Bestuurskunde 7(7): 292-301.

Provincie Overijssel (1998a). Reactienota zienswijzen over de Startnotities Dijken achter Ramspol. B. b. R. 1998", Gedeputeerde Staten van Overijssel: Quoted literally by informant no.10 [I10:116].

Provincie Overijssel (1998b). Richtlijnen voor het opstellen van het Milieueffectrapport (MER) voor het Dijkversterkingsplan Dijken Achter Ramspol. Zwolle, Gedeputeerde Staten van Overijssel.

Provincie Overijssel (2002). Regionale keringen in Overijssel. Een voorstel voor het aanwijzen van regionale keringen in Overijssel. Juni 2002.

Provincie Overijssel (2003). GS-nota betreffende Dar 1-2/Keersluis Zwolle. Zwolle, Gedeputeerde Staten.

Ramspol (1988). Beleidsanalyse / milieu-effectrapport t.b.v. de beveiliging van WestOverijssel. Stuurgroep Ramspol.

Ramspol (1995). Projectnota / MER keersluis Ramspol. Stuurgroep Ramspol

Randers, J., Ed. (1980). Elements of the system dynamics method. Wright-Allen series in system dynamics. Geilo, Norway, August 8-15, 1976, Cambridge, Mass., M.I.T. Press.

Ravetz, J. R. (1987). "Usable Knowledge, Usable Ignorance - Incomplete Science with Policy Implications." Knowledge: Creation, Diffusion, Utilization 9(1): 87-116.

Ravetz, J. R. (1999). "What is Post-Normal Science? (editorial)." Futures 31(7): 647653.

Ravetz, J. R. (2002). "Ruskin and the scientists." Science \& Public Affairs October: 2425.

Reinshagen, E.A. (2005). Masters Thesis project, University of Twente.

Rieger, B. (1977). "Bedeutungskonstitution, einige bemerkungen zuf semiotischen problematik eines linguistischen problems." Semiotik (Zeitschrift fur Literaturwissenschaft und Linguistik) 27/28: 55-68.

Rip, A. (1996). 'Usable Ignorance' en onzekerheid troef.

Rip, A. (1997). Filosofie en sociologie van modellen. collegedictaat Universiteit Twente, vakcode $162340,1997 / 1998$.

Rittel, H. (1972). On the planning crisis : systems analysis of the "First and second generations", Berkeley : Institute of Urban and Regional Development.

Rogers, P. P. and M. B. Fiering (1986). "Use of Systems Analysis in Water Managemen." Water Resources Research 22(9): 146S-158S. Referenced in Ford, K., A. J. Cañas, et al. (1991).

Roozenburg, N. F. M. and J. Eekels (1998). Productontwerpen, structuur en methoden. Utrecht, LEMMA.

Rotmans, P. d. i. J. (1999). Integrated Assessment Models, Uncertainty, Quality and Use. ICES Maastricht University Working paper: I99-E005. Maastricht.

RWS (2001). Hydraulic boundary conditions for safety assessment primary flood water defences (in Dutch;

Schneider, S. H. (1997). "Integrated assessment modeling of global climate change: Transparent rational tool for policy making or opaque screen hiding value-laden assumptions?" Environmental Modeling and Assessment 2: 229-249.

Scholten, H., R. H. v. Waveren, et al. (2000). Good Modelling Practice in water management. HydroInformatics, 23-27 July, Cedar Rapids, IA, USA. 
Schön, D. A. and M. Rein (1994). Frame Reflection - Toward the Resolution of Intractable Policy Controversies. New York, Basic Books.

Schoumans, O. F., J. Mol-Dijkstra, et al. (2002). "SIMPLE: Assessment of non-point phosphorus pollution from agricultural land to surface waters by means of a new methodology." Water Science \& Technology 45(9): 177-182.

Schwamb, K. B. (1990). Mental Models: A Survey. unpublished.

Senge, P. M. (1990). The Fifth Discipline: The Art and Practice of the Learning Organisation. New York, Doubleday Currency.

Senge, P. M., A. Kleiner, et al. (1994). The fifth discipline fieldbook: Strategies and tools for building a learning organization. New York, Currency Doubleday.

Spranger, E. (1928/1966) Types of men; the psychology and ethics of personality. New York, NY: Johnson.

Sterman, J. D. (2000a). Business Dynamics, Systems Thinking and Modeling for a Complex World, McGraw-Hill.

Sterman, J. D. (2000b). Business Dynamics: Systems Thinking and Modeling for a Complex World. Boston MA, Irwin McGraw-Hill.

STOWA (1999). Vloeiend modelleren in het waterbeheer, Handboek "Good Modelling Practice (GMP)". STOWA-rapport 99-05, Rijkswaterstaat IZA-rapport 99.036.

Stroomgebiedsvisie (2003). WB21 Stroomgebiedsvisie Vecht-Zwarte Water, een ruimtelijke uitwerking van het waterbeheer in Overijssel en Zuid-Drenthe, Bestuurlijk Waterplatform Vecht-Zwarte Water.

Suter II, G. W., L. W. Barnthouse, et al. (1987). "Treatment of Risk in Environmental Impact Assessment." Environmental Management 11(3): 295-303.

TAW (1985). Guidelines for design of river dikes, Part 1 - Upper river area (in Dutch; original title: Leidraad voor het ontwerpen van rivierdijken. Deel 1 Bovenrivierengebied). S. Technical Advisory Committee on Flood Defence, Rijkswaterstaat, Dienst Weg- en Waterbouwkunde.

TAW (1989). Guidelines for design of river dikes, Part 2 - Lower river (in Dutch; original title: Leidraad voor het ontwerpen van rivierdijken. Deel 2 -

Benedenrivierengebied). S. Committee on Flood Defence, Rijkswaterstaat, Dienst Weg- en Waterbouwkunde.

TAW (1996a). Hydraulische randvoorwaarden voor Primaire Waterkeringen. Delft, Directoraat-Generaal Rijkswaterstaat, Dienst Weg- en Waterbouwkunde.

TAW (1996b). Leidraad Toetsen op Veiligheid. Delft, Technische Adviescommissie Waterkeringen.

Terwindt, Joost (2001). Discussion paper on the structure and cohesion of the Division Wh\&M, 18 december 2001, internal report department Wh\&M, University of Twente.

Thompson, M. (1997). "Cultural Theory and integrated assessment." Environmental Modeling and Assessment 2(3): 139-150.

Trochim, W. (1989). "An introduction to concept mapping for planning and evaluation." In W. Trochim (Ed.) A Special Issue of Evaluation and Program Planning 12: 116.

Van Asselt, M. B. A. (2000). Perspectives on uncertainty and risk: the PRIMA approach to decision-support. ICIS. Maastricht, the Netherlands, University of Maastricht.

Van Asselt, M. B. A., J. Rotmans, et al. (1995). Uncertainty in integrated assessment modelling. A curltural perspective based approach., RIVM. 
Van Koningsveld, M. (1998). Grafentheorie als hulpmiddel bij conceptuele modellering, De ontwikkeling van een methode voor het opstellen van conceptuele modellen van grote ecosystemen op basis van teksten, met behulp van de grafentheorie. Civil Engineering and Management, University of Twente.

Van Koningsveld, M. (2003). Matching specialist knowledge with end user needs Bridging the gap between coastal science and coastal management. Enschede, Universiteit Twente: XI, 173.

Van der Schrier, D. (2000). De balgstuw Ramspol en zijn overlaten. De Vriendenkring Cultuurhistorisch tijdschrift voor Flevoland, 41e jaargang nr. 1 Lente 2001, 2540.

Van der Schrier, D. (2002). "Overbodige keersluis in Zwolle." Land + Water 5: 33-35.

Van der Schrier, D. (2003). "Wet op de waterkering in opspraak." Omgevingsrecht 3(4).

Van der Sluijs, J. P. (1996). Integrated Assessment Models and the Management of Uncertainties. Laxenburg, Austria, IIASA Working Paper no. WP-96-119.

Van der Sluijs, J. P. (1997). Anchoring amid uncertainty - On the management of uncertainties in risk assessment of anthropogenic climate change, University of Utrecht, 21 april 1997.

Van der Sluijs, J. P. (1999). Tuning UNSAP for its use in Integrated Model Quality Assurance - the Case of Climate Change. Utrecht, Department of Science, Technology and Society, Utrecht University: 34.

Van der Sluijs, J. P. and Schulte Fischedick, K. (1997). Omgaan met onzekerheden in wetenschap voor (milieu)beleid - een inventarisatie van theorieën en aanpakken, Universiteit Utrecht, Faculteit Scheikunde, Sectie Natuurwetenschap en Samenleving.

Van Hall, A. (2001). Beantwoording adviesaanvraag t.b.v. goedkeuringsprocedure GS Overijssel inzake keersluis Zwolle.

Van Hall, A. (2003). "Noot bij uitspraak Raad van State Nr. 200200353/1." Administratiefrechtelijke Beslissingen ( $A B)$ 103(13): Deventer: Kluwer.

Van Slobbe, E. (2002). Waterbeheer tussen crisis en vernieuwing - Een studie naar vernieuwingsprocessen in de sturing van regionaal waterbeheer. Social Sciences. Wageningen, Wageningen University.

Verbeeten, T. (1999). Wijs met de Waddenzee? Een onderzoek naar leerprocessen. Disciplinegroep Milieukunde en Omgevingsbeleid, Faculteit Ruimtelijke Wetenschappen. Utrecht, Universiteit Utrecht: 247.

Vermeer, K. (2001). Keersluis Zwolle, notitie "second opinion", HKV Lijn in water.

Vogelezang, Remco (2002). Of een participatieladder beklommen kan worden Probleemkenmerken en de mate van interactief beleid bij infrastructuur. Civil Engeneering and Management. Enschede, University of Twente: 101.

Von Glasersfeld, E. (1995). Radical Constructivism: A Way of Knowing and Learning. London, Falmer Press.

Walker, W. E., P. Harremoës, et al. (2003). "Defining uncertainty, a conceptual basis for uncertainty management in model-based decision support." Integrated Assessment 4(1): 5-17.

Weick, K. E. (1989). "Theory Construction as Disciplined Imagination." Academy of Management Review 14(9): 516-531.

Wikipedia (2004). Zwolle. 2005. 
Willard, C. A. (1996). Liberalism and the problem of knowledge: a new rhetoric for modern democracy. Chicago, University of Chicago press.

Wilson, B. (1993). Systems: Concepts, Methodologies, and Applications, John Wiley.

Wolfenden, J. (1997). A systematic approach to dealing with the complex issues typically encountered within the context of Integrated Catchment Management. Armidale, NWS, Australia, New England Ecological Economics Group, Centre for Water Policy Research, University of New England Armidale.

Woolsey, R. E. D. and H. S. Swanson (1975). Operations Research for Immediate Application: A Quick and Dirty Manual. New York, Harper and Row. Referenced in Ford, K., A. J. Cañas, et al. (1991).

Young, P. (1983). Validity and credibility of models for badly defined systems. Uncertainty and forecasting of water quality,, Laxenburg, Springer Verlag, Berlin [etc.]. 



\section{APPENDIX A: Translation of some Dutch terms related to water management}

\section{Acts}

Waterstaatswet $1900=$ Public Works Act

Wet op de waterhuishouding $1981=$ Water Management Act.

Waterschapswet $1991=$ Water Boards Act.

DGR (Deltaplan Grote Rivieren) = Delta Plan for the Major Rivers project. OR: Main Rivers Delta Plan.

Deltawet grote rivieren 1995 = Delta (Major Rivers) Act. Adopted in 1995 and withdrawn in 2005.

WWK (Wet op de Waterkering 1996) = Flood defences Act 1996. OR: Flood Defence Structures Act. Maintaining general rules to ensue the safety of flood defences against inundation from outer water and regulation of several related matters.

WTS (Wet tegemoetkoming schade bij rampen en zware ongevallen, 1998) = Law on compensation of damage in disasters and large accidents.

\section{Institutions}

V\&W (Ministerie van Verkeer en Waterstaat) $=$ Ministry of Transport, Public Works and Water Management. See http://www.verkeerenwaterstaat. $n \mathrm{l} /$ ? $\mid \mathrm{c}=\mathrm{uk} \&$ page $=77$

RWS (Rijkswaterstaat) $=$ Directorate-General of Public Works and Water Management. Part of V\&W. Also referred to as the National Water Board.

DWW (Dienst Weg en Waterbouw) = Road and Hydraulic Engineering Institute (DWW) of $V \& W$. It is the advisory institute for technical and environmental aspects of road and hydraulic engineering. It carries out research, advises and transfers knowledge on nature and environmental engineering of the physical infrastructure, water and flood defence systems, and supply of raw construction materials, including environmental aspects.

TAW (Techische Adviescomissie Waterkering) = Technical Advisory Committee on Flood Defence. This committee was installed by the Ministry of Transport, Public Works and Water Management in 1965. The Committee advises the Minister on all technical and scientific aspects that might be significant for an efficient construction and maintenance of flood defences, and also on the safety of the areas protected by water defences. Its operational tasks are performed by DWW. See http://www.tawinfo.nl/ 
CieMER (Commissie voor Milieu Effect Rapportage) = The Netherlands Commission for EIA. CieMER is a private foundation, with a budget of its own funded by government subsidies. It acts as an independent expert committee and is involved in all Environmental Impact Assessments in the Netherlands. See http://www.commissiemer.nl/eia/commission/index.htm

Commisaris der Koningin = Queen's Commissioner / Governor for the Province. See http://www.overheid.nl/guest/aboutgov/government/provinces/

Gedeputeerde staten $=$ Provincial Executive Council.

Provinciale staten $=$ Provincial General Council.

Waterschap $=$ Water Board. See

http://www.overheid.nl/guest/aboutgov/government/waterboards/

Dijkgraaf $=$ Water Board Chair Person.

Raad van State $=$ The Council of State advises the Dutch government and parliament on legislation and governance and is the country's highest administrative court. Citizens and community organizations that object to a decision which affects their interests - decisions on grants, for example - can appeal to the administrative court and the Council of State. Public authorities can in turn lodge an appeal with the Council of State against decisions by the ordinary administrative court. The Council's administrative law department deals mainly with government decisions in the areas of spatial planning, the environment the issuing of licences, for example - and appeals relating to aliens affairs. See http://www.raadvanstate. $n \mathrm{l} /$

\section{Guidelines}

TAW-leidraden en richtlijnen $=$ Guidelines issued by the TAW.

TAW Leidraad Toetsen op Veiligheid = Guide on Safety Monitoring. OR: Guidelines for safety assessment.

TAW Leidraad voor het ontwerpen van van rivierdijken = Guide for Designing River Dikes.

TAW Technisch rapport erosiebestendigheid van grasland als dijkbekleding $=$ Technical Report on erosion resistance of grassland as dike cover.

Hydraulische randvoorwaarden (Regeling hydraulische randvoorwaarden primaire waterkeringen) $=$ Hydraulic Preconditions for Primary Flood Defences.

KRW (Europese Kaderrichtlijn Water) = European Framework directive Water 
WB21 (Waterbeheer 21ste eeuw) = the Dutch vision for Water Management in the 21st century. In 2003 the WB21 has been merged with the KRW into the "Nationaal Bestuursakkoord Water".

\section{Miscellaneous}

Adviesgroep = Local advisory group.

Afsluitdijk = Closure-Dike dam of the Lake IJsselmeer, which separates the former

"Zuiderzee" from the Wadden Sea. See

http://www.rdij.nl/rdij/ijsselmeergebied/afsluitdijk/index uk.htm

Noodoverlaat $=$ emergency spillway.

Buitendijks = land outside the dike, subject to flooding at high water levels.

GS-nota $=$ policy document for the Provincial Executive Council

Klankbordgroep $=$ Regional advisory group.

LNC (Lanschap, Natuur en Cultuurhistorische waarden) = Landscape, nature, environment and cultural-history. OR: Landscape, nature and cultural heritage.

MHW (Maatgevend Hoog Water) = Design high water level. OR: Normative High Water level.

Nota van uitgangspunten $=$ Notification of intent .

CieMER richtlijnadvies = Scooping guidelines of the Commission for EIA. OR: Advisory guidelines

CieMER toetsingsadvies = Advisory review of the Commission for EIA

Oppertoezichthouder $=$ super-supervisor.

Schouw $=$ regular inspection of the maintenance condition of the local watercourses by means of a survey by the Water Board.

Startnotie $=$ Inception memorandum. OR: starting note.

Ter inzage leggen = put on public display

Toetsen $=$ monitoring. OR: assessing

Toezichthouder $=$ supervisor.

Verordening $=$ bylaw .

Waakhoogte $=$ freeboard, retaining height.

Waterkering $=$ Flood defence structure. OR: Water embankment.

Waterschap $=$ A Water Board is an independent Dutch administrative water authority.

Waterschapsbestuur (algemeen) = Water Board General Council / Board of governors

Waterschapsbestuur (dagelijks) $=$ Water Board Executive Council.

Wettelijk buitenwater $=$ Outside water. Water outside the primary flood defences within the meaning of the WWK. Outside water originates from the large rivers, Lake IJsselmeer, or the sea (WWK article 1). The notion of "larger river" is not defined in the WWK.

Windopzet (Opwaaiing) $=$ Rise of the water level due to wind action. 



\section{APPENDIX B: The EIA procedure (in Dutch)}

Integrating the legal and the governance system is the procedure along which the EIA is conducted. This procedure is described in appendix 7 of the EIA report (2001:117-121), a reproduction of which is included here. The original version of the procedure appeared in (Grontmij_Projectbureau_DAR 1997a) and is identical to the 2001 version. The appendix describes the decision procedure for dike improvements according to the "Wet op de Waterkering 1996". Citation starts below.

\section{Bijlage 7 Procedure na Projectnota/MER}

\section{B 7.1 Algemeen}

Deze bijlage beschrijft in kort bestek de planvoorbereidings- en besluitvormingsprocedure voor dijkverbetering volgens de Wet op de Waterkering die op 15 januari 1996 van kracht is geworden. Belangrijk is dat de wet aangeeft dat:

- voor het goedkeuringsbesluit van Gedeputeerde Staten van Overijssel (ex.art. 7 Wet op de Waterkering) een milieueffectrapportage (m.e.r.) doorlopen moet worden;

- op het moment van ter inzage legging van het conceptontwerpplan dijkverbetering ook de Projectnota/MER, de benodigde vergunningaanvragen, het eventuele benodigde herziene ontwerp bestemmingsplan en de grondverwervingstekeningen ter inzage worden gelegd;

- de besluitvorming over dijkverbeteringsplan, bestemmingsplan en vergunningen parallel geschakeld wordt;

- de Provincie de mogelijkheid heeft een coördinerende rol te vervullen bij de besluitvorming;

- na vaststelling van het plan zo nodig een korte administratieve onteigeningsprocedure kan worden gevolgd.

De hierna beschreven documenten en procedures worden per onderscheiden deelgebied opgesteld respectievelijk doorlopen.

\section{B 7.2 Procedure}

In figuur B 7.1 zijn de verschillende stappen van de te volgen dijkverbeteringsprocedure schematisch weergegeven. Uitgaande van de referentieplanning voor Dijkverbetering Achter Ramspol is indicatief aangegeven op welk moment de verschillende stappen verwacht worden. De stappen in de procedure zijn hieronder toegelicht. 


\section{Startnotitie}

De procedure voor milieueffectrapportage is vastgelegd in de Wet Milieubeheer en voorziet bij aanvang van de procedure in het opstellen van een startnotitie. Deze stap wordt ook in de dijkverbeteringsprocedure genomen en wordt daarbij gebruikt als gezamenlijke eerste stap voor planvoorbereiding en milieueffectrapportage. De startnotitie beschrijft het voornemen, de aanleiding voor het voornemen, de bestaande situatie, het beleidskader, de in de Projectnota/MER te onderzoeken alternatieven en varianten, een indicatie van de mogelijke milieueffecten en de wijze waarop het meest milieuvriendelijke alternatief wordt samengesteld. Bij de Dijkverbetering Achter Ramspol is gekozen voor een uitgebreide startnotitie.

\section{Inspraak en richtlijnen}

De startnotitie ligt gedurende vier weken ter inzage. In deze periode wordt ook een voorlichtingsavond georganiseerd. Een ieder kan gedurende de inspraakperiode en op de voorlichtingsavond zijn/haar reactie kenbaar maken aan de Provincie Overijssel. Deze reacties betrekt de Commissie voor de milieueffectrapportage (Cmer) bij haar advies voor richtlijnen aan het bevoegd gezag.

Het bevoegd gezag stelt vervolgens, rekening houdend met de reacties, met het advies van de Cmer en met het advies van de wettelijke adviseurs (inspecteur en de directeur Landbouw, Natuur en Openluchtrecreatie), de definitieve richtlijnen vast. Dit gebeurt binnen dertien weken na de publicatie van de startnotitie.

De richtlijnen geven aan waaraan het onderdeel MER van de Projectnota/MER moet voldoen. Daarbij wordt onder meer ingegaan op de alternatieven en varianten en op de aspecten die beschouwd moeten worden.

\section{Ontwerpplan en Projectnota/MER}

In artikel 7 van de Wet op de waterkering is aangegeven dat wijziging in richting, vorm, afmeting of constructie van een primaire waterkering geschiedt overeenkomstig een door de beheerder vastgesteld en door Gedeputeerde Staten goedgekeurd plan. Het plan bevat:

- de te treffen voorzieningen voor aanpassing van de waterkering;

- de te treffen voorzieningen voor het ongedaan maken of beperken van de gevolgen van de aan te passen waterkering;

- de te treffen voorzieningen ter bevordering van het belang van landschap, natuur of cultuurhistorie rechtstreeks verband houdende met de uitvoering van het werk. 


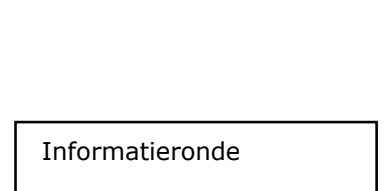

Inspraak

Inspraak

Beroepsmogelijheid

\begin{tabular}{|l|}
\hline Waterschap \\
\hline Aankondiging \\
\hline
\end{tabular}

\begin{tabular}{l}
\hline Waterschap \\
\hline $\begin{array}{l}\text { Instellen adviesgroepen } \\
+ \text { klankbordgroep }\end{array}$ \\
\hline
\end{tabular}

\section{Waterschap met advies adviesgroep}

Startnotitie

\begin{tabular}{|l|}
\hline Provincie \\
\hline Richtlijnen \\
\hline
\end{tabular}

\begin{tabular}{|l|}
\hline $\begin{array}{l}\text { Waterschap met } \\
\text { advies adviesgroep }\end{array}$ \\
\hline Projectnota/MER \\
+ ontwerpplan \\
\hline
\end{tabular}

\begin{tabular}{|l|}
\hline Waterschap \\
\hline Vaststelling plan \\
\hline
\end{tabular}

\section{Overheden}

Nemen definitieve besluiten
Waterschap +

klankbordgorep +

Bilateraal overleg

Vergunning aanvragen

\begin{tabular}{|l|}
\hline Provincie \\
\hline Goedkeuring plan \\
\hline
\end{tabular}

\section{Waterschap}

Bestek en uitvoering

Figuur B 7.1 Hoofdlijnen Procedure Dijkverbetering 
In het artikel wordt aangegeven dat in de toelichting op het plan wordt vermeld welke gevolgen aan de uitvoering van het plan zijn verbonden en op welke wijze met de daarbij betrokken belangen rekening is gehouden. Deze toelichting wordt in de procedure gecombineerd met het op te stellen MER voor het goedkeuringsbesluit tot één rapport, de Projectnota/MER.

De Projectnota/MER vormt de verantwoording van het dijkverbeteringsplan (Ontwerpplan), zoals dat door het bestuur van het waterschap wordt vastgesteld en voor goedkeuring wordt ingediend bij GS van Overijssel. Dit rapport bevat:

- $\quad$ een beschrijving van de gemaakte keuze (het voorkeursplan);

- $\quad$ een beschrijving van het planvoorbereidingsproces, de afwegingen die tijdens dit proces zijn gemaakt en de informatie die hierbij is gebruikt;

- een beschrijving van het meest milieuvriendelijke alternatief en eventueel de redenen waarom dit niet is gekozen;

- $\quad$ een onderbouwing van het plan. Het bevat de verantwoording van het technisch ontwerp zoals dat is gepresenteerd in ontwerpplan. De uitgebreide technische verantwoording wordt verwoord in het Ontwerpplan en de rapportage van het Geotechnisch onderzoek.

Bij het opstellen van de Projectnota/MER is rekening gehouden met de vastgestelde richtlijnen. De Projectnota/MER biedt alle relevante informatie ten behoeve van het vervolg van de besluitvorming en presenteert de uitgewerkte alternatieven en varianten en vergelijkt de milieueffecten en andere gevolgen van de verschillende oplossingen. Het in de Projectnota/MER gepresenteerde voorkeursalternatief is gedetailleerd uitgewerkt in het Ontwerpplan.

\section{Inspraak en toetsing voor vaststellingsbesluit}

GS beoordelen binnen drie weken na indiening de aanvaardbaarheid van het MER. Daarbij bekijken zij of het rapport voldoet aan de wettelijke eisen, tegemoet komt aan de richtlijnen en of het geen onjuistheden bevat.

Het Ontwerpplan, de Projectnota/MER, de grondverwervingstekeningen, het herziene bestemmingsplan en de vergunningaanvragen worden daarna gedurende vier weken ter inzage gelegd. Daarbij wordt door de Provincie Overijssel als coördinerend Bevoegd Gezag inspraak georganiseerd.

Een ieder kan zijn/haar zienswijze op het Ontwerpplan en de Projectnota/MER kenbaar 'maken bij de Provincie Overijssel. Reacties op het bestemmingsplan en de vergunningaanvragen worden gericht aan de verantwoordelijke overheden. 
De Commissie voor de m.e.r. en de wettelijke adviseurs (inspecteur en de directeur Landbouw, Natuur en Openluchtrecreatie) brengen uiterlijk vijf weken na het einde van de ter inzage legging en rekening houdend met de ingebrachte zienswijzen aan Gedeputeerde Staten een toetsingsadvies uit over het MER.

De uitgebrachte adviezen worden door de waterschappen Wold en Wieden en Groot Salland betrokken bij de vaststelling van het dijkverbeteringsplan. Na vaststelling wordt dit plan ter goedkeuring aangeboden aan Gedeputeerde Staten van de Provincie Overijssel.

\section{Goedkeuring dijkverbeteringsplan en Projectnota/MER}

Het bestuur van het waterschap stelt het dijkverbeteringsplan en de daarbij horende toelichting vast binnen zes weken na de laatste dag van de ter inzage legging en zendt het binnen die termijn ter goedkeuring naar GS (art. 21, Wet op de waterkering). Bij de indiening van het plan dient het definitieve besluit over het dijkverbeteringsplan en de Projectnota/MER te worden gevoegd.

Ook de andere bestuursorganen zenden binnen 6 weken na het einde van de ter inzage legging hun ontwerp besluiten met betrekking tot de vergunningsaanvragen aan Gedeputeerde Staten.

GS nemen een goedkeuringsbesluit binnen zes weken na toezending van het dijkverbeteringsplan. Zij beoordelen het dijkverbeteringsplan op strijd met het recht of strijd met het algemeen belang. Als toetsingskader fungeren het provinciaal milieubeleidsplan, het streekplan en het gemeentelijk planologisch kader. Bij de toetsing wordt gelet op de gevolgde procedure, de kwaliteit van het dijkverbeteringsplan, het voldoen aan technische normen en de maatschappelijke verantwoording van de kosten. GS geven hun goedkeuring aan het dijkverbeteringsplan volgens artikel 7 van de Wet op de waterkering en publiceren het genomen besluit.

Ten aanzien van de vergunningaanvragen (zie hierna) nemen de voor de verlening van toestemming verantwoordelijke overheden het besluit binnen drie weken na goedkeuring van GS. Dit is bij toepassing van de aanbevolen termijnen maximaal vijftien weken na de laatste dag van ter inzage legging.

\section{Beroep}

Na goedkeuring door GS bestaat er de mogelijkheid van beroep bij de Raad van State. Vanaf het moment van goedkeuring hebben betrokkenen zes weken om hun beroep in te dienen. De Raad van State doet uitspraak binnen twaalf weken na verstrijken van de beroepstermijn. Deze termijn kan met ten hoogste zes weken worden verlengd. Dit 
betekent dat normaal gesproken het dijkverbeteringsplan onherroepelijk kan zijn binnen 33 weken na de laatste dag van de ter inzage legging.

\section{B 7.3 Vergunningen en grondverwerving}

Alvorens het dijkverbeteringsplan te kunnen uitvoeren moeten verschillende vergunningen en toestemmingen worden verkregen. Het gaat mogelijk om vergunningen en toestemming in het kader van:

- Wet Ruimtelijke Ordening;

- Wet Milieubeheer;

- Wet Verontreiniging Oppervlaktewateren;

- Wet Bodembescherming;

- Monumentenwet;

- Onteigeningswet;

- Ontgrondingenwet;

- Rivierenwet;

- Wet Geluidhinder;

- Natuurbeschermingswet.

De Wet op de Waterkering voorziet ten aanzien van de herziening van het bestemmingsplan en het verkrijgen van andere toestemmingen een gecoördineerde aanpak. De coördinerende taak wordt in artikel 20 toegekend aan Gedeputeerde Staten. Dit houdt in dat naast de eigenlijke ontwikkeling van het plan

en voor de ter inzage legging van Ontwerpplan en Projectnota/MER de aanvraag van de vergunningen en de eventuele herziening van het bestemmings plan wordt voorbereid. Dit kan zodra duidelijk is welk voorkeursalternatief voorgesteld wordt.

\section{Grondverwerving}

Bij aanvang van de werken dient de benodigde grond verworven te zijn. Afgestemd op de voortgang van de werkzaamheden is het nodig tijdig na te gaan waar grondverwerving knelpunten oplevert. De wet voorziet in het gelijktijdig met het Ontwerpplan ter inzage leggen van de grondverwervingstekeningen. Zo nodig kan het waterschap na het goedkeuringsbesluit van Gedeputeerde Staten beginnen met onteigeningsprocedures. De Wet op de Waterkering voorziet voor de administratieve onteigening een proceduretijd van drie maanden.

\section{B 7.4 Uitvoering}

Op basis van het goedgekeurde dijkverbeteringsplan worden door de initiatiefnemer de bestekken voor de te realiseren werken opgesteld. Na goedkeuring van de bestekken door 
het bevoegd gezag worden de benodigde middelen voor de uitvoering beschikbaar gesteld. De initiatiefnemer verzorgt de uitbesteding en uitvoering van het werk. Een begeleidingsgroep wordt geformeerd om de uitvoering te begeleiden. Na oplevering van het werk draagt de initiatiefnemer zorg voor onderhoud en beheer van de dijk.

\section{B 7.5 Evaluatie}

$\mathrm{Na}$ uitvoering van het dijkverbeteringsplan verrichten Gedeputeerde Staten als bevoegd gezag in het kader van de m.e.f. een evaluatie en zorgen voor bekendmaking van dit evaluatieverslag. Het evaluatieverslag geeft de waargenomen gevolgen voor het milieu weer en geeft een beoordeling van die gevolgen. 



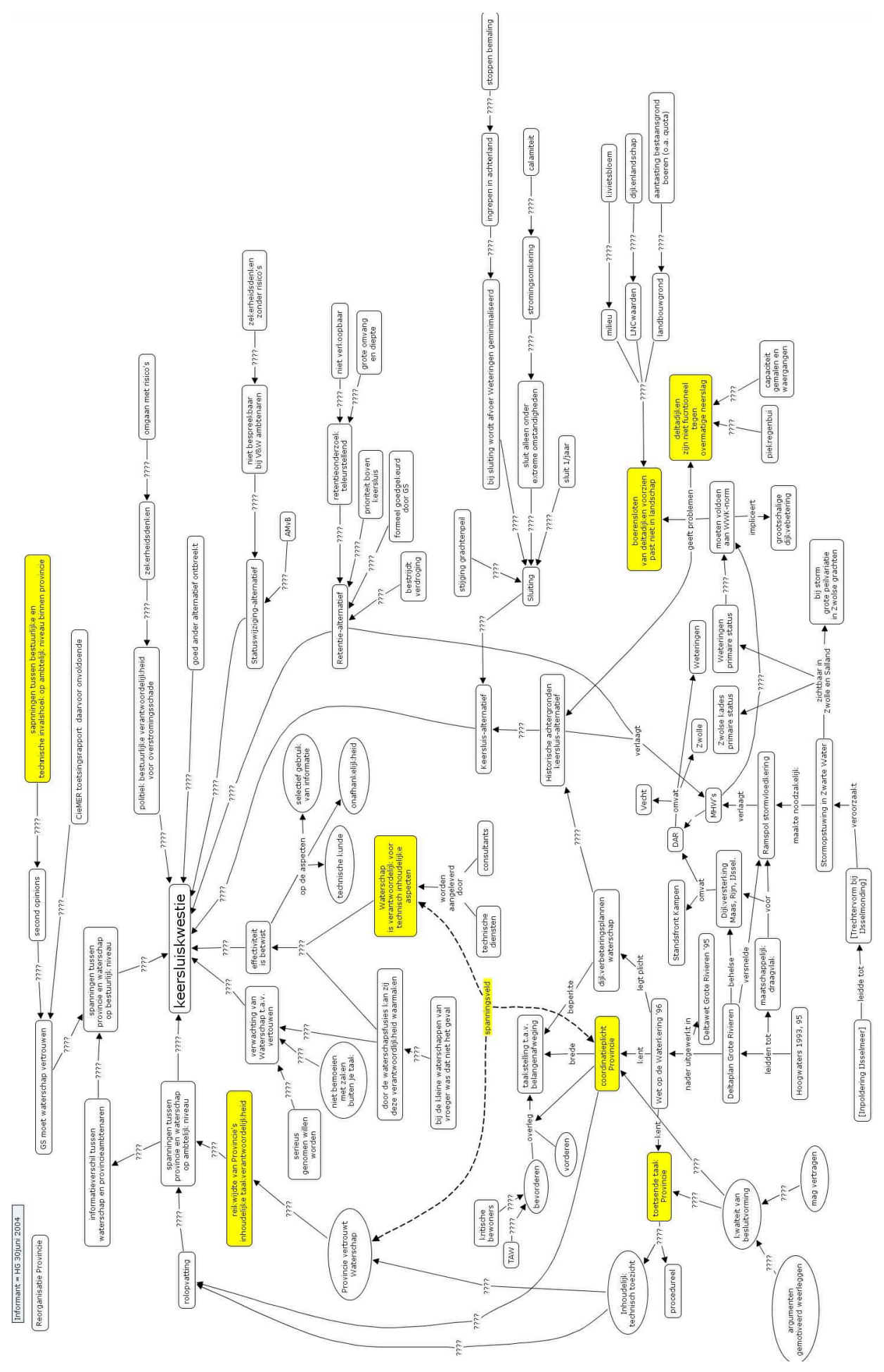


230 CONTROVERSIES IN WATER MANAGEMENT: FRAMES AND MENTAL MODELS 


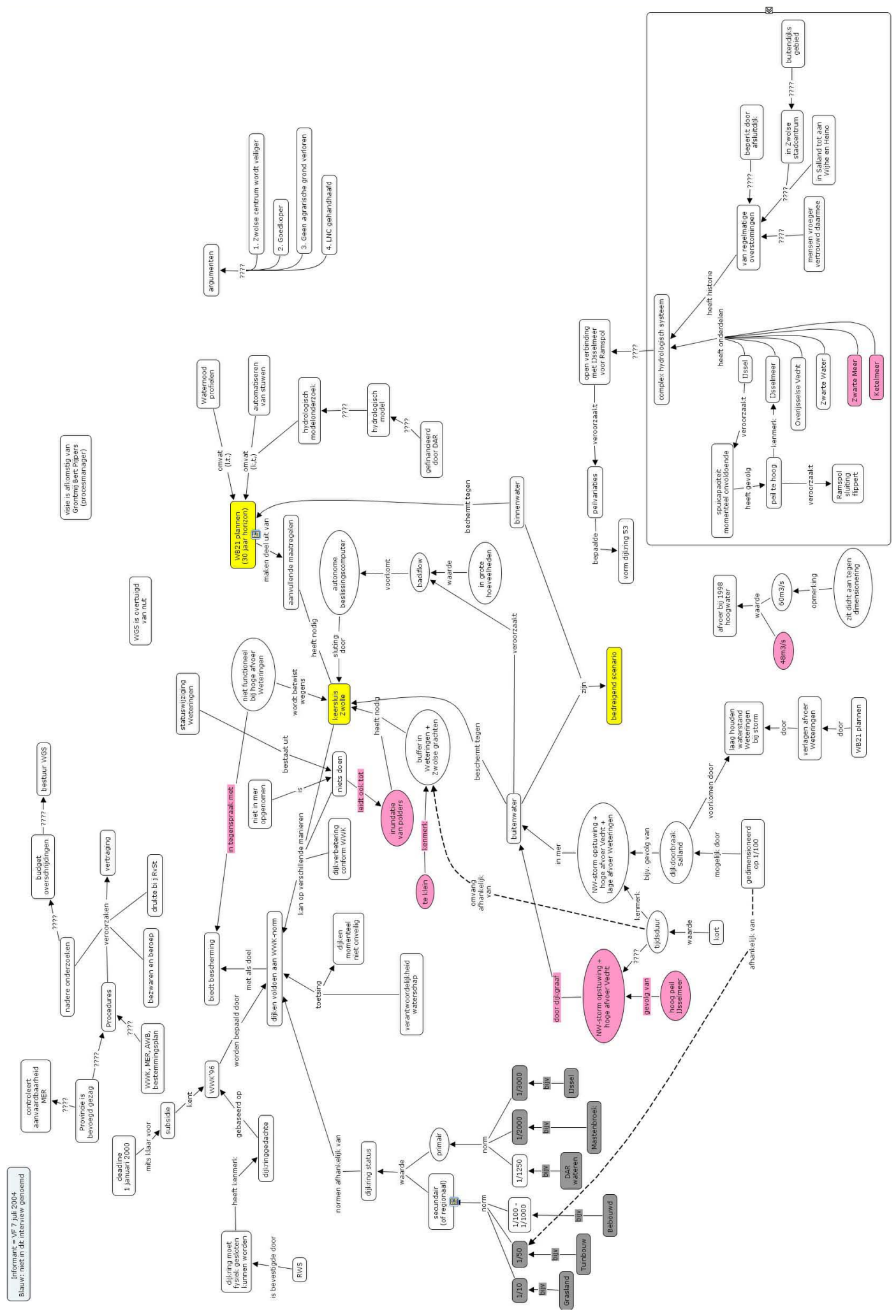


232 CONTROVERSIES IN WATER MANAGEMENT: FRAMES AND MENTAL MODELS 